\title{
ANALYSIS OF THE FACTORS AFFECTING HYBRID GROUND-SOURCE HEAT PUMP INSTALLATION POTENTIAL
}

by

\author{
Hiep Van Nguyen \\ Bachelor of Engineering, Ryerson University, Toronto, Canada, 2012
}

\author{
A thesis \\ presented to Ryerson University \\ in partial fulfillment of the \\ requirement for the degree of \\ Master of Applied Science \\ In the Program of \\ Mechanical and Industrial Engineering
}

Toronto, Ontario, Canada, 2014

CHiep Van Nguyen 2014 


\section{AUTHOR'S DECLARATION FOR ELECTRONIC SUBMISSION OF A THESIS}

I hereby declare that I am the sole author of this thesis. This is a true copy of the thesis, including any required final revisions, as accepted by my examiners.

I authorize Ryerson University to lend this thesis to other institutions or individuals for the purpose of scholarly research.

I further authorize Ryerson University to reproduce this thesis by photocopying or by other means, in total or in part, at the request of other institutions or individuals for the purpose of scholarly research.

I understand that my thesis may be made electronically available to the public. 


\title{
Abstract
}

\section{ANALYSIS OF THE FACTORS AFFECTING HYBRID GROUND-SOURCE HEAT PUMP INSTALLATION POTENTIAL}

Master of Applied Science, 2014

\author{
Hiep Van Nguyen
}

Mechanical and Industrial Engineering

Ryerson University

\begin{abstract}
A series of sensitivity analysis was performed to a variety of design parameters as a way of increasing the knowledge base of automatically sizing GSHPs as a component of a hybrid system. The present work investigates the effects of geographical location (weather patterns and utility rates), operating costs (fixed vs. time-of-use rates), inflation rates, the control strategies used, project life, heat pump entering fluid temperature (EFT), carbon taxation, and building retrofit on the sizing of hybrid GSHP systems in North America. Based on an economic approach to sizing hybrid GSHP systems by selecting the most economical design (based on minimizing the net present value of capital and operating costs), significant energy and cost savings and reductions in $\mathrm{CO}_{2}$ emissions can be achieved.
\end{abstract}




\section{Acknowledgements}

I would like to thank my two supervisors, Dr. Seth B. Dworkin and Dr. Wey H. Leong, for providing me with the opportunity to be a part of this research. The completion of my degree was largely in part due to their time, patience, knowledge and guidance. I would also like to thank Dr. Philip R. Walsh, Dr. Alan S. Fung, and my three colleagues Mr. Masih Alavy (for his time and help during my studies), Miss Xiaoyan Zhou, and Miss Ying Lam Law, who were undergraduate assistants in our research group. Dr. Philip Walsh provided guidance and expert advice for the business and energy policy aspects of my research. I received a MITACS internship due to Dr. Alan Fung's and Dr. Seth Dworkin's assistance. Miss Xiaoyan Zhou helped me in co-developing the algorithm and generating the results to determine the optimal entering fluid temperatures of a heat pump (varying inlet temperature) for Chapter 4 of this thesis. Miss Ying Lam Law helped me in co-developing the algorithm and generating the results for the $\mathrm{CO}_{2}$ analysis in Chapter 4 of this thesis.

I would also like to acknowledge Mr. Robert Van Duynhoven and Mr. Farzin Rad of CleanEnergy ${ }^{\mathrm{TM}}$, a full service geothermal energy company, for having advised and provided me the building data. Lastly, I would like to thank the Faculty of Engineering and Architectural Science at Ryerson University, NSERC, MITACS, HydroOne, and the Toronto Atmospheric Fund for financial support. 


\section{Dedication}

To my parents, Le, Jordan, Michelle, Dr. Dworkin, Dr. Leong, and my best friends for helping me become a better person every day. My current achievements and success are due to your undying support and encouragements. 


\section{Table of Contents}

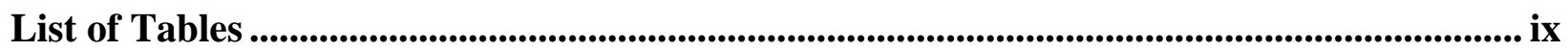

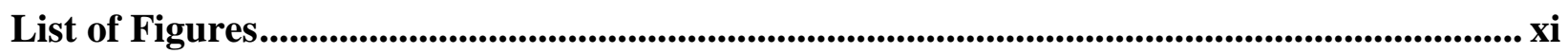

List of Terms and Abbreviations........................................................................................................ $\mathrm{xv}$

Chapter 1 Introduction........................................................................................................................................... 1

1.1 Motivation and Objectives ...................................................................................... 1

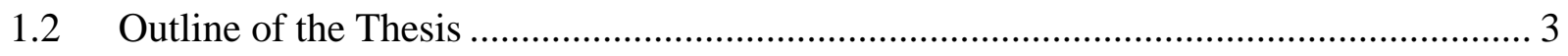

Chapter 2 Literature Review .................................................................................................. 4

2.1 Ground-Source Heat Pumps ...................................................................................... 4

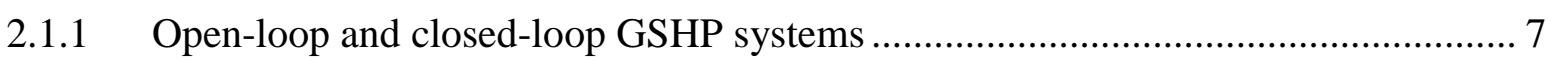

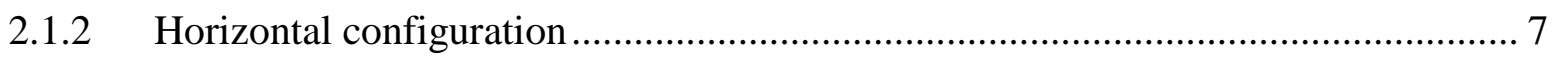

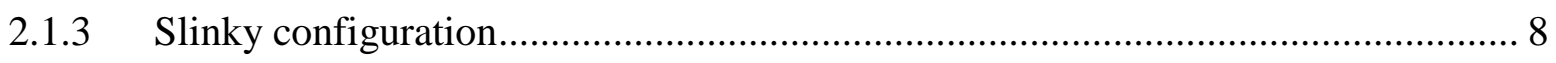

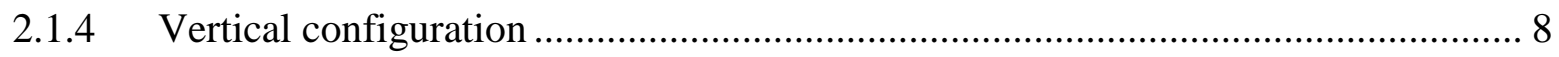

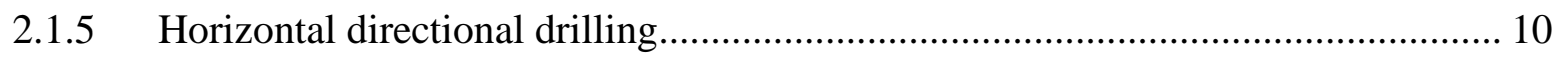

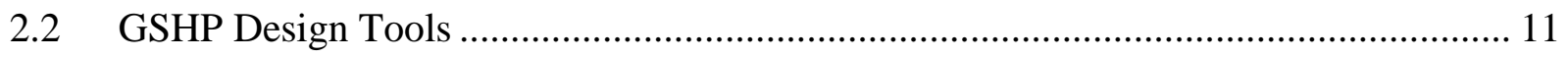

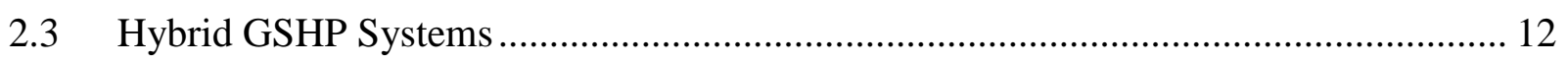

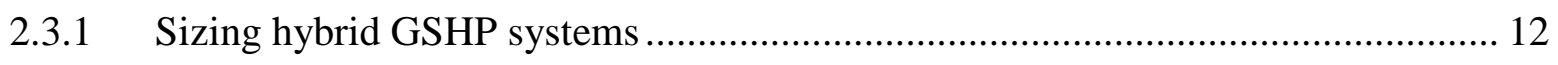

2.3.2 Sizing hybrid GSHP systems (approach used in the thesis) ……………………...... 15

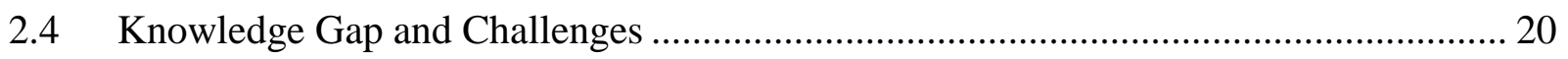

2.4.1 Heat pump entering fluid temperature and carbon taxation.................................. 20

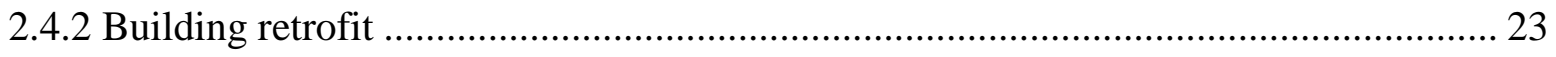

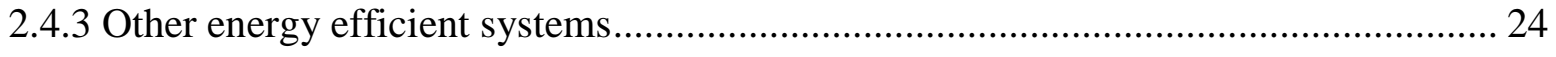

Chapter 3 Study \#1: Hybrid-GSHP Sensitivity Analysis ................................................................... 26

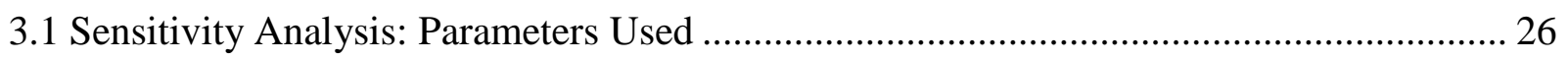

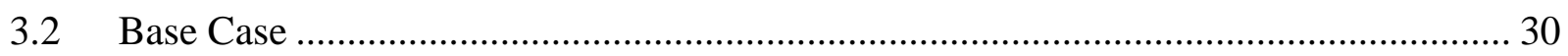


3.3 Analysis \#1 - Electricity Rates: Fixed vs. Time-of-Use.......................................... 34

3.4 Analysis \#2 - Toronto Fixed Rates with Variable Weather ........................................ 37

3.5 Analysis \#3 - Variable Weather and Local Rates .................................................... 42

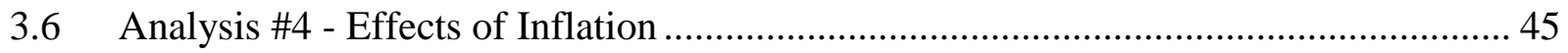

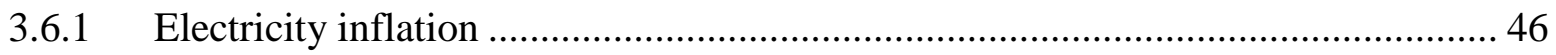

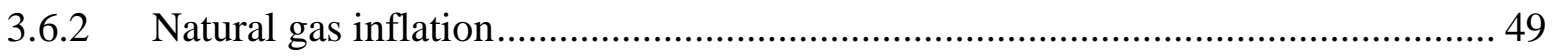

3.7 Analysis \#5 - Control Strategy: Seasonality ...................................................... 50

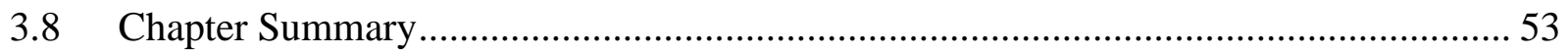

Chapter 4 Study \#2: Analysis of Heat-Pump Entering Fluid Temperatures, and $\mathrm{CO}_{2}$

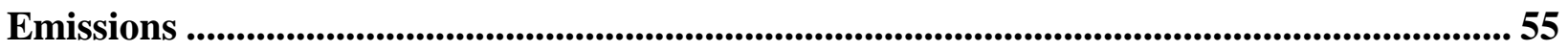

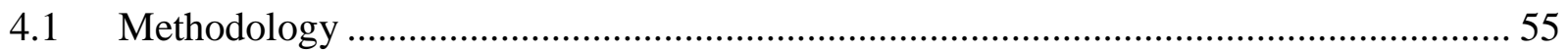

4.1.1 Heat-pump entering fluid temperature (EFT) .......................................... 56

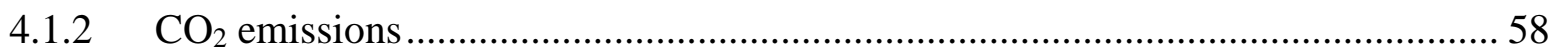

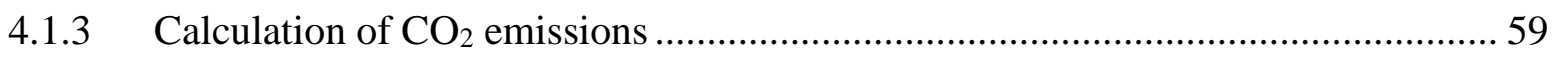

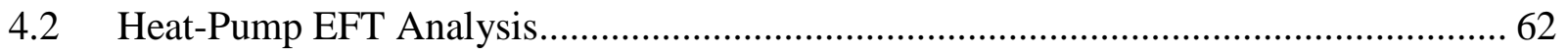

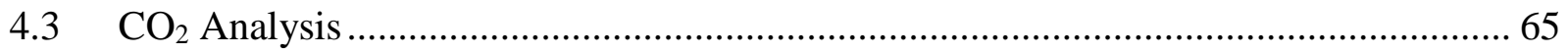

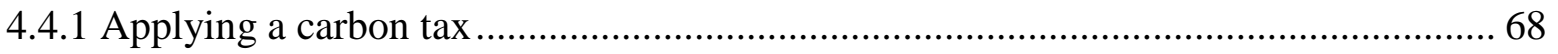

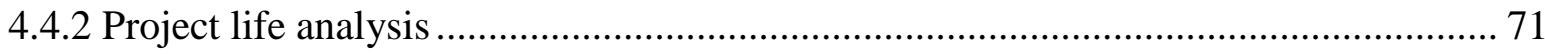

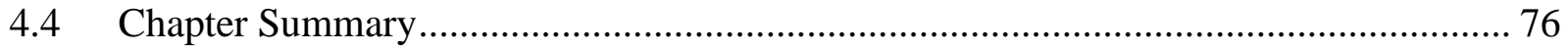

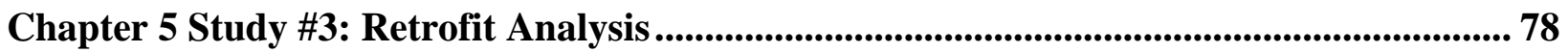

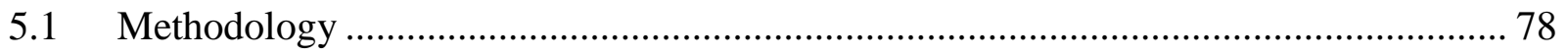

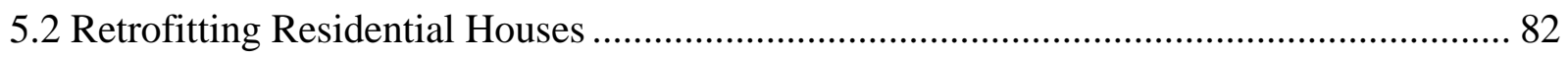

5.2.1 Test \#1: only GSHP initial cost considered ............................................. 83

5.2.2 Test \#2: ductwork and major overhaul costs .............................................. 87

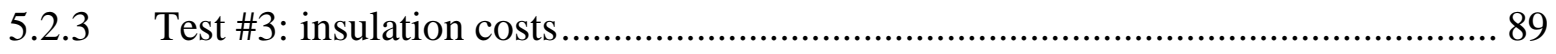




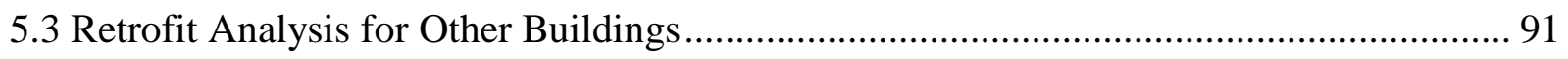

5.3.1 Test \#1: baseboard heaters and window air conditioners ................................. 91

5.3.2 Test \#2: baseboard heaters and cooling towers............................................... 95

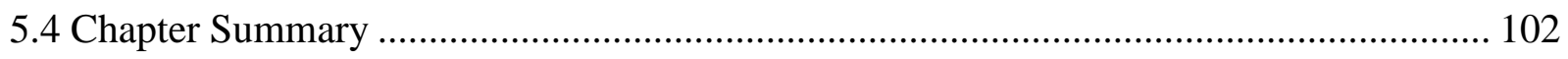

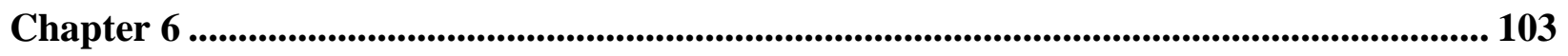

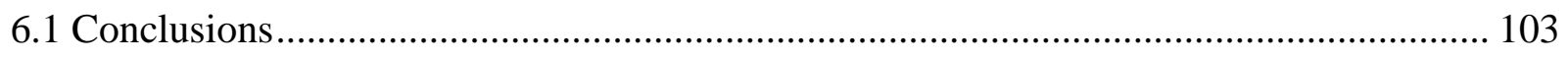

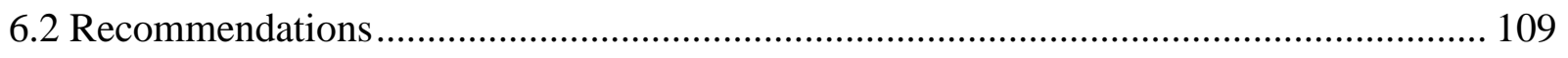

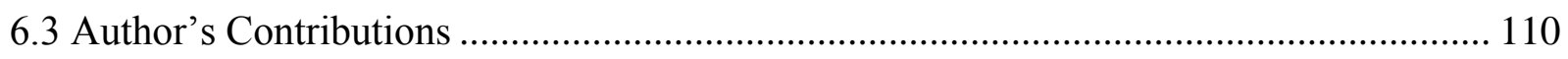

Appendix A Building Loads ............................................................................................................ 112

References............................................................................................................................................... 122 


\section{List of Tables}

Table 2.1: Horizontal ground loop advantages and disadvantages ....................................... 8

Table 2.2: Vertical ground loop advantages and disadvantages ........................................... 9

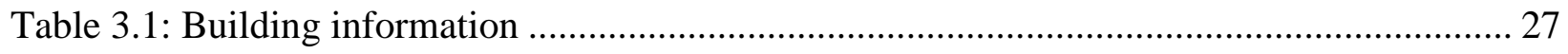

Table 3.2: General costs of hybrid GSHP system components ........................................... 27

Table 3.3: General design parameters (data courtesy of CleanEnergy ${ }^{\mathrm{TM}}$ )................................ 28

Table 3.4: Mid-rise multi-residential building (cooling dominant) ......................................... 31

Table 3.5: Payback periods - Toronto fixed electricity rates ............................................... 33

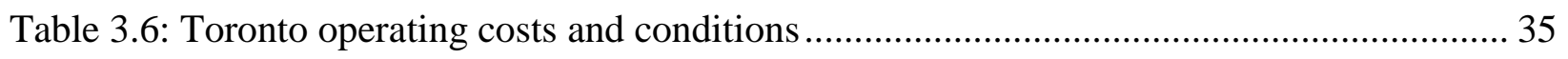

Table 3.7: Low optimal shave factor cases using Toronto's fixed rates.................................. 42

Table 3.8: Natural gas prices for 2011 (US dollars) ............................................................... 43

Table 3.9: Average electricity prices for 2010 (US dollars) ................................................. 43

Table 3.10: Office building - Phoenix, Arizona (weather and local rates) .............................. 44

Table 3.11: Optimal design - mean and median payback periods ......................................... 45

Table 3.12: Economical cases due to $10 \%$ electricity inflation ............................................ 49

Table 3.13: Economical cases due to natural gas inflation rate of $20 \%$..................................... 50

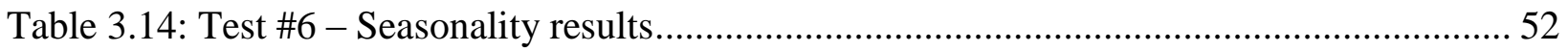

Table 4.1: General design parameters (data courtesy of CleanEnergy ${ }^{\mathrm{TM}}$ )............................ 56

Table 4.2: General costs of hybrid GSHP system components ............................................. 56

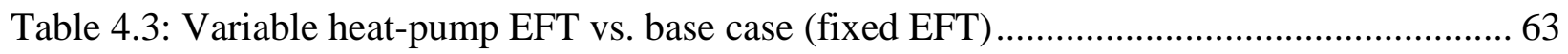

Table 4.4: Summary of annual $\mathrm{CO}_{2}$ emission for the 8 buildings, located in Toronto, Canada... 68

Table 4.5: Changes in shave factors and payback periods due to a carbon tax ......................... 70

Table 4.6: Project life and $\mathrm{CO}_{2}$ analysis for a fast-food restaurant ........................................ 73

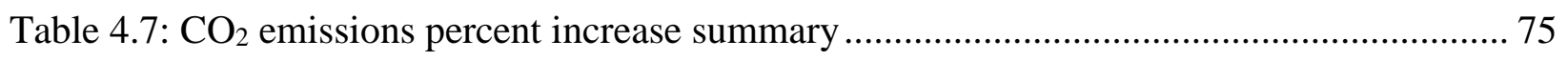

Table 5.1: Retrofit - heating and cooling COP of equipment .............................................. 79

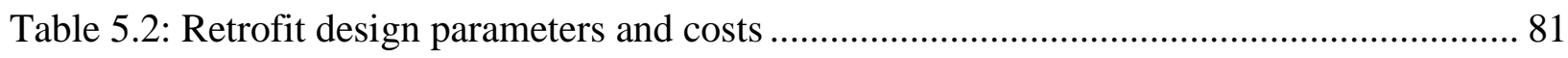

Table 5.3: Houses A and B annual energy consumption and conventional operating costs ........ 82 


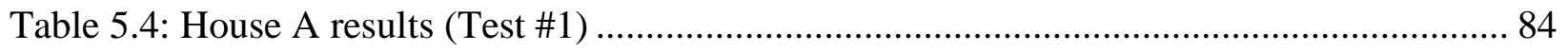

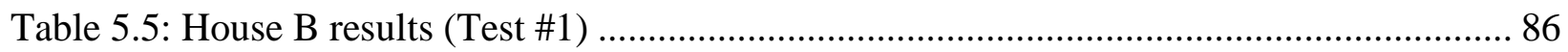

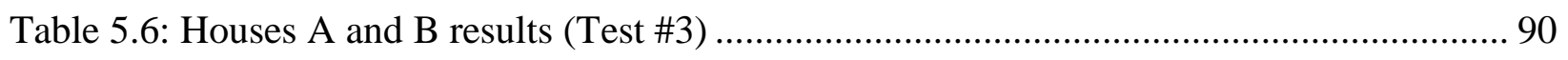

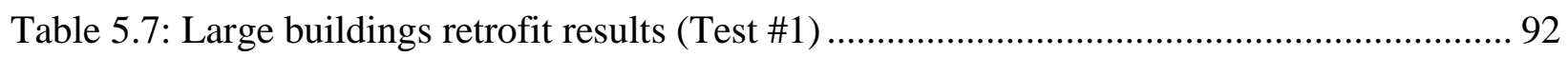

Table 5.8: Large buildings retrofit results (Test \#2) ……………………………....................... 97

Table 6.1: Summary of trends based on sensitivity variations ................................................. 108 


\section{List of Figures}

Figure 2.1: Graphical representation of the relationship between ground depth and ground temperature (reproduced from [8]) …………………….................................... 5

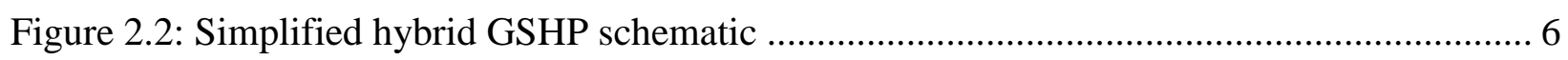

Figure 2.3: Horizontal ground loop configuration (reproduced from [5]) ..................................... 7

Figure 2.4: Slinky loop configuration (reproduced from [20]) ……………………….............. 8

Figure 2.5: Vertical ground loop configuration (reproduced from [8]) ………………................ 9

Figure 2.6: Horizontal directional drilling schematic ............................................................... 10

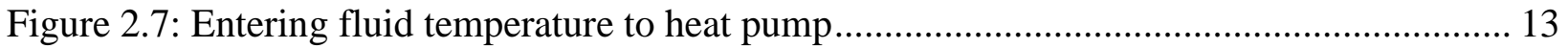

Figure 2.8: Sizing hybrid GSHP systems - Hourly cooling loads for a transit facility located in

Toronto, Ontario ............................................................................................ 15

Figure 2.9: Sizing hybrid GSHP systems - Hourly heating loads for a transit facility located in

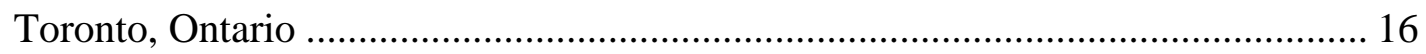

Figure 2.10: Sizing hybrid GSHP systems - Shave factor schematic for a transit facility located in

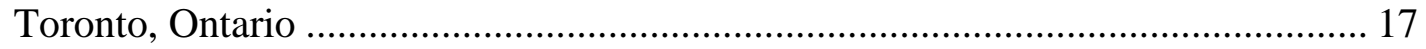

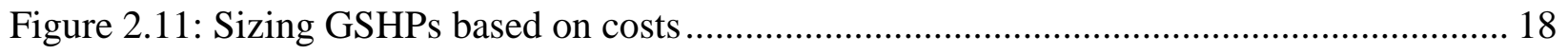

Figure 2.12: Sizing hybrid GSHP systems - Optimal design of a transit facility located in Toronto,

Ontario (reproduced from [15]) ……………………….................................... 19

Figure 3.1: Daily heating and cooling loads of a school in Toronto, Ontario, Canada ................ 29

Figure 3.2: shave factor vs. TEDM for a school located in Toronto, Ontario .............................. 29

Figure 3.3: Hybrid GSHP data for eight buildings (base case) in Toronto, Ontario, Canada. ..... 33

Figure 3.4: Toronto time-of-use electricity rates results for eight buildings in Toronto, Ontario,

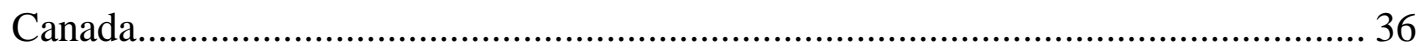

Figure 3.5: $\Delta$ initial cost (IC) savings, $\Delta$ total savings, and $\Delta$ shave factor for Toronto fixed vs. time-

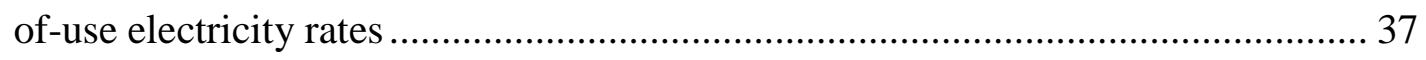

Figure 3.6: $\Delta$ Total Savings: variable weather, Toronto rates. The base case, Toronto's weather patterns and fixed rates, was used for comparison 39

Figure 3.7: $\triangle S F$ : variable weather, Toronto rates. The base case, Toronto's weather patterns and fixed rates, were used for comparison. 39 
Figure 3.8: $\Delta$ Ground loop length - fast food restaurant ................................................. 41

Figure 3.9: $\triangle$ PBP: variable weather, Toronto rates ........................................................ 41

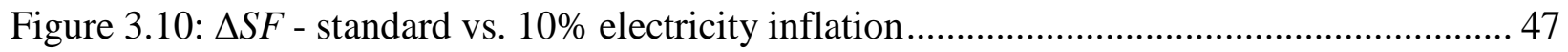

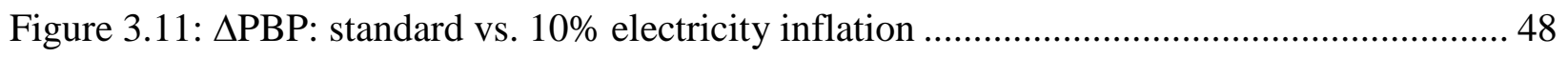

Figure 4.1: EFT analysis for a school located in Toronto, Ontario. ........................................ 58

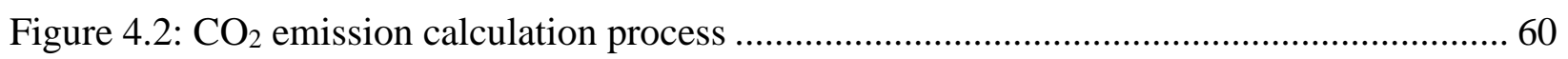

Figure 4.3: Coefficient of performance of a heat pump $\left(\right.$ CleanEnergy $^{\mathrm{TM}}$, model PC0018) ......... 62

Figure 4.4: Annual $\mathrm{CO}_{2}$ emissions of a fast-food restaurant located in Toronto, Ontario, as a

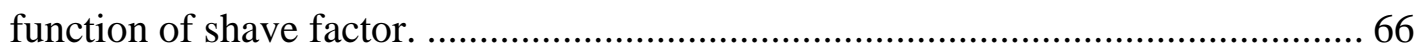

Figure 4.5: Annual $\mathrm{CO}_{2}$ emissions of high-rise (II) building located in Markham, Ontario ........ 67

Figure 4.6: Net present value per operating year (\$/year) vs. operating duration (project life) for a fast food restaurant located in Toronto, Ontario ................................................. 72

Figure 4.7: $\mathrm{CO}_{2}$ emissions per operating year vs. operating duration (project life) for a fast-food restaurant located in Toronto, Ontario ........................................................... 73

Figure 4.8: Payback period vs. operating duration (project life) of a fast-food restaurant located in

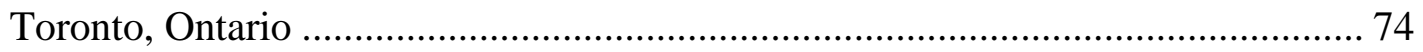

Figure 5.1: Retrofit analysis - calculation of total costs (in net present value) ......................... 79

Figure 5.2: Shave factor vs. total costs (Test \#1) - Retrofit analysis for House A..................... 84

Figure 5.3: PBP vs. other retrofit costs (Test \#1) - Retrofit analysis for House A .................... 85

Figure 5.4: PBP vs. other retrofit costs (Test \#1) - Retrofit analysis for House B..................... 86

Figure 5.5: PBP vs. other retrofit costs (Test \#2) - Retrofit analysis for House A .................... 87

Figure 5.6: PBP vs. other retrofit costs (Test \#2) - Retrofit analysis for House B..................... 88

Figure 5.7: PBP vs. other retrofit costs (Test \#2) - Retrofit analysis for House B..................... 89

Figure 5.8: PBP vs. other retrofit costs (Test \#1) - Retrofit analysis for a school located in Toronto,

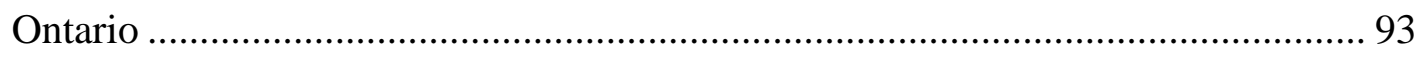

Figure 5.9: PBP vs. other retrofit costs (Test \#1) - Retrofit analysis for High-rise A located in

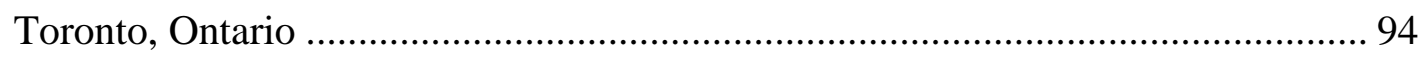

Figure 5.10: PBP vs. other retrofit costs (Test \#1) - Retrofit analysis for an office located in

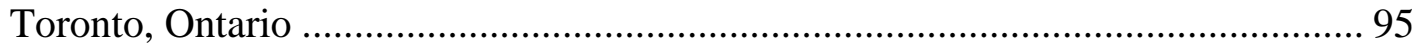


Figure 5.11: PBP vs. other retrofit costs (Test \#2) - Retrofit analysis for High-rise A located in Toronto, Ontario 96

Figure 5.12: PBP vs. other retrofit costs (Test \#2) - Retrofit analysis for High-rise B located in Toronto, Ontario 98

Figure 5.13: PBP vs. other retrofit costs (Test \#2) - Retrofit analysis for a school located in Toronto, Ontario 99

Figure 5.14: Office - PBP vs. other retrofit costs (Test \#2) - Retrofit analysis for an office located in Toronto, Ontario 100

Figure 5.15: PBP vs. other retrofit costs (Test \#2) - Retrofit analysis for a mid-rise multi-residential building located in Toronto, Ontario 101

Figure A.1: Hourly heating loads for a hospital located in Toronto, Ontario 112

Figure A.2: Hourly cooling loads for a hospital located in Toronto, Ontario ..... 112

Figure A.3: Hourly heating loads for an office building located in Toronto, Ontario. 113

Figure A.4: Hourly cooling loads for an office building located in Toronto, Ontario 113

Figure A.5: Hourly cooling loads for a restaurant located in Toronto, Ontario 114

Figure A.6: Hourly heating loads for a fast-food restaurant located in Toronto, Ontario 114

Figure A.7: Hourly cooling loads for a fast-food restaurant located in Toronto, Ontario 115

Figure A.8: Hourly heating loads for a transit facility located in Toronto, Ontario 115

Figure A.9: Hourly cooling loads for a transit facility located in Toronto, Ontario 116

Figure A.10: Hourly heating loads for a mid-rise multi-residential building located in Toronto, Ontario 116

Figure A.11: Hourly cooling loads for a mid-rise multi-residential building located in Toronto, Ontario 117

Figure A.12: Hourly heating loads for High-rise A (multi-residential building) located in Toronto, Ontario. 117

Figure A.13: Hourly cooling loads for High-rise A (multi-residential building) located in Toronto, Ontario 118

Figure A.14: Hourly heating loads for High-rise B (multi-residential building) located in Toronto, Ontario 118 
Figure A.15: Hourly cooling loads for High-rise B (multi-residential building) located in Toronto, Ontario 119

Figure A.16: Hourly heating loads for High-rise C (multi-residential building) located in Toronto, Ontario 119

Figure A.17: Hourly cooling loads for High-rise C (multi-residential building) located in Toronto,

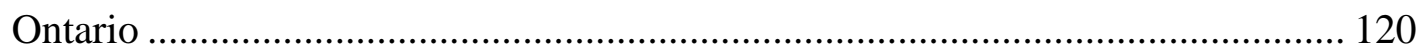

Figure A.18: Hourly heating loads for a school located in Toronto, Ontario ......................... 120

Figure A.19: Hourly cooling loads for a school located in Toronto, Ontario.......................... 121 


\section{List of Terms and Abbreviations}

\begin{tabular}{|c|c|}
\hline AOPC & Annual Operating Costs \\
\hline ASHP & Air Source Heat Pump \\
\hline $\mathrm{CD}$ & Cooling Dominant \\
\hline$C_{f c}$ and $C_{f h}$ & $\begin{array}{l}\text { Correction factors accounting for the heat rejected or absorbed by the heat } \\
\text { pump }\end{array}$ \\
\hline $\mathrm{CMHC}$ & Canada Mortgage and Housing Corporation \\
\hline $\mathrm{CO}_{2}$ & Carbon Dioxide \\
\hline $\mathrm{COP}$ & Coefficient of Performance \\
\hline CSA & Canadian Standard Association \\
\hline CTMY & Canadian Typical Meteorological Year \\
\hline DHP & Ductless Heat Pump (mini-split) \\
\hline DX & Direct-Expansion \\
\hline EER & Energy Efficiency Ratio \\
\hline EFT & Entering Fluid Temperature \\
\hline$F_{S C}$ & Short-circuit heat loss \\
\hline GHG & Green House Gas \\
\hline GLD & Ground Loop Design (Geothermal Software) \\
\hline GSHP & Ground Source Heat Pump \\
\hline GHX & Ground Heat Exchanger \\
\hline GTA & Greater Toronto Area \\
\hline HD & Heating Dominant \\
\hline HDD & Horizontal Directional Drilling \\
\hline HDPE & High Density Polyethylene \\
\hline IC Savings & Initial Cost Savings \\
\hline$L_{c}$ & Required ground loop length for cooling (m) \\
\hline$L_{h}$ & Required ground loop length for heating (m) \\
\hline MURB & Multiunit Residential Building \\
\hline NPV & Net Present Value \\
\hline OD & Operating Duration (project life) \\
\hline
\end{tabular}




$\begin{array}{ll}\text { PBP } & \text { Payback Period } \\ P L F_{m} & \text { Part-load factor during design month } \\ q_{a} & \text { Net annual heat transfer to the ground }(\mathrm{W}) \\ q_{l c} & \text { Building design cooling load }(\mathrm{W}) \\ q_{l h} & \text { Building design heating load }(\mathrm{W}) \\ R_{b} & \text { Thermal resistance of bore }(\mathrm{m} \cdot \mathrm{K} / \mathrm{W}) \\ R_{g a} & \text { Effective thermal resistance of the ground, annual pulse }(\mathrm{m} \cdot \mathrm{K} / \mathrm{W}) \\ R_{g d} & \text { Effective thermal resistance of the ground, daily pulse }(\mathrm{m} \cdot \mathrm{K} / \mathrm{W}) \\ R_{g m} & \text { Effective thermal resistance of the ground, monthly pulse }(\mathrm{m} \cdot \mathrm{K} / \mathrm{W}) \\ S F & \text { Shave Factor } \\ \text { TEDM } & \text { Percentage of Total Energy Demand Met by the ground-source heat pump } \\ & \text { system } \\ t_{w M Y} & \text { Typical Meteorological Year }(\text { United States }) \\ t_{g} & \text { Undisturbed ground temperature }\left({ }^{\circ} \mathrm{C}\right) \\ t_{p} & \text { Temperature Penalty } \\ t_{w i} & \text { Liquid temperature at heat pump inlet }\left({ }^{\circ} \mathrm{C}\right) \\ & \text { Liquid temperature at heat pump outlet }\left({ }^{\circ} \mathrm{C}\right)\end{array}$




\section{Chapter 1}

\section{Introduction}

When it comes to dealing with global warming and climate change, there are two approaches, through mitigation and/or adaptation [1]. With the major contributor of climate change being greenhouse gasses (GHGs), policies are created in attempts of reducing emissions. These policies are evaluated according to an economic analysis in order to determine the appropriate level of action in relation to the two mentioned approaches [1].

Based on the current progress in reducing GHG emissions, and a strong economic influence, the rate of change to reduce GHGs will be slow and will favour adaptation [1]. However, GHG emissions can be significantly reduced through mitigation. Electricity and natural gas consumption accounts for almost half of the required energy in Canada [2]. Space heating and cooling is responsible for a large portion, over $60 \%$ and $50 \%$ for Canadian residential and commercial sectors, respectively, of a building's total energy demands [3]. A substantial reduction in energy consumption, and emissions, can be achieved by providing heating and cooling energy demands to the residential and commercial sectors using clean renewable alternatives.

Due to increasing environmental concerns and potential resource shortages, there is an ongoing drive to develop and implement sustainable alternatives. Ground-source heat pump (GSHP) systems have shown great success and potential, making them a popular clean renewable alternative to consider [4-8]. GSHPs are versatile, economically preferable to conventional systems, and can be combined with other renewable alternatives [9-14].

\subsection{Motivation and Objectives}

High upfront costs and long payback periods are currently presenting obstacles to significant market penetration of GSHP systems. In many cases, market penetration impedance for GSHP systems can be alleviated with the use of appropriate computational tools for design analyses. Improving the economic outlook of potential installations can be addressed by hybridizing GSHP systems with an auxiliary system; the buildings' base load energy demands are met by the GSHP 
system and any excessive peaks are met by an auxiliary system [15]. However, due to the highly variable nature of sizing GSHP systems, general standards currently used by the industry do not always correspond to an optimized design [15, 16]. Addressing the problem, Alavy et al. [15] developed a new computational approach, replacing the rule-of-thumb method of sizing hybrid GSHPs.

The methodology outlined in Alavy et al. [15] showed that rough standards currently used by the industry do not always correspond to an optimized design [15]. For example, in Sagia et al.'s study [17], the cooling tower (auxiliary cooling system) was sized to meet 20\%, 30\%, and $50 \%$ of a particular building's cooling load [17], with the balance met by a GSHP. By contrast, the methodology proposed by Alavy et al. [15] automatically sizes the heating and cooling systems, meeting the building's peak cooling and heating loads, with continuously variable auxiliary system capacity. The most economical design is selected based on the lowest net present value of capital and operating costs. Since this methodology was developed recently and is still poorly understood, a significant knowledge gap exists on how best to apply these new techniques. Furthermore, Alavy et al. [15] limited their study to ten buildings in the region of Southern Ontario, Canada. The ten real buildings in [15] were analyzed using Toronto, Canada's weather patterns, natural gas and fixed electricity rates. However, the paper focused on explaining and validating the methodology; as such, sensitivity analyses to a variety of design parameters remain valuable to explore as a way of increasing the knowledge base of automatically sizing GSHPs as a component of a hybrid system.

Using the methodology outlined in Alavy et al. [15], the present work investigates the effects that geographical location (weather patterns and utility rates), operating costs (fixed vs. time-of-use rates), inflation rates, the control strategies used, project life, heat pump entering fluid temperature (EFT), carbon taxation, and building retrofit have on the sizing of hybrid GSHP systems in North America. By performing a series of sensitivity analysis, based on the studies performed, a framework has been established and the algorithms and results can be used as tools and guides to complement existing ground loop design tools and aid the engineers during the design process. 


\subsection{Outline of the Thesis}

This thesis includes data and information from two published journal articles and one submitted manuscript that is currently under review at the time of writing. A total of three studies were performed, the following chapters are organized as follows:

Chapter 2, a literature review on GSHPs, begins with an introduction to common GSHP system designs followed by design tools used to size GSHPs, hybrid GSHP systems, and knowledge gap/challenges.

Chapter 3, Study \#1, analyzes the effects electricity rates (fixed vs. time-of-use), geographical location (weather patterns and utility rates), electricity and natural gas inflation, and a seasonality control strategy have on the sizing of hybrid GSHP systems in North America.

Chapter 4, Study \#2, two new algorithms have been created for the methodology outlined in Alavy et al. [15]. The effects of optimizing entering fluid temperature for heat pump and carbon taxation were studied for a variety of commercial installations. Furthermore, the economic viability of varying the project life of a hybrid GSHP system was also studied.

Chapter 5, Study \#3, a retrofit analysis was performed (hybrid GSHP system) for electrically heated and cooled buildings (baseboard heaters and air-conditioners/cooling towers), in order to investigate the viability of retrofitting existing buildings with a hybrid GSHP system.

Lastly, in Chapter 6, the overall conclusions for the thesis, recommendations, and future work are presented. 


\section{Chapter 2}

\section{Literature Review}

\subsection{Ground-Source Heat Pumps}

GSHPs (also called earth-energy systems, and GeoExchange systems), based on an old technology, were originally developed for the residential sector [18]. A GSHP functions in the same manner as an air-source heat pump (ASHP). Instead of air, like for an ASHP, the ground is used as a heat source and heat sink. In a GSHP system, high-density polyethylene (HDPE) pipes are buried into the ground and a working fluid, usually water or a water-antifreeze solution, is used to extract or inject heat into the ground. In a direct-expansion (DX) system, refrigerant is used as the working fluid instead of an anti-freeze solution [5, 18]. A GSHP system consists of three major components, heat pumps, the ground heat exchanger (GHX or ground loop), and a heating/cooling distribution system $[8,18]$.

The advantage of using a GSHP system is that the ground's temperature is more stable than that of the air. This stability of the ground temperature allows the system to meet heating and cooling energy demands more efficiently throughout the year compared to ASHPs [18-19]. The heat pumps have a coefficient of performance (COP) value of three to four, in the heating mode. The COP of a heat pump is calculated as the heat supplied (removed) divided by the required work input (Equation 2.1). This means that, for $1 \mathrm{kWh}$ of electricity, the heat pump can extract and supply 3 to $4 \mathrm{kWh}$ of heat. The water-to-air heat pump is commonly used in a GSHP system [8, 18]. This designation indicates the system's connection are as follows: ground loop (water side), heat pump, and distribution system (in this case an air distribution system) $[8,18]$.

$$
\text { COP } P_{\text {heat pump }}=\frac{\text { Heat Supplied }}{\text { Work Input }}
$$

Figure 2.1, reproduced from [8], is a graphical representation of the ground temperature variation as a function of depth. These profiles vary depending on geographical location and weather patterns. As a result, the configuration of the ground loop plays an important role in the 
performance and economics of a GSHP system. The deep ground temperatures, corresponding to a location, can be approximated using the "long-term averages of annual average ambient air temperature" [59]. The deep ground temperature in Toronto is approximately $10^{\circ} \mathrm{C}$. By contrast, in Hawaii, due to warmer weather patterns, the deep ground temperature is approximately $25^{\circ} \mathrm{C}$ [59].

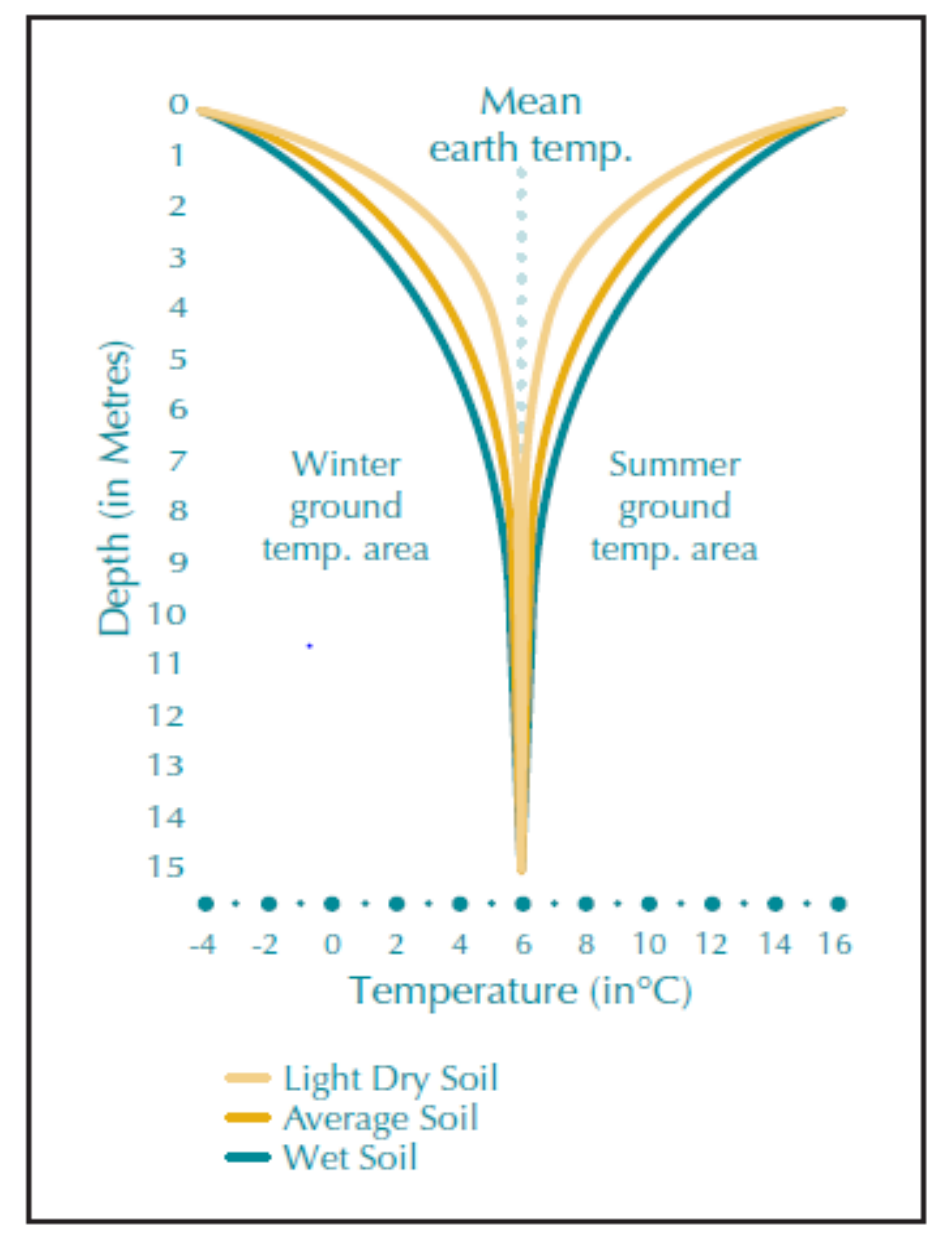

Figure 2.1: Graphical representation of the relationship between ground depth and ground temperature (reproduced from [8])

GSHP systems can reduce up to $66 \%$ of greenhouse gas (GHG) emissions compared to conventional heating and cooling systems [5]. The high initial costs of a GSHP system can be alleviated by hybridizing it with an auxiliary system [15]. In a hybrid GSHP system, the GSHP provides the buildings' base load energy demands and any excessive peaks are met by an auxiliary system [15]. Figure 2.2 is a simplified schematic of a hybrid-GSHP system. A ground loop is used 
to extract from or inject heat to the ground. Heat is transferred between the ground loop and distribution system by a heat pump. A common water loop was used as the distribution system in the study by Alavy et al. [15]. Similarly, the heating and cooling auxiliary systems are also connected to the common loop and heat is transferred by a heat pump and heat exchanger. For the case of a GSHP system (non-hybrid), the auxiliary heating and cooling systems do not exist.

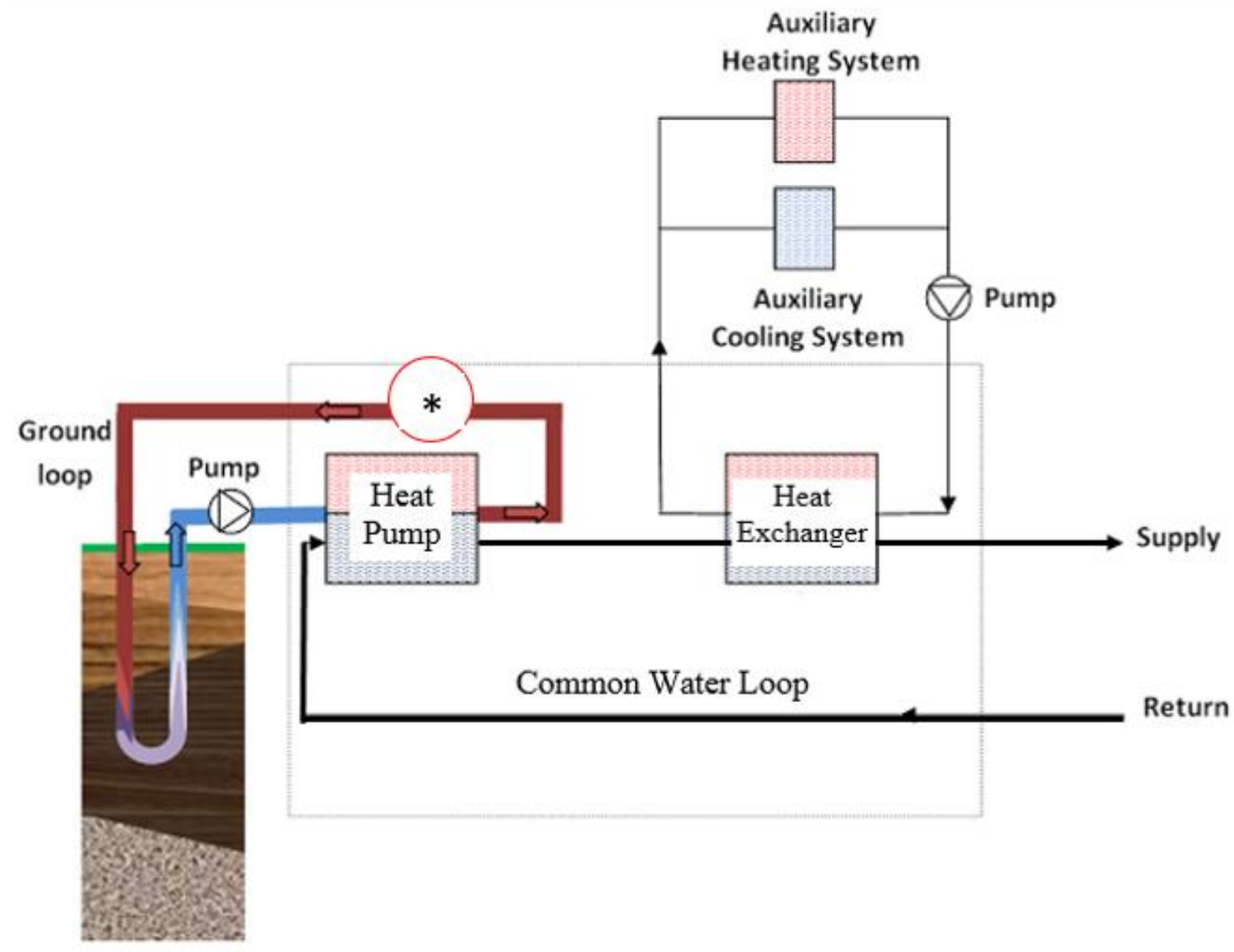

Figure 2.2: Simplified hybrid GSHP schematic

*Alternative placement of the auxiliary cooling systems. For example, a cooling tower would be placed here, the working fluid would be pre-cooled by the cooling tower before entering the ground loop. 


\subsubsection{Open-loop and closed-loop GSHP systems}

GSHP systems can be classified as an open-loop or a closed-loop system [8, 18]. In an open-loop system, the working fluid (water) is extracted from the ground (or water bodies). Water is used as the medium with which heat will be transferred to and from the thermal sink $[8,18]$. In order for such a system to operate, it will need a constant supply of fluid to circulate. These types of systems have been successfully implemented for decades and flourish in environments that have large bodies of water or sustainable aquifers [5, 8]. However, meeting the requirements for a sustainable water source may not be feasible for certain applications, such as buildings situated in urban environments, and/or any strict regulations that exist [18].

On the contrary, in a closed-loop system, a fixed volume of a working fluid is contained within the system; it continuously circulates and never exits the ground loop. Closed-loop systems can also be further classified based on the configuration of the ground loop (horizontal, vertical, and slinky) $[5,8,18]$.

\subsubsection{Horizontal configuration}

A horizontal ground loop (Figure 2.3) is the simplest to install of the three configurations. Horizontal loops tend to be more desired where ample land is available such as buildings situated in rural areas [5]. Pipes are generally laid into relatively dense patterns. When trying to install these densely oriented configurations, the top surface of soil is typically required to be excavated. This will allow for the pipe configuration to be seated properly and the soil to redistribute evenly [5]. Typically 35-55 meters of pipe is installed per $\mathrm{kW}$ of heating/cooling capacity, at a depth range of 1.5 to 3 meters [8]. The primary thermal recharge, of the ground, for horizontal ground loops is mainly by solar radiation [5]. Table 2.1 outlines the advantages and disadvantages of a horizontal ground loop.

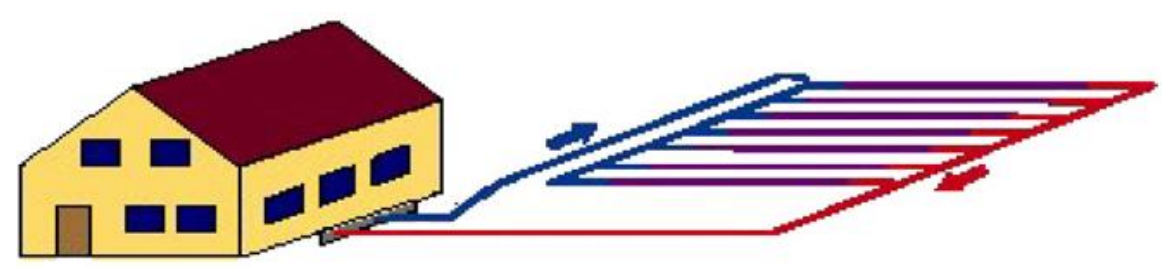

Figure 2.3: Horizontal ground loop configuration (reproduced from [5]) 
Table 2.1: Horizontal ground loop advantages and disadvantages

\begin{tabular}{|c|c|}
\hline Advantages [5, 8, 18] & Disadvantages [5, 8, 18] \\
\hline Simplest to install & $\begin{array}{c}\text { Requires large ground areas } \\
\text { (may not be suitable for urban areas) }\end{array}$ \\
\hline Low costs & $\begin{array}{c}\text { Longer pipe lengths compared to vertical } \\
\text { ground loops }\end{array}$ \\
\hline trenching costs lower than drilling costs) & $\begin{array}{c}\text { At shallow depths, ground temperature } \\
\text { subject to seasonal variance }\end{array}$ \\
\hline & $\begin{array}{c}\text { At shallow depths, soil thermal properties } \\
\text { fluctuate }\end{array}$ \\
\hline
\end{tabular}

\subsubsection{Slinky configuration}

The slinky loop (Figure 2.4) generally requires more piping than the other loop configurations, but requires less trenching (compared to horizontal loops), approximately 500-1000 feet of pipe per ton of cooling [5]. For the installation of a horizontally oriented slinky, trench width typically ranges between 3 to 6 feet, with a spacing of 12 feet apart. When installing a vertically oriented slinky trench width is generally 6 inches [5]. The disadvantages of the slinky loop configuration are similar to that of the horizontal loop configuration.

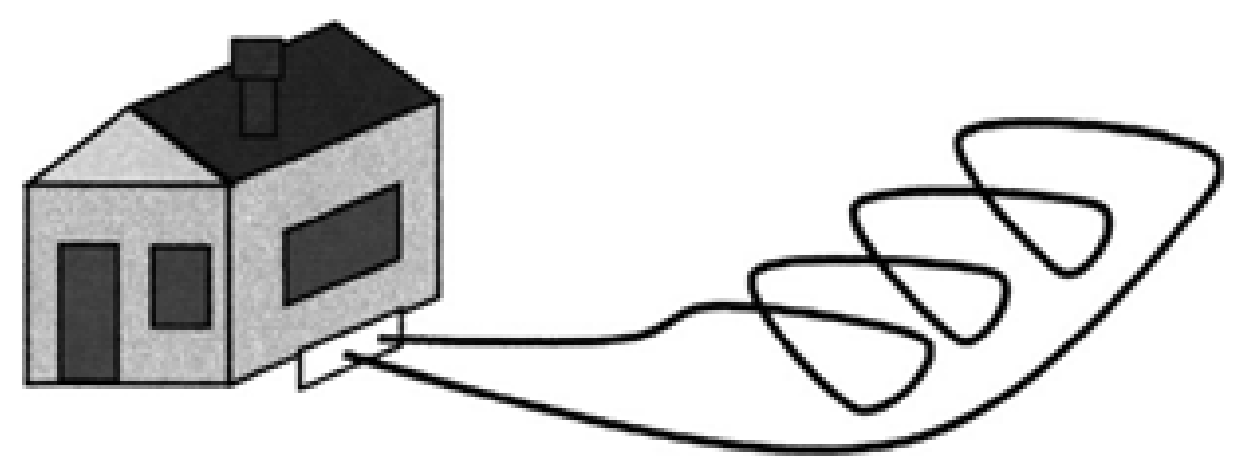

Figure 2.4: Slinky loop configuration (reproduced from [20])

\subsubsection{Vertical configuration}

The vertical loop (Figure 2.5) is the most commonly used configuration in GSHP applications [8]. The vertical loop configuration is well suited in applications with buildings that have bedrock close to the surface [8]. When little acreage is available, the vertical configuration is favorable compared to the slinky and horizontal loop configurations [5]. Boreholes are drilled 15 to 150 meters deep 
into the ground. U-tubes are installed into the borehole. The borehole is then filled with grout to ensure good thermal conductivity between the pipes and the soil $[5,8]$. The advantages and disadvantages of the vertical ground loop configuration are outlined in Table 2.2.

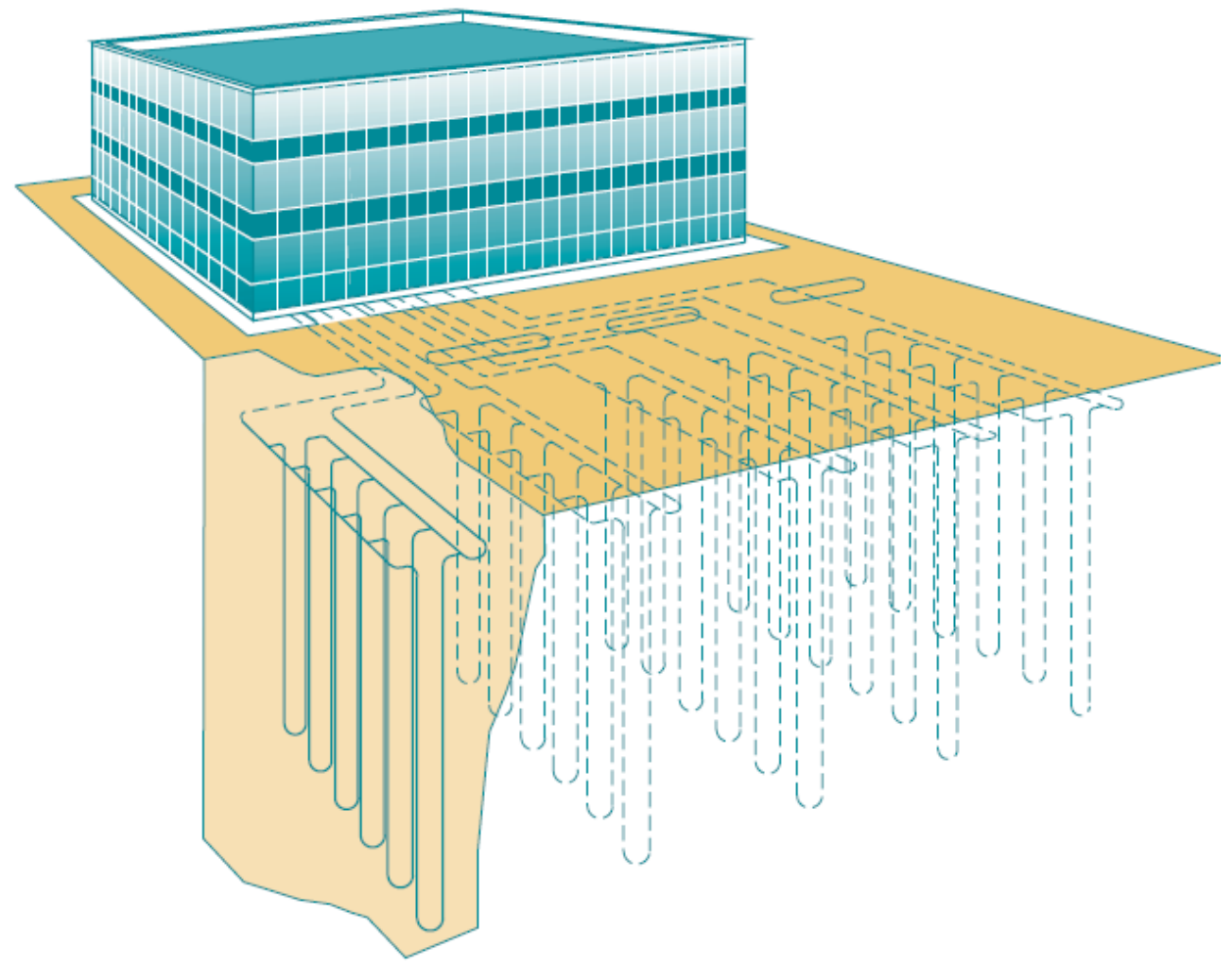

Figure 2.5: Vertical ground loop configuration (reproduced from [8])

Table 2.2: Vertical ground loop advantages and disadvantages

\begin{tabular}{|c|c|}
\hline Advantages $[\mathbf{5 , 8 , 1 8}]$ & Disadvantages $[\mathbf{5 , 8 , 1 8}]$ \\
\hline Requires less total pipe length & $\begin{array}{c}\text { Higher upfront costs } \\
\text { (i.e., drilling, equipment costs) }\end{array}$ \\
\hline Requires the least pumping energy & $\begin{array}{r}\text { Long-term heat buildup if spacing between } \\
\text { boreholes is inadequate }\end{array}$ \\
\hline Low surface ground area requirement & \\
\hline More consistent ground temperatures & \\
\hline
\end{tabular}




\subsubsection{Horizontal directional drilling}

Horizontal directional drilling (HDD) is growing in popularity as an alternative approach for installing the ground heat exchanger. HDD is advantageous in urban areas, landscaped areas can be preserved, because it causes minimal disruption to the surface ground compared to trenching (horizontal) and vertical drilling [21]. However, HDD requires a full layout of the ground to avoid damaging utility lines and underground infrastructure. A simple schematic of HDD is presented in Figure 2.6, a ground pit is used for drilling and installation of the pipes. The costs of HDD is cheaper than that of vertical drilling [personal communication with Mr. Duynhoven and Mr. Rad, June 19, 2013]. The pipes installed by HDD are generally deeper than that of the horizontal configuration. For the case of an HDD ground loop installation outlined in [21], six $250 \mathrm{ft}$ loops at a depth of $35 \mathrm{ft}$ were installed for a residential house located in Rock Hill, South Carolina (resulting in no damage to the house's backyard).

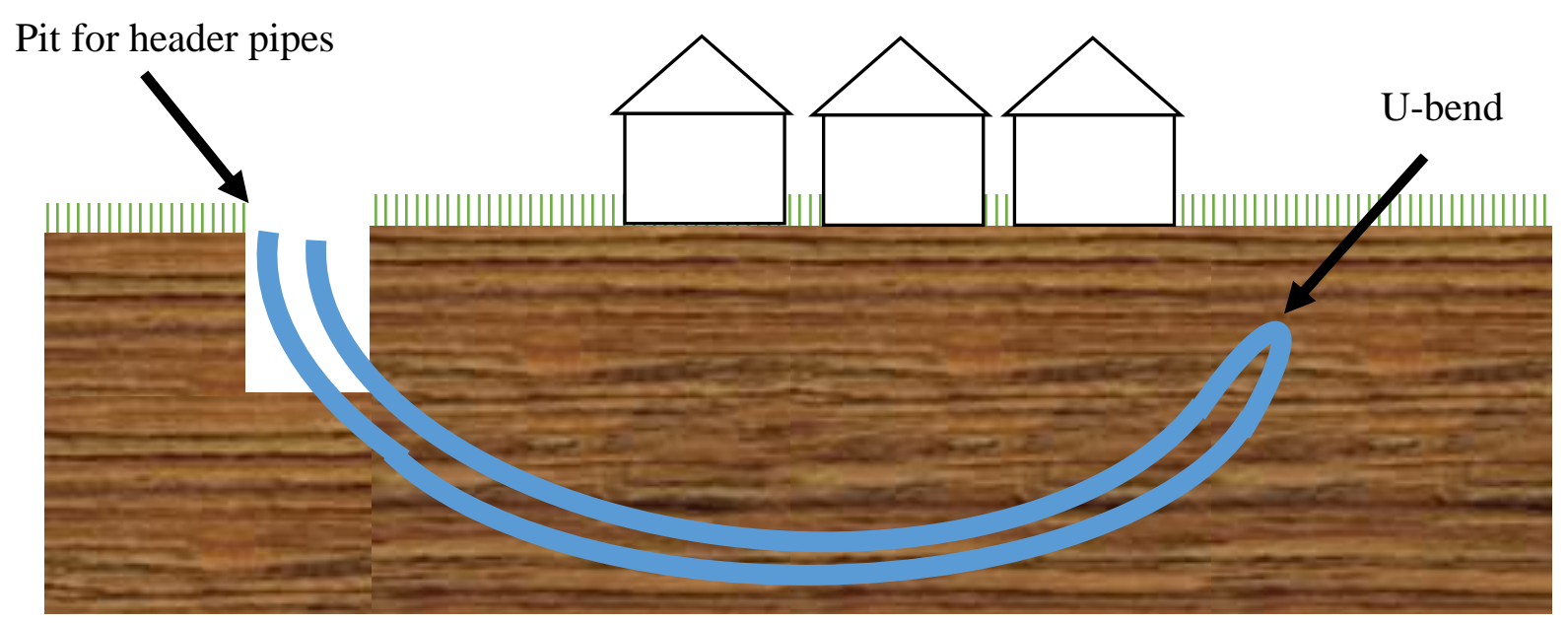

Figure 2.6: Horizontal directional drilling schematic 


\subsection{GSHP Design Tools}

Sizing GSHPs is usually a two-stage process. Building energy modelling software (first stage), such as eQUEST [27], TRNSYS [28], and EnergyPlus [29], is commonly used in the industry to simulate a particular building's energy demands. These programs are used to generate a building's hourly heating and cooling loads for a given year based on user defined inputs such as building geometry, insulation materials, thermostat setting, occupancy patterns, and local weather patterns.

To size the ground loop (second stage), a GSHP ground loop sizing software is typically used. The building's annual hourly loads (8760 hourly loads) are imported into the program and the ground loop is sized based on the loop configuration and other user defined inputs such as heat pump EER/COP, properties of the working fluid, heating and cooling inlet temperatures, soil properties, and piping properties. There are several design software programs available, such as:

- Ground Loop Design (GLD) [22] is the industry leading software for designing GSHPs, it can design GSHP systems of any kind. It is capable of AutoCad integration, and has a system analyzer module for energy/cost analysis.

- GeoAnalyser [23] is a web-based, eliminating the software installation requirements and the use of a USB dongle (e.g., GLD). GeoAnalyser is capable of designing horizontal and vertical GSHPs for residential projects.

- GLHEPRO [24] designs the GSHPs, most suited for vertical configuration, based on monthly heating and cooling loads. GLHEPRO currently is not capable of horizontal or open loop designs.

- RETScreen [25] is a free software provided by the Government of Canada. It can be used for vertical and horizontal closed-loop systems [26]. 


\subsection{Hybrid GSHP Systems}

Since 2005, the total installed capacity of GSHPs has increased by 78.9\% [34]. Qi et al. [34] emphasizes the importance of addressing the problem of imbalance between heating and cooling loads, especially for buildings situated in extreme hot or cold climate, which in turn affects system performance and economics [34]. Implementing proper control strategies is important in optimizing GSHP system performance [35-38]. High upfront costs and long payback periods are currently presenting obstacles to significant market penetration. For large buildings that require large amounts of cooling/heating (cooling/heating dominant), there is a potential long term thermal imbalance of the ground. To address this problem, and account for ground temperature subject to seasonal variance (for horizontal configurations), it is required to have a larger ground loop and/or distance between boreholes. However, in doing so would result in higher upfront costs. In many cases, market penetration impedance for GSHP systems can be alleviated with the use of appropriate computational tools for design analyses. Improving the economic outlook of potential installations can be addressed by hybridizing GSHP systems with an auxiliary system [15, 39-44]; a building's base load energy demands are met by the GSHP system and any excessive peaks are met by an auxiliary system, addressing the problem of long-term thermal imbalance of the ground.

\subsubsection{Sizing hybrid GSHP systems}

The study in Alavy et al. [15] shows there are few research papers available on design strategies of hybrid GSHP systems in an automated manner. To increase the knowledge base of automatically sizing GSHPs as a component of a hybrid system, Alavy et al. [15] developed a computerized approach to automatically size hybrid GSHPs. The results by [15] shows that current rules-ofthumb used, such as that proposed by the CSA (Canadian Standard Association) [54], to size hybrid GSHP systems does not always correspond to an optimized design. For example, CSA suggests (for residential buildings) sizing the ground loop to meet $70 \%$ of the building's peak energy demands and the remainder by auxiliary heating and cooling systems. Furthermore, there are no rules-of-thumb to size GSHPs for commercial buildings, and most often the economics of a conventional system is compared to that of a full GSHP installation. 
The methodology outlined in Alavy et al. [15], for sizing vertical ground loop lengths, produces comparable results to that of the leading ground loop design software GLD. In recent versions of GLD (i.e., 2014 version [22]) there is an option to size hybrid GSHPs; however, this functionality is very limited and time consuming compared to the automated approach outlined in Alavy et al. [15]. In GLD the user defines what portion of the building's peak energy demands are met by the ground loop and auxiliary system. By contrast, the methodology outlined in Alavy et al., [15] automatically sizes the heating and cooling systems, meeting the building's peak cooling and heating loads, with continuously variable auxiliary system capacity. The most economical design (optimal design) after 20 years of operation (or any other project life) is automatically determined.

The calculations for the computerized approach in Alavy et al. [15] are based on the governing equations outlined in ASHRAE's design strategy [18]. Using an energy modelling software (i.e., eQuest, TRNSYS) to obtain the building's annual hourly cooling and heating loads, 8760 hourly loads, which are used towards sizing the ground loop lengths for the cooling and heating loads. Based on the assumption of long-term GSHP operation, the approach uses averaged values of equipment EER (energy efficiency ratio) and COP (coefficient of performance) [18]. For example, the COP and EER of the heat pump are based on the entering fluid temperature as illustrated in Figure 2.7.

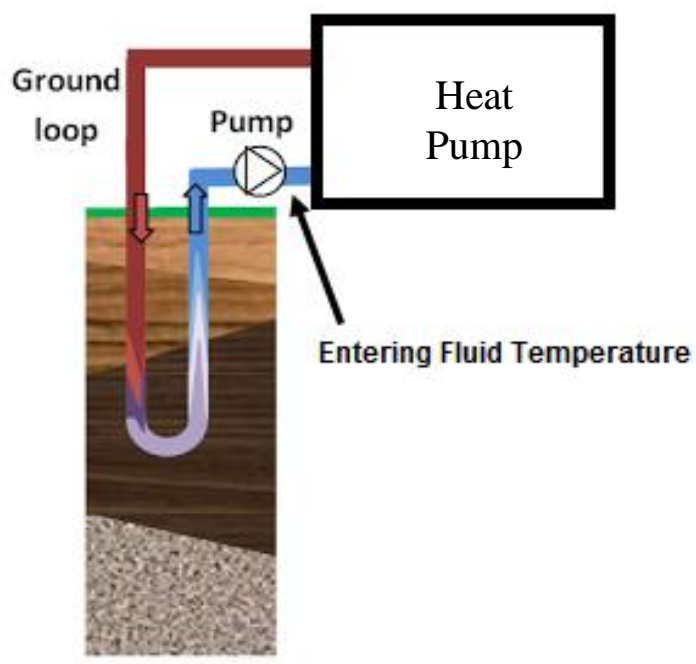

Figure 2.7: Entering fluid temperature to heat pump 
The long-term temperature change in the ground due to excessive extraction or injection of heat is accounted for in the ground loop length calculations using a temperature penalty $\left(t_{p}\right)$ parameter. By introducing a shave factor [15] for the portion of peak demands met by the GSHP, the hybrid design can be determined by varying it between 0 and 1 . A shave factor value of 0.6 indicates that $60 \%$ of the building peak demands are met by the GSHP and the remainder by an auxiliary system (i.e., conventional system). Two sets of ground loop lengths are determined, based on varying the shave factor, for the heating and cooling loads respectively.

The equations used to determine the vertical borehole length for the cooling loads $\left(L_{c}\right)$ and heating loads $\left(L_{h}\right)$ are respectively presented by Equations 2.2 and 2.3, as outlined by Kavanaugh and Rafferty [18]. If $L_{c}$ is greater than $L_{h}$ for peak demands, then the building is classified as cooling dominant and the analysis in varying the shave factor (Chapter 2.3.2) will be based on $L_{c}$ (vice versa for heating dominant). For further calculation details, refer to [18].

$$
\begin{aligned}
& L_{c}=\frac{q_{a} R_{g a}+\left(C_{f c} q_{l c}\right)\left(R_{b}+P L F_{m} R_{g m}+R_{g d} F_{S c}\right)}{t_{g}-\frac{t_{w i}+t_{w o}}{2}-t_{p}} \\
& L_{h}=\frac{q_{a} R_{g a}+\left(C_{f h} q_{l h}\right)\left(R_{b}+P L F_{m} R_{g m}+R_{g d} F_{s c}\right)}{t_{g}-\frac{t_{w i}+t_{w o}}{2}-t_{p}}
\end{aligned}
$$

where [18],

$$
\begin{array}{lll}
L_{c} & =\text { Required ground loop length for cooling }(\mathrm{m}) \\
L_{h} & =\text { Required ground loop length for heating }(\mathrm{m}) \\
q_{a} & =\text { Net annual heat transfer to the ground }(\mathrm{W}) \\
R_{g a} & =\text { Effective thermal resistance of the ground, annual pulse }(\mathrm{m} \cdot \mathrm{K} / \mathrm{W}) \\
C_{f c} \text { and } C_{f h} & =\text { Correction factors accounting for the heat rejected or absorbed by the } \\
q_{l c} & =\text { heat pump } \\
q_{l h} & =\text { Building design cooling load }(\mathrm{W}) \\
R_{b} & = & \text { Thermal resistance of borehole }(\mathrm{m} \cdot \mathrm{K} / \mathrm{W}) \\
P L F_{m} & = & \text { Part-load factor during design month }
\end{array}
$$




$$
\begin{array}{ll}
R_{g m} & =\text { Effective thermal resistance of the ground, monthly pulse }(\mathrm{m} \cdot \mathrm{K} / \mathrm{W}) \\
R_{g d} & =\text { Effective thermal resistance of the ground, daily pulse }(\mathrm{m} \cdot \mathrm{K} / \mathrm{W}) \\
F_{s c} & =\text { Short-circuit heat loss } \\
t_{g} & =\text { Undisturbed ground temperature }\left({ }^{\circ} \mathrm{C}\right) \\
t_{w i} & =\text { Liquid temperature at heat pump inlet }\left({ }^{\circ} \mathrm{C}\right) \\
t_{w o} & =\text { Liquid temperature at heat pump outlet }\left({ }^{\circ} \mathrm{C}\right) \\
t_{p} & =\text { Temperature penalty for interference of adjacent boreholes }\left({ }^{\circ} \mathrm{C}\right)
\end{array}
$$

The constant values for the parameters listed can be found in Table 3.3.

\subsubsection{Sizing hybrid GSHP systems (approach used in the thesis)}

Peak cooling and heating demands, as observed in Figures 2.8 and 2.9 for a transit facility located in Toronto, Ontario only occur on the hottest and coldest days in a given year. Since GSHP systems are cheaper to operate but more expensive to install compared to conventional heating and cooling systems, it is not always economical to size the GSHP system to meet peak demands [15]. By introducing a shave factor which is the portion of peak demands met by the GSHP system, the high upfront costs of a GSHP system can be reduced.

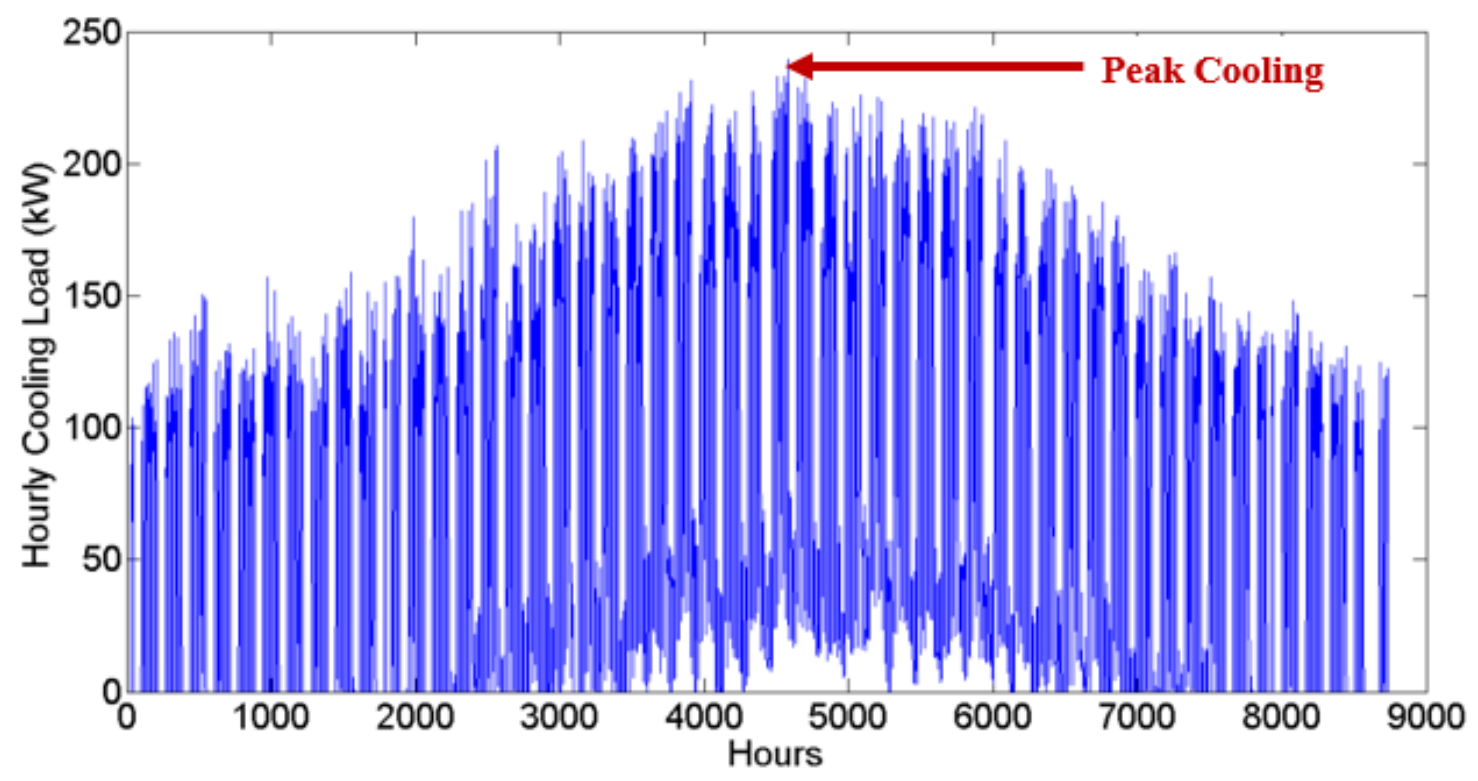

Figure 2.8: Sizing hybrid GSHP systems - Hourly cooling loads for a transit facility located in Toronto, Ontario. The hours in a year (8760 hours in a year) are along the abscissa. 


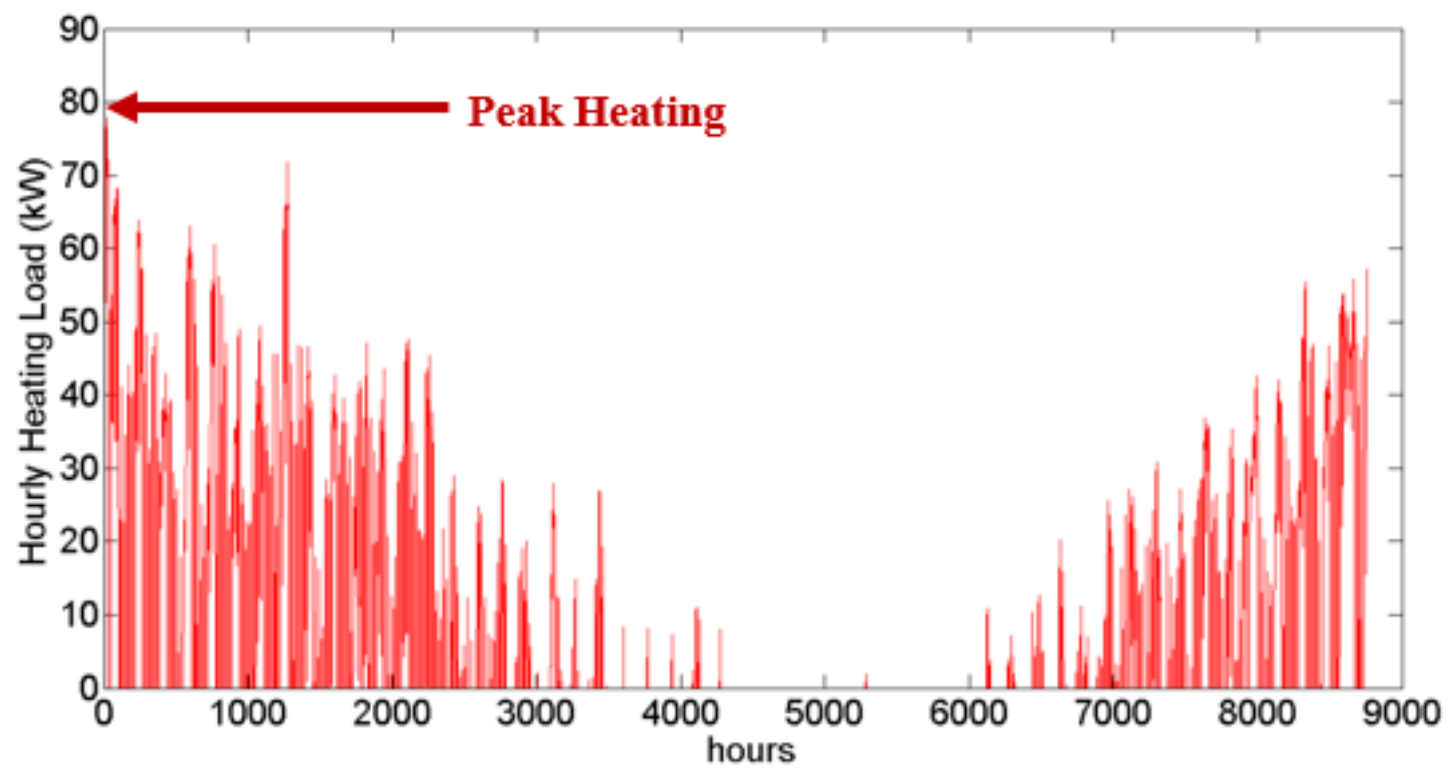

Figure 2.9: Sizing hybrid GSHP systems - Hourly heating loads for a transit facility located in Toronto, Ontario. The hours in a year ( 8760 hours in a year) are along the abscissa.

Figure 2.10 illustrates the use of the shave factor parameter in order to reduce the high upfront costs of the GSHP system for a transit facility located in Toronto, Ontario. The dashed line represents the shave factor $(S F)$. For this particular example the shave factor is set at $60 \%$ of the transit facility's peak demands for the cooling and heating curves respectively. This set point indicates that $60 \%$ of the peak demands are met by the GSHP (base load) and the remainder by an auxiliary system (peak demands). It can be observed that a large portion of the building's energy demands are still met by the GSHP without the high upfront costs of sizing it to meet $100 \%$ of peak demands. By varying the shave factor between $0 \%$ and $100 \%$ of the building's peak cooling and heating demands, the hybrid GSHP system corresponding to the lowest cost in the net present value (NPV) is the most economical (optimal) design. 


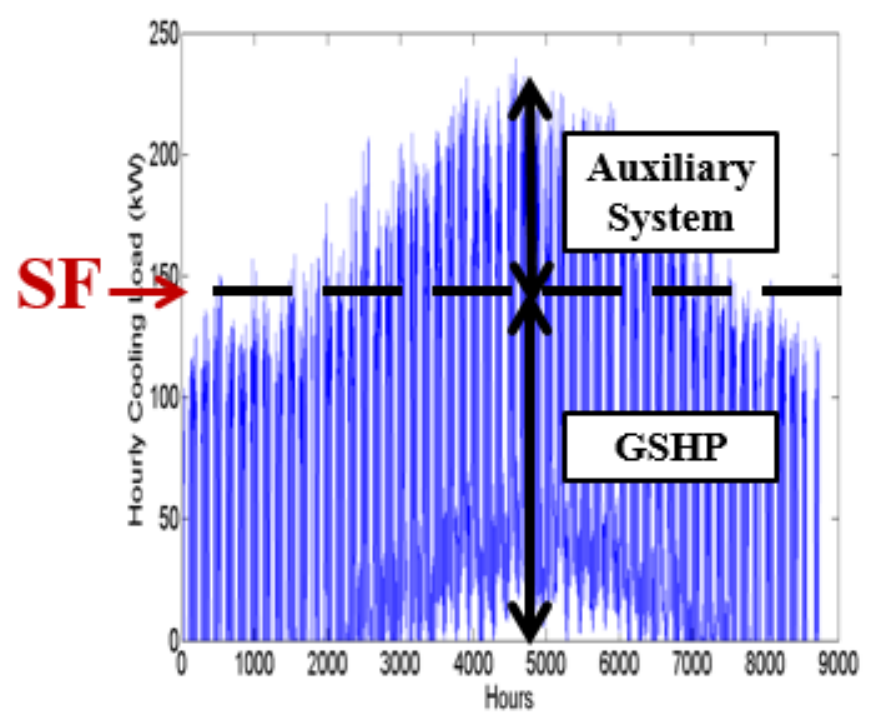

Cooling Loads

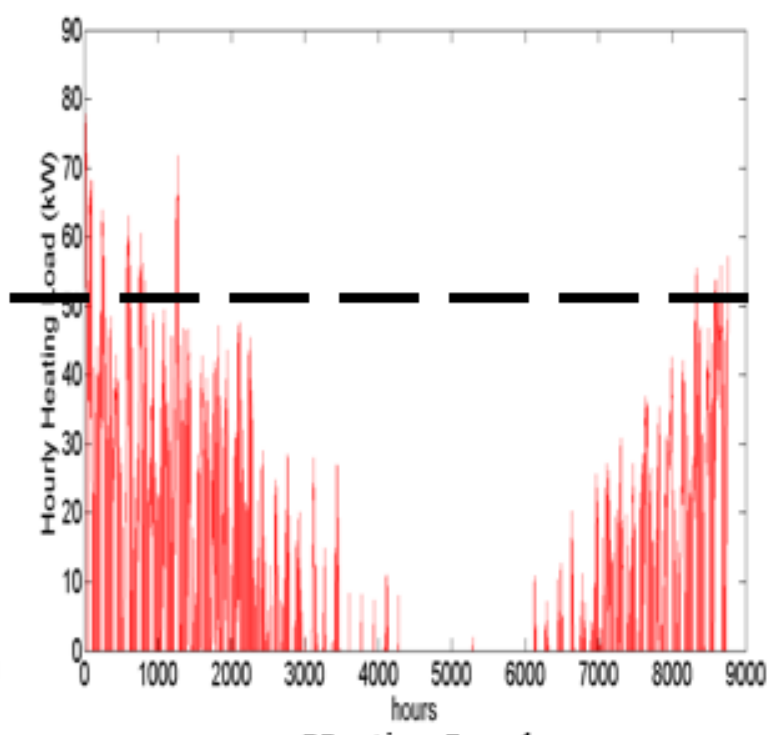

Heating Loads

Figure 2.10: Sizing hybrid GSHP systems - Shave factor schematic for a transit facility located in Toronto, Ontario. The hours in a year ( 8760 hours in a year) are along the abscissa and hourly cooling/heating loads are along the ordinate.

In this thesis, hybrid GSHPs are sized using the methodology in [15] which defines optimal for hybrid GSHPs in terms of costs as presented in Figure 2.11. The costs consists of the initial costs, the operating/maintenance costs, and inflation. In Chapter 3 (Study \#1), Chapters 4 (Study \#2) and 5 (Study \#3) of this thesis, the costs associated with utilities, carbon tax, and building retrofit costs will be considered. Discounting these costs into a total cost in net present value (NPV) dollars, by varying the shave factor between $0 \%$ and $100 \%$ of peak demands, the shave factor corresponding to the lowest total cost is deemed to be the most optimal hybrid GSHP system design (most economical design). In Figure 2.12, the total costs corresponding to each shave factor value are plotted. The upfront costs and operating costs of the hybrid GSHP system are represented by the blue and red curves, respectively. The total costs in net present value (green curve) is obtained by combining the costs upfront and operating costs (blue and red curves). For the case of the transit facility, the most economical design occurs at the shave factor value of 0.48 ( $48 \%$ of peak demand) at the minimum NPV. 


\section{Study \#1:}

- Electricity rates

- Weather

- Inflation

- Control

Study \#2:

- Entering fluid temperature

- Carbon Tax

Study \#3:

- Retrofit Costs

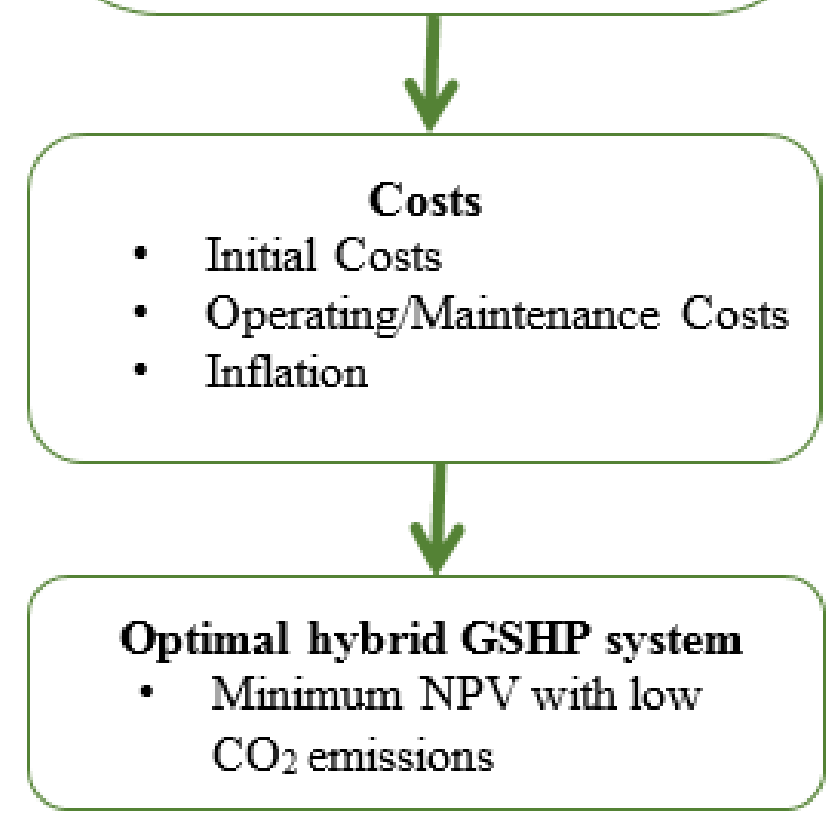

Figure 2.11: Sizing GSHPs based on costs 


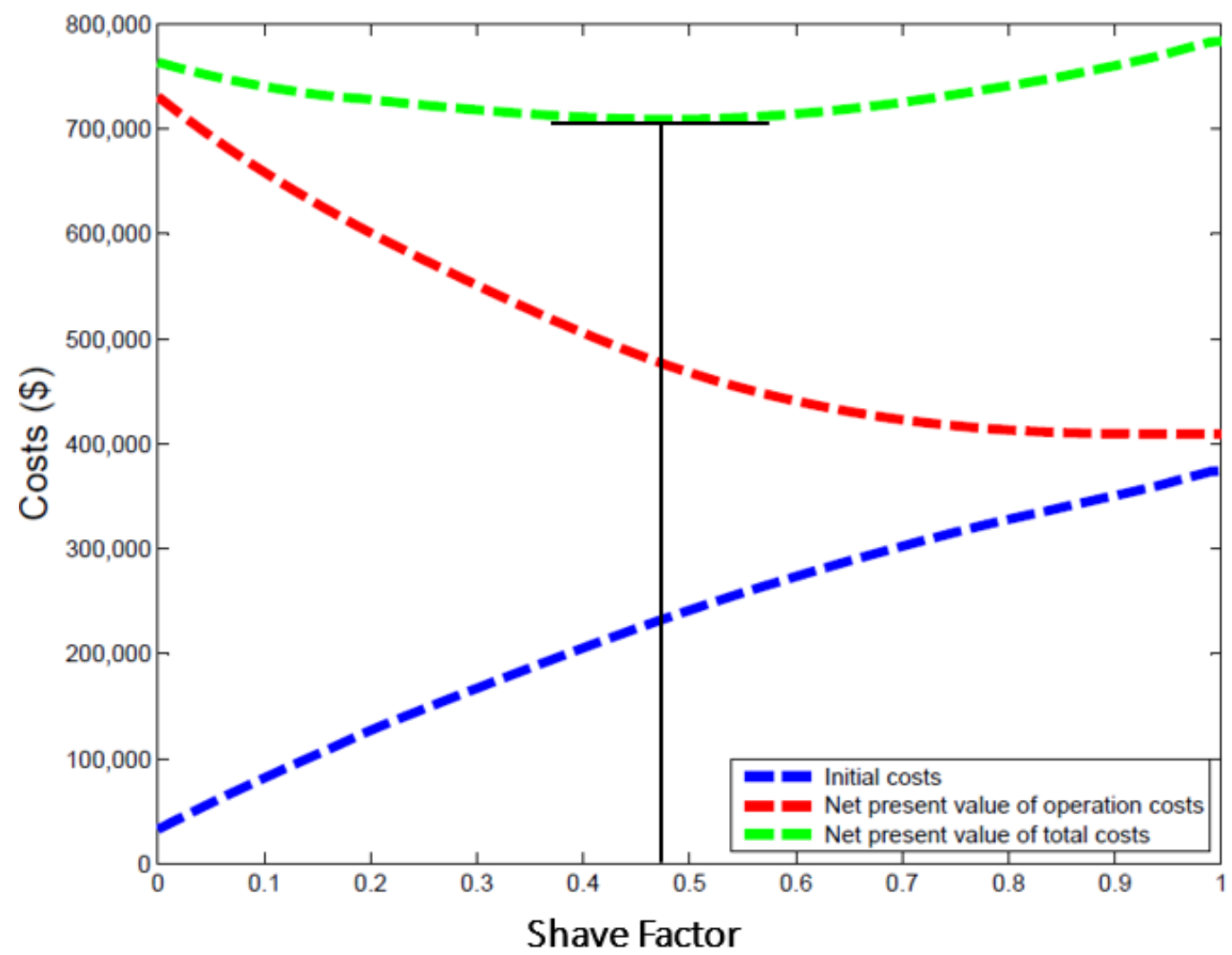

Figure 2.12: Sizing hybrid GSHP systems - Optimal design of a transit facility located in Toronto, Ontario (reproduced from [15]). The total costs in net present value are along the ordinate.

The procedure in determining an optimal design in this thesis consists of the following steps [15]:

- The building is modelled in accordance with an established building code through the use of a building energy modelling software (i.e., eQUEST or TRNSYS). The building's annual energy demands, 8760 hourly heating and cooling loads (8760 hours/year), are generated using the long-term averaged weather data available in most building modelling software.

- The building's hourly heating and cooling loads are imported into the recently developed algorithm in [15] in order to determine the ground loop lengths $L_{c}$ and $L_{h}$ as explained in section 2.3.1 (equations 2.2 and 2.3). If $L_{c}>L_{h}$ the building is defined as cooling dominant, and the shave factor is varied (between $0 \%$ and $100 \%$ of peak demands) based on the building's cooling loads (vice versa for heating dominant). 
- The capital and operating costs for each shave factor value are calculated and discounted into a net present value cost. The shave factor with the lowest total costs in net present value is deemed to be the optimal design.

\subsection{Knowledge Gap and Challenges}

Using the methodology outlined in Alavy et al. [15], a sensitivity analysis for a variety of design parameters will be explored as a way of increasing the knowledge base of automatically sizing GSHPs as a component of a hybrid system. In doing so, time consuming and tedious processes in sizing hybrid GSHP systems can be eliminated. For example, it can take several hours to obtain the ground loop lengths and determine upfront costs for all shave factors from 0 to 1 for a particular building, using existing software such as GLD.

The present work using the methodology outlined in [15], consisting of three studies, will investigate the economic viability of GSHPs based on various parameters such as geographical location, operating costs, inflation rates, operating duration (or project life), heat pump entering fluid temperature (EFT), carbon taxation, and building retrofit.

\subsubsection{Heat pump entering fluid temperature and carbon taxation}

In a GSHP system the ground is a relatively stable medium for heat transfer throughout the year. Compared to outdoor air, GSHP systems requires less electricity to operate and emit less greenhouse gas (GHG) relative to conventional heating and cooling methods due to high efficiency of the GSHP systems [5]. At soil depths less than two metres, the ground temperature is largely dependent on the outdoor air temperature. As the depth increases beyond two metres, the effect of seasonal changes in temperature is reduced and the ground temperature profile stabilizes to become constant, that of the local average annual outdoor air temperature [20, 64].

In a GSHP system, EFT to heat pump plays a crucial role in determining the efficiency of the heat pump and total costs of the system. The effects of various ground layers and single or double Utube configuration on the borehole heat transfer performance is addressed in [65]. The authors in [65] find from their numerical model that the fluid temperature in the U-tubes varies non-linearly 
along the tubes. More heat is transferred in the first stage (down-flow tube) than in the second stage (up-flow tube) of the U-tube, as the temperature differences between the fluid and its surroundings are higher in the first stage. They also find that better heat transfer performance of the U-tubes can be obtained if the upper ground layers have high thermal conductivity. They conclude that although double U-tubes cost 22-29\% more than single U-tube, the heat transfer performance of double U-tubes (in parallel or in series) are more superior than single U-tube by $26-29 \%$ (in parallel) or $42-59 \%$ (in series). For a given heat transfer from a heat pump in cooling mode, a more efficient ground loop will mean lower entering fluid temperature to the heat pump. Therefore, an appropriate design of ground loop is very important as the heat pump performance depends on the heat transfer efficiency of the ground loop.

In [39], hybrid GSHP systems with a supplemental cooling-tower loop, which is connected in parallel to the condenser of the heat pump or in series with the ground loop, were analyzed. The results show that the coefficients of performance (COPs) of the hybrid GSHP systems with the parallel and serial configurations are $18 \%$ and $6 \%$ higher than that of the GSHP alone, respectively, when the exiting fluid temperature of the ground loop is $40^{\circ} \mathrm{C}$ [39].

In [66], the effects of optimizing entering fluid temperature to a GSHP were studied. The authors utilized a building automation system to monitor the temperature of the liquid entering and leaving the heat pump. The GSHP system that they studied uses a primary-secondary system in which there are two loops to control the simultaneous heating and cooling demands in a building. The results of the study indicate that by optimizing the entering fluid temperature to a GSHP, there is an increase in the COP and energy efficiency rating (EER) of the system.

In [5], the author compares energy efficiency and $\mathrm{CO}_{2}$ emissions of various heating systems. The systems include oil fired boilers, gas fired boilers, electrical heating, conventional electricity for cooling and a GSHP, and green electricity (i.e., hydro, solar, wind) and a GSHP [5]. Electrical heating generates the highest $\mathrm{CO}_{2}$ emissions of $0.9 \mathrm{~kg} \mathrm{CO}_{2} / \mathrm{kWh}$ and the lowest primary energy efficiency of $36 \%$ [5]. However, this result is dependent on location and the source of electricity (United Kingdom). The energy efficiency of $36 \%$ indicates that the output energy of the system is only $36 \%$ of the input. On the other hand, green electricity coupled with a GSHP system results in 
no GHG emissions and a primary energy efficiency of up to 400\% [5]. Since GSHPs operate using electricity, green energy contributes to a much greater emissions savings than conventional electricity would otherwise.

The study by Soimakallio et al. [68], there are two types of $\mathrm{CO}_{2}$ emissions, direct and indirect. Direct emissions are those that result during the operation of the heating and cooling system and indirect emissions are those that are connected such as the emissions that result from electricity production and consumption by the pumps and compressors. In [68], the authors acknowledge that there is a large uncertainty in determining emissions for GSHP systems. GHG emission calculations are greatly dependent on the following limitations: choice of heating method, actual COP of the heat pump, and electricity supply mix $[69,70]$.

Similarly, in a study by Greening and Azapagic [67], a heat pump is used to completely replace the gas boilers inside a building. The direct $\mathrm{CO}_{2}$ emissions of the heating system reduced from $0.220 \mathrm{~kg} \mathrm{CO}{ }_{2}$ equivalent $/ \mathrm{kWh}$ to $0.178 \mathrm{~kg} \mathrm{CO}_{2}$ equivalent $/ \mathrm{kWh}$ [67]. It was concluded that replacement of the gas boiler with a GSHP resulted in a savings of $12.8 \%$ of direct GHG emissions and only $2.4 \%$ in total GHG emissions [67]. Again, because of the dependence on the electricity supply mix, this result would be location dependent.

Although recent studies indicate that there are potential reductions in GHG emissions with the use of GSHPs, the studies are limited to complete replacements of conventional systems with that of a GSHP system. Similarly, in previous studies, the analyses on the effects of entering fluid temperature changes are limited to pure GSHP systems. There exists a knowledge gap in regards to analyses on optimizing entering fluid temperature to heat pump and $\mathrm{CO}_{2}$ emissions savings for hybrid GSHPs. Entering fluid temperature to heat pump affects the COPs of a hybrid GSHP system. As such, improving the COP in turn reduces GHG emissions. The methodology outlined in Alavy et al. [15], which is used in this study, automatically sizes hybrid GSHP systems with continuously variable ground loop and auxiliary system capacity, based on minimizing the net present value of total costs. The method has been applied to study the utility model of GSHPs [97]. Using the methodology outlined in [15], a techno-economic analysis of optimizing entering fluid 
temperature to heat pump, and carbon taxation for hybrid GSHP systems in Toronto, Canada was performed to determine and better understand the potential economic and environmental benefits.

\subsubsection{Building retrofit}

The literature shows that there is a challenge in retrofitting buildings with GSHP systems. For example, in the UK, there is a lack of understanding in determining the advantages of heat pumps for a particular house [30]. A growing body of evidence suggests the lack of determining the advantages for a heat pump system, for new builds and retrofits, is a result of poor installation and operating performance such as poor underestimation of the ground area for horizontal GSHP systems. Sizing heat pumps remain a challenge, in which oversizing the system would result in higher capital cost and longer payback periods [30].

Zhu et al. [31] performed a ground water heat pump retrofit case study for a hotel situated in Wuhan, China. The system was sized to replace a conventional air-to-water system and meet the building's cooling and heating loads of $208 \mathrm{~kW}$ and $170 \mathrm{~kW}$ respectively (total air conditioning area of $1,862 \mathrm{~m}^{2}$ ). The retrofit proved to be economical, with the heat pump's COP ranging between 3.1 and 6.8 [31]. Although the installation was economically viable, it may be of interest to further optimize the system by continuously varying the capacity of an auxiliary system.

Between the 1960's and 1980's, many multiunit residential buildings (MURBs) used electric baseboard heaters as the main source of heating because of low capital cost, easy installation/nonintrusive, and low electricity costs [32]. However, current regulations for more efficient HVAC (heating, ventilation, and air conditioning) systems and high electricity rates make electric baseboards undesirable. As a result, there exist a large demand to economically retrofit buildings (i.e., MURBs) with existing electric baseboard heaters. In 2002, a study was performed by the Canada Mortgage and Housing Corporation (CMHC) [32] to retrofit baseboard heaters with waterto-water GSHPs. The GSHP was sized to meet all of the building's heating demands; however, the building's cooling demands were not accounted for in the study resulting in long payback periods of over twenty years [32]. 
Similarly, Larson et al. [33] retrofitted electric baseboard heaters with ductless mini-split heat pumps (DHPs/ASHPs) for multifamily and commercial buildings. However, the buildings' heating energy demands were estimated based on the buildings' energy-use billing history. As a result, several buildings were rejected from the study due to unavailable/incomplete billing histories. Furthermore, buildings that underwent major envelope upgrades were excluded from the study because it would be difficult to attribute DHP savings [33].

There exists a knowledge gap to retrofit buildings heated by electric baseboard heaters with GSHP systems and in several instances space cooling was not accounted for by the heat pump. To fill the knowledge gap, using the methodology outlined in Alavy et al. [15], the retrofit designs can be optimized in an automated manner.

\subsubsection{Other energy efficient systems}

Much work has been done on implementing renewable alternatives to provide heating and cooling energy for the residential sector. For example, a typical single-family house designed for very low energy consumption, located in Germany, has all of its heating and electricity demands met by renewable energy sources [98]. All water consumption used for toilet flushing, garden irrigation, and washing machines are met by a $5500 \mathrm{~L}$ rainwater storage tank. Heating and electricity demands are met by a solar heating system and PV system respectively. Similar systems are installed in residential houses in France, Switzerland, Sweden, and the Netherlands [98]. However, these systems still lack space cooling capabilities.

Alternatively, cogeneration systems which simultaneously produce electricity and heat (for space heating and hot water production) can be considered. These systems are suitable in temperate and arctic regions of North America and are often referred to as CHP (combined heat and power) systems [99-100]. In a CHP system, a Stirling engine is commonly used to generate electricity using natural gas. However, in the summer months there is very little demands for space heating. A lot of the generated heat, by the Stirling engine, becomes waste heat. With the addition of an absorption chiller a co-generation system becomes a tri-generation system (combined heat, cooling and power). The waste heat becomes a heat source for the absorption chiller [99-100]. 
Hasib [100] investigated the performance of a tri-generation system using a ClimateWell ${ }^{\circledR}$ absorption chiller. The experiment was carried out in Vaughan, Ontario, using a Toronto and Regional Conservation Authority (TRCA) house. This project is the first of its kind to use a Trigeneration system for residential purposes, in Canada, using ClimateWell ${ }^{\circledR}$ technology [100]. In addition to the tri-generation system, a ground loop is installed at the TRCA house. The results obtained from this study can be used towards incorporating the ground loop for the TRCA house in an optimized manner. 


\section{Chapter 3}

\section{Study \#1: Hybrid-GSHP Sensitivity Analysis}

To better understand optimization factors in sizing hybrid GSHP systems, a series of sensitivity analysis have been performed. Using a rigorous mathematical, computational approach to size hybrid GSHP systems recently published in [15], the use of sensitivity analyses has allowed for a better determination of the impact that variations in input parameters have on the performance of GSHPs. A total of five analyses were performed to determine the effects that operating costs, inflation, geographical location within North America, and a seasonality control strategy have on sizing hybrid GSHP systems.

\subsection{Sensitivity Analysis: Parameters Used}

The literature on environmental modelling supports the need for sensitivity analysis when undertaking a model-based study [46]. In particular, the application of sensitivity analysis is useful when the parameters employed in the model are impacted by uncertainties related to the parameter data [47] and can provide for a better understanding of the impact of changes in input data on a model's results. Decisions arising from performance modelling are better informed by the results of sensitivity analysis. Otherwise, a risk of misunderstanding the behaviours suggested by the model may result in inferences leading to improper choices [48].

When evaluating performance modelling of GSHP and hybrid-GSHP energy systems, the more recent literature has recognized the need for the use of sensitivity analysis related to model parameters such as electricity and natural gas pricing, interest rates, annual operating hours and ground temperatures when presenting the results of modelled outcomes [49-53].

For the purpose of sensitivity analysis, ten real buildings ranging from large multi-residential to

commercial were analyzed as detailed in Table 3.1, data courtesy of CleanEnergy ${ }^{\mathrm{TM}}$. Based on these buildings a total of five sensitivity cases are investigated using the parameters, such as heat pump inlet temperature, boiler cost, interest and inflation rates, listed in Tables 3.2 and 3.3. The 
criteria in determining the optimal GSHP size is based on one which produces the minimum total costs in net present value dollars, considering both installation and operating costs (Chapter 2.3.2).

Based on a building's energy demands, for space heating and cooling, two ground loop lengths are calculated [15]. If the ground loop length required to meet peak heating demand is greater than that required to meet peak cooling demand, then the building is heating dominant (and vice versa). If a building is heating (cooling) dominant, the ground loop length is sized as a function of shave factor (the portion of peak demand met by the GSHP) based on the building's heating (cooling) demands (Chapter 2.3). The most economical design is selected, based on the optimal shave factor, corresponding to the lowest net present value of capital (of the entire hybrid system) and operating costs [15].

Table 3.1: Building information

\begin{tabular}{|l|c|}
\hline \multicolumn{1}{|c|}{ Building Info* } & Sector \\
\hline 1. Hospital (Hosp.) & Commercial \\
\hline 2. Office & Commercial \\
\hline 3. Restaurant (Rest.) & Commercial \\
\hline 4. Fast-Food Restaurant (FF Rest.) & Commercial \\
\hline 5. Transit Facility (TF) & Commercial \\
\hline 6. Mid-rise, Multi-residential (MR) & Residential \\
\hline 7. High-rise, Multi-residential A (HR A) & Residential \\
\hline 8. High-rise, Multi-residential B (HR B) & Residential \\
\hline 9. High-rise, Multi-residential C (HR C) & Residential \\
\hline 10. School & Commercial \\
\hline
\end{tabular}

*Refer to Appendix A for full building details.

Table 3.2: General costs of hybrid GSHP system components (data courtesy of CleanEnergy ${ }^{\mathrm{TM}}$ )

\begin{tabular}{|l|c|}
\hline \multicolumn{1}{|c|}{ Item } & Cost \\
\hline $\begin{array}{l}\text { Ground heat exchanger } \\
\text { (installation and materials) }\end{array}$ & $\$ 65.6 / \mathrm{m}(\$ 20 / \mathrm{ft})$ \\
\hline $\begin{array}{l}\text { Cooling tower, plate heat exchanger including } \\
\text { controls and auxiliary equipment }(\mathrm{COP}=2)\end{array}$ & $\$ 14 / \mathrm{kW}$ of tower design capacity \\
\hline Boiler (efficiency $=78 \%)$ & $\$ 20 / \mathrm{kW}$ of boiler design capacity \\
\hline
\end{tabular}


Table 3.3: General design parameters (data courtesy of CleanEnergy ${ }^{\mathrm{TM}}$ )

\begin{tabular}{|l|c|}
\hline \multicolumn{1}{|c|}{ Parameters } & Value \\
\hline Cooling Design Entering Water Temperature to HP & $29.4^{\circ} \mathrm{C}$ \\
\hline Heating Design Entering Water Temperature to HP & $1.7^{\circ} \mathrm{C}$ \\
\hline Heat Pump & $\begin{array}{c}\text { CleanEnergy Developments/ PC0018 } \\
\left(\text { COP }_{\text {heating }}=3.1, \mathrm{COP}_{\text {cooling }}=3.78\right)\end{array}$ \\
\hline Soil Thermal Conductivity & $2.94 \mathrm{~W} / \mathrm{m} \cdot \mathrm{K}$ \\
\hline Soil Thermal Diffusivity & $0.072 \mathrm{~m} / \mathrm{day}$ \\
\hline Duration of Operation & 20 years \\
\hline Borehole Thermal Resistance & $0.136 \mathrm{~m} \cdot \mathrm{K} / \mathrm{W}$ \\
\hline Pipe Resistance & $0.06 \mathrm{~m} \cdot \mathrm{K} / \mathrm{W}$ \\
\hline Pipe Size & $32 \mathrm{~mm}$ \\
\hline Borehole Diameter & $127 \mathrm{~mm}$ \\
\hline Grout Thermal Conductivity & $1.47 \mathrm{~W} / \mathrm{m} \cdot \mathrm{K}$ \\
\hline Number of boreholes across & 11 \\
\hline Number of boreholes down & 4 \\
\hline Inflation Rate & $4 \%$ \\
\hline Interest Rate & $8 \%$ \\
\hline$C_{f c}$ and $C_{f h}[18]$ & 1.04 \\
\hline
\end{tabular}

GSHP Configuration: single U-tube vertical closed-loop

It is important to note that several factors (i.e., insulation, and occupancy patterns) contribute to determining the buildings' heating or cooling dominance. Based on the definition of heating/cooling dominance, using Toronto's weather patterns, only the hospital and office building were found to be heating dominant [15]. For example, occupancy activities such as cooking is accounted for as heating which results in residential buildings requiring less heating from a GSHP (during the winter months) and more cooling during the summer months.

The building's TEDM (percentage of Total Energy Demand Met by the GSHP) can be determined by varying the shave factor. As the shave factor increases so does the TEDM, however, this relationship is not linear. For example, Figures 3.1 and 3.2 illustrate the relationship between shave factor and TEDM for a school situated in Toronto, Ontario. For this particular example, a shave factor of 0.78 is capable of providing close to $100 \%$ of the building's TEDM (Figure 3.2); there are only a few days in a year where a building's peak loads occur and exceed the GSHP's capacity, which can be negligible compared to the total annual loading (Figure 3.1). 


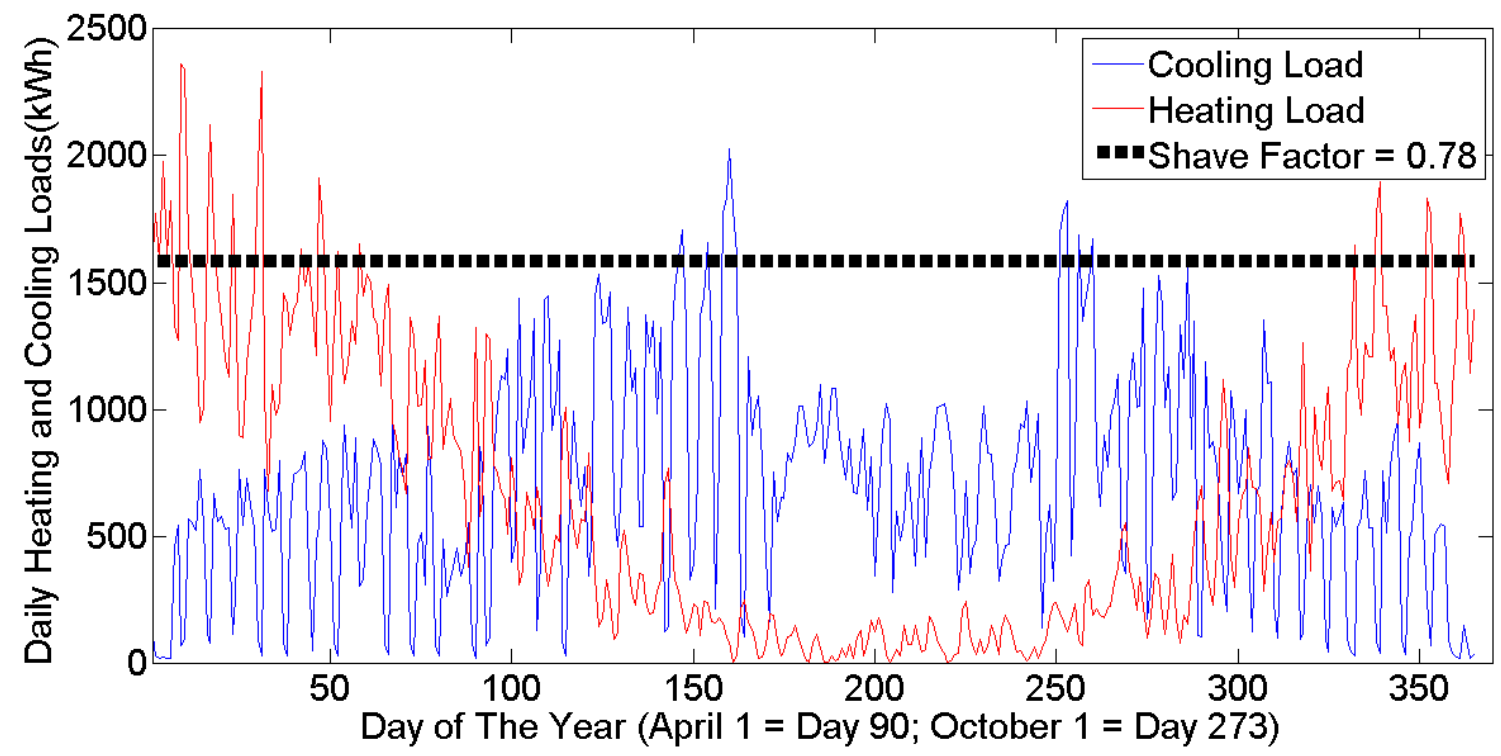

Figure 3.1: Daily heating and cooling loads of a school in Toronto, Ontario, Canada The abscissa represents the days of the year (365 days). The blue and red line represents the cooling and heating loads $(\mathrm{kWh})$ respectively.

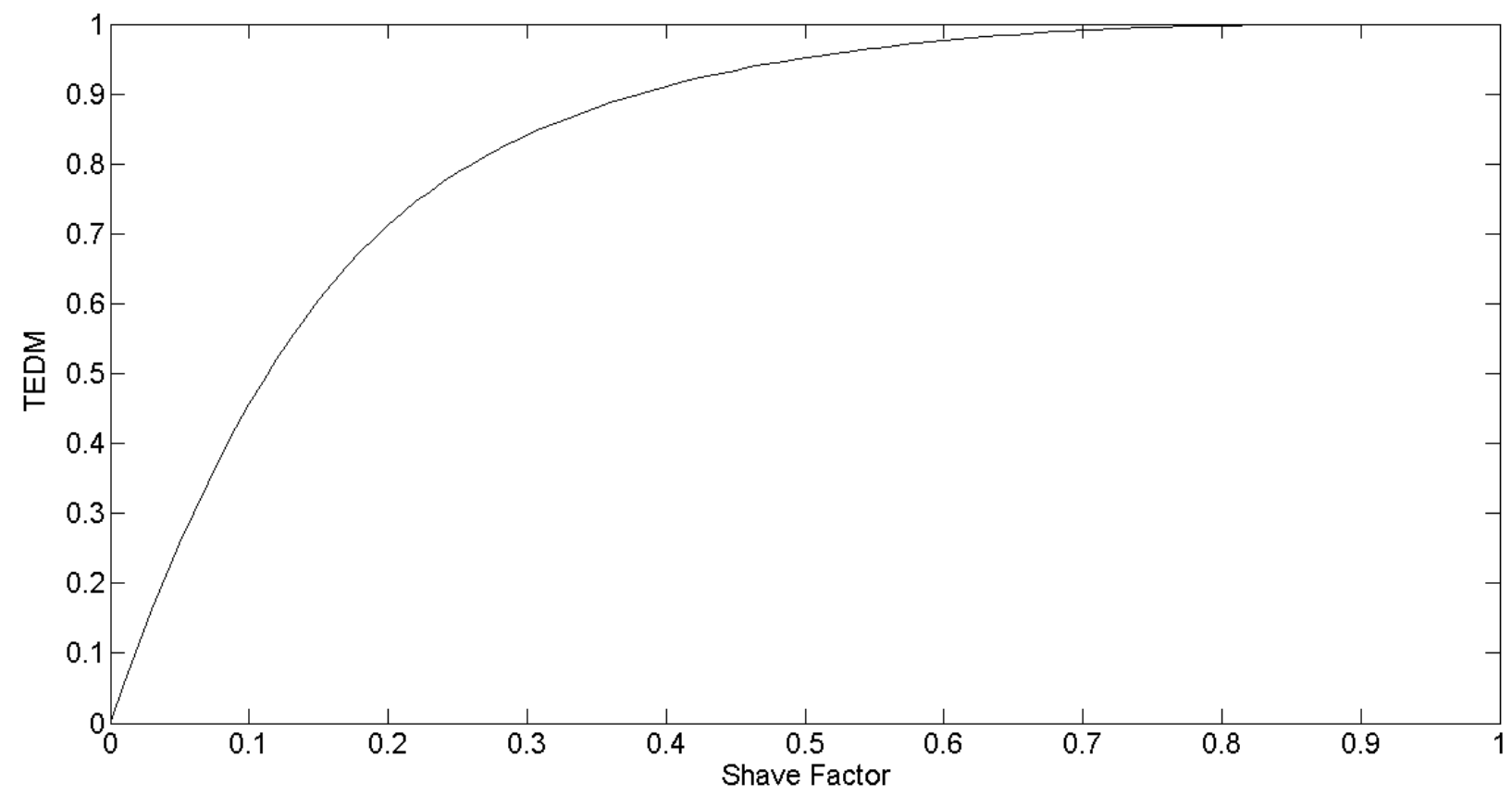

Figure 3.2: shave factor vs. TEDM for a school located in Toronto, Ontario

Although economics determine the optimal sizing of the systems, the incurring annual maintenance costs for these systems are not considered. Furthermore a project life of 20 years was 
selected on the notion that payback periods exceeding this would be unappealing, since boilers, cooling towers and heat-pumps operate for approximately 20 years before needing major overhaul or replacement [5]. In this study inflation of electricity and natural gas prices, interest rates and constant values were taken into consideration in determining the annual savings and payback periods.

To determine the optimal hybrid GSHP size for the buildings listed in Table 3.1, the requirements are [15]:

1. The mentioned parameters (Tables 3.2 and 3.3).

2. The buildings' hourly cooling and heating loads (8760 hours/year).

3. Electricity and natural gas rates.

4. Project life (20 years)

\subsection{Base Case}

Toronto's weather patterns and fixed rates will be used as the base case for comparison. The ten real buildings (Table 3.1), will be analyzed using a project life or operating duration (OD) of 20 years, natural gas and electricity rates of $\$ 0.35 / \mathrm{m}^{3}$ and $\$ 0.17 / \mathrm{kWh}$ respectively.

In [15], payback period was calculated using the annual operating costs (AOPC) of the first year $(i=1)$, as given by Equations 3.1a and 3.1b. The first and second terms on the right hand side of equation $3.1 \mathrm{~b}$ correspond to the annual operating costs for $S F=0$ and $0<S F \leq 1$ respectively. In this analysis the annual savings calculations is modified, as shown in Equation 3.1c. The new annual savings is calculated using the averaged AOPC discounted into net present value (NPV).

$$
\text { Payback Period }=\frac{\text { Initial Cost }}{\text { Annual Savings }}
$$

where:

$$
\begin{aligned}
& \text { Annual Savings }_{[18]}=A O P C(S F=0, i=1)-A O P C(S F, i=1) \\
& \text { Annual Savings } S_{\text {Present }}=\frac{\sum_{i=1}^{O D} A O P C_{N P V}(S F=0, i)-\sum_{i=1}^{O D} A O P C_{N P V}(S F, i)}{O D}
\end{aligned}
$$


Note that, in Equation 3.1b and 3.1c, $i$ denotes the year and $S F$ is the shave factor. The shave factor is defined as the portion of the peak building cooling (heating) demand that is to be supplied by a GSHP, and the remaining portion is supplied by conventional equipment [15]. $S F=0$ represents a purely conventional system (i.e., no GSHP). $S F=1$ represents a GSHP system only (i.e., no conventional equipment). For $0<S F<1$, a hybrid-GSHP system is considered.

For demonstrative purposes, using the new payback period calculations, building \#6 a mid-rise multi-residential building (Table 3.1) will be discussed. Applying the fixed electricity rate of $\$ 0.17 / \mathrm{kWh}$ resulted in an optimal system size with a shave factor of 0.37 . The optimal hybridGSHP size (optimal shave factor) is compared to shave factor values that correspond to 0 and 0.7 for residential buildings, which denotes $0 \%$ and $70 \%$ of the building's peak demand to be supplied by the GSHP respectively [15]. For non-residential buildings, the optimal hybrid-GSHP size is compared to hybrid shave factor of 0 and 1.

The results are illustrated in Table 3.4. As expected, it is apparent that the conventional system prevailed in achieving minimum upfront costs $(\$ 81,694)$. However, the optimal hybrid-GSHP system proved to be the most cost effective (total costs) after 20 years of operation; meeting $77.7 \%$ of the building's total energy needs, even though the GSHP is only sized to meet $37 \%$.

Table 3.4: Mid-rise multi-residential building (cooling dominant)

\begin{tabular}{|c|c|c|c|c|c|c|}
\hline $\begin{array}{c}\text { Shave } \\
\text { Factor }\end{array}$ & $\begin{array}{c}\text { Ground loop } \\
\text { Length } \\
\text { (meter) }\end{array}$ & $\begin{array}{c}\text { TEDM } \\
(\boldsymbol{\%})\end{array}$ & $\begin{array}{c}\text { Total Costs } \\
\text { NPV } \\
\mathbf{( \$ )}\end{array}$ & $\begin{array}{c}\text { Initial } \\
\text { Costs } \\
\mathbf{( \$ )}\end{array}$ & $\begin{array}{c}\text { AOPC } \\
\mathbf{( \$ )}\end{array}$ & $\begin{array}{c}\text { Payback } \\
\text { Period } \\
\text { (years) }\end{array}$ \\
\hline 0 & 0 & 0 & 975,414 & 81,694 & 44,686 & - \\
\hline $0.37 *$ & 3,743 & $77.7 \%$ & 868,766 & 279,598 & 29,458 & 13 \\
\hline $\begin{array}{c}0.7 \\
\text { (Standard) }\end{array}$ & 6,130 & $98.4 \%$ & 917,800 & 418,400 & 24,970 & 17 \\
\hline
\end{tabular}

TEDM (percentage of total energy demand met by GSHP) AOPC (annual operating costs)

*Optimal system size

In terms of total and initial cost (IC) savings, Equations 3.2 and 3.3 are used respectively:

Total Savings $=(\text { Total Costs NPV })_{\text {Standard }}-(\text { Total Costs NPV })_{\text {Optimal } S F}$ where: net present value is abbreviated to NPV 
IC Savings $=(\mathrm{IC})_{\text {Standard }}-(\mathrm{IC})_{\text {Optimal }} S F$

In this analysis, the standard systems which are referred to in Equations 3.2 and 3.3 are for $S F=$ 0.7 and 1.0 for residential and non-residential buildings, respectively.

Applying Equations 3.2 and 3.3, the optimal design for the mid-rise multi-residential building provided significant savings; with initial cost savings of $\$ 138,800$, a total savings of $\$ 49,000$ and the payback period reduced by four years from 17 to 13 . The remaining analyses will focus on comparing the net changes between the optimal-design determined by the methodology to that of the standard shave factors currently used in the industry ( 0.7 for residential, 1 for non-residential). A positive value, in Equations 3.2 and 3.3., denotes net savings by the optimal design compared to standard sizing.

The results of the base case are illustrated in Table 3.5 and Figure 3.3. GSHP installations for buildings \#1 and \#2 (hospital and office) were uneconomical and excluded from the figure. The current low rates of natural gas in Toronto make it uneconomical to install a GSHP system for the heating dominant buildings (the hospital and office). Although the standard shave factor for sizing GSHP for residential buildings is 0.7 [54], the shave factor for buildings \#6-9 did not exceed 0.42. For example, substantial initial cost savings and total savings $(\$ 136,000$ and $\$ 46,000)$ can be achieved using the optimal shave factor design which produces a minimum TEDM (percentage of total energy demand met by the GSHP) of $71 \%$ for high-rise A (building \#7). The same patterns are observed for non-residential buildings. The optimal shave factor are well below 0.7 (70\%) and the minimum TEDM is $83 \%$. It is established that if the payback period is greater than the duration of operation (20 years), the system is uneconomical. For buildings \#5, \#7, \#8 and \#10, using the standard $S F$ s resulted in long payback periods. According to Table 3.5, if an optimal shave factor exists, its payback period will be shorter than the payback period associated with the rule-of-thumb design standard. 
Table 3.5: Payback periods - Toronto fixed electricity rates

\begin{tabular}{|c|c|c|c|c|c|c|c|c|}
\hline \multirow{2}{*}{$\begin{array}{c}\text { Payback } \\
\text { Period } \\
\text { Years) }\end{array}$} & $\begin{array}{c}\mathbf{\# 3} \\
\text { Rest. }\end{array}$ & $\begin{array}{c}\mathbf{\# 4} \\
\text { FF- } \\
\text { Rest }\end{array}$ & $\begin{array}{c}\mathbf{\# 5} \\
\text { TF }\end{array}$ & $\begin{array}{c}\# \mathbf{H} \\
\text { MR }\end{array}$ & $\begin{array}{c}\# \mathbf{7} \\
\text { HR-A }\end{array}$ & $\begin{array}{c}\# \mathbf{H} \\
\text { HR-B }\end{array}$ & $\begin{array}{c}\# 9 \\
\text { HR-C }\end{array}$ & $\begin{array}{c}\# 10 \\
\text { School }\end{array}$ \\
\hline $\begin{array}{c}\text { Optimal } \\
\text { Payback } \\
\text { Period }\end{array}$ & 12.5 & 12.8 & 14.4 & 13 & 12.7 & 13.5 & 12.7 & 15.8 \\
\hline $\begin{array}{c}\text { Standard } \\
\text { Payback } \\
\text { Period }\end{array}$ & 14.5 & 15 & 20 & 17 & 18.7 & 18.1 & 15.9 & 30 \\
\hline
\end{tabular}

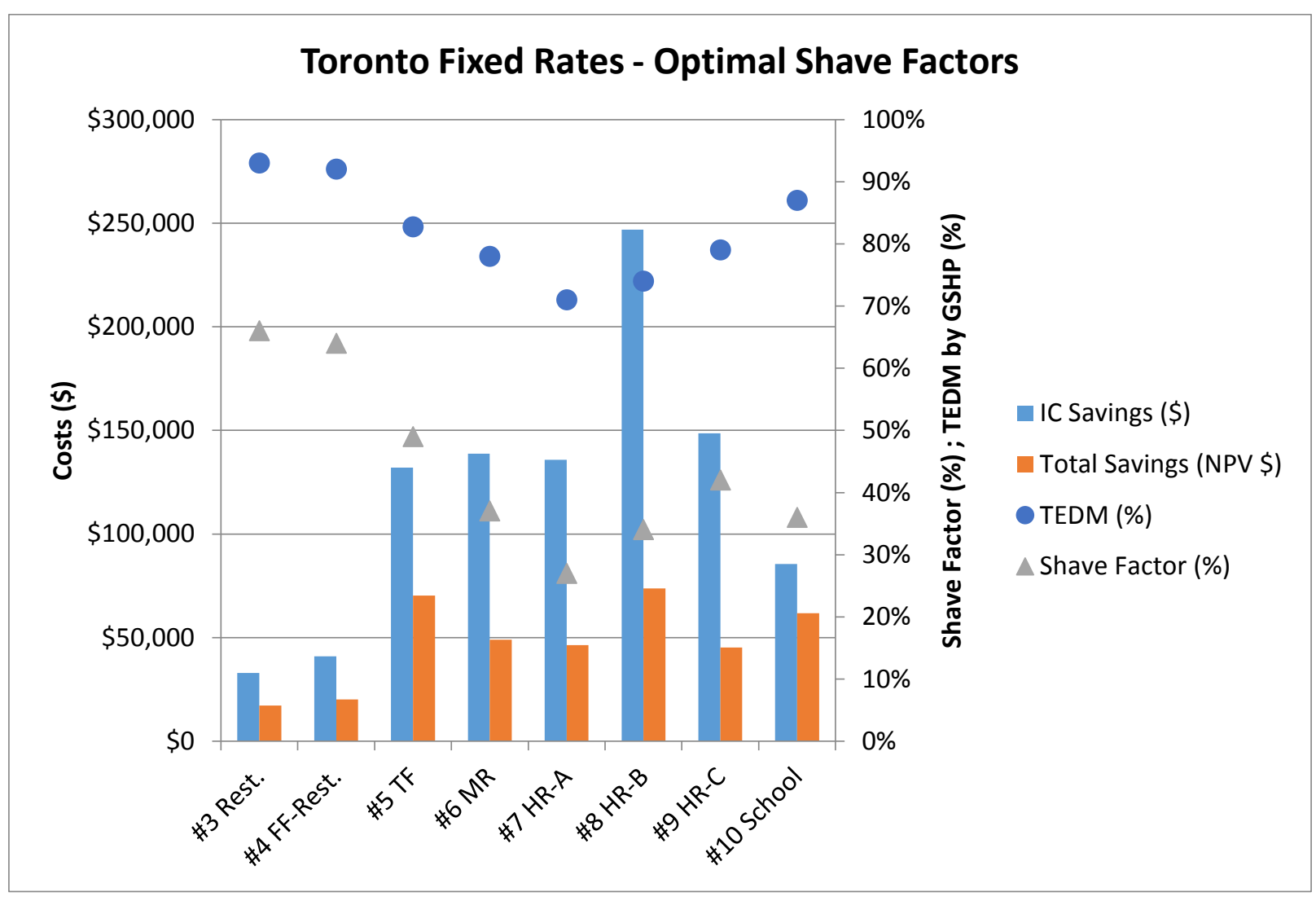

Figure 3.3: Hybrid GSHP data for eight buildings (base case) in Toronto, Ontario, Canada.

With regard to Figure 3.3, building \#3 is a restaurant, building \#4 is a fast food restaurant, building \#5 is a transit facility, building \#6 is a mid-rise (multi-residential building), building \#7-9 are highrises (multi-residential buildings), and building \#10 is a school. The blue bars represent the savings in initial costs (IC) associated with using an optimized hybrid GSHP system as compared to using industry design rules-of-thumb. The orange bars represent the net present value (NPV) of total 
savings associated with using an optimized hybrid GSHP system as compared to using industry design rules-of-thumb. The triangles and circles represent the $S F$ (shave factor) and total energy demands met (TEDM), respectively, associated with using an optimized hybrid GSHP system.

\subsection{Analysis \#1 - Electricity Rates: Fixed vs. Time-of-Use}

Conventional heating and cooling consume large amounts of natural gas and electricity, with operating costs affected by rising costs of resources. It is imperative to understand the effects of fixed vs. time-of-use electricity rates, which has become prevalent in North America. The most recent weather data, the CTMY2 (Canadian typical meteorological year) [55], was used to simulate the buildings' hourly loads using eQUEST Version 3.64 [27].

Due to the ease of obtaining data for weather, electricity and natural gas costs, and as it is representative of many North American and European locales in terms of climate and GSHP potential, the present study considers Toronto, in the province of Ontario, Canada. Table 3.6 presents the operating costs and conditions used in this analysis. Since the electricity tax rates vary depending on many factors, it was impractical to derive a mathematical algorithm to approximate these taxes and fees. However, based on information available from the Ontario Energy Board [56], electricity prices used in this analysis, the adjusted values are also presented in Table 3.6. If a building operates for twenty-four hours in a day, using the time-of-use rates, the average electricity rate is $\$ 0.17 / \mathrm{kWh}$ (the same as fixed rate). However, most buildings operate during peak demands and the weighted average cost based on time-of-use rates would exceed that of the fixed rate of $\$ 0.17 / \mathrm{kWh}$. 
Table 3.6: Toronto operating costs and conditions

\begin{tabular}{|l|c|}
\hline Project Life & 20 years \\
\hline Ground Temperature & $10^{\circ} \mathrm{C}^{\dagger}$ \\
\hline Natural Gas & $\$ 0.35 / \mathrm{m}^{3 \dagger}$ \\
\hline 2012 Electricity Fixed Rate & $\$ 0.87 / \mathrm{kWh}^{[57]}$ \\
\hline 2012 Time-of-Use Rates ${ }^{[8]}$ & $\$ 0.117 / \mathrm{kWh}$ \\
Peak & $\$ 0.1 / \mathrm{kWh}$ \\
Mid-Peak & $\$ 0.065 / \mathrm{kWh}$ \\
Off-Peak & $\$ 0.17 / \mathrm{kWh}$ \\
\hline Adjusted: 2012 Electricity Fixed Rate & \\
\hline Adjusted 2012 Time-of-Use Rates & $\$ 0.228 / \mathrm{kWh}$ \\
Peak & $\$ 0.195 / \mathrm{kWh}$ \\
Mid-Peak & $\$ 0.127 / \mathrm{kWh}$ \\
Off-Peak & \\
\hline
\end{tabular}

${ }^{\dagger}$ Data courtesy of CleanEnergy ${ }^{T M}$

The net difference from the results (fixed and time-of-use rates) are calculated as follows:

$$
\begin{aligned}
& \Delta \text { Total Savings }=(\text { Total Savings })_{\text {time-of-use }}-(\text { Total Savings })_{\text {Fixed }} \\
& \Delta \text { Initial Cost Savings }=(\text { IC Savings })_{\text {time-of-use }}-(\text { IC Savings })_{\text {Fixed }} \\
& \Delta \text { Payback Period }=\left(\mathrm{PBP}_{\text {Optimal Design }}\right)_{\text {Fixed }}-\left(\mathrm{PBP}_{\text {Optimal Design }}\right)_{\text {time-of-use }} \\
& \Delta S F_{\text {Optimal Design }}=\left(S F_{\text {Optimal Design }}\right)_{\text {time-of-use }}-\left(S F_{\text {Optimal Design }}\right)_{\text {Fixed }}
\end{aligned}
$$

Based on Equations 3.4 to 3.7, time-of-use rates are more economical than fixed rates if values for $\Delta$ Total Savings, $\triangle \mathrm{IC}$ Savings (initial cost) or $\triangle \mathrm{PBP}$ (payback period) are positive. For the case of $\Delta S F$ (shave factor, the portion of peak demand met by the GSHP), a positive value indicates the time-of-use's GSHP system capacity is larger than the fixed rates' and smaller if it is negative.

Similar to the base case in Figure 3.3, optimal GSHP size for Toronto time-of-use rates are presented in Figure 3.4. Implementing Equations 3.4-3.7, the results for this analysis are presented in Figure 3.5. Time-of-use electricity pricing was an incentive to reduce peak power usage by rewarding cheaper rates during off-peak times. However, this strategy may have adverse effects on buildings with GSHPs. The restaurants showed reduced costs due to long operating hours and 
high cooling demands during cheaper off-peak times. This reduction contributed to downsizing of the GSHP system for these buildings; reducing the upfront costs contributed to a positive $\Delta$ Total Savings and $\Delta$ Initial Cost Savings. However, it also resulted in a decrease in annual operating costs savings which contributed to longer payback periods.

For the case of the school, most of the cooling demands occur during peak rates. As a result, the GSHP size was increased (increasing the shave factor: $\Delta S F=0.03$ ), resulting in a negative $\Delta$ Total Savings and $\Delta$ Initial Cost Savings. However, during the summer months (holiday months) it is common for schools to not provide space cooling. The hospital's and office's heating dominance prevents feasibility for a GSHP system as in the electricity fixed-rate scenario. As observed in Figure 3.5, comparing between fixed and time-of-use rates, an increase in shave factor results in poorer economics.

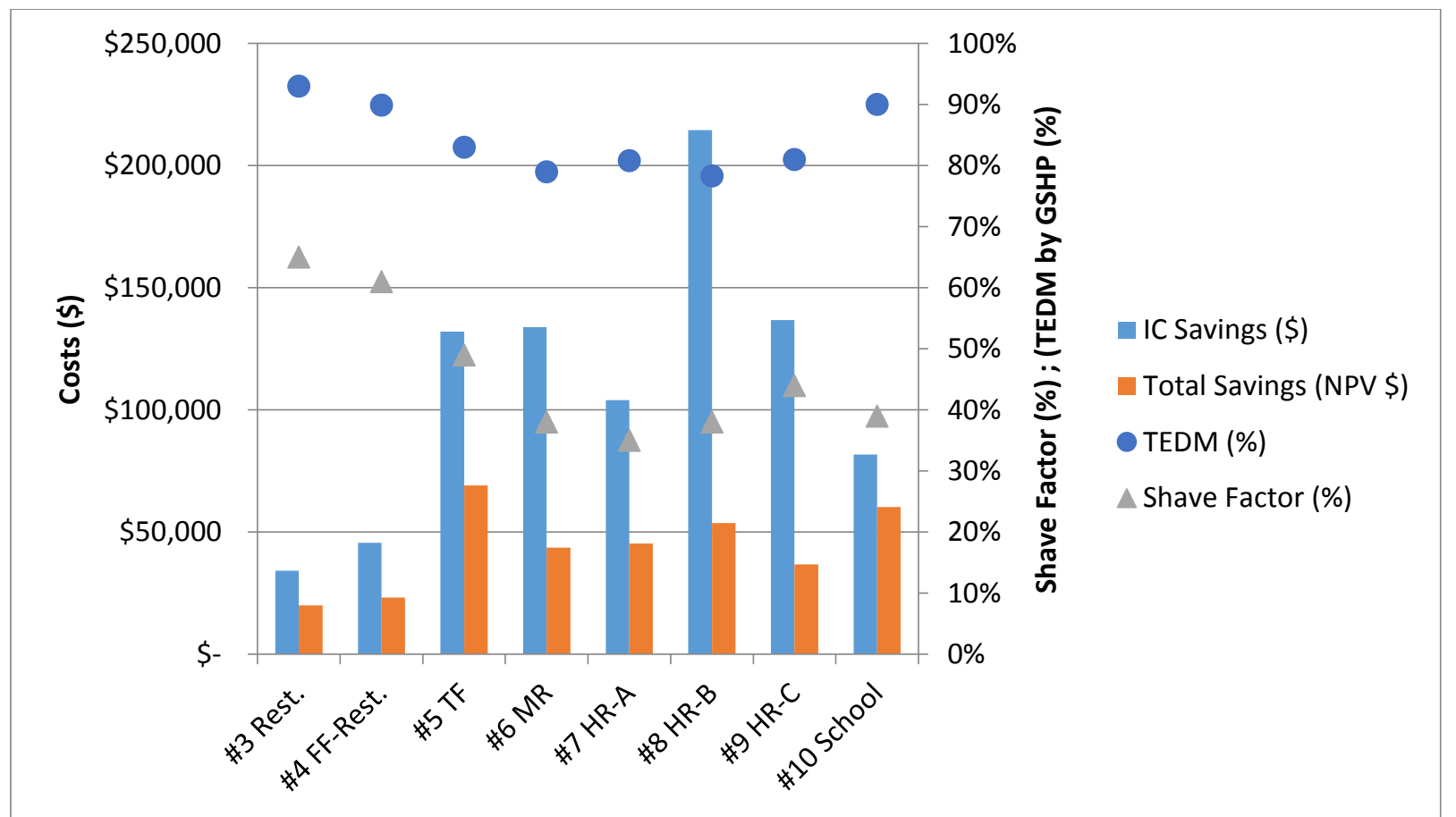

Figure 3.4: Toronto time-of-use electricity rates results for eight buildings in Toronto, Ontario, Canada

In Figure 3.4, the buildings are the same as those depicted in Figure 3.3. The blue bars represent the savings in initial costs (IC) associated with using an optimized hybrid GSHP system as compared to using industry design rules-of-thumb. The orange bars represent the net present value 
(NPV) of total savings associated with using an optimized hybrid GSHP system as compared to using industry design rules-of-thumb. The triangles and circles represent the $S F$ (shave factor) and total energy demands met (TEDM), respectively, associated with using an optimized hybrid GSHP system.

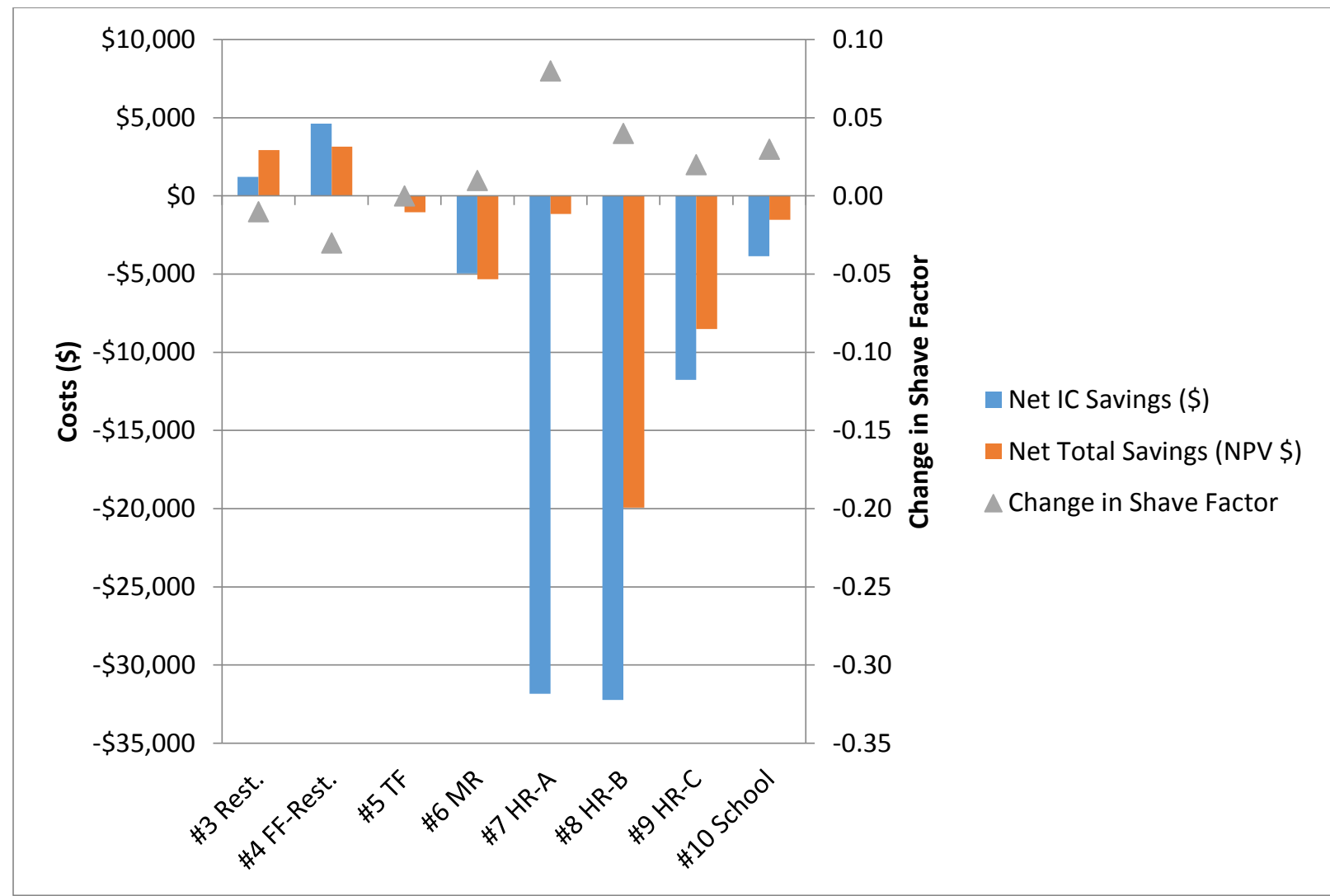

Figure 3.5: $\Delta$ initial cost (IC) savings, $\Delta$ total savings, and $\Delta$ shave factor for Toronto fixed vs. time-of-use electricity rates

\subsection{Analysis \#2 - Toronto Fixed Rates with Variable Weather}

A weather sensitivity test was conducted in this analysis using weather data from other North American cities. A total of 11 US locations focusing on weather extremities were considered. Since the effect of weather is analyzed here, Toronto's fixed rates, the same rates used in Analysis \#1, were applied. If the local rates were also considered, the effect of weather may not be clearly shown. 
The hourly cooling and heating demands for buildings \#1-6 and \#10 were simulated in eQUEST using the TMY3 weather data [55]. The ground temperatures corresponding to each of the 11 locations are approximated using the "long-term averages of annual average ambient air temperature" retrieved from [59].

The optimal hybrid-GSHP system designs are rivalled to the standards currently used in the industry (in prior discussion: 0.7 for residential and 1 for non-residential buildings). With varying weather patterns, the savings can be compared as follows:

$$
\Delta \text { Total Savings }=(\text { Total Savings })_{\text {Other }}-(\text { Total Savings })_{\text {Reference Location }}
$$

$$
\Delta \text { Initial Cost Savings }=(\text { IC Savings })_{\text {Other }}-(\text { IC Savings })_{\text {Reference Location }}
$$

$$
\Delta \mathrm{PBP}=\left(\mathrm{PBP}_{\text {Optimal Design }}\right)_{\text {Reference Location }}-\left(\mathrm{PBP}_{\text {Optimal Design }}\right)_{\text {Other }}
$$

$$
\Delta S F_{\text {Optimal Design }}=\left(S F_{\text {Optimal Design }}\right)_{\text {Other }}-\left(S F_{\text {Optimal Design }}\right)_{\text {reference }}
$$

$$
\Delta \text { GroundLoopLength }=\frac{(\text { GroundLoopLength })_{\text {other }}-(\text { GroundLoopLength })_{\text {reference }}}{(\text { GroundLoopLength })_{\text {reference }}}
$$

The results are compared to those using Toronto's weather patterns (reference location). The alternative location is more economical than Toronto's if values for $\Delta$ Total Savings, $\Delta$ Initial Cost Savings or $\triangle \mathrm{PBP}$ (payback period) are positive. For the case of $\Delta S F$ ( $\Delta$ Shave Factor), a positive value indicates the system size for the building situated with that particular weather pattern is larger than that which would be in Toronto; smaller if $\triangle S F$ is negative.

In the following figures, only buildings with an optimal shave factor are plotted. Since the hospital and office were heating dominant in Toronto's weather, resulting in a shave factor value of zero (most economical by a conventional system), they were omitted from the figures. Based on the results, weather patterns have a strong effect on payback periods and costs. In warmer weather there is a larger initial cost savings which contributes to a net positive total savings (Figure 3.6). 
This savings was achieved by downsizing the GSHP and expanding the conventional equipment to meet the peak demands (Figure 3.7).

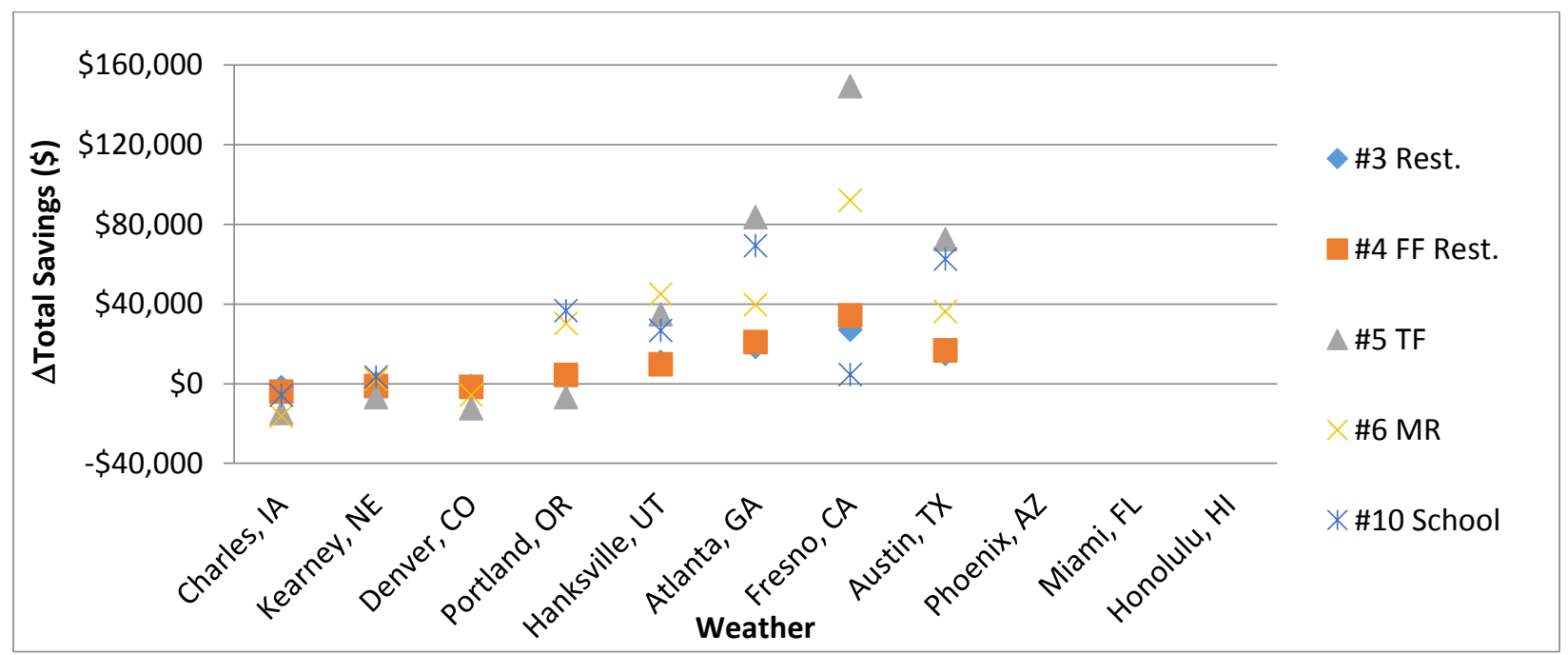

Figure 3.6: $\Delta$ Total Savings: variable weather, Toronto rates. The base case, Toronto's weather patterns and fixed rates, was used for comparison. The ordinate represents the change in savings in net present value (NPV) associated with using an optimized hybrid GSHP system as compared to using industry design rules-of-thumb.

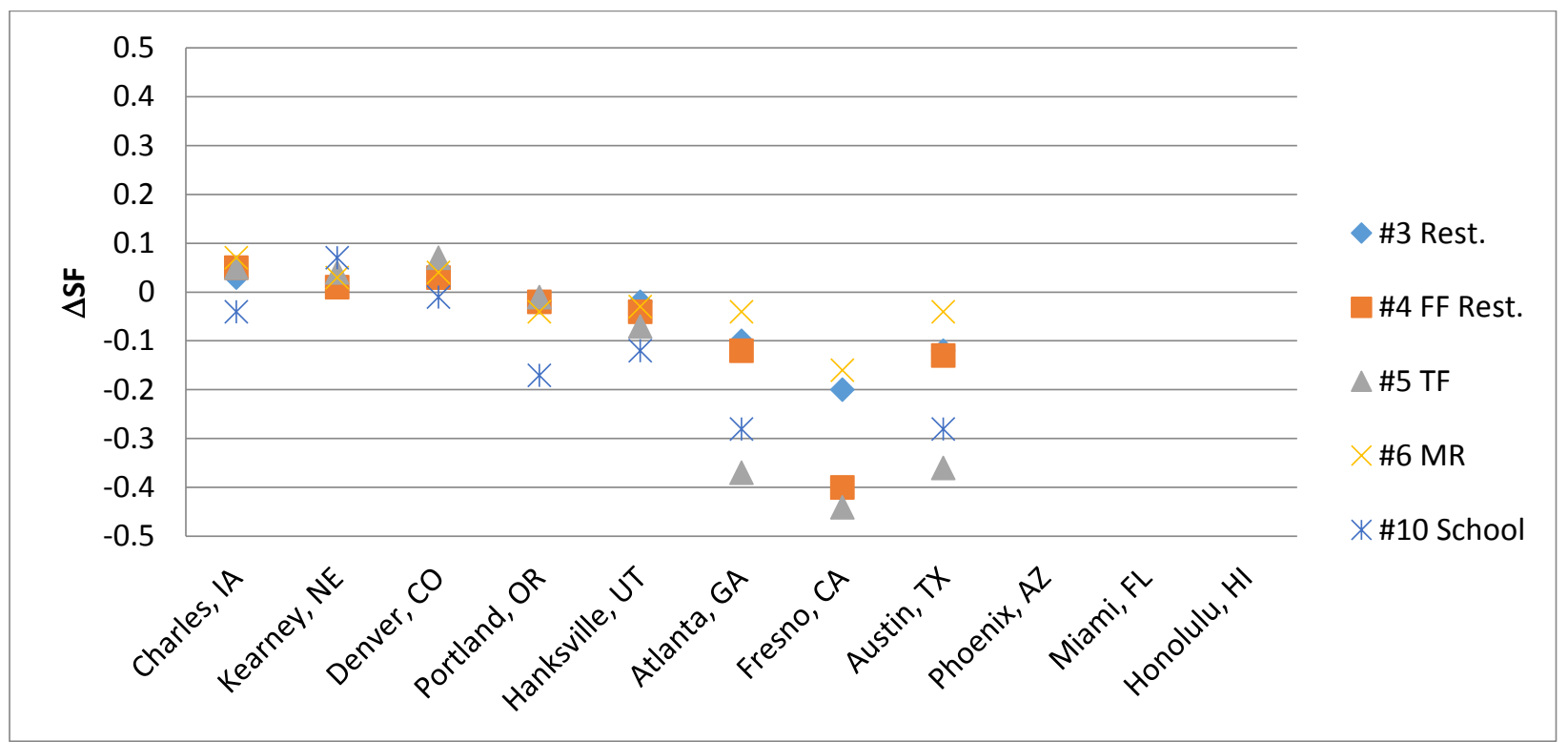

Figure 3.7: $\triangle S F$ : variable weather, Toronto rates. The base case, Toronto's weather patterns and fixed rates, were used for comparison. 
There are several factors contributing to smaller shave factors (Figure 3.7). Firstly, in warmer weather (states: AZ, FL, HI) the average ground temperature is significantly higher than that of Toronto. As a result, this increase in ground temperature requires a longer ground loop length to meet the buildings' energy demands. In Figure 3.8, the fast-food restaurant was used to compare the effects warmer weather have on ground loop lengths using a shave factor of 1 ( $S F=1$ for Equation 3.12). For Honolulu's weather patterns, the fast-food restaurant requires a $\sim 70 \%$ longer ground loop in order to provide $100 \%$ of the building's total energy demands compared to if it were subject to Toronto weather. For a larger building such as the school, it requires a 140\% longer ground loop if the school were to be located in Arizona, instead of Toronto.

Although buildings require more cooling in warmer weather, due to higher ground temperatures, downsizing the ground loop length and expanding the cooling tower was most economical. Based on California's and Atlanta's mild winter, heating demands are kept minimal which helps to produce large savings compared to Toronto. Denver, Charles and Kearney have similar weather patterns to that of Toronto. As a result, after applying Toronto's rates, the net change in ground loop length, savings and payback periods (Figure 3.9) were not as substantial compared to other locations. Using Toronto's rates no optimal shave factor exists for Phoenix, Miami and Honolulu (uneconomical to install GSHP system). 


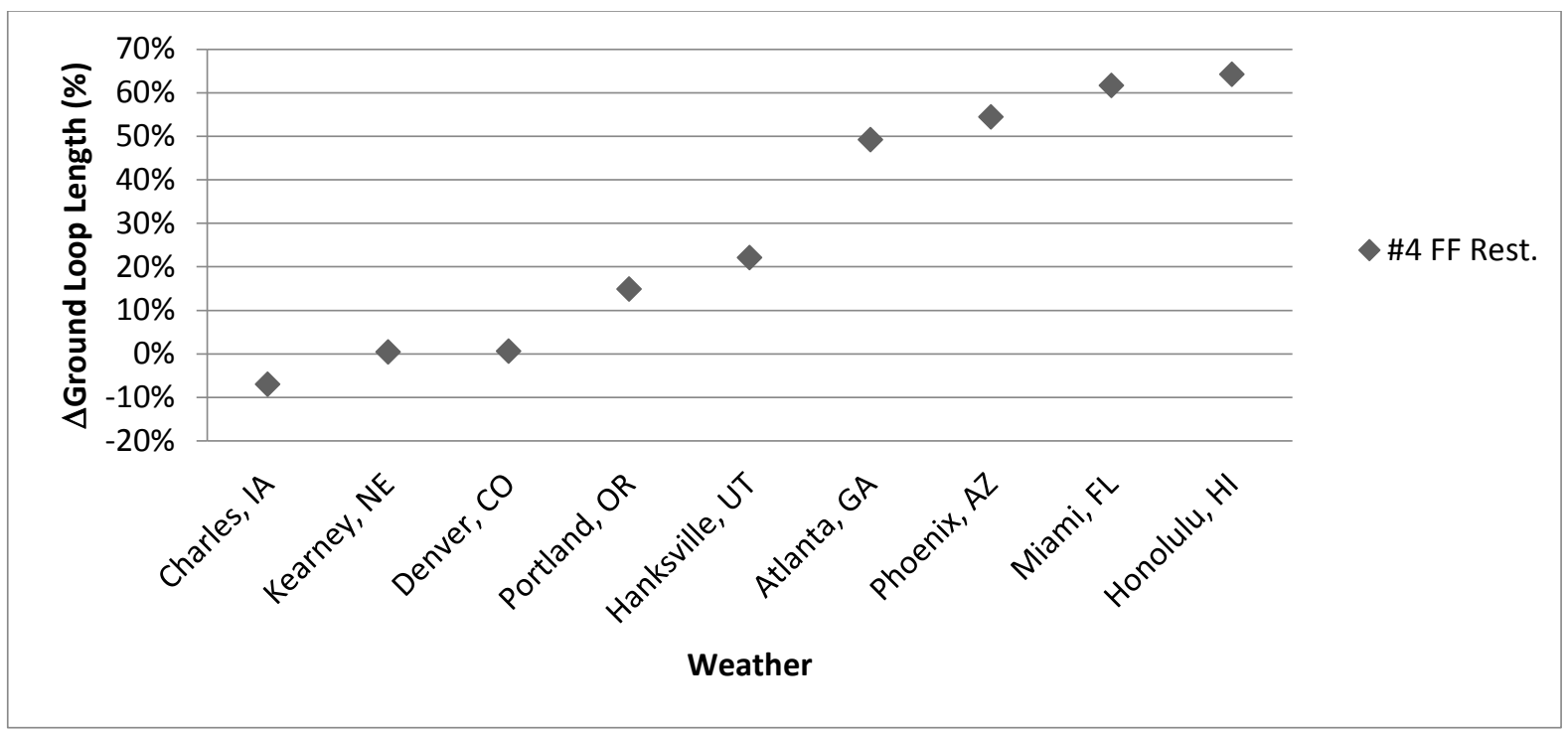

Figure 3.8: $\Delta$ Ground loop length - fast food restaurant. The abscissa represents the weather patterns, for the US cities, used in this analysis. The base case, Toronto's weather patterns and fixed rates, was used for comparison. The ordinate represents the change in ground loop length, for $S F=1$, associated with using Toronto's weather patterns as the base case for comparison.

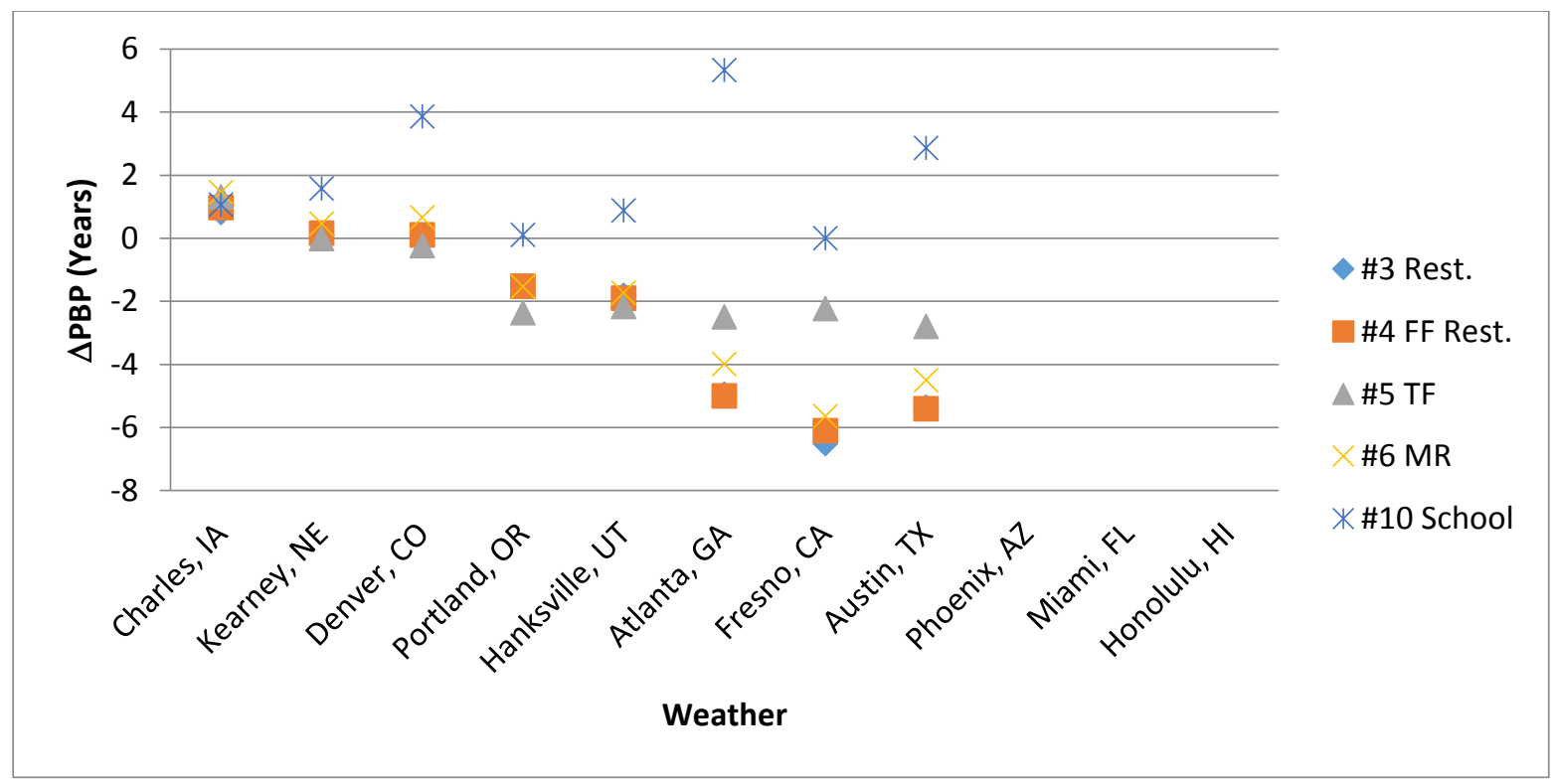

Figure 3.9: $\triangle \mathrm{PBP}$ : variable weather, Toronto rates. The ordinate represents the change in payback period ( $\triangle \mathrm{PBP}$ ) associated with using an optimized hybrid GSHP system as compared to using industry design rules-of-thumb. If the payback period for the US cities in the abscissa is shorter than that of the base case, $\triangle \mathrm{PBP}$ is positive. 
It is interesting to note some unique cases where a very small optimal shave factor produces significant savings compared to the standard shave factor (Table 3.7). For example, with a shave factor of 0.09 meeting $48 \%$ TEDM (percentage of total energy demand met by the GSHP), the office with Austin's weather patterns and Toronto's rates produces significant savings (over $\$ 1,000,000)$ compared to a standard shave factor of $1(S F=1)$. About half of the building's energy demands are met, requiring only $13 \%$ of the standard's ground loop length.

Table 3.7: Low optimal shave factor cases using Toronto's fixed rates

\begin{tabular}{|c|c|c|c|c|c|}
\hline $\begin{array}{c}\text { Building } \\
\text { (Weather Patterns) }\end{array}$ & $\begin{array}{c}\text { Shave } \\
\text { Factor }\end{array}$ & $\begin{array}{c}\text { TEDM } \\
\mathbf{( \% )}\end{array}$ & $\begin{array}{c}\text { Total } \\
\text { Savings } \\
\mathbf{( \$ )}\end{array}$ & $\begin{array}{c}\text { Initial } \\
\text { Costs } \\
\text { Savings } \mathbf{( \$ )}\end{array}$ & $\begin{array}{c}\text { Payback } \\
\text { Period } \\
\text { (years) }\end{array}$ \\
\hline $\begin{array}{c}\text { Hospital } \\
\text { (Atlanta, GA) }\end{array}$ & $0.14^{*}$ & 44 & 117,411 & 236,463 & 12.2 \\
\hline $\begin{array}{c}\text { Hospital } \\
\text { (Portland, OR) }\end{array}$ & $0.14^{*}$ & 61 & 88,324 & 146,225 & 12.8 \\
\hline $\begin{array}{c}\text { Office } \\
\text { (Austin, TX) }\end{array}$ & $0.09^{*}$ & 48 & $1,014,326$ & $1,440,203$ & 8.0 \\
\hline $\begin{array}{c}\text { School } \\
\text { (Austin, TX) }\end{array}$ & $0.08^{* *}$ & 28 & 124,376 & 278,055 & 12.9 \\
\hline
\end{tabular}

*To meet peak heating **to meet peak cooling

\subsection{Analysis \#3 - Variable Weather and Local Rates}

In this analysis, the same approach and conditions were used as that of Analysis \#2. The only exception is that, instead of using Toronto's rates, the most recent local rates for the cities tested were used (Tables 3.8 and 3.9) [60-62]. In this analysis, only the local natural gas and electricity rates are considered; labor, supplies, installation and other rates are still assumed to be the same as in Toronto, so that the effects of local natural gas and electricity prices can be studied. The exchange rates between the Canadian and US currency were assumed to be the same when this study was performed (June, 2012). 
Table 3.8: Natural gas prices for 2011 (US dollars)

\begin{tabular}{|l|c|c|c|}
\hline \multicolumn{1}{|c|}{ State } & City & $\begin{array}{c}\text { Natural Gas Price (2011) } \\
\text { Residential Average Price } \\
\left(\mathbf{\$} / \mathbf{m}^{\mathbf{3}} \mathbf{~}^{\mathbf{6 0 0}]}\right.\end{array}$ & $\begin{array}{c}\text { Commercial Average Price } \\
\left(\mathbf{\$} / \mathbf{m}^{\mathbf{3}}\right)^{\mathbf{6 1}]}\end{array}$ \\
\hline Arizona & Phoenix & 0.53 & 0.35 \\
\hline California & Fresno & 0.35 & 0.29 \\
\hline Colorado & Denver & 0.29 & 0.28 \\
\hline Florida & Miami & 0.65 & 0.39 \\
\hline Georgia & Atlanta & $0.54^{*}$ & 0.37 \\
\hline Hawaii & Honolulu & 1.95 & 1.61 \\
\hline Iowa & Charles & 0.34 & 0.27 \\
\hline Nebraska & Kearney & 0.32 & 0.23 \\
\hline Oregon & Portland & $0.44^{*}$ & $0.36^{*}$ \\
\hline Texas & Austin & $0.38^{*}$ & 0.26 \\
\hline Utah & Hanksville & 0.3 & 0.25 \\
\hline
\end{tabular}

"2010 prices were used (unavailable 2011 prices)

Table 3.9: Average electricity prices for 2010 (US dollars)

\begin{tabular}{|c|c|c|c|}
\hline \multicolumn{4}{|c|}{ Average Electricity Prices (2010) } \\
\hline Location & City & Residential $(\$ / k W h)^{[62]}$ & Commercial $(\$ / k W h)^{[62]}$ \\
\hline Arizona & Phoenix & 0.1097 & 0.0947 \\
\hline California & Fresno & 0.1475 & 0.131 \\
\hline Colorado & Denver & 0.1104 & 0.0913 \\
\hline Florida & Miami & 0.1144 & 0.0976 \\
\hline Georgia & Atlanta & 0.1007 & 0.0906 \\
\hline Hawaii & Honolulu & 0.281 & 0.2593 \\
\hline Iowa & Charles & 0.1042 & 0.0791 \\
\hline Nebraska & Kearney & 0.0894 & 0.0763 \\
\hline Oregon & Portland & 0.0887 & 0.0759 \\
\hline Texas & Austin & 0.116 & 0.0919 \\
\hline Utah & Hanksville & 0.0871 & 0.0715 \\
\hline
\end{tabular}

This analysis produced similar results to that of Analysis \#2. Higher ground temperatures were a significant factor for the downsizing of the system's ground loop and longer payback periods. Since shave factor (the portion of peak demand met by the GSHP) is a measure of the building's peak demands met, it can be uneconomical to increase the shave factor (increasing ground loop increases initial cost) for cooling dominant buildings in warmer climates. However, the effects can be alleviated if the local rates were high enough. This can be observed for the case of Honolulu, Hawaii. In Analysis \#2, installation of a GSHP system in Honolulu proved to be uneconomical, 
but by applying the actual local electricity rates, which are quite high $(\$ 0.281 / \mathrm{kWh}$ and $0.2593 / \mathrm{kWh}$ for residential and commercial respectively), an optimal design is found. Similar patterns are obtained for the case of Phoenix and Miami. Previously, using Toronto's rates there was no shave factor for any buildings with Phoenix's or Miami's weather patterns; applying the actual local rates produces optimal shave factors and improved payback periods.

Thus far, this methodology has provided valuable insight in sizing hybrid GSHPs compared to the standards currently used by the industry. Based on the assumed $\mathrm{COP}_{\mathrm{GSHP}}$ and $\mathrm{COP}_{\text {cooling_tower, }}$ warmer climates lead to total savings when compared to Toronto's climate (reference) - the optimal design produces a shave factor that would otherwise be undetermined by installers using current standards of 0.7 or 1 . As a result, high upfront costs from large ground loops are minimized. Locations with warmer climate than in Toronto have poorer payback periods due to ground temperatures and loop lengths (except Hawaii, which has predominating electricity prices). For example, for the case of the fast-food restaurant building situated in Phoenix, it has an optimal shave factor of 0.16 and 27\% TEDM (optimal shave factor of $0.64,92 \%$ TEDM for Toronto's weather and rates). This is a substantial drop in shave factor due to the weather and higher ground temperature. Another example would be the office located in Phoenix (Table 3.10). Installers would likely overlook the optimal shave factor of 0.23 using current sizing standards. Approaching the problem with a shave factor of 0.7 or 1 would lead the installer to believe that a GSHP is unfeasible since it would be costlier than a conventional system. However, this is not true, and implementing a shave factor of 0.23 (compared to 0) leads to a savings of over $\$ 330,000$ in net present costs.

Table 3.10: Office building - Phoenix, Arizona (weather and local rates)

\begin{tabular}{|c|c|c|c|c|c|}
\hline $\begin{array}{c}\text { Shave } \\
\text { Factor }\end{array}$ & $\begin{array}{c}\text { TEDM } \\
(\boldsymbol{\%})\end{array}$ & $\begin{array}{c}\text { Total Costs } \\
\mathbf{( N P V )} \\
\mathbf{( \$ )}\end{array}$ & $\begin{array}{c}\text { Initial } \\
\text { Cost } \\
\mathbf{( \$ )}\end{array}$ & $\begin{array}{c}\text { Annual } \\
\text { Operating } \\
\text { Cost } \\
\mathbf{( \$ )}\end{array}$ & $\begin{array}{c}\text { Payback } \\
\text { Period } \\
\text { (years) }\end{array}$ \\
\hline 0 & 0 & $2,532,587$ & 185,575 & 177,167 & 0 \\
\hline $0.23^{*}$ & 62.06 & $2,202,834$ & $1,163,198$ & 78,478 & 11.79 \\
\hline 0.7 & 98.81 & $2,797,625$ & $2,673,894$ & 9,340 & 15.93 \\
\hline 1 & 100 & $3,412,982$ & $3,318,836$ & 7,107 & 19.52 \\
\hline
\end{tabular}

*Optimal shave factor 
The effects local weather and rates have on payback periods are summarized in Table 3.11. Only payback periods from the buildings that have an optimal shave factor are summarized. Toronto, Denver, Kearney and Charles have similar weather patterns and rates, thus their payback periods are similar. Higher ground temperatures lead to longer payback periods with Hawaii as the exception due to high electricity rates. The location with the longest payback period is Phoenix and the shortest is Hawaii.

Table 3.11: Optimal design - mean and median payback periods

\begin{tabular}{|c|c|c|c|}
\hline Location & $\begin{array}{c}\text { Mean Payback } \\
\text { Period } \\
\text { (Years) }\end{array}$ & $\begin{array}{c}\text { Median Payback } \\
\text { Period } \\
\text { (Years) }\end{array}$ & $\begin{array}{c}\text { Ground } \\
\text { Temperature [59] } \\
\left({ }^{\circ} \text { C) }\right.\end{array}$ \\
\hline Charles, IA & 13.9 & 12.8 & 8 \\
\hline Kearney, NE & 14.2 & 14 & 10 \\
\hline Denver, CO & 12.9 & 12.1 & 10 \\
\hline Toronto, ON & 13.7 & 13 & 10 \\
\hline Portland, OR & 13.2 & 14.9 & 13 \\
\hline Hanksville, UT & 14 & 15.6 & 17 \\
\hline Atlanta, GA & 15.4 & 16.8 & 20 \\
\hline Fresno, CA & 14.7 & 14.5 & 24 \\
\hline Austin, TX & 15.7 & 16 & 25 \\
\hline Phoenix, AZ & 18.1 & 18.6 & 25 \\
\hline Miami, FL & 16.7 & 16.9 & 18 \\
\hline Honolulu, HI & 9.4 & 9 & \\
\hline
\end{tabular}

Actual weather patterns and rates are used for each corresponding location

\subsection{Analysis \#4 - Effects of Inflation}

The analyses performed thus far assumed an inflation rate of $4 \%$ for both natural gas and electricity. In this analysis, the effects of inflation for electricity and natural gas are tested. The average annual inflation rate for the past 20 years was calculated using data provided in [60], [61] and [62] for the 11 US locations. Hawaii's highest average electricity cost inflation rates were $13.4 \%$ in the residential sector between 2002 and 2008, and 15.2\% in the commercial sector between 2004 and 2008. For natural gas [60], Georgia experienced the worst average inflation of 28.2\% (1999-2008). The residential average inflation for natural gas and electricity, for the 11 US locations between 1990 and 2010, are 4.4\% (4.5\% for commercial) and 2.3\% (2.0\% for commercial), respectively. The locations with the lowest average residential natural gas and 
electricity are: $3 \%$ for Utah (3.8\% for commercial in Texas) and 1\% in Arizona (0.7\% for commercial in Arizona). Although unlikely, the effects of inflation will be analyzed using the worst case scenario of $10 \%$ and $20 \%$ for electricity and natural gas, respectively. The data from Analysis \#3 (standard rates) will be compared to its worst case scenario inflation counterpart.

In this analysis, a discount rate of $8 \%$ was used. However, it is interesting to note that by increasing the discount rate from $4 \%$ to $8 \%$ the payback period will increase. For example, based on a discount rate increase from $4 \%$ to $8 \%$ the payback period for the fast-food restaurant, mid-rise multi-residential building, and transit facility increased by 3.7, 3.2, and 2.3 years respectively.

\subsubsection{Electricity inflation}

In this analysis, the worst inflation of $10 \%$ for electricity will be used while the standard inflation rate of $4 \%$ for natural gas will remain. The results are compared to its counterpart, standard $4 \%$ natural gas and electricity inflation rates.

It is predictable that as electricity rates increase, so does the GSHP system size in order to counter the high operating costs as observed in Figure 3.10. However, the increase in optimal shave factor (the portion of peak demand met by the GSHP) results in higher upfront costs (increased ground loop length). Furthermore, by increasing the optimal shave factor, in most cases, the difference between the optimal shave factor and the standard shave factor reduces. As this gap reduces, the savings potential in using an optimization methodology (optimal vs. standard) is reduced. In Figure 3.11 , the overall payback period is improved ( $\triangle \mathrm{PBP}$ is positive) when larger electricity inflation occurs; lower annual operating costs are achieved from increasing the ground loop thereby achieving a larger TEDM (percentage of total energy demand met by the GSHP) by the system. 


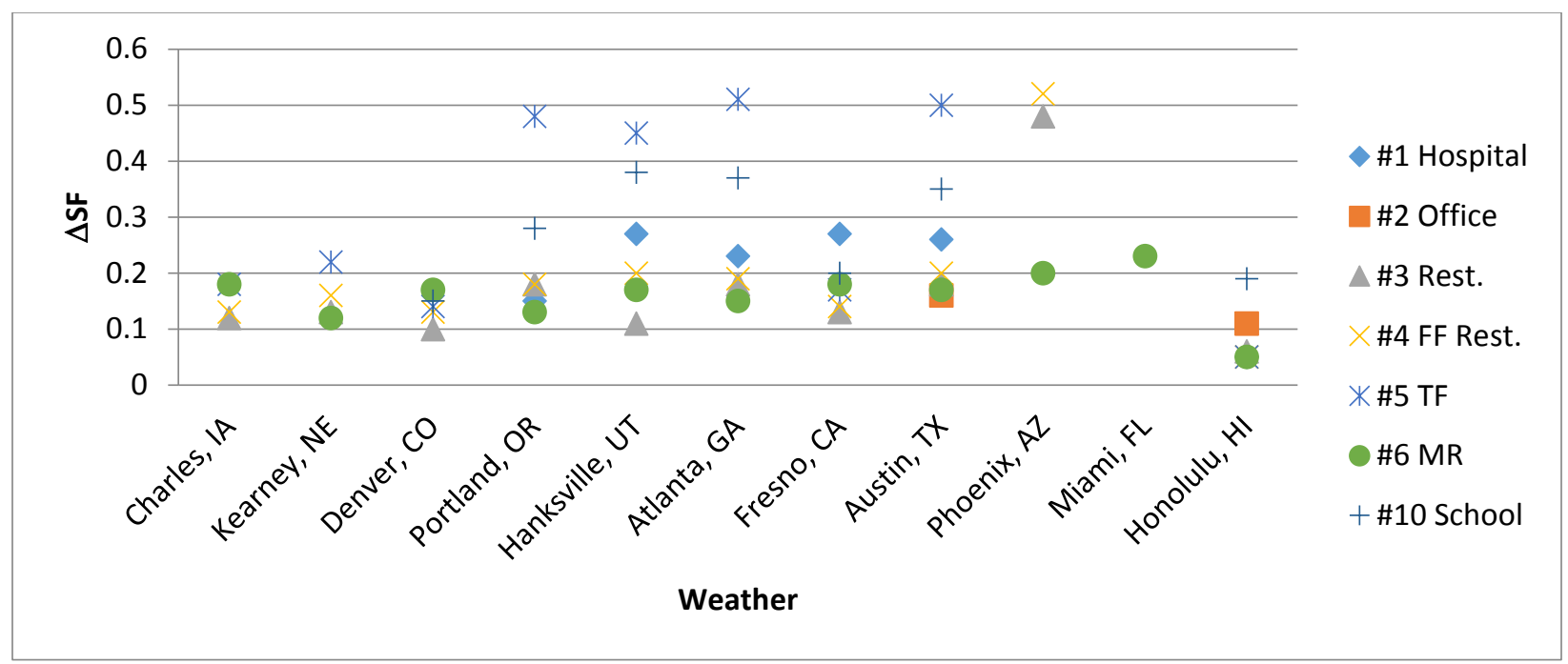

Figure 3.10: $\triangle S F$ - standard vs. $10 \%$ electricity inflation. The ordinate represents the change in shave factor $(S F)$ associated with using an optimized hybrid GSHP system as compared to using industry design rules-of-thumb.

The cause of the increased payback periods (negative $\triangle \mathrm{PBP}$ ) in Figure 3.11 results from several factors. For example, in the case of the school with electricity inflation of $4 \%$, the optimal shave factor was $0.08(\Delta S F=0.28)$ and $0.07(\Delta S F=0.37)$ for Portland's and Hanksville's weather, respectively. The optimal shave factor substantially increases in the $10 \%$ inflation scenario. As a result, higher upfront costs lead to longer payback periods. Furthermore, Hanksville would require a building similar to the school to have a heating component. Since the heat pump is powered by electricity, inflation of electricity rates will have adverse effects on the economics on GSHP systems that are required to provide heating. Because of these factors, inflation in electricity may benefit or disadvantage a GSHP system, depending on the building needs. 


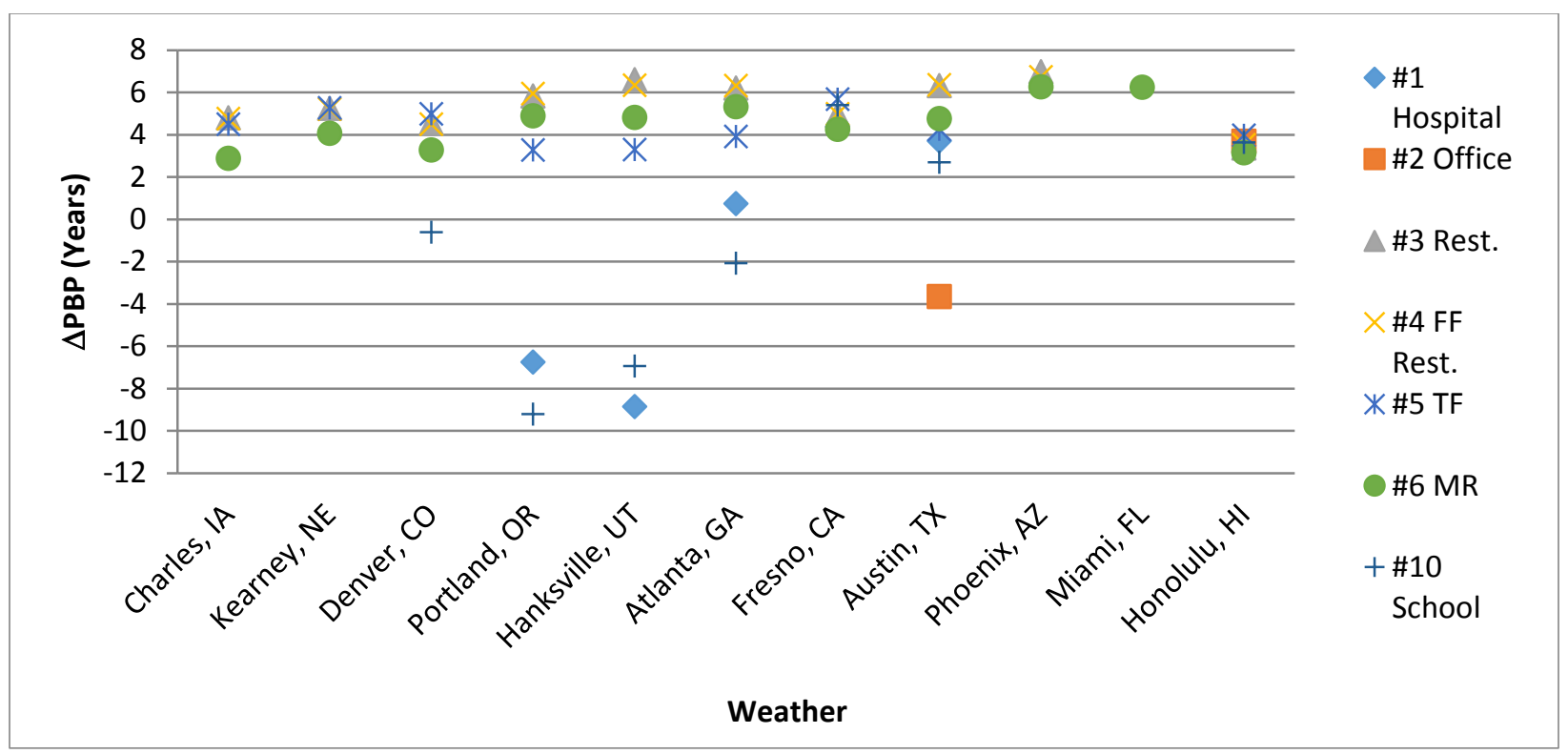

Figure 3.11: $\triangle \mathrm{PBP}$ : standard vs. $10 \%$ electricity inflation. The ordinate represents the change in payback period $(\triangle \mathrm{PBP})$ associated with using an optimized hybrid GSHP system as compared to using industry design rules-of-thumb. If the payback period for the $10 \%$ inflation is shorter compared to standard inflation $\triangle \mathrm{PBP}$ will be positive.

It is interesting to note that a higher electricity inflation rate produces viable non-zero shave factor in cases that otherwise would be uneconomical for cities with high ground temperatures like Phoenix, AZ. Table 3.12 lists some scenarios where a shave factor exists from $10 \%$ electricity inflation. For example, if the office building was located in Phoenix, 75\% of the building's energy demands can be met using an optimal shave factor of 0.32 , resulting in a payback period of 16.3 years and total savings of $\$ 515,000$. The results shows that in locations with warmer climate and high ground temperatures, inflation in electricity makes GSHP more appealing due to the high cooling demands. Similar trends are observed for the case of Toronto's weather patterns and rates when a $10 \%$ electricity inflation was applied. 
Table 3.12: Economical cases due to $10 \%$ electricity inflation

\begin{tabular}{|c|c|c|c|c|c|}
\hline $\begin{array}{c}\text { Building } \\
\text { (Weather } \\
\text { Patterns) }\end{array}$ & $\begin{array}{c}\text { Shave } \\
\text { Factor }\end{array}$ & $\begin{array}{c}\text { TEDM } \\
\mathbf{( \% )}\end{array}$ & $\begin{array}{c}\text { Total } \\
\text { Savings } \\
\mathbf{( \$ )}\end{array}$ & $\begin{array}{c}\text { Initial Costs } \\
\text { Savings } \\
\mathbf{( \$ )}\end{array}$ & $\begin{array}{c}\text { Payback } \\
\text { Period } \\
\text { (years) }\end{array}$ \\
\hline $\begin{array}{c}\text { Hospital } \\
\text { (Phoenix) }\end{array}$ & 0.47 & 82.2 & $\$ 80,800$ & $\$ 164,800$ & 13.7 \\
\hline $\begin{array}{c}\text { Hospital } \\
\text { (Miami) }\end{array}$ & 0.48 & 85 & $\$ 66,600$ & $\$ 133,000$ & 13 \\
\hline $\begin{array}{c}\text { Office } \\
\text { (Phoenix) }\end{array}$ & 0.32 & 75 & $\$ 515,400$ & $\$ 882,900$ & 16.3 \\
\hline $\begin{array}{c}\text { Office } \\
\text { (Miami) }\end{array}$ & 0.3 & 77.7 & $\$ 870,600$ & $\$ 1,262,200$ & 14 \\
\hline $\begin{array}{c}\text { Restaurant } \\
\text { (Miami) }\end{array}$ & 0.69 & 93.5 & $\$ 26,300$ & $\$ 50,600$ & 13 \\
\hline $\begin{array}{c}\text { School } \\
\text { (Phoenix) }\end{array}$ & 0.48 & 83.5 & $\$ 95,000$ & $\$ 170,600$ & 15.1 \\
\hline
\end{tabular}

Savings are compared between optimal SF and standard SF, using $10 \%$ electricity inflation

All buildings listed are "Cooling Dominant"

\subsubsection{Natural gas inflation}

Similar to section 3.6.1, the worst inflation rate of $20 \%$ for natural gas was used (4\% electricity inflation rate). This inflation increase affects heating dominant buildings the most. Locations with high ground temperatures were unaffected because very little to no heating was required (extremely cooling dominant). For example, the restaurant and fast-food restaurant require only cooling. The only two buildings that are heating dominant are the hospital and office.

Unlike electricity inflation in which heating requirements would counteract the benefits, natural gas inflation does not contribute to the GSHP's operational costs. Thus unlike with electricity, which can have either a positive or negative effect, natural gas inflation only serves to increase the viability of GSHP systems as observed in Table 3.13. In addition, using the methodology outlined in Alavy et al. [15] shows a clear advantage in heating dominant cases where natural gas inflation is high. Most shave factors listed (Table 3.13) are below 0.5 and the GSHP is still capable of providing most of the building's total energy demands (TEDM). Furthermore, payback periods are substantially less than the case where $S F=1$. For the office building with Hankville's weather patterns, the optimal design yields a payback period of 4.8 years whereas using a shave factor of 
0.7 and 1.0 yields payback periods of 12 (not shown) and 18.8 years respectively. The most notable shave factor for the office occurs in Hanksville where $S F=0.22$ yields a TEDM of $88.1 \%$, total savings of $\$ 675,700$ and a payback period of 4.8 years (compared to 18.8 years for $S F=1$ ). Similar trends are observed for the case of Toronto's weather patterns and rates when a $20 \%$ natural gas inflation was applied.

Table 3.13: Economical cases due to natural gas inflation rate of $20 \%$

\begin{tabular}{|c|c|c|c|c|c|c|c|}
\hline Building & $\begin{array}{l}\text { Weather } \\
\text { Patterns }\end{array}$ & $\begin{array}{c}\text { Optimal } \\
\text { Shave } \\
\text { Factor }\end{array}$ & $\begin{array}{c}\text { TEDM } \\
(\%)\end{array}$ & $\begin{array}{c}\text { Total } \\
\text { Savings } \\
(\mathbf{x} \$ 1,000)\end{array}$ & $\begin{array}{c}\text { Initial } \\
\text { Costs } \\
\text { Savings } \\
\quad \$ \text { ) }\end{array}$ & $\begin{array}{c}\text { PBP } \\
\text { (Years) }\end{array}$ & $\begin{array}{c}\text { PBP } \\
S F=1 \\
\text { (Years) }\end{array}$ \\
\hline \multirow{5}{*}{ Office } & Denver & 0.41 & 95.1 & 620.7 & 776,000 & 6.2 & 12.4 \\
\hline & Charles & 0.43 & 92.7 & 853.7 & $1,157,800$ & 6.6 & 13.4 \\
\hline & Kearney & 0.37 & 92.1 & 892.8 & $1,141,400$ & 7.4 & 16.4 \\
\hline & Portland & 0.64 & 98.6 & 136.4 & 183,800 & 2.9 & 4.3 \\
\hline & Hanksville & 0.21 & 88.1 & 675.7 & 687,400 & 4.8 & 18.8 \\
\hline \multirow{3}{*}{ Hospital } & Denver & 0.48 & 93.1 & 42.6 & 58,000 & 3.9 & 7 \\
\hline & Charles & 0.42 & 95.6 & 129 & 155,700 & 7.5 & 18.7 \\
\hline & Kearney & 0.37 & 75.9 & 95.8 & 96,100 & 4.7 & 18.6 \\
\hline
\end{tabular}

\subsection{Analysis \#5 - Control Strategy: Seasonality}

The final analysis is to determine the effects of a control strategy on the sizing of the hybrid-GSHP system. Some buildings in Toronto produces demands for simultaneous heating and cooling, especially during the shoulder seasons. For example, in Figure 3.1, the school requires a moderate amount of space heating and cooling during the shoulder seasons.

In prior analyses (Analysis \#1 to Analysis \#4) the hybrid-GSHP system was sized based on the 8760 hourly loads. The system provided all the heating and cooling demands throughout the year. In this analysis instead of sizing the system for all 8760 hourly loads, during the winter months, all cooling demands (building cooling loads) will be set to zero. Similarly, during the summer months all heating 
demands (building heating loads) will be set to zero. This control strategy assumes the building will obtain free cooling (heating) during winter (summer) from outdoor air. The cooling season will begin at the start of May and ends on the last day of October. For the purposes of this analysis, in cooling mode (summer months) all heating demands are assumed to be achieved through free heating from hot outdoor air. Conversely, the remaining months will be considered the heating season and all cooling demands will be provided from cold outdoor air (no costs). Realistically, such a control strategy could not be implemented in most buildings, however, this analysis is useful in demonstrating the sensitivity of optimal design to the potential use of free heating or cooling.

Using the above-mentioned definition for seasonality, Toronto's fixed electricity rates and a project life of 20 years, the results for the optimal shave factor (the portion of peak demand met by the GSHP) and associated costs are produced in Table 3.14. Interestingly, under this condition, a GSHP system is only economical for residential buildings. The hospital and office are heating dominant, regardless if seasonality was considered it still remains a fact that heating by a conventional system is cheaper than by a GSHP due to the current low rates of natural gas. For all the remaining non-residential buildings, although they are cooling dominant, the summer is the only period for the system to generate savings. Due to the high upfront costs and short cooling season, the savings are hindered during the winter months where heating by the GSHP produces expenses instead of savings. All these factors make a conventional system cheaper to install and operate for twenty years than a hybrid-GSHP system. However, for residential buildings (buildings \#6 to \#9), a substantial savings in net present value dollars can be achieved compared to either a conventional system or installing hybrid GSHPs using the standard shave factor of 0.7 . The midrise multi-residential building achieved the greatest savings $(\$ 55,500)$ using an optimal shave factor value of 0.31. Similarly, for the high-rise A $(S F=0.12)$, high-rise B $(S F=0.11)$, and high-rise C $(S F=0.36)$ a savings of $\$ 58000, \$ 130000$, and $\$ 52500$ can be achieved. 
Table 3.14: Test \#6 - Seasonality results

\begin{tabular}{|l|c|c|c|c|c|c|}
\hline \multicolumn{1}{|c|}{ Building } & HD/CD & $\begin{array}{c}\text { Optimal } \\
\boldsymbol{S F}\end{array}$ & $\begin{array}{c}\text { TEDM } \\
\mathbf{( \% )}\end{array}$ & $\begin{array}{c}\text { Total } \\
\text { Savings } \\
\mathbf{( N P V ~} \mathbf{\text { I }}\end{array}$ & $\begin{array}{c}\text { IC } \\
\text { Savings } \\
\mathbf{( \$ )}\end{array}$ & $\begin{array}{c}\text { PBP } \\
(\text { Years })\end{array}$ \\
\hline 1. Hospital & HD & 0 & 0 & N/A & N/A & N/A \\
\hline 2. Office & HD & 0 & 0 & N/A & N/A & N/A \\
\hline 3. Restaurant & CD & 0 & 0 & N/A & N/A & N/A \\
\hline $\begin{array}{l}\text { 4. Fast-Food Restaurant } \\
\text { 5. Transit Facility }\end{array}$ & $\mathrm{CD}$ & 0 & 0 & N/A & N/A & N/A \\
\hline $\begin{array}{l}\text { 6. Mid-rise, Multi- } \\
\text { residential }\end{array}$ & $\mathrm{CD}$ & 0.31 & 67.9 & 55,500 & 169,900 & 16.4 \\
\hline $\begin{array}{l}\text { 7. High-rise, Multi- } \\
\text { residential A }\end{array}$ & $\mathrm{CD}$ & 0.12 & 44.51 & 58,000 & 206,059 & 13.3 \\
\hline $\begin{array}{l}\text { 8. High-rise, Multi- } \\
\text { residential B }\end{array}$ & $\mathrm{CD}$ & 0.11 & 41.3 & 130,000 & 457,000 & 10.6 \\
\hline $\begin{array}{l}\text { 9. High-rise, Multi- } \\
\text { residential C }\end{array}$ & $\mathrm{CD}$ & 0.36 & 72.5 & 52,500 & 185,200 & 16.2 \\
\hline 10. School & $\mathrm{CD}$ & 0 & 0 & N/A & N/A & N/A \\
\hline
\end{tabular}

Savings are compared between optimal $S F$ and standard $S F$

$H D$ (Heating Dominant) $\quad C D($ Cooling Dominant $)$ 


\subsection{Chapter Summary}

In this chapter the relationship between two parameters, shave factor and TEDM, were presented for a school located in Toronto, Canada. For most of the buildings analyzed the relationship between the two parameters are non-linear, making the shave factor an important parameter to consider for optimization of hybrid GSHPs, as presented in Alavy et al. [15]. If an optimal shave factor exists, its payback period will be shorter than the payback period associated with the ruleof-thumb design standard.

Extremely cooling dominant buildings had longer payback periods in weather warmer than Toronto (i.e. California, Georgia, and Hawaii). This is due to the higher ground temperatures which requires a larger ground loop to meet the buildings' energy demands. However, based on the

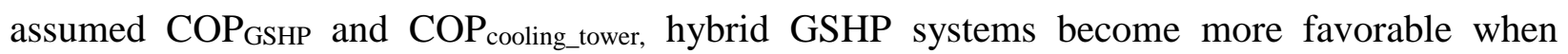
electricity rates or inflation is increased. For heating dominant buildings, the current low rates of natural gas make it uneconomical to install a GSHP system; the cost of natural gas per kWh heating is cheaper than electricity.

In Analysis \#1, the effects of fixed and time-of-use electricity rates were explored. Net differences were computed in terms of changes in total savings, initial cost savings, payback period, and shave factor. The time-of-use rates varied depending on the time of electricity usage; rates increased during peak hours and decreased during off-peak hours. In buildings with long operating hours during off-peak periods, the GSHP system was downsized, reducing initial costs. However, downsizing the system caused a decrease in annual operating cost savings, which resulted in longer payback periods.

In Analysis \#2, fixed rates (Toronto) were applied on 11 US locations to study the effects of varying weather patterns. Results of the study showed that in warmer weather where ground temperatures were higher, it was most economical to downsize the ground loop length and expand the cooling tower. 
In Analysis \#3, both the local rates and local weather were used to determine the trends in optimal design of GSHPs. The results of the analysis demonstrated that the widely varying electricity rates in North America significantly affect the shave factor values - in some cases generating much more economically viable designs.

In Analysis \#4, the effects of electricity and natural gas inflation were studied. As electricity rates increased, the GSHP system size also increased to counter the high operating costs. As a result of the optimal shave factor, upfront costs also increased. The economics for buildings with GSHPs that provided heating were worsened when electrical prices increased but were improved when natural gas prices increase. As a result, inflation for natural gas or electricity rates can benefit or adversely affect the hybrid GSHP system depending on the building and weather patterns; the shave factors generally increase proportionally with rate increases, but nonetheless, designs should be tailored to each specific building.

In Analysis \#5, a control strategy of seasonality was applied to study the effects on sizing hybridGSHP system. In the winter months, all cooling demands were set to zero and in the summer months, all heating demands were also set to zero. Under these conditions, a GSHP system is only economical for the residential buildings that were considered. For all non-residential buildings considered, although some are cooling dominant, the summer is the only period for the system to generate savings. Due to the high upfront costs, and short cooling season, the savings are hindered during the winter months where heating by the GSHP produces expenses instead of savings. All these factors make a conventional system less expensive to install and to operate for twenty years compared to a hybrid-GSHP system when a sophisticated seasonal control strategy is being implemented. 


\section{Chapter 4}

\section{Study \#2: Analysis of Heat-Pump Entering Fluid Temperatures, and $\mathrm{CO}_{2}$ Emissions}

For a GSHP system, the choice of entering fluid temperature (EFT) to the heat pump plays a crucial role in determining the efficiency of the heat pump and operating costs of the system. To continue expanding the knowledge base of efficiently sizing GSHPs as a component of a hybrid system, the effect of choosing an EFT for a heat pump and the system $\mathrm{CO}_{2}$ emissions are analyzed in the present study. Using a computational approach to size hybrid GSHP systems recently published in [15], the effects of optimizing EFT for heat pump and $\mathrm{CO}_{2}$ emissions were studied for a variety of commercial installations.

\subsection{Methodology}

In this study, the methodology outlined in Alavy et al. [15] will be used. In this methodology, a shave factor (the portion of peak demand met by the GSHP) based on the building's heating (cooling) demands is used to size and determine the optimal hybrid GSHP system design. By varying the shave factor between zero and one, the most economical design (based on the net present value of capital and operating costs) is selected as the optimal hybrid GSHP system design.

As this methodology was developed recently, a significant knowledge gap exists with regard to the best possible ways to use hybrid system optimization in GSHP design. Alavy et al. [15] focused on explaining and validating the methodology. A utility model was also investigated by Alavy et al. [97] to determine the feasibility of a common ground loop for multiple commercial and industrial buildings. As such, to continue expanding the knowledge base of automatically sizing GSHPs as a component of a hybrid system, two new algorithms have been created for the present study as discussed in sections 4.1.1 and 4.1.2. The parameters used in the present study are listed in Tables 4.1 and 4.2 . 
Table 4.1: General design parameters (data courtesy of CleanEnergy ${ }^{\mathrm{TM}}$ )

\begin{tabular}{|l|c|}
\hline \multicolumn{1}{|c|}{ Parameters } & Value \\
\hline Cooling Design Entering Fluid Temperature to HP & $29.4^{\circ} \mathrm{C}$ \\
\hline Heating Design Entering Fluid Temperature to HP & $1.7^{\circ} \mathrm{C}$ \\
\hline Heat Pump & $\begin{array}{c}\text { CleanEnergy Developments/ PC0018 } \\
\text { (COPheating }=3.1, \text { COP }\end{array}$ \\
\hline Soil Thermaling $=3.78)$
\end{tabular}

GSHP Configuration: closed-loop vertical single U-tube

Table 4.2: General costs of hybrid GSHP system components (data courtesy of CleanEnergy ${ }^{\mathrm{TM}}$ )

\begin{tabular}{|l|c|}
\hline \multicolumn{1}{|c|}{ Item } & Cost \\
\hline $\begin{array}{l}\text { Ground heat exchanger } \\
\text { (installation, materials, and heat pump) }\end{array}$ & $\$ 65.6 / \mathrm{m}$ \\
\hline $\begin{array}{l}\text { Cooling tower, plate heat exchanger including } \\
\text { controls and auxiliary equipment (COP }=2)\end{array}$ & $\$ 14 / \mathrm{kW}$ of tower design capacity \\
\hline Boiler (efficiency $=78 \%)$ & $\$ 20 / \mathrm{kW}$ of boiler design capacity \\
\hline
\end{tabular}

\subsubsection{Heat-pump entering fluid temperature (EFT)}

Using the methodology outlined in [15], total costs (in net present value) of a hybrid GSHP system was calculated as a function of shave factor. By varying the shave factors from zero to one - a two-dimensional optimization (total cost as a function of shave factor) - the most economical hybrid GSHP system is determined. However, the methodology in [15] sizes and determines the optimal hybrid GSHP system (optimal shave factor) based on a fixed pair of heat-pump EFTs (for the heating and cooling modes) specified by the designer [15]. For Toronto's weather patterns, a fixed heat pump EFT pair used for the heating and cooling modes were $35^{\circ} \mathrm{F}$ and $85^{\circ} \mathrm{F}\left(1.7^{\circ} \mathrm{C}\right.$ and $29.4^{\circ} \mathrm{C}$ ) respectively. 
In this study, the methodology outlined in [15] was modified to consider an array of operational heat-pump EFT pairs with corresponding heat-pump COP values, since the COPs depend on the temperature pairs (higher COP values corresponds to less GHG emissions). For example, there would be a total of 121 possible heat-pump EFT pairs (22 COP values) if a particular heat pump model can operate in the EFT ranges of $35-45^{\circ} \mathrm{F}$ and $85-95^{\circ} \mathrm{F}\left(1.7-7.2^{\circ} \mathrm{C}\right.$ and $\left.29.4-35^{\circ} \mathrm{C}\right)$ for the heating and cooling modes, respectively, considering $1.0^{\circ} \mathrm{F}$ increments. Each COP value will be used to calculate the operating costs of the hybrid GSHP system in the heating and cooling modes respectively. As such there would be 121 optimal shave factors calculated, one for each temperature pair, the temperature pair with the lowest net present value cost would be selected as the most economical design.

Using the methodology outlined in [15] but also varying the EFT pairs, the total cost of a hybrid GSHP system becomes a function of shave factor and heat-pump EFT pair (a three-dimensional optimization problem). As a result, a three-dimensional surface is generated, as shown for example in Figure 4.1, in which the total costs are plotted against the corresponding shave factors and heatpump EFT pairs. The shave factors ranged from zero to one, and the temperature pairs range from 1 to the maximum number of EFT pair combinations. For a school located in Toronto (Figure 4.1), the assigned operational heat-pump EFTs were $25-42^{\circ} \mathrm{F}$ and $60-100^{\circ} \mathrm{F}\left(\left[-3.9^{\circ} \mathrm{C}, 5.6^{\circ} \mathrm{C}\right]\right.$ and $\left[15.6^{\circ} \mathrm{C}\right.$, $\left.37.8^{\circ} \mathrm{C}\right]$ ) for the heating and cooling modes respectively $\left(738\right.$ temperature pairs using $1.0^{\circ} \mathrm{F}$ increments).

In Figure 4.1, there are three low-lying areas. The first low-lying area occurs in the region nearby the shave factor value of $20 \%$ (or 0.20) and is the lowest at the EFT pair index 557 corresponding to $41^{\circ} \mathrm{F}$ and $90^{\circ} \mathrm{F}$. The second low-lying area occurs near the shave factor value of $40 \%(0.40)$ and EFT pairs $100-200$, which correspond to the temperature ranges $25-42^{\circ} \mathrm{F}$ and $65-71^{\circ} \mathrm{F}\left(\left[-3.9^{\circ} \mathrm{C}\right.\right.$, $\left.5.6^{\circ} \mathrm{C}\right]$ and $\left.\left[18.3^{\circ} \mathrm{C}, 21.7^{\circ} \mathrm{C}\right]\right)$ for heating and cooling modes respectively. The third low-lying area occurs near shave factor value of 50\% (0.50) and EFT pairs 400-700, which correspond to the temperature ranges $25-42^{\circ} \mathrm{F}$ and $82-98^{\circ} \mathrm{F}\left(\left[-3.9^{\circ} \mathrm{C}, 5.6^{\circ} \mathrm{C}\right]\right.$ and $\left.\left[27.8^{\circ} \mathrm{C}, 36.7^{\circ} \mathrm{C}\right]\right)$ for heating and cooling modes respectively. These low-lying regions indicate that for this particular building, there might be three good design strategies that a designer might want to implement. The first low-lying region might be more economical and have a slightly lower payback, but the second and third low- 
lying regions would have more environmental benefit since it has a higher shave factor value. Therefore analyzing $\mathrm{CO}_{2}$ emissions becomes important too. This methodology shows a designer what their design freedoms are and provides them with a tool to better analyze potential designs.

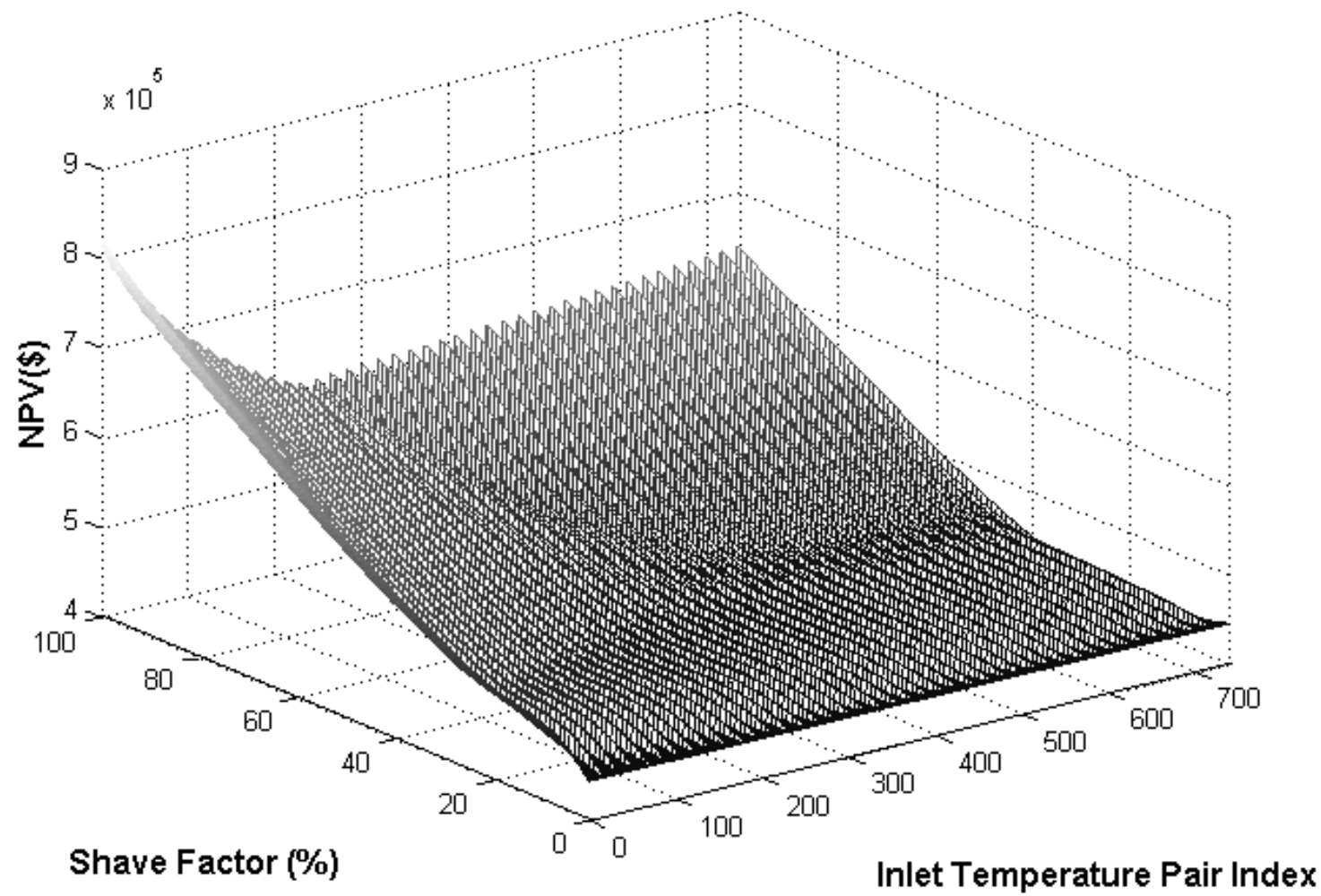

Figure 4.1: EFT analysis for a school located in Toronto, Ontario.

\subsection{2 $\mathrm{CO}_{2}$ emissions}

The total amount of $\mathrm{CO}_{2}$ emitted as a result of using a hybrid GSHP system is dependent on the heating fuel that is used for the conventional system, the electricity consumed by pumps and compressors and the $\mathrm{CO}_{2}$ emission factors of the local electricity supply mix. $\mathrm{CO}_{2}$ emission factors are the factors indicating the amount (measured in $\mathrm{kg} / \mathrm{kWh}$ and $\mathrm{kg} / \mathrm{m}^{3}$ ) of $\mathrm{CO}_{2}$ that is emitted into the air. The supply mix breakdown consists of percentage make-ups of each fuel source such as nuclear, hydro, coal, wind, gas/oil, and other electricity production sources. The breakdown used in this analysis corresponds to an averaged supply mix in Ontario between 2011 and 2012. The supply mix for Ontario is assumed as follows: $51.95 \%$ from nuclear energy, $23.05 \%$ from 
hydroelectricity, $13.74 \%$ from coal energy, $1 \%$ from wind energy, $9.45 \%$ from gas/oil combustion, and $0.81 \%$ from other sources [75].

In the present study, natural gas was assumed to be the fuel for the conventional component of the heating system. The $\mathrm{CO}_{2}$ emissions factor for natural gas is $1.8750 \mathrm{~kg}-\mathrm{CO}_{2} / \mathrm{m}^{3}$ [76]. Similarly, for space cooling by a conventional or a GSHP system, the $\mathrm{CO}_{2}$ emission factors are based on kg- $\mathrm{CO}_{2}$ per kWh of electricity $\left(\mathrm{kg}-\mathrm{CO}_{2} / \mathrm{kWh}\right)$. For electricity production in Ontario, the emission factors used in this analysis are $0.002 \mathrm{~kg}-\mathrm{CO}_{2} / \mathrm{kWh}$ for nuclear [71], $0.023 \mathrm{~kg}-\mathrm{CO}_{2} / \mathrm{kWh}$ for hydro [71], $1.02 \mathrm{~kg}-\mathrm{CO}_{2} / \mathrm{kWh}$ for coal [72], $0.002 \mathrm{~kg}-\mathrm{CO}_{2} / \mathrm{kWh}$ for wind [71], $0.2786 \mathrm{~kg}-\mathrm{CO}_{2} / \mathrm{kWh}$ for oil [73], and $0.0261 \mathrm{~kg}-\mathrm{CO}_{2} / \mathrm{kWh}$ other electricity generation methods [74]. The emission factor of $0.0261 \mathrm{~kg}-\mathrm{CO}_{2} / \mathrm{kWh}$ by other electricity generation methods is associated with biomass (wood chips and pellets) electricity generation. The emission factor $0.0261 \mathrm{~kg}-\mathrm{CO}_{2} / \mathrm{kWh}$ from biomass electricity generation is achieved by taking the average of $0.0149 \mathrm{~kg}-\mathrm{CO}_{2} / \mathrm{kWh}$ for wood chips and $0.0373 \mathrm{~kg}-\mathrm{CO}_{2} / \mathrm{kWh}$ for wood pellets [74], assuming an equal mix of the two fuels.

Using these emission factors, $\mathrm{CO}_{2}$ (or $\mathrm{CO}_{2}$ equivalent) emission rates by a hybrid GSHP system can be determined. To quantify the effects GHG emissions have on hybrid GSHP systems, a carbon tax is implemented (section 4.4.1). Using the methodology outlined in Alavy et al. [15], the costs associated with GHG emissions is added with the annual operating costs. The most economical design is selected based on the shave factor which produces the lowest total costs in net present value (capital and operating costs). The process in determining the $\mathrm{CO}_{2}$ emissions are outlined in the subsequent section (section 4.1.3).

\subsubsection{Calculation of $\mathrm{CO}_{2}$ emissions}

To quantify environmental benefits generated by a hybrid GSHP system, a process for calculating $\mathrm{CO}_{2}$ emissions is used in the present study. It is illustrated in Figure 4.2. 


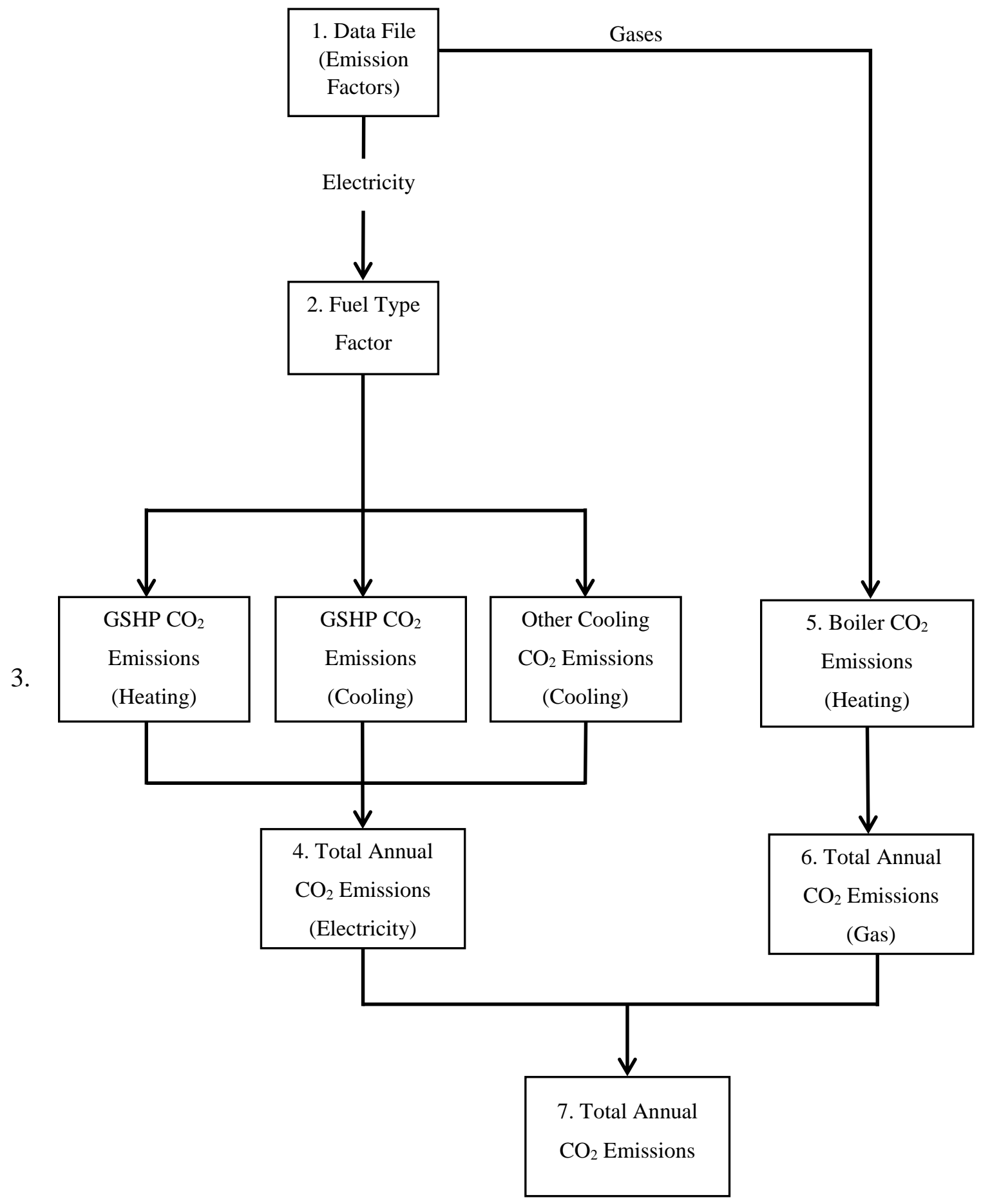

Figure 4.2: $\mathrm{CO}_{2}$ emission calculation process

In step 1, the $\mathrm{CO}_{2}$ emission factor values are entered into the module. The intermediate fuel type factors can be calculated in step 2 for each fuel source type using Equation 4.1. For example, the nuclear fuel type factor is calculated by multiplying the $\mathrm{CO}_{2}$ emission factor for nuclear energy 
$\left(0.002 \mathrm{~kg}-\mathrm{CO}_{2} / \mathrm{kWh}\right)$ with the electricity supply mix of nuclear energy (51.95\% of total electricity supply).

Fuel type factor $_{i}=\mathrm{CO}_{2}$ emission factor $_{i} \times$ electricity supply mix break down $n_{i}(4.1)$ where:

$i=$ nuclear, hydro,coal,wind, gas/oil, and other electricity generation methods

In a hybrid GSHP system, the conventional systems (boiler and cooling tower) and GSHP system (heat pump) are the major components that use electricity and natural gas to provide space heating and cooling. In step 3, the $\mathrm{CO}_{2}$ emissions emitted from each component are calculated using Equation 4.2. For example, for the cooling tower (other cooling $\mathrm{CO}_{2}$ emissions), the $\mathrm{CO}_{2}$ emissions contributed from nuclear energy can be calculated by multiplying the nuclear factor with the electricity consumed by the cooling tower.

$$
\mathrm{CO}_{2} \text { emission }_{j, i}=\text { Fuel type } \text { factor }_{i} \times \text { electricity consumed }
$$

where:

$$
\begin{aligned}
& i=\text { nuclear, hydro, coal, wind, gas/oil, and other electricity generation methods } \\
& j=\text { heating (heat pump), cooling (heat pump), cooling (cooling tower) }
\end{aligned}
$$

In step 4, the total annual $\mathrm{CO}_{2}$ emission from electricity consumption is calculated by the summation of all the $\mathrm{CO}_{2}$ emissions in Equation 4.3 (step 3).

$$
\text { Total } \mathrm{CO}_{2} \text { emission (electricity) }=\sum_{j} \mathrm{CO}_{2} \text { emission }_{j}
$$

where:

$$
j=\text { heating }(G S H P), \text { cooling }(G S H P), \text { cooling (conventional) }
$$

In step 5, a similar equation to that of step 3 is used to calculate the $\mathrm{CO}_{2}$ emitted from natural gas consumption. In Equation 4.4, the $\mathrm{CO}_{2}$ emission factor of natural gas (or other gases used for heating) is multiplied with the volume of natural gas or other heating gases used for space heating by the boiler. 


$$
\mathrm{CO}_{2} \text { emission }_{\text {gas }}=\mathrm{CO}_{2} \text { emission } \text { factor }_{\text {gas }} \times \text { volume consumed }_{\text {gas }}
$$

In step 6, the $\mathrm{CO}_{2}$ emissions are summed up to find the total $\mathrm{CO}_{2}$ emissions from all heating gases. Since the only gas used in the analysis is natural gas, the result of step 6 is the same as step 5 . The total $\mathrm{CO}_{2}$ emissions are calculated in step 7, by summing up the electricity and natural gas $\mathrm{CO}_{2}$ emissions from steps 4 and 6 , respectively.

\subsection{Heat-Pump EFT Analysis}

In this analysis, two ranges of operational EFTs of a heat pump are used to determine the effects they have on the economics of hybrid GSHP systems. Depending on the mode (heating or cooling), varying the heat pump's EFT, within its operational ranges, will affect its COP values (for the heating and cooling modes). The COPs of the heat pump used in this analysis, based on the EFTs, are shown in Figure 4.3. The plot represented by squares and triangles corresponds to the COPs of the heat pump operating in the cooling and heating modes, $60-100^{\circ} \mathrm{F}$ and $25-60^{\circ} \mathrm{F}\left(\left[15.6^{\circ} \mathrm{C}, 37.8^{\circ} \mathrm{C}\right]\right.$ and $\left.\left[-3.9^{\circ} \mathrm{C}, 15.6^{\circ} \mathrm{C}\right]\right)$ respectively.

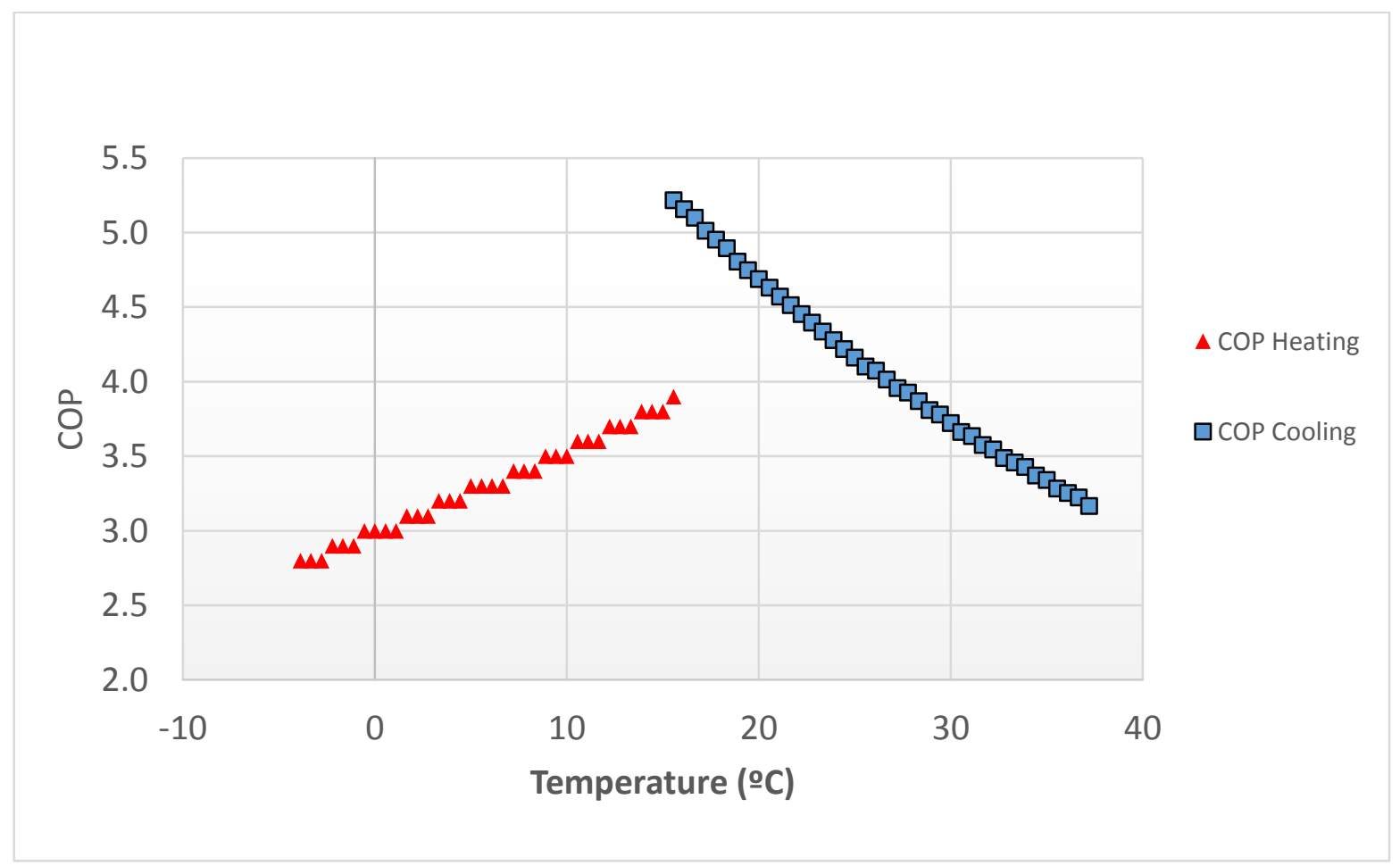

Figure 4.3: Coefficient of performance of a heat pump (CleanEnergy ${ }^{\mathrm{TM}}$, model PC0018) 
The parameters used in this analysis are listed in Tables 4.1 and 4.2 - an inflation rate of $4 \%$, electricity rate of $\$ 0.17 / \mathrm{kWh}$, and natural gas rate of $\$ 0.35 / \mathrm{m}^{3}$ are used. A total of ten real buildings are studied, with their data provided by CleanEnergy ${ }^{\mathrm{TM}}$. The buildings consists of a hospital, an office, a restaurant, a fast-food restaurant, a transit facility, a mid-rise multi-residential building, three high-rise multi-residential buildings, and a school.

The results of this three-dimensional optimization analysis are compared to that of the base case (fixed heat-pump EFT pair of $1.7^{\circ} \mathrm{C}$ and $29.4^{\circ} \mathrm{C}$ ) presented in Table 4.3. In Table 4.3, the ten buildings are listed in the first column and the optimal shave factors corresponding to each building are listed in columns two and three. Columns two and three correspond to the optimal shave factors for the base case (fixed EFT pair) and variable EFT pairs, respectively. The corresponding EFT pairs are listed in columns four and five for the base case (fixed EFT pair) and column six and seven for the case of varying EFT pairs.

Table 4.3: Variable heat-pump EFT vs. base case (fixed EFT)

\begin{tabular}{|c|c|c|c|c|c|c|c|c|c|}
\hline \multirow{3}{*}{ Buildings } & \multicolumn{2}{|c|}{$\begin{array}{c}\text { Optimal Shave } \\
\text { Factor }\end{array}$} & \multicolumn{4}{|c|}{ Optimal Temperature Pair } & \multicolumn{2}{|c|}{$\begin{array}{c}\text { Minimum Total } \\
\text { Costs } \\
\$\left(\times \mathbf{1 0}^{5}\right)\end{array}$} & \multirow{3}{*}{$\begin{array}{c}\text { Total } \\
\text { Costs } \\
\text { Savings } \\
(\%)\end{array}$} \\
\hline & \multirow[b]{2}{*}{$\begin{array}{l}\text { Base } \\
\text { Case }\end{array}$} & \multirow[b]{2}{*}{ Variable } & \multicolumn{2}{|c|}{ Base Case } & \multicolumn{2}{|c|}{ Variable } & \multirow[b]{2}{*}{$\begin{array}{l}\text { Base } \\
\text { Case }\end{array}$} & \multirow[b]{2}{*}{ Variable } & \\
\hline & & & $\begin{array}{c}\mathbf{T}_{\mathbf{c}} \\
\left({ }^{\circ} \mathrm{C}\right)\end{array}$ & $\begin{array}{c}\mathbf{T}_{\mathbf{h}} \\
\left({ }^{\circ} \mathrm{C}\right)\end{array}$ & $\begin{array}{c}\mathbf{T}_{\mathbf{c}} \\
\left({ }^{\circ} \mathrm{C}\right)\end{array}$ & $\begin{array}{c}\mathbf{T}_{\mathbf{h}} \\
\left({ }^{\circ} \mathrm{C}\right)\end{array}$ & & & \\
\hline 1. School & 0.22 & 0.24 & \multirow{10}{*}{29.4} & \multirow{10}{*}{1.7} & 32.2 & 5 & 4.36 & 4.20 & 3.6 \\
\hline 2. Office & - & - & & & - & - & - & - & - \\
\hline 3. Hospital & - & - & & & - & - & - & - & - \\
\hline 4. Restaurant & 0.65 & 0.65 & & & 29.4 & 5 & 8.25 & 8.25 & 0 \\
\hline $\begin{array}{l}\text { 5. Fast food } \\
\text { restaurant }\end{array}$ & 0.62 & 0.62 & & & 29.4 & 5 & 4.74 & 4.74 & 0 \\
\hline 6. High-rise (I) & 0.25 & 0.27 & & & 33.9 & 5 & 6.45 & 6.4 & 0.84 \\
\hline 7. High-rise (II) & 0.23 & 0.25 & & & 33.9 & 5 & 14.6 & 14.5 & 0.98 \\
\hline 8. High-rise (II) & 0.39 & 0.41 & & & 32.2 & 5 & 11.6 & 11.5 & 0.5 \\
\hline 9. Mid-rise & 0.34 & 0.36 & & & 32.2 & 5 & 8.71 & 8.66 & 0.47 \\
\hline $\begin{array}{l}\text { 10. Transit } \\
\text { facility }\end{array}$ & 0.44 & 0.48 & & & 33.9 & 5 & 7.18 & 7.11 & 0.96 \\
\hline
\end{tabular}


Since the ground temperature in Toronto is approximated to be $50^{\circ} \mathrm{F}\left(10^{\circ} \mathrm{C}\right)$, using the COP values in Figure 4.3, the heat-pump EFTs for the heating and cooling modes were varied in the ranges of $25-42^{\circ} \mathrm{F}$ and $60-100^{\circ} \mathrm{F}\left(\left[-3.9^{\circ} \mathrm{C}, 5.6^{\circ} \mathrm{C}\right]\right.$ and $\left.\left[15.6^{\circ} \mathrm{C}, 37.8^{\circ} \mathrm{C}\right]\right)$ respectively. The EFTs in the range of $43-49^{\circ} \mathrm{F}\left(6.1-9.4^{\circ} \mathrm{C}\right)$ for the heating mode were omitted to reduce computational time, because there were no savings when these specific temperatures were analyzed separately (due to the associated need for larger ground loop lengths when operating in cooling mode).

The minimum total cost for the base case (column eight) and variable EFT analysis (column nine) are used to determine the total costs savings presented in column 10 associated with using a threedimensional optimization. Of the ten buildings analyzed, the school in Table 4.3 produced the most savings compared to the base case. A total of $3.6 \%$ reduction in cost was achieved when all the possible combinations of heat pump EFTs are assessed compared to the base case design standard. For a typical installation, this level of savings can translate to $\$ 1,000$ per year. However, the observed savings for the remaining buildings were less than $1 \%$.

Based on the building's heating and cooling loads, two ground loop lengths are calculated as outlined in Alavy et al. [15]. If the cooling ground loop length is larger than that of the heating ground loop, the building is cooling dominant (vice versa for heating dominant). Buildings, \#1 and \#4-10 are cooling dominant. As a result, although the optimal EFT for heating mode is $5^{\circ} \mathrm{C}$ compared to the base case of $1.7^{\circ} \mathrm{C}$, the effects it has on the hybrid GSHP system's economics are negligible for certain buildings such as the restaurant and fast-food restaurant (the two most cooling dominant sample buildings). For the restaurant and fast-food restaurant, the optimal shave factors between the base case and the variable EFT scenario remained the same for these two buildings because they are very cooling dominant throughout the year, with negligible heating requirements.

Although there is some merit in continuously varying the heat-pump EFT pairs using the existing methodology in [15], the effects of varying heat-pump EFT has shown to be negligible (for buildings situated in Toronto) compared to other parameters such as weather patterns, operating costs, and inflation rates as investigated in Chapter 3. In most cases, the effects of varying EFTs 
is modest as compared to shave factor. This analysis was repeated for many variations in EFT pairs, such as $33^{\circ} \mathrm{F}-37^{\circ} \mathrm{F}$ and $83^{\circ} \mathrm{F}-87^{\circ} \mathrm{F}\left(0.6-2.8^{\circ} \mathrm{C}\right.$ and $\left.28.3-30.6^{\circ} \mathrm{C}\right)$ for the heating and cooling mode respectively. The trends and conclusions remain the same.

\section{3 $\mathrm{CO}_{2}$ Analysis}

By applying a $\mathrm{CO}_{2}$ emissions module, Figures 4.4 and 4.5 plot the shave factors, i.e., the portion of peak demand that could be met by the GSHP, against total annual $\mathrm{CO}_{2}$ emission $(\mathrm{kg})$. In Figure 4.4, the curved line represents the $\mathrm{CO}_{2}$ emission (of a fast food restaurant) for each shave factor value from 0 to 1 . To generate the curve, 100 shave factors were considered, each corresponding to a differently sized GSHP system. The intersection point between the vertical and horizontal line represent the location of the optimal shave factor. Using the methodology outlined in Alavy et al. [15], the optimal shave factor for the fast food restaurant, as presented in Figure 4.4, is 0.62. It can be observed that the $\mathrm{CO}_{2}$ emitted when the system is sized with an optimal shave factor value of $0.62(23,595 \mathrm{~kg})$ is very near the minimum $\mathrm{CO}_{2}$ emissions $(21,750 \mathrm{~kg})$. For the case of the fastfood restaurant, the optimization based on Alavy et al.'s methodology [15] results in a $\mathrm{CO}_{2}$ emissions reduction of $74 \%$ (compared to a conventional system) of that which would be achieved with a GSHP system meeting peak demand, but at a much lower cost (a savings of $\$ 26,400$ in net present value). 


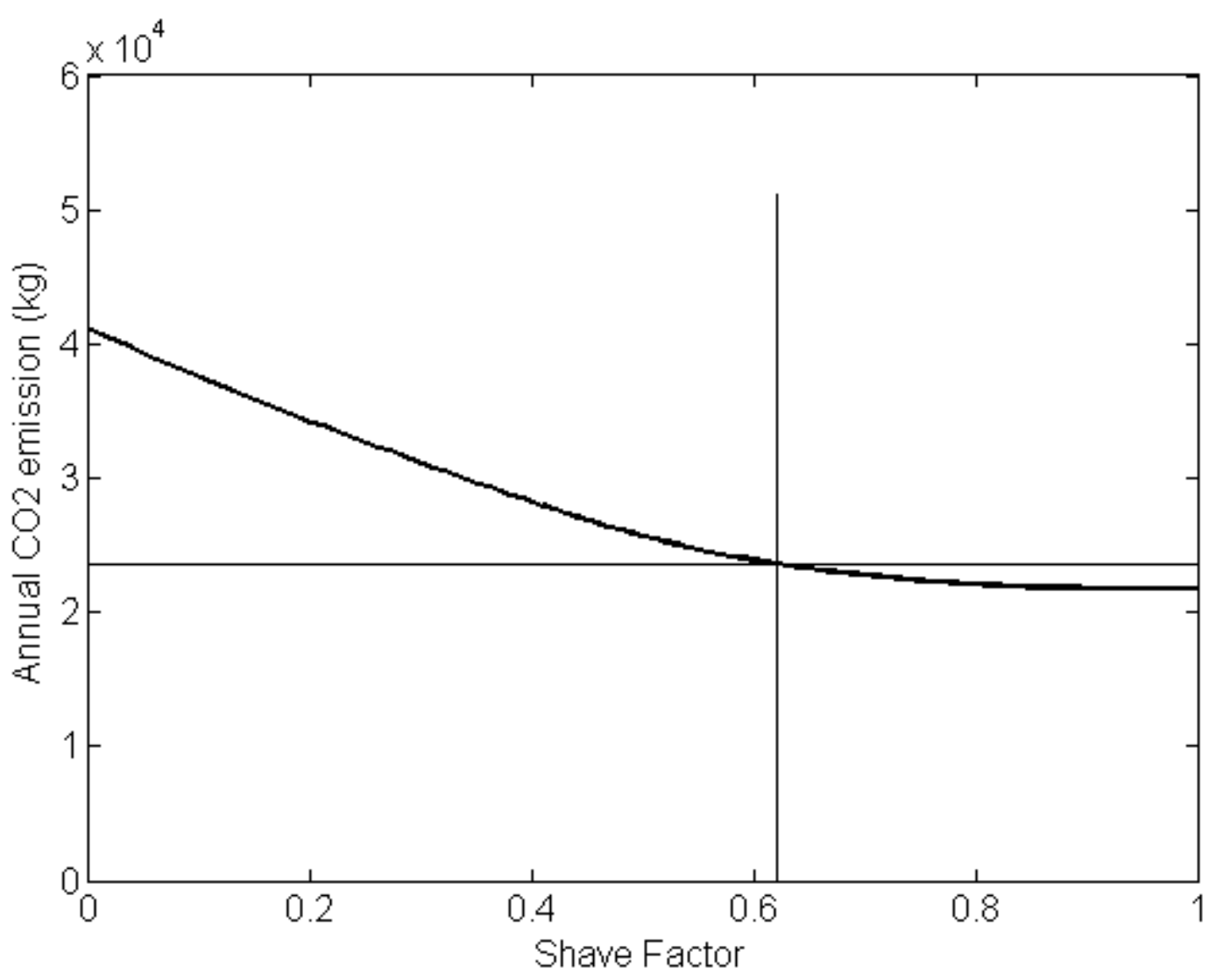

Figure 4.4: Annual $\mathrm{CO}_{2}$ emissions of a fast-food restaurant located in Toronto, Ontario, as a function of shave factor.

In some cases, a design based on the optimal shave factor (based on net present value) results in a hybrid GSHP system that produces $20 \%$ or more $\mathrm{CO}_{2}$ than the minimum $\mathrm{CO}_{2}$ emitting GSHP system (with a shave factor of 1.0). For example, in Figure 4.5, the optimal shave factor of a highrise (II) building located in Toronto, Ontario is 0.23 (most economical design in terms of net present value). The corresponding annual $\mathrm{CO}_{2}$ emission of the system is $87,119 \mathrm{~kg}$ (minimum $\mathrm{CO}_{2}$ emissions is $65,250 \mathrm{~kg}$ ). However, if reduction in $\mathrm{CO}_{2}$ emissions were a higher priority, the installer can size the system to a shave factor of 0.6 , the annual $\mathrm{CO}_{2}$ emissions would reduce to $68,385 \mathrm{~kg}$ resulting in a $25 \%$ reduction in $\mathrm{CO}_{2}$ emissions. The corresponding cost increase would be $4.2 \%$. It can be seen that this method of plotting and analysis can give designers and engineers the ability to understand the trade-off between cost, payback period, and environmental impacts. 


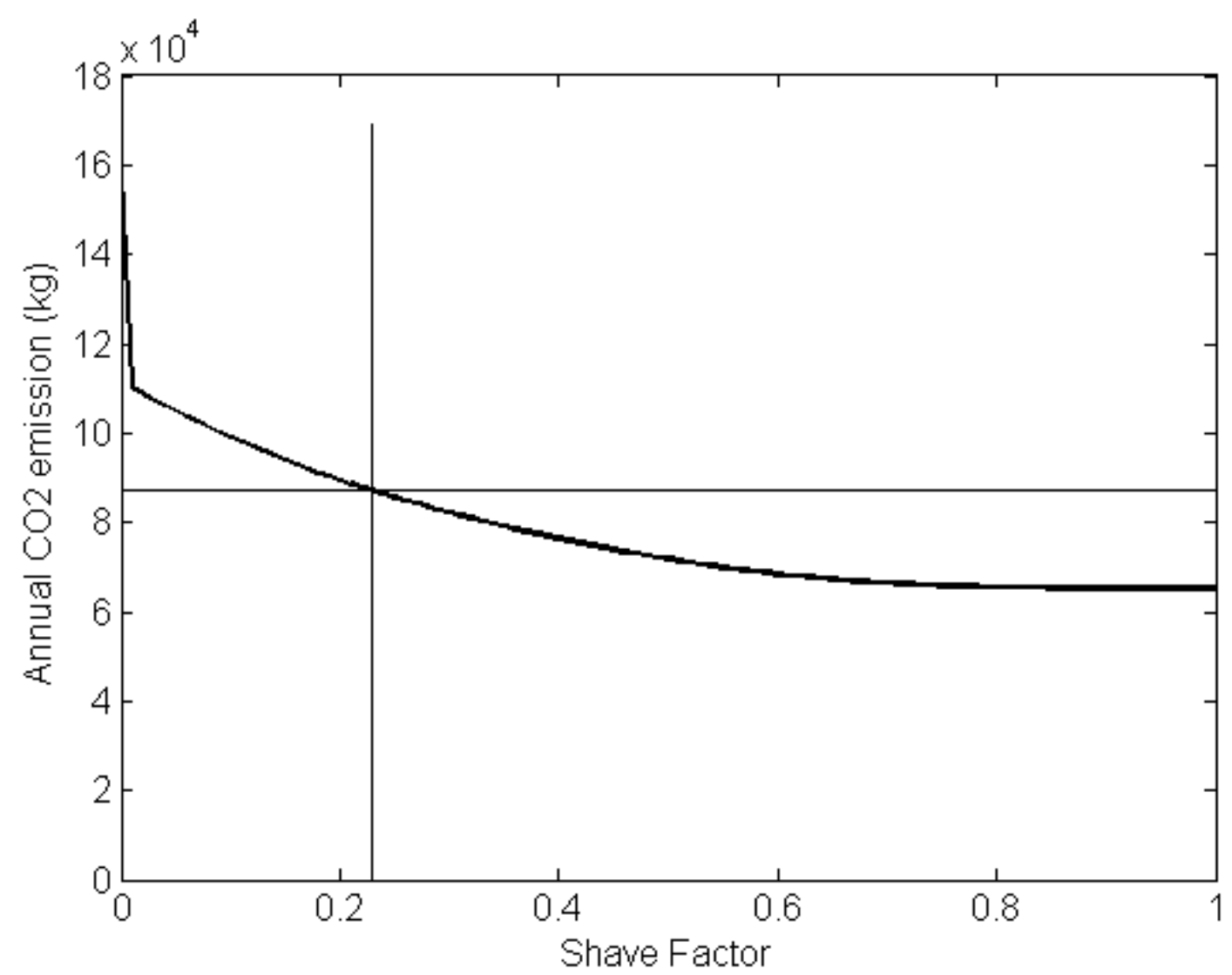

Figure 4.5: Annual $\mathrm{CO}_{2}$ emissions of high-rise (II) building located in Markham, Ontario

A total of eight buildings are analyzed and the results are summarized in Table 4.4. In Table 4.4, the optimal shave factors are listed in the second row and the corresponding $\mathrm{CO}_{2}$ emissions are listed in the third row. The $\mathrm{CO}_{2}$ emissions for each building corresponding to a shave factor of 1 (GSHP meeting full demand) are listed in the fourth row, and represent the minimum $\mathrm{CO}_{2}$ emissions that can be achieved using a full GSHP installation. The $\mathrm{CO}_{2}$ emissions of the optimized hybrid GSHP systems are the closest to the minimum possible $\mathrm{CO}_{2}$ emissions for buildings that are extremely cooling dominant, such as the fast-food restaurant, for which the optimized shave factor results in emissions that are only $8.5 \%$ more than the minimum possible amount. There was no economically viable hybrid-GSHP design for the office building (most economical using a conventional system). As a result, the average percentage increase in $\mathrm{CO}_{2}$ emissions for the office building using a conventional system is $326 \%$ (maximum percentage increase) compared to a full GSHP installation (shave factor value of 1). Using the optimal shave factor approach outlined in Alavy et al. [15] produces acceptable levels of $\mathrm{CO}_{2}$ emissions even when the optimal shave factors 
are below 0.50, as is often the case. For example, the shave factor for the high-rise (III) building is 0.39 and the corresponding percentage increase in $\mathrm{CO}_{2}$ emissions is only $21 \%$ with respect to the shave factor of 1. Similarly, the transit facility and mid-rise building have optimal shave factor values of 0.44 and 0.34 , respectively, while their average percentage increases in $\mathrm{CO}_{2}$ emissions are $19.5 \%$ and $22.8 \%$, respectively. For these buildings, much of the reduction in $\mathrm{CO}_{2}$ emissions is still realized when switching from the conventional system to the hybrid GSHP system which is designed based purely on economic optimization. Based on the optimal design, all the buildings reduced their $\mathrm{CO}_{2}$ by at least $70 \%$ compared to a purely conventional system. The mid-rise building and transit facility reduced the minimum (70\%) and most $(84.6 \%) \mathrm{CO}_{2}$ respectively.

Table 4.4: Summary of annual $\mathrm{CO}_{2}$ emission for the 8 buildings, located in Toronto, Canada

\begin{tabular}{|c|c|c|c|c|c|c|c|c|}
\hline Building & $\begin{array}{c}\text { High- } \\
\text { rise (I) }\end{array}$ & $\begin{array}{c}\text { High-rise } \\
\text { (II) }\end{array}$ & $\begin{array}{c}\text { High-rise } \\
\text { (III) }\end{array}$ & Office & Restaurant & $\begin{array}{c}\text { Fast food } \\
\text { Restaurant }\end{array}$ & $\begin{array}{c}\text { Transit } \\
\text { Facility }\end{array}$ & Mid-rise \\
\hline $\begin{array}{c}\text { Optimal } \\
\text { Shave } \\
\text { Factor }\end{array}$ & 0.25 & 0.23 & 0.39 & 0 & 0.65 & 0.62 & 0.44 & 0.34 \\
\hline $\begin{array}{c}\mathrm{CO}_{2 \_ \text {optimal } S F}(\mathrm{~kg}) \\
\mathrm{CO}_{2 \_S F=1}\end{array}$ & 36,427 & 87,119 & 61,934 & N/A & 21,035 & 23,595 & 37,603 & 46,490 \\
\hline $\mathrm{kg})$ & 28,553 & 65,248 & 51,166 & 146,560 & 14,656 & 21,750 & 31,457 & 37,845 \\
\hline $\begin{array}{c}\mathrm{CO}_{2 \_S F=0} \\
(\mathrm{~kg})\end{array}$ & 67,001 & 159,010 & 108,616 & 624,291 & 37,287 & 41,121 & 69,411 & 79,067 \\
\hline
\end{tabular}

\subsubsection{Applying a carbon tax}

The reduction in carbon emissions provided by renewable energy sources is a benefit that is difficult for the end-use customer to quantify. Typically it is the savings related to any energy efficiency arising from the renewable energy technology that provides the potential for customer adoption. If those savings are marginal then the carbon reduction benefit is not likely to stimulate energy consumers into paying more for technologies that reduce emissions. However, by implementing policies that introduce a cost to the emitting of carbon, such as a carbon tax, then an incentive exists for customers to consider adopting costlier renewable energy technologies [80]. 
The use of a carbon tax has been identified in the climate policy literature as an effective tool for stimulating emissions reduction. It is preferred by most economists because it is seen as a mechanism for reducing carbon in the most economically efficient manner even though putting a carbon tax into practice can be problematic as the general public tends to reactive negatively to increased taxation [81].

Currently, Finland, Australia, Sweden, Great Britain, New Zealand, and some provinces in Canada have implemented a carbon tax as an initiative to reduce their carbon footprint [77-79]. In Canada, for every tonne of $\mathrm{CO}_{2}\left(\mathrm{CO}_{2}\right.$ equivalent), a cost is charged based on the regulations set by the province. Alternatively, some jurisdictions may impose a carbon incentive, providing a tax break for companies that take measures to reduce their emissions. For example, a cost of $\$ 30$ is charged (pre-applied to fuel consumption) for every tonne of $\mathrm{CO}_{2}$ emitted into the air in British Columbia, Canada [77]. The provinces of Quebec and Alberta, Canada have also begun adopting carbon taxes. In the present analysis, a carbon tax of $\$ 30$ for every tonne of $\mathrm{CO}_{2}$ emitted is adopted (British Columbia's rate) in order to understand the effect that it has on the economic viability of hybrid GSHP installations. Using the value of a carbon tax as a proxy for the cost of carbon when undertaking the economic evaluation of renewable energy technologies is not uncommon in the recent literature [82-83]

The total annual carbon tax costs were determined using the calculations outlined in section 4.1.3. Using a 20 year system project life and the methodology outlined in Alavy et al. [15], the calculated annual carbon tax was added to the total annual costs (which includes operation and any overhead costs) for years 1 through 20 before they are all discounted into net present values. The shave factor that corresponds to the minimum total costs in net present value was selected as the optimal shave factor. As the operating costs change with the consideration of a carbon tax, the optimal shave factor is expected to change. The main objective of this analysis is to determine to what extent the optimal shave factor varies, so as to understand how carbon taxation should be considered in hybrid GSHP design. 
The results of implementing a carbon tax are presented in Table 4.5. Due to the carbon tax, the overall total costs increase. As a result, in order to alleviate the increase in operation costs, the optimal shave factor increases (emitting less $\mathrm{CO}_{2}$ ) as compared to the cases without the carbon tax. Furthermore, an increase in shave factor contributes to a reduction in payback periods due to savings in operating costs from the carbon tax incentive (especially for the case when the shave factor is 0 , i.e. conventional system with no reduction in $\mathrm{CO}_{2}$ emissions). For example, as presented in Table 4.5, the transit facility's shave factor increased from 0.44 (no carbon tax) to 0.47 (with a carbon tax) resulting in a reduction in payback period from 19.4 years to 18.7 years.

As presented in Table 4.5, in some cases, a slight increase in shave factor values result in a moderate reduction in the payback period. The high-rise (I) and high-rise (II) buildings achieved a reduction in payback periods of 1.1 and 1.5 years, respectively, due to the impact of a carbon taxation. The restaurant and fast-food restaurant achieved a negligible reduction in payback periods of 0.32 and 0.28 years respectively. It can be concluded that if a carbon tax were to be applied, the shave factor would increase to offset the increase in operating costs (resulting in shorter payback periods), but in most cases the increase is modest. It is interesting to find that, for the heating-dominant office building, there is still no economically viable hybrid-GSHP design even with a carbon tax of $\$ 30 /$ tonne $\mathrm{CO}_{2}$.

Table 4.5: Changes in shave factors and payback periods due to a carbon tax

\begin{tabular}{|c|c|c|c|c|c|c|c|c|}
\hline Building & $\begin{array}{l}\text { High- } \\
\text { rise (I) }\end{array}$ & $\begin{array}{l}\text { High-rise } \\
\text { (II) }\end{array}$ & $\begin{array}{c}\text { High- } \\
\text { rise (III) }\end{array}$ & Office & Restaurant & $\begin{array}{l}\text { Fast Food } \\
\text { Restaurant }\end{array}$ & $\begin{array}{c}\text { Transit } \\
\text { Facility }\end{array}$ & $\begin{array}{l}\text { Mid- } \\
\text { rise }\end{array}$ \\
\hline \multicolumn{9}{|c|}{ No carbon tax: } \\
\hline $\begin{array}{l}\text { Shave } \\
\text { Factor }\end{array}$ & 0.25 & 0.23 & 0.39 & 0 & 0.65 & 0.62 & 0.44 & 0.34 \\
\hline $\begin{array}{c}\text { Payback } \\
\text { Period } \\
\text { (years) }\end{array}$ & 20.88 & 22.13 & 17.93 & - & 14.29 & 14.62 & 19.42 & 18.39 \\
\hline \multicolumn{9}{|c|}{ With a carbon $\operatorname{tax}\left(\$ 30 /\right.$ tonne $\left.\mathrm{CO}_{2}\right)$ : } \\
\hline $\begin{array}{l}\text { Shave } \\
\text { Factor }\end{array}$ & 0.25 & 0.24 & 0.40 & 0 & 0.65 & 0.63 & 0.47 & 0.35 \\
\hline $\begin{array}{c}\text { Payback } \\
\text { Period } \\
\text { (years) }\end{array}$ & 19.79 & 20.61 & 17.36 & - & 13.97 & 14.34 & 18.73 & 17.83 \\
\hline
\end{tabular}




\subsubsection{Project life analysis}

In the previous analyses, a project life of 20 years was used. However, depending on how long a building owner might plan to own a building, other project life may be of interest. If operating

durations (project life) other than 20 years are assumed, then the algorithm will determine a different shave factor because it is factored into determining the net present value of the annual operating costs and/or possible equipment replacement costs. Therefore, depending on the assumed project life of the hybrid system, a different optimal shave factor, and therefore $\mathrm{CO}_{2}$ emissions might be the desired design parameter. In this section, two analyses were carried out to determine the effects project life have on annual costs (net present value) and $\mathrm{CO}_{2}$ emissions. In these two analyses, the conventional system and GSHP system are replaced every 20 and 40 years respectively.

\section{Project life: NPV/year analysis}

In this section, a new variable "NPV/operating duration" was calculated. The total cost (capital, operating costs, overhaul costs of cooling towers, heat pumps, boilers, and the ground loop) in net present value (NPV) is divided by the operating duration (project life) to determine the amortized system costs per year. The "NPV/operating duration" parameter, analogous to payback period, is useful in visually displaying the amortized system costs per year. Using the methodology outlined in Alavy et al. [15] will determine the payback period and corresponding total costs of a GSHP system in net present value for a particular optimal shave factor. However, if GSHPs are installed and rented out (a utility model), as is often the case with boilers and furnaces for residential and commercial buildings, by using this parameter the installer can determine the appropriate shave factor (system size) and project life in order to achieve the optimal NPV per operating year using the "NPV/operating duration" parameter.

In Figure 4.6, the net present value cost per operating year is plotted against the project life (in years). As expected, as project life increases, the annual system costs decreases. This decrease is attributed to the fact that the capital cost is spread over a longer timeframe (when considered as an averaged costs). For most buildings, such as the fast food restaurant associated with Figure 4.6, net present value cost per operating year levels off after very long durations of operation - greater 
than 70 years. However, sizing a hybrid GSHP system based on an economic analysis of 70 years or more is impractical.

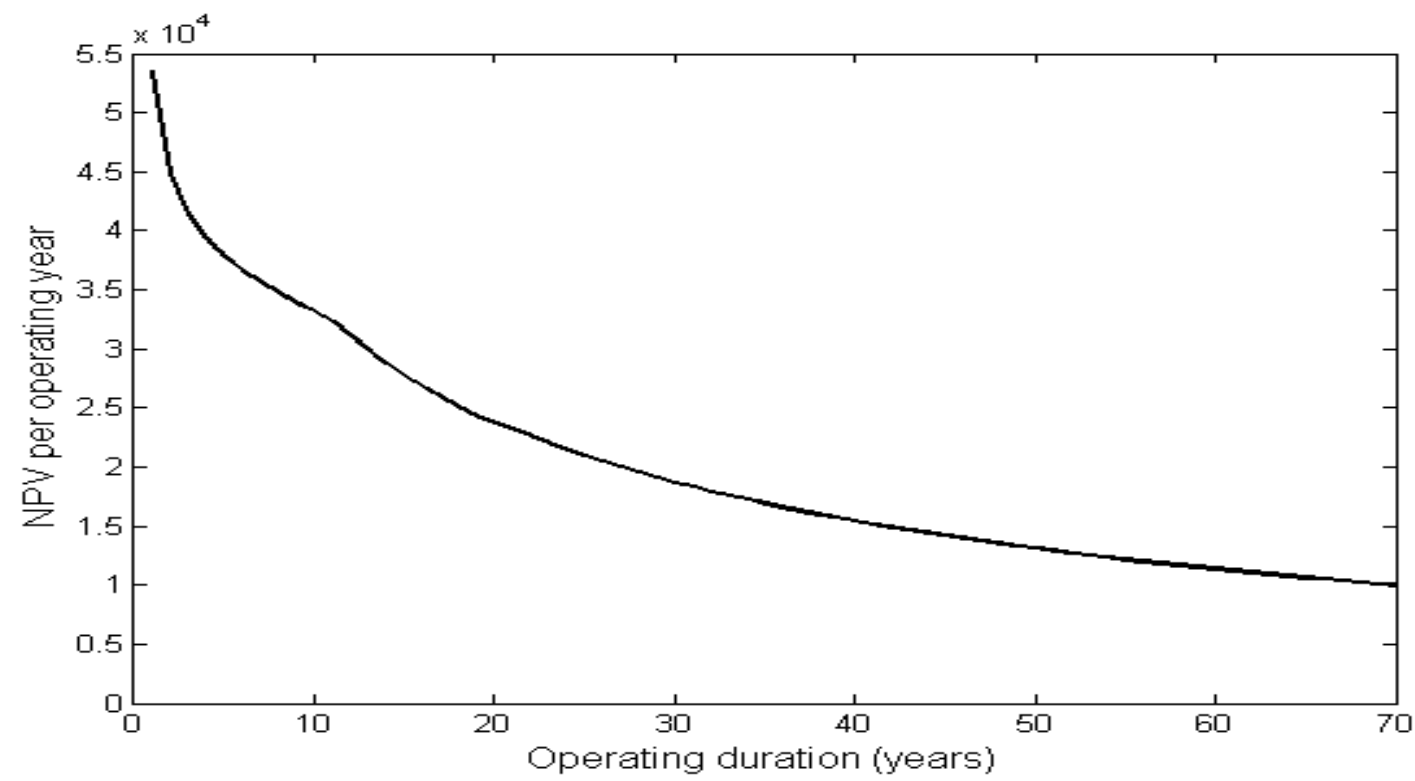

Figure 4.6: Net present value per operating year (\$/year) vs. operating duration (project life) for a fast food restaurant located in Toronto, Ontario

\section{Project life: $\mathrm{CO}_{2}$ analysis}

By varying the project life (investment timeframe) from 10 to 100 years, the annual $\mathrm{CO}_{2}$ emissions asymptote at around 50 to 100 years of operation for all the buildings analyzed. The costs in this analysis include replacement costs of components such as the cooling tower, and boilers every twenty years and the ground loop every forty years. Table 4.6 illustrates the effects that project life have on the hybrid system economics. As the assumed project life increases, the shave factor and $\mathrm{CO}_{2}$ emissions level off at values of 0.8 and 22,076 kg, respectively, for the fast food restaurant. This relationship is plotted in Figure 4.7. In Figure 4.7, it can be observed that the $\mathrm{CO}_{2}$ emissions per operating year decreases with project life and begins to level off at around 20 years of operation. It can be concluded that the reduction of $\mathrm{CO}_{2}$ emissions per operating year for project life greater than 20 years are not much greater than the project life of 20 years for buildings similar to that of the fast-food restaurant. Similar trends are also observed for the other buildings tested. 
Table 4.6: Project life and $\mathrm{CO}_{2}$ analysis for a fast-food restaurant

\begin{tabular}{|c|c|c|}
\hline $\begin{array}{c}\text { Project Life } \\
\text { (Years) }\end{array}$ & Shave Factor & $\begin{array}{c}\mathrm{CO}_{2} \\
\text { Emissions per Operating Year } \\
\left(\mathrm{kg}-\mathrm{CO}_{2} / \text { year }\right)\end{array}$ \\
\hline 10 & 0.01 & 40,744 \\
\hline 20 & 0.62 & 23,595 \\
\hline 30 & 0.73 & 22,494 \\
\hline 40 & 0.75 & 22,355 \\
\hline 50 & 0.77 & 22,233 \\
\hline 60 & 0.78 & 22,178 \\
\hline 70 & 0.79 & 22,125 \\
\hline 80 & 0.8 & 22,076 \\
\hline 90 & 0.8 & 22,076 \\
\hline 100 & 0.8 & 22,076 \\
\hline
\end{tabular}

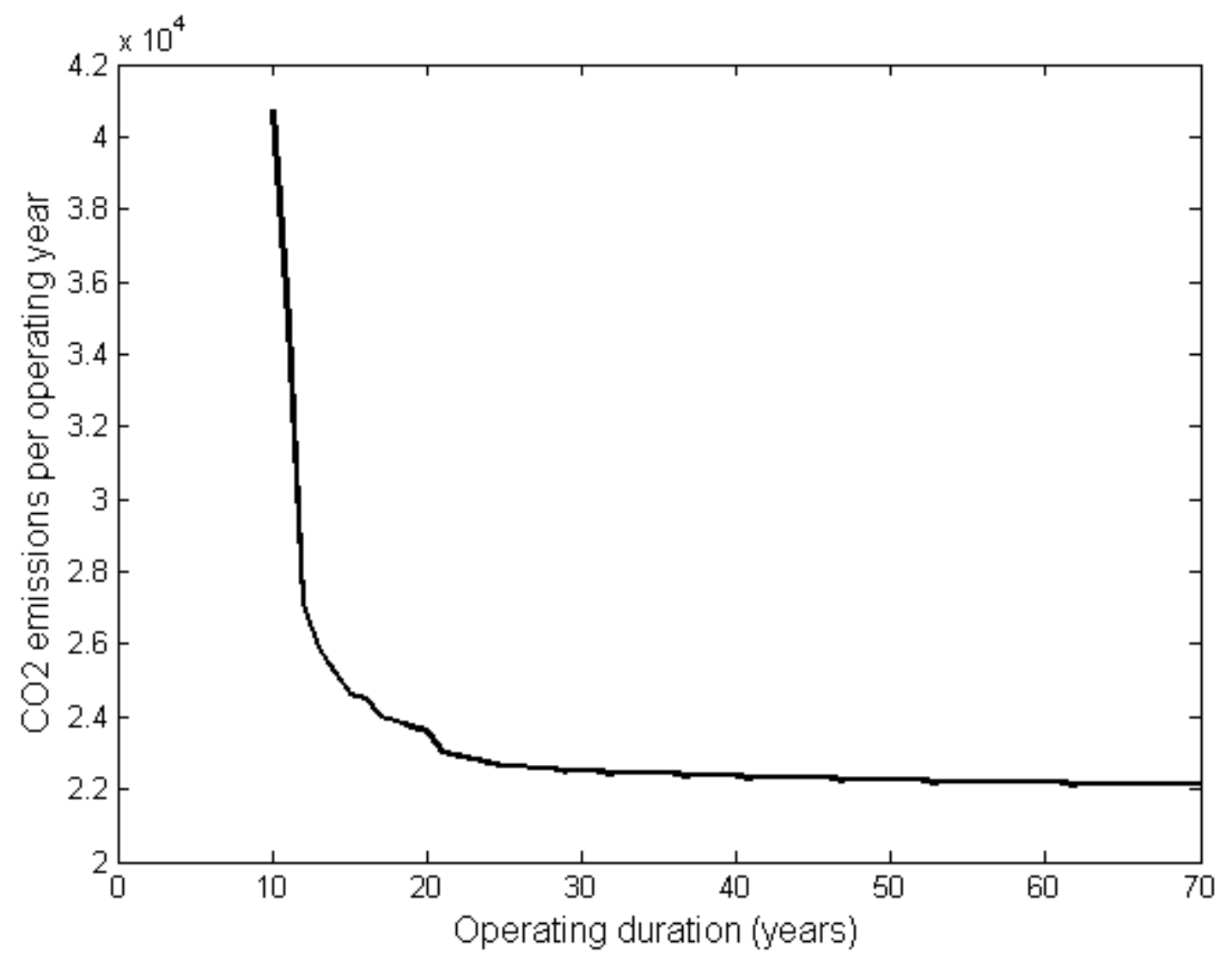

Figure 4.7: $\mathrm{CO}_{2}$ emissions per operating year vs. operating duration (project life) for a fast-food restaurant located in Toronto, Ontario 
The relationship between payback period and project life is presented in Figure 4.8. In Figure 4.8, the solid line represents the payback period corresponding to the project life of the hybrid GSHP system and the dashed line tracks the assumed project life. When the payback period is greater than the assumed project life, the system is not economically viable. When the payback period is shorter than the project life, an economically viable system is feasible. The break-even point of the hybrid GSHP system is the point of intersection between the two lines, for the fast-food restaurant being analyzed in Figure 4.8, the break-even point occurs at year 13. If the system operates for 13 years or less, there is no economic benefit. The payback period is calculated as the total costs (discounted to net present value) divided by savings. As a result, an inverse relationship exists between payback period and project life before the break-even point (no economic benefit).

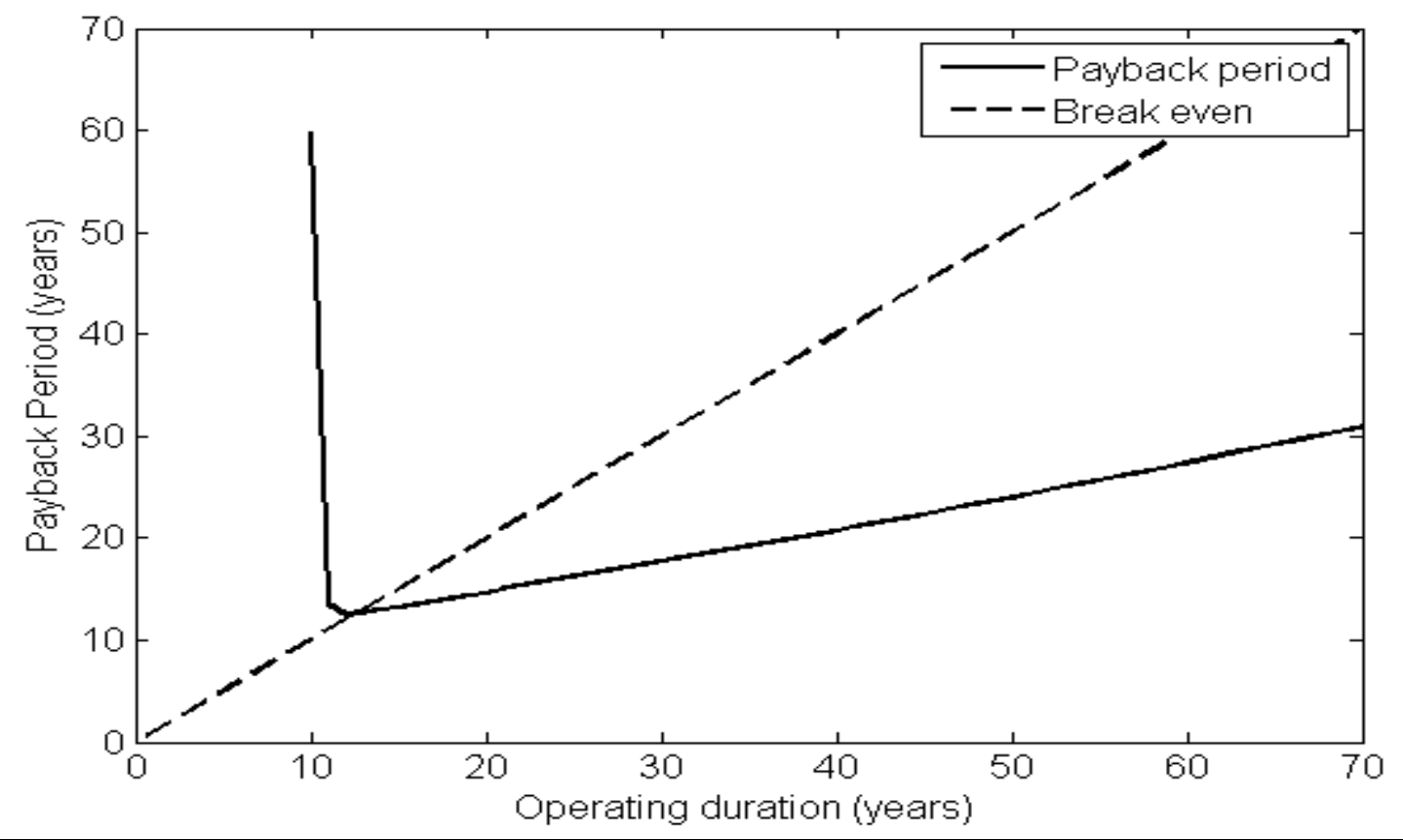

Figure 4.8: Payback period vs. operating duration (project life) of a fast-food restaurant located in Toronto, Ontario

Table 4.7 summarizes the buildings' project life. As observed, between 20 and 25 years of operation, most of the environmental benefit can be achieved compared to that of 100 years; the three high-rises all produce only $9 \%$ more $\mathrm{CO}_{2}$. 
Table 4.7: $\mathrm{CO}_{2}$ emissions percent increase summary

\begin{tabular}{|c|c|c|}
\hline Building & $\begin{array}{c}\text { Project life } \\
\text { (Years) }\end{array}$ & $\begin{array}{c}\text { CO2 emissions } \\
\text { percent increase } \\
\text { compared to 100 years } \\
(\%)\end{array}$ \\
\hline High-rise I & 20 & 9 \\
\hline High-rise II & 24 & 9 \\
\hline High-rise III & 21 & 9 \\
\hline Fast-food restaurant & 20 & 7 \\
\hline Restaurant & 20 & 10 \\
\hline Transit facility & 22 & 7 \\
\hline Mid-rise & 25 & 5 \\
\hline
\end{tabular}

The values are rounded (up) to the nearest percent 


\subsection{Chapter Summary}

The present study shows that although heat-pump EFT plays a crucial role in determining the efficiency of the system, the effects of varying the EFT pairs on the optimal design is unsubstantial compared to other parameters such as weather patterns and utility rates. Varying the heat-pump EFT directly affects the COPs of the heating and cooling modes of the heat pump (operating costs), as such, improving the COP in turn reduces GHG emissions. However, EFT pairs that improve the COPs requires a larger ground loop which results in higher upfront costs (vice versa for reducing upfront costs). As a result, the largest savings achieved from the ten real buildings analyzed, compared to the base case (fixed EFT pair) was only 3.6\% for a school located in Toronto, Canada.

In the $\mathrm{CO}_{2}$ emissions analysis, based on a carbon tax of $\$ 30$ per tonne of $\mathrm{CO}_{2}$ emitted, a carbon tax increases the operating costs of a hybrid GSHP system. To accommodate the increase in operating costs, for all of the buildings analyzed the optimal shave factor increased, contributing to a reduction in $\mathrm{CO}_{2}$ emissions and payback periods (especially for the case of a shave factor of 0.0). In the analysis in which a carbon tax was not applied, using the optimization methodology outlined in Alavy et al. [15] yields $\mathrm{CO}_{2}$ emission levels similar to that of a shave factor $=1.0$, in some cases such as that of the fast-food restaurant with a shave factor value of $0.62\left(8.5 \%\right.$ more $\mathrm{CO}_{2}$ emissions than $S F=1)$.

If total costs and $\mathrm{CO}_{2}$ emissions are equally important, sizing the system based on the optimal shave factor may result in higher $\mathrm{CO}_{2}$ emissions than desired, whereas sizing the system to a shave factor of 1.0 might result in high upfront costs than desired. An example would be the high-rise (II) building with an optimal shave factor of 0.23 in which sizing the system to a shave factor of 0.6 would reduce $\mathrm{CO}_{2}$ emissions comparable to that of $S F=1$. The methods of analysis presented in this chapter empower a designer to understand the increment in NPV and payback period associated with such an adjustment so as to make an informed decision. For the ten buildings analyzed, the average reduction in $\mathrm{CO}_{2}$ emissions for project life greater than 20 years (long term) are similar to those of 20 years operation. 
The project life analysis was performed to determine its economic and environmental effects on sizing hybrid GSHP systems. Using the "NPV/operating duration" parameter, to determine the amortized system cost per year, reductions in annual amortized system costs are achieved as the assumed operating duration (project life) increases. However, the economic benefits of increasing a hybrid GSHP's assumed project life (exceeding the break-even point) begins to asymptote at year 50. This analysis may be of particular interest when government owned buildings or schools are considered, as such buildings infrequently change ownership. The same conclusions are also observed for $\mathrm{CO}_{2}$ emissions. For the case of the fast-food restaurant, when the project life exceeds the break-even point (13 years), the reduction in $\mathrm{CO}_{2}$ emissions per operating year is greatest at the project life of 30 years and asymptotes thereafter. 


\section{Chapter 5}

\section{Study \#3: Retrofit Analysis}

\subsection{Methodology}

In Canada, it is estimated that $27 \%$ of all buildings use electric baseboards as the main source of heating. By province, 66\% of buildings in Quebec (highest percentage) rely on baseboard heating (7\% for Ontario) [84]. With the rising costs of electricity, and high heating demands for buildings situated in Ontario, a retrofit analysis was performed to determine the economic feasibility of a hybrid GSHP system. In this analysis, the buildings are assumed to be heated and cooled by electric baseboard heaters and window air conditioner units (or by a cooling tower) respectively (base case). Energy loss from outdoor air infiltration can offset the actual overall performance of window air conditioner units. Furthermore, window air conditioners have a shorter life cycle compared to that of heat pumps, 10 years compared to 20 years respectively $[5,86]$.

In this analysis two scenarios are considered. In the first scenario, the buildings are heated by electric baseboard heaters and cooled by window air conditioner units as the base case. Similarly, for the second scenario, cooling towers are used during the cooling mode instead of window air conditioners. As outlined in Table 5.1, the COP values for window unit GSHP systems in cooling mode are 3.4 [85] and 3.8 (CleanEnergy Developments/PC0018) respectively. In the heating mode, the electric baseboard heater and heat pump are assumed to operate with a COP of 1.0 and 3.1 , respectively.

The retrofit analysis was performed using the methodology outlined in Alavy et al. [15], for which the algorithm was modified to consider the total costs of the electric baseboard heating, building envelope retrofit costs, ductwork costs, and other retrofit costs. The total costs (in net present value) corresponding to each shave factor, as outlined in Figure 5.1, are based on the initial cost, operating costs, and other retrofit costs. 
Table 5.1: Retrofit - heating and cooling COP of equipment

\begin{tabular}{|c|c|}
\hline Heating/Cooling Equipment & Assumed COP \\
\hline Electric baseboard heater & 1.0 \\
\hline Cooling tower & 2.0 \\
\hline Window air conditioner unit & 3.4 \\
\hline Heat pump: heating mode & 3.1 \\
\hline Heat pump: cooling mode & 3.8 \\
\hline
\end{tabular}

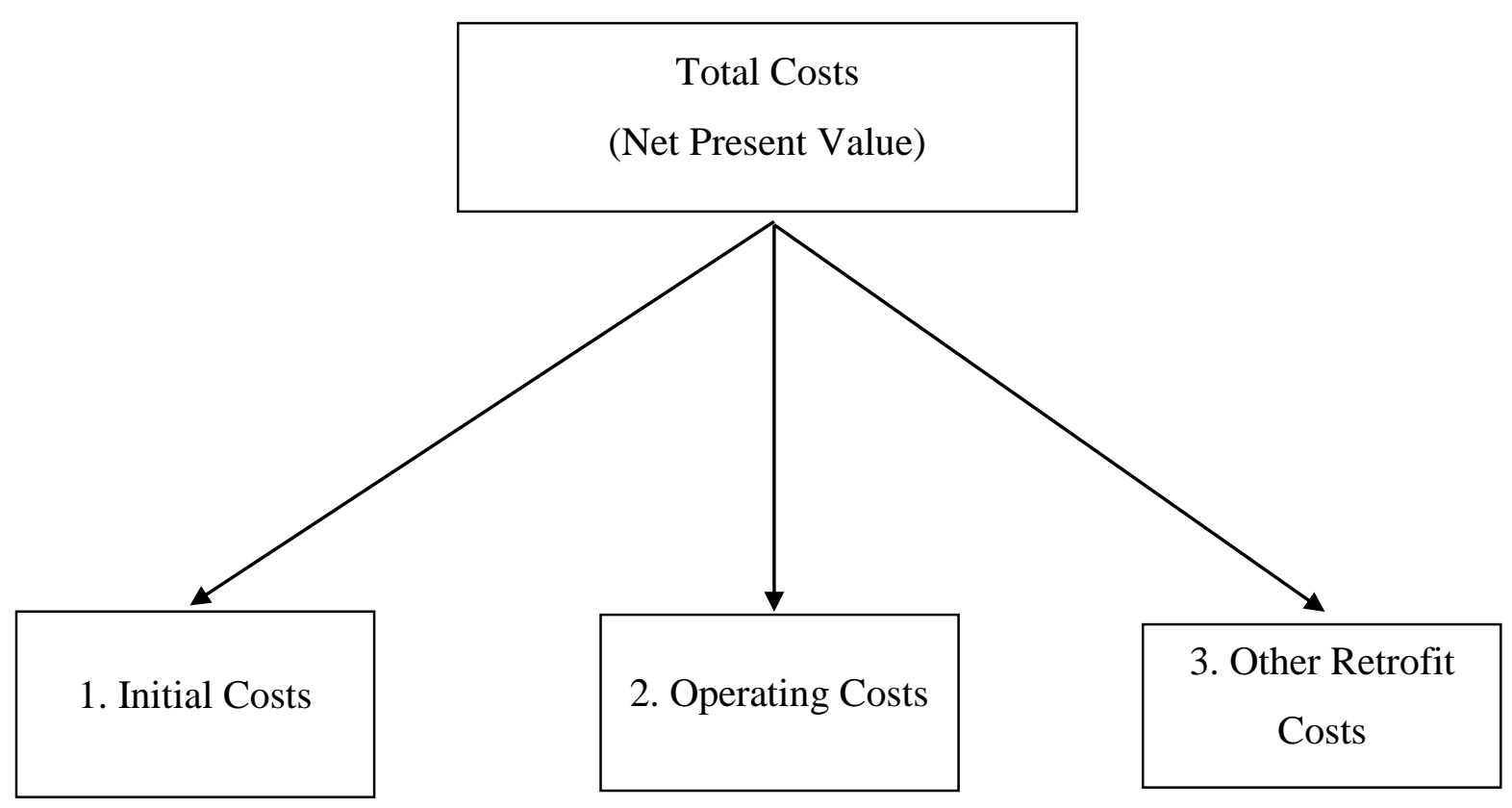

Figure 5.1: Retrofit analysis - calculation of total costs (in net present value)

The initial costs, for each shave factor value ranging from 0 to 1 with a step size of 0.01 , consists of:

- Upfront electric baseboard heater cost (conventional heating), major overhaul cost.

- Upfront window air conditioner or cooling tower cost, replaced every 10 and 20 years, respectively (conventional cooling).

- Upfront GSHP system costs.

For example, a shave factor of 0.2 (for a heating dominant building) indicates that $20 \%$ of the building's peak heating demands are met by the GSHP and the remainder by the conventional system. For a shave factor of 0.2 , if the peak heating demand is $100 \mathrm{~kW}$, then the GSHP and 
baseboard heater (major overhaul costs) will be sized to meet $20 \mathrm{~kW}$ and $80 \mathrm{~kW}$ respectively. This calculation outlined in Alavy et al. [15] was used to determine the initial costs for all shave factor values (from 0 to 1 ).

The initial costs for the hybrid GSHP system can be calculated using the parameters outlined in Table 5.2. A 1.2-kW baseboard heater unit costs $\$ 400$ ( $\$ 200$ per unit and $\$ 200$ for installation cost) [87-88]. The cost of a $12,000 \mathrm{Btu} / \mathrm{h}(3.5 \mathrm{~kW})$ air conditioner unit was assumed to cost $\$ 500$ after taxes [89-91]. Upon consulting with several contractors in the GTA (Greater Toronto Area) (personal communication with [92-94], February 10, 2014), the retrofit costs for ductwork are commonly between $\$ 6,000$ and $\$ 10,000$ for a 3,000 $\mathrm{ft}^{2}$ house (total costs for materials and labour). Furthermore, the costs of adding additional insulation to bring a residential house up to code costs $\$ 1-\$ 3$ per $\mathrm{ft}^{2}$ (total costs of materials and labour for wall or ceiling) ([95] and personal communication with [93-94], February 10, 2014). For the analysis of two residential houses, in the subsequent section, the ductwork retrofit (assuming no major wall or subfloor modifications) and insulation costs per $\mathrm{ft}^{2}$ (R-value up to code for walls and attic floor) was assumed to be $\$ 3.3$ and $\$ 1.5$, respectively.

The operating costs are based on electricity consumption using a fixed rate of $\$ 0.17 / \mathrm{kWh}$. Other retrofit costs (depending on the building being studied) are costs that were not accounted for such as environmental/waste disposal fees, or additional insulation/ductwork costs if the values used in the present study were underestimated. 
Table 5.2: Retrofit design parameters and costs

\begin{tabular}{|l|c|}
\hline \multicolumn{1}{|c|}{ Parameters } & Value \\
\hline Electric Baseboard Heater (RCC12012C $-1200 \mathrm{~W})^{[88]}$ & $\$ 400 / 1.2 \mathrm{~kW}$ \\
\hline Window Air Conditioner Unit ${ }^{[89-91]}$ & $\$ 500 / 3.5 \mathrm{~kW}(\$ 42 \mathrm{per} \mathrm{kBtu} / \mathrm{h})$ \\
\hline Cooling Design Entering Fluid Temperature to HP* & $29.4^{\circ} \mathrm{C}$ \\
\hline Heating Design Entering Fluid Temperature to $\mathrm{HP}^{*}$ & $1.7^{\circ} \mathrm{C}$ \\
\hline Ductwork (retrofit) costs for residential houses & $\$ 3.3 / \mathrm{ft}^{2}$ (floor area) \\
\hline Wall insulation upgrade costs for residential houses & $\$ 1.5 / \mathrm{ft}^{2}($ walls and attic floor) \\
\hline $\begin{array}{l}\text { Vertical borehole ground heat exchanger (installation and } \\
\text { materials)* }\end{array}$ & $\$ 65.6 / \mathrm{m}$ \\
\hline $\begin{array}{l}\text { Cooling tower, plate heat exchanger including controls and } \\
\text { auxiliary equipment }(\mathrm{COP}=2)^{*}\end{array}$ & $\$ 14 / \mathrm{kW}$ of tower design \\
\hline Soil Thermal Diffusivity* & $0.072 \mathrm{~m} / \mathrm{day}$ \\
\hline Soil Thermal Conductivity & $2.94 \mathrm{~W} / \mathrm{m} \cdot \mathrm{K}$ \\
\hline Duration of Operation* & $20 \mathrm{years}$ \\
\hline Borehole Thermal Resistance* & $0.136 \mathrm{~m} \cdot \mathrm{K} / \mathrm{W}$ \\
\hline Pipe Resistance* & $0.06 \mathrm{~m} \cdot \mathrm{K} / \mathrm{W}$ \\
\hline Pipe Size* & $32 \mathrm{~mm}$ \\
\hline Borehole Diameter* & $127 \mathrm{~mm}$ \\
\hline Grout Thermal Conductivity* & $1.47 \mathrm{~W} / \mathrm{m} \cdot \mathrm{K}$ \\
\hline Electricity rate & $\$ 0.17 / \mathrm{kWh}$ \\
\hline Inflation Rate* & $4 \%$ \\
\hline Interest Rate* & $8 \%$ \\
\hline
\end{tabular}




\subsection{Retrofitting Residential Houses}

Two detached residential houses, a 2,000 $\mathrm{ft}^{2}$ bungalow (House A) and a 5,000 $\mathrm{ft}^{2}$ 2-storey residential house (House B), were modelled in eQuest using Toronto's weather patterns [55]. The two houses were modelled in accordance with 1986 OBC (Ontario Building Code) minimum insulation requirements for the building exterior [96]. Insulation for the ceiling below roof space was R30 (R50 for 2012 new building code) and exterior wall was R13 (R29 for 2012 new building code). The buildings were heated by electric baseboard heaters and the thermostat set points were set to $71^{\circ} \mathrm{F}$ and $75^{\circ} \mathrm{F}\left(\sim 22^{\circ} \mathrm{C}\right.$ and $\left.24^{\circ} \mathrm{C}\right)$ for the heating and cooling modes respectively. Table 5.3 outlines House A's and B's annual heating and cooling loads and operating costs (based on $\$ 0.17 / \mathrm{kWh}$ ). As presented in Table 5.3, simply upgrading the building's insulation showed a substantial reduction in energy consumption. For House A, the heating and cooling loads reduced by $24.3 \%$ and $1.6 \%$ respectively. A $\$ 5,400$ investment to upgrade House A's insulation results in an annual savings of $\$ 566$, a payback period of 9.5 years. For House B, upon upgrading the insulation $(\$ 10,500)$ the heating and cooling loads reduced by $33.8 \%$ and $1.2 \%$ respectively ( $\$ 1,168$ annual savings). Further savings can be achieved if better HVAC systems were implemented for these vintage 1986 buildings.

Table 5.3: Houses A and B annual energy consumption and conventional operating costs

\begin{tabular}{|c|c|c|c|c|c|}
\hline & $\begin{array}{c}\text { Annual } \\
\text { Cooling } \\
\text { Load } \\
(\mathbf{k W h})\end{array}$ & $\begin{array}{c}\text { Annual } \\
\text { Baseboard } \\
\text { Heating } \\
\text { Load } \\
\text { (kWh) }\end{array}$ & $\begin{array}{c}\text { Annual Cooling } \\
\text { Costs } \\
\text { (Window Unit) } \\
(\$)\end{array}$ & $\begin{array}{c}\text { Annual } \\
\text { Baseboard } \\
\text { Heating Costs } \\
(\$)\end{array}$ & $\begin{array}{c}\text { Insulation Cost } \\
\left(\$ 1.5 / \mathbf{f t}^{2}\right)\end{array}$ \\
\hline $\begin{array}{c}\text { House A } \\
1986 \text { OBC }\end{array}$ & 2,135 & 13,600 & 363 & 2,312 & - \\
\hline $\begin{array}{c}\text { House A } \\
\text { New } \\
\text { Insulation }\end{array}$ & 2,100 & 10,300 & 357 & 1,751 & 5,400 \\
\hline $\begin{array}{c}\text { House B } \\
1986 \text { OBC }\end{array}$ & 5,775 & 20,100 & 982 & 3,417 & - \\
\hline $\begin{array}{c}\text { House B } \\
\text { New } \\
\text { Insulation }\end{array}$ & 5,700 & 13,300 & 970 & 2,261 & $\$ 10,500$ \\
\hline
\end{tabular}


A total of three tests were performed for retrofitting House A and B. In the first test, only the initial cost of the GSHP system was considered for each corresponding shave factor value from 0 to 1. The insulation upgrade (no insulation costs), ductwork costs, and major overhaul costs for the conventional system were all not considered for the analysis (Test \#1). The objective of the first test, which is a highly idealized scenario, was to provide an overview on the feasibility of a hybrid GSHP system and potential savings before applying other retrofit costs. In the second test the retrofit costs considered in the analysis include ductwork costs and major overhaul costs for the window air conditioner units $(\$ 42$ per $\mathrm{kBtu} / \mathrm{h})$ and electric baseboard heaters $(\sim \$ 333 / \mathrm{kW})$. In the third test, the insulation upgrade costs were considered.

\subsubsection{Test \#1: only GSHP initial cost considered}

Applying the aforementioned retrofit approach, the optimal shave factor for installation of a hybrid GSHP system for House A and B are 0.6 and 0.37 respectively. The total costs in net present value for House A are presented in Figure 5.2, in which the total costs for each corresponding shave factor value from 0 to 1 are presented by the blue curve. Based on an optimal shave factor value of 0.6 for House A (Table 5.4), the GSHP is still capable of providing $96 \%$ of the house's energy demands based on a ground loop length of $93 \mathrm{~m}$. The total costs for house A after 20 years of operation is $\$ 21,370$. This optimal hybrid design results in a total savings of $\$ 13,925$ when compared with the base case in which all building energy demands are met by electric baseboard heaters and window air conditioners (shave factor value of 0 ). The initial costs of the GSHP, based on the assumed average cost of $\$ 65.6 / \mathrm{m}$ of vertical borehole length (which is more applicable for large buildings), is too low for residential houses due to the rental and/or transportation costs of drilling equipment. However, the study will continue to use the average cost of $\$ 65.6 / \mathrm{m}$ as a framework for the present work. 


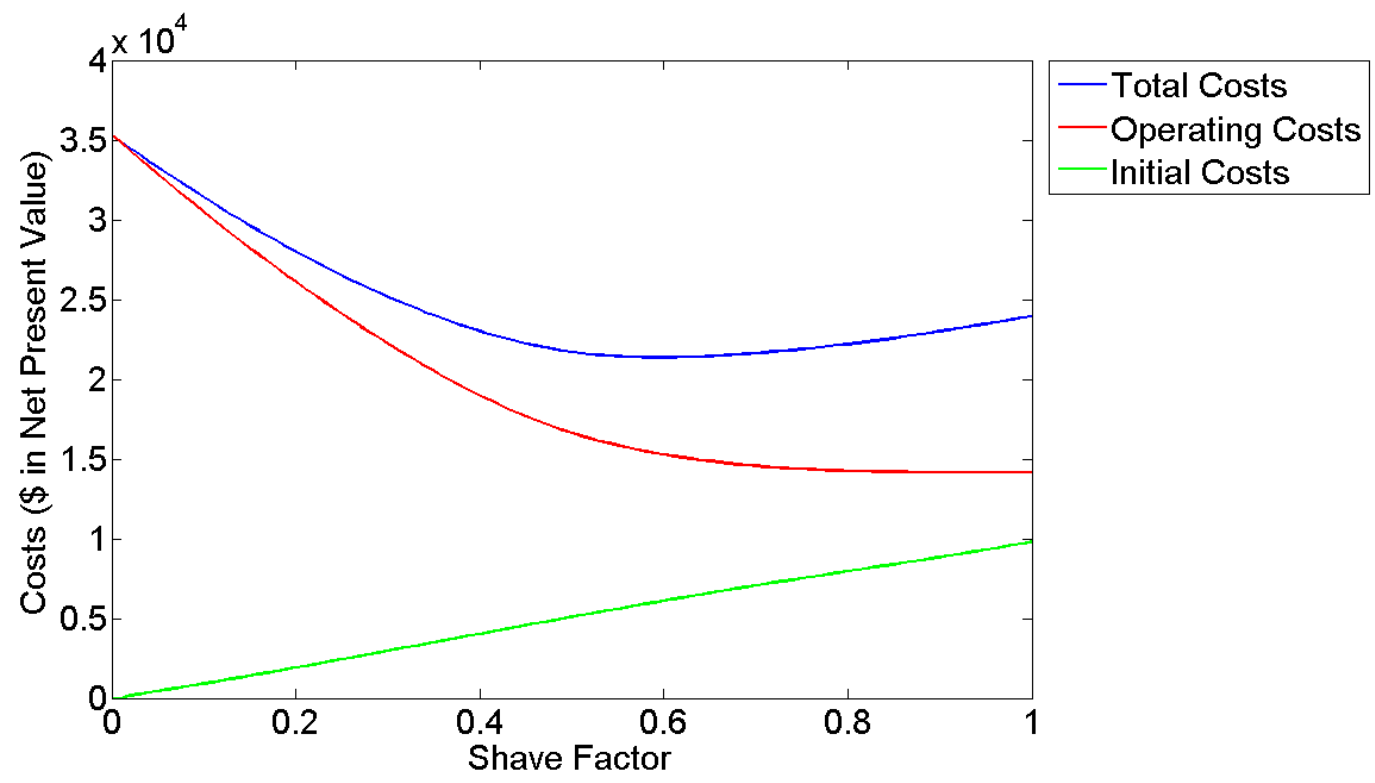

Figure 5.2: Shave factor vs. total costs (Test \#1) - Retrofit analysis for House A. This analysis only considers the cost of the GSHP system.

Table 5.4: House A results (Test \#1)

\begin{tabular}{|c|c|c|c|c|c|}
\hline $\begin{array}{c}\text { Shave } \\
\text { Factor }\end{array}$ & $\begin{array}{c}\text { Ground } \\
\text { Loop } \\
\text { Length } \\
(\mathrm{m})\end{array}$ & $\begin{array}{c}\text { Average } \\
\text { TEDM } \\
(\%)\end{array}$ & $\begin{array}{c}\text { Total Costs } \\
\text { (Net Present Value) } \\
(\$)\end{array}$ & $\begin{array}{c}\text { Initial } \\
\text { Costs } \\
(\$)\end{array}$ & $\begin{array}{c}\text { Payback period } \\
\text { (years) }\end{array}$ \\
\hline $0^{*}$ & 0 & 0 & 35,295 & 0 & - \\
\hline $\mathbf{0 . 6}^{* *}$ & $\mathbf{9 3}$ & $\mathbf{9 6 . 3}$ & $\mathbf{2 1 , 3 7 0}$ & $\mathbf{6 , 0 9 9}$ & $\mathbf{6 . 1}$ \\
\hline 0.7 & 108 & 98.7 & 21,623 & 7,063 & 6.8 \\
\hline 1 & 149 & 100 & 23,942 & 9,788 & 9.3 \\
\hline
\end{tabular}

*Base case (no retrofit) **Optimal shave factor Total energy demands met by GSHP (TEDM)

Figure 5.3 presents the payback periods for the hybrid GSHP for any additional retrofit costs not considered during the analysis. These additional retrofit costs for this scenario are costs for the GSHP system that are not accounted for or were underestimated (i.e., maintenance/repair costs, waste disposal). The linear curves range from $\$ 0$ to the maximum savings of $\$ 13,925, \$ 13,672$, and $\$ 11,353$ (compared to base case) for the optimal shave factor, a shave factor of 0.7 , and 1 , respectively. The payback periods reach 20 years for the three shave factors plotted in Figure 5.3 when the total savings compared to the base case approaches $\$ 0$. The curves for all "other retrofit 
costs" figures are plotted based on 1\% increments of the total savings (compared to the base case). For example, the total savings for the optimal design compared to the base case was $\$ 13,925$, and based on $1 \%$ increments, the "other retrofit costs" are incremented based on a step-size of \$139.25. Similarly, the "other retrofit costs" for the shave factor of 0.7 and 1.0 curves are incremented by $\$ 136.72$ and $\$ 113.53$, respectively. If other retrofit costs (in addition to the GSHP initial costs) are less than the total savings, the retrofit costs are considered to be economically justifiable. Otherwise, the retrofit costs exceed the total savings and will require more than 20 years to payback (longer than the assumed duration of operation).

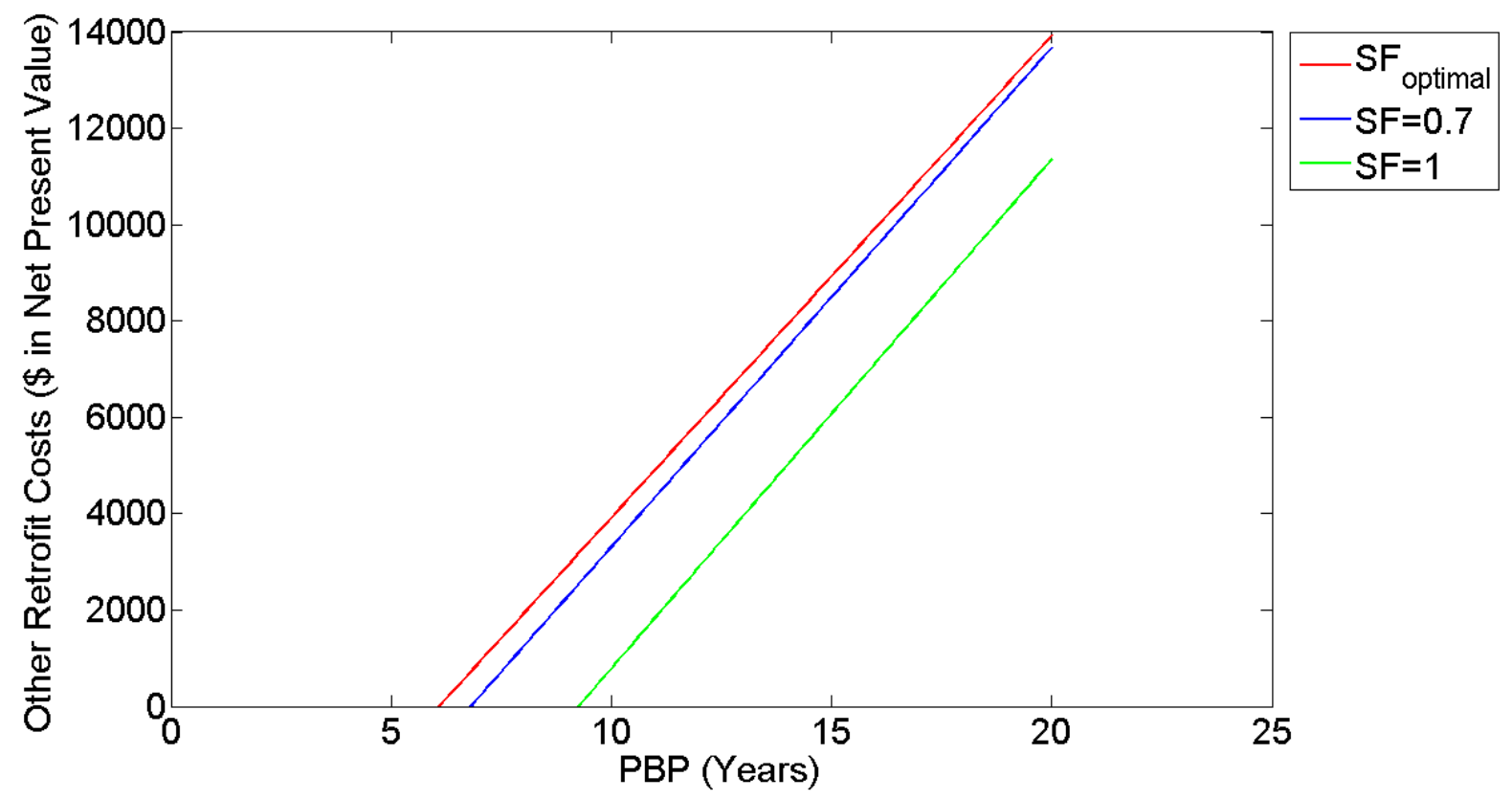

Figure 5.3: PBP vs. other retrofit costs (Test \#1) - Retrofit analysis for House A. The ordinate corresponds to "other retrofit costs". For the case of $\$ 0$ for "other retrofit costs", the payback period corresponds to only the cost of the GSHP system.

Similar results can be observed for House B as shown in Table 5.5 and Figure 5.4. The optimal shave factor is 0.37 , meeting $83.8 \%$ of the building's total energy demands and a savings of $\$ 20,821$ compared of shave factor of 0 . Total savings of $\$ 15,932$ and $\$ 10,328$ can be found for the shave factors of 0.7 and 1.0 , respectively. 
Table 5.5: House B results (Test \#1)

\begin{tabular}{|c|c|c|c|c|c|}
\hline $\begin{array}{c}\text { Shave } \\
\text { Factor }\end{array}$ & $\begin{array}{c}\text { Ground } \\
\text { Loop } \\
\text { Length } \\
(\mathrm{m})\end{array}$ & $\begin{array}{c}\text { Average } \\
\text { TEDM } \\
(\%)\end{array}$ & $\begin{array}{c}\text { Total Costs } \\
\text { (Net Present Value) } \\
(\$)\end{array}$ & $\begin{array}{c}\text { Initial } \\
\text { Costs } \\
(\$)\end{array}$ & $\begin{array}{c}\text { Payback period } \\
\text { (years) }\end{array}$ \\
\hline $0^{*}$ & 0 & 0 & 58,197 & 0 & - \\
\hline $\mathbf{0 . 3 7}^{* *}$ & $\mathbf{1 3 8}$ & $\mathbf{8 3 . 8}$ & $\mathbf{3 7 , 3 7 6}$ & $\mathbf{9 , 0 6 3}$ & $\mathbf{6 . 1}$ \\
\hline 0.7 & 243 & 99.1 & 42,265 & 15,967 & 10 \\
\hline 1 & 329 & 100 & 47,869 & 21,594 & 13.5 \\
\hline
\end{tabular}

*Base case (no retrofit) **Optimal shave factor

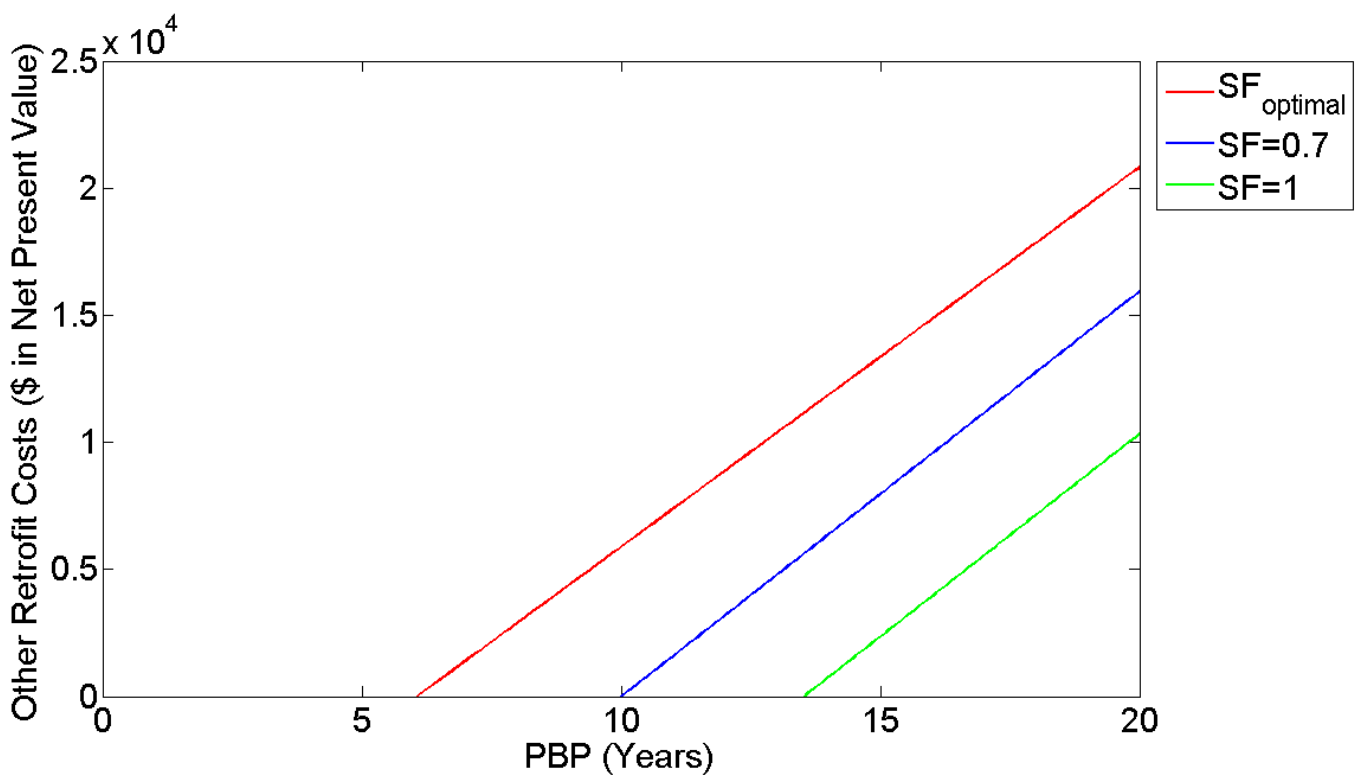

Figure 5.4: PBP vs. other retrofit costs (Test \#1) - Retrofit analysis for House B. The ordinate corresponds to "other retrofit costs". For the case of $\$ 0$ for "other retrofit costs", the payback period corresponds to only the cost of the GSHP system.

For Test \#1, comparing between Houses A and B, it can be seen that the potential savings ( $\$ 20,821$ vs. $\$ 13,925)$ for House $B$ is higher than for House $A$ at their respective optimal shave factors. In addition, the payback periods are the same (6.1 years), despite higher hybrid GSHP initial costs for House B. This data indicates that a hybrid GSHP system is more economically viable for retrofitting bigger houses with higher electric baseboard heaters and window air conditioners (House B vs. House A). 


\subsubsection{Test \#2: ductwork and major overhaul costs}

In this analysis a framework is provided for determining acceptable ductwork and retrofit costs. The ductwork costs and major overhaul costs for the window air conditioner units ( $\$ 42$ per $\mathrm{kBtu} / \mathrm{h})$ and electric baseboard heaters $(\sim 333 / \mathrm{kW})$ are considered. The major overhaul costs of window air conditioners and baseboard heaters are only for their capacities in excess of the GSHP's capacity to cover the peak cooling and heating loads. The ductwork costs for Houses A and B are $\$ 6,600$ and \$16,500 respectively. Using 1986 building insulation standards, the optimal shave factor for House A is 0.7 (TEDM of $98 \%$ and payback period of 13.9 years) in which a total savings of $\$ 17,000$ can be achieved compared to the base case. Similar to Test \#1, Figure 5.5 illustrates the effects that additional retrofit costs have on the payback period of the hybrid GSHP system. Additional cost of $\$ 6,280$ and $\$ 4,800$ can be added to shave factors of 0.7 (optimal) and 1.0, respectively, before payback periods exceed 20 years.

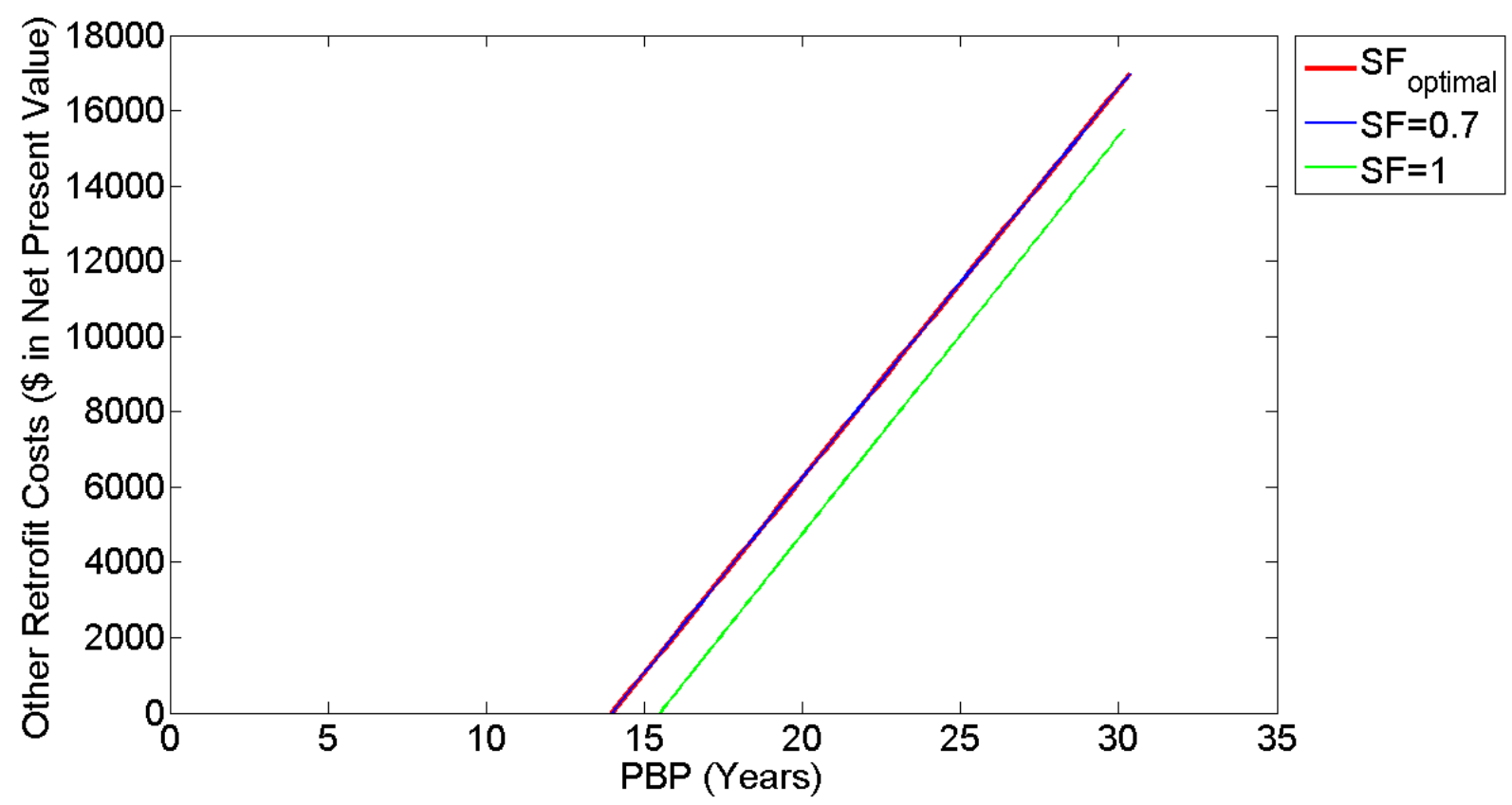

Figure 5.5: PBP vs. other retrofit costs (Test \#2) - Retrofit analysis for House A. The ordinate corresponds to "other retrofit costs". For the case of $\$ 0$ for "other retrofit costs", the payback period corresponds to the costs of the GSHP system, overhaul costs, and ductwork costs. 
For House B, the addition of the ductwork costs of $\$ 16,500$ and major overhaul costs of the conventional system make hybrid GSHPs an uneconomical solution even for the optimal shave factor of 0.45 and TEDM of $90 \%$, because the payback periods exceed twenty years as presented in Figure 5.6. However, if the ductwork costs were \$10,000, then the optimal shave factor of 0.45 for House B produces a payback period of 15.9 years (less than twenty years of operation) as presented in Figure 5.7.

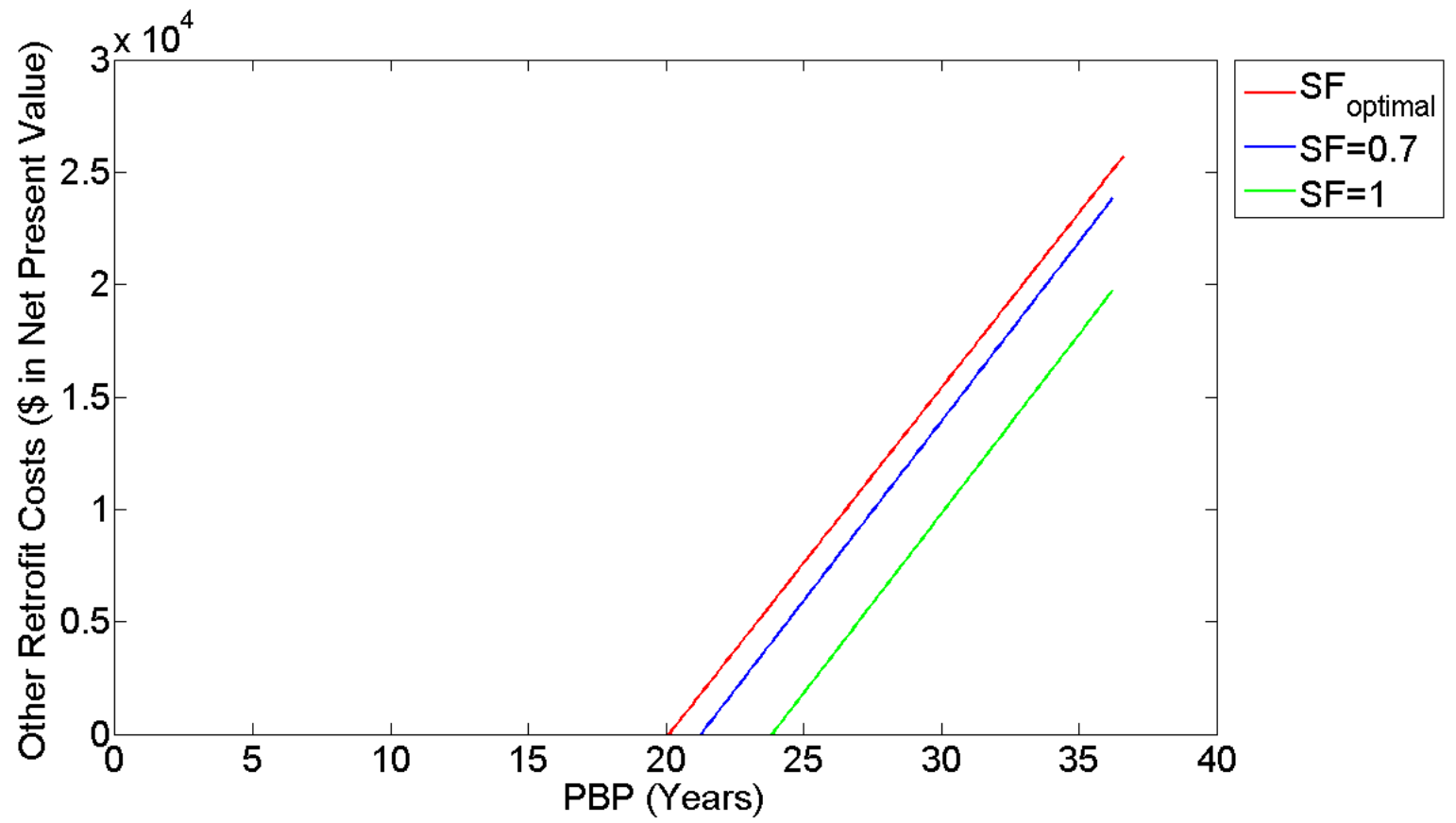

Figure 5.6: PBP vs. other retrofit costs (Test \#2) - Retrofit analysis for House B. The ordinate corresponds to "other retrofit costs". For the case of $\$ 0$ for "other retrofit costs", the payback period corresponds to the costs of the GSHP system, overhaul costs, and ductwork costs $(\$ 16,500)$. 


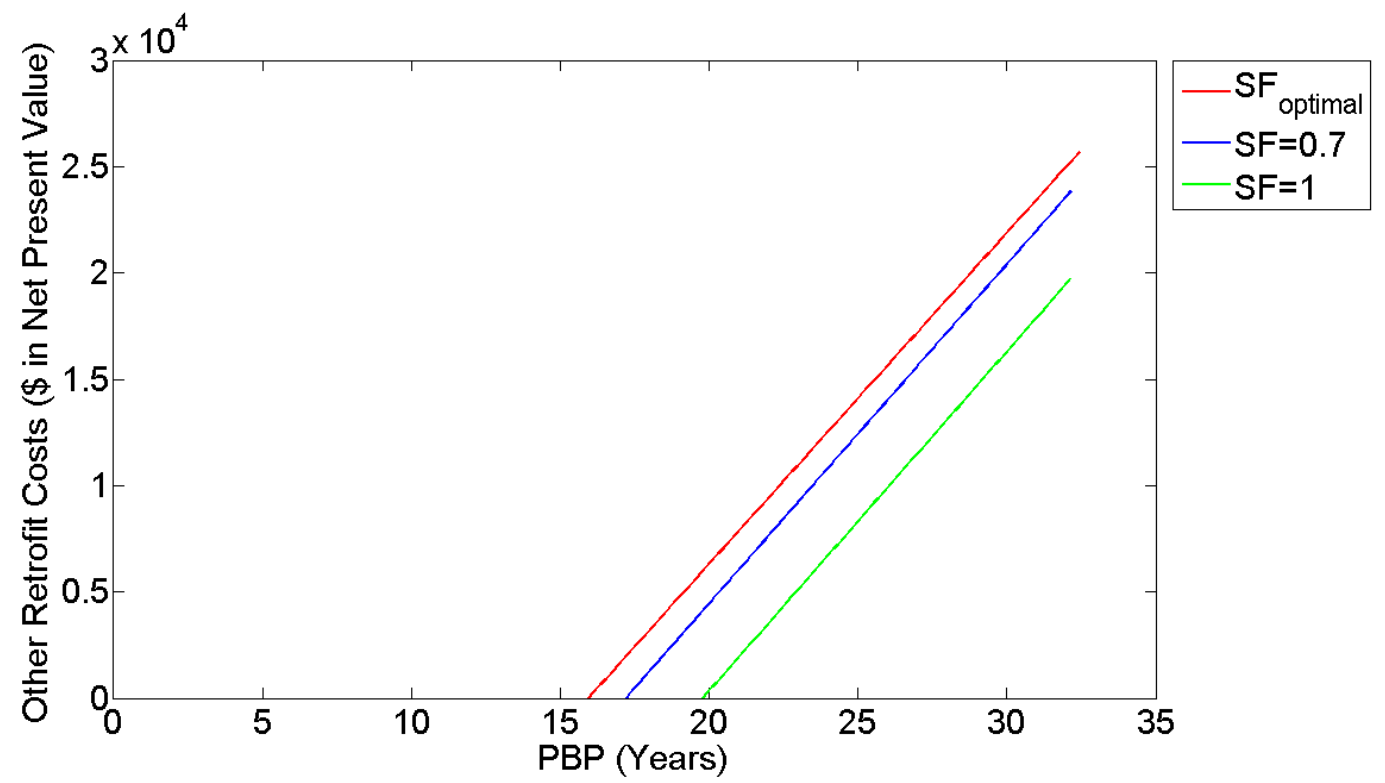

Figure 5.7: PBP vs. other retrofit costs (Test \#2) - Retrofit analysis for House B. The ordinate corresponds to "other retrofit costs". For the case of $\$ 0$ for "other retrofit costs", the payback period corresponds to the costs of the GSHP system, overhaul costs, and ductwork costs $(\$ 10,000)$.

For Test \#2, because of higher retrofit costs for ductwork $(\$ 16,500$ vs. \$6,600) and for the major conventional system overhaul $(\$ 4,100$ vs. $\$ 1,100)$ compared to House A, there is no savings within the twenty years of operation for House B even for the optimal shave factor of 0.45 and TEDM of 90\%. Comparing Tests \#1 and \#2, it can be seen that the additional retrofit costs of ductwork and overhauling can change the optimal shave factor ( 0.37 vs. 0.45$)$ for House $B$, as well as resulting in longer payback periods (6.1 years vs. 20.1 years). However, the additional retrofit costs have also changed the optimal shave factor (0.6 vs. 0.7) for House A, as well as resulting longer payback period (6.1 years vs. 13.9 years); but the hybrid GSHP system for House A is still economically viable due to lower retrofit costs.

\subsubsection{Test \#3: insulation costs}

In addition to the costs considered in Test \#2, the insulation of the two houses are upgraded, from R13 to R29 and R30 to R50 for the exterior walls and ceiling respectively. The insulation upgrade costs are incorporated into the analysis. Using $\$ 1.5$ per $\mathrm{ft}^{2}$ of insulation, the insulation costs for Houses A and B are \$5,400 and \$10,600 as previously mentioned in Table 5.3. As expected, from 
Test \#1 and Test \#2, although upgrading the insulation reduces the total building's energy demands, the high upfront costs of retrofitting a hybrid GSHP system makes it an uneconomical solution compared to a conventional system for Houses A and B. The payback period exceeds 20 years when the cost of insulation costs, ductwork costs, and major overhaul costs are considered. Although the optimal hybrid GSHP designs for Houses A and B produce respectively a total savings of about $\$ 13,000$ and $\$ 17,000$, the payback period (optimal design) for Houses A and B are 23 and 37.3 years (Table 5.6), respectively. Again, the additional retrofit costs of insulation can effect a different optimal shave factor for the hybrid GSHP design. For House A, the optimal shave factors are $0.6,0.7$ and 0.64 for Tests \#1, \#2 and \#3, respectively. Whereas, for House B, the optimal shave factors are $0.37,0.45$ and 0.28 for Tests \#1,\#2 and \#3, respectively. Furthermore, it is clear that, as the retrofit costs increase from Test \#1 to Test \#3, the optimal shave factor may not monotonically increase or decrease. Therefore, it is beneficial to perform this kind of optimization study for each considered case.

Table 5.6: Houses A and B results (Test \#3)

\begin{tabular}{|c|c|c|c|c|c|c|}
\hline Building & $\begin{array}{l}\text { Shave } \\
\text { Factor }\end{array}$ & $\begin{array}{l}\text { Ground } \\
\text { Loop } \\
\text { Length } \\
\text { (m) }\end{array}$ & $\begin{array}{c}\text { Average } \\
\text { TEDM } \\
(\%)\end{array}$ & $\begin{array}{c}\text { Total Costs } \\
\text { (Net Present Value) } \\
(\$)\end{array}$ & $\begin{array}{l}\text { Initial } \\
\text { Costs } \\
(\$)\end{array}$ & $\begin{array}{c}\text { Payback period } \\
\text { (years) }\end{array}$ \\
\hline \multirow{4}{*}{ House A } & $0 *$ & 0 & 0 & 43,594 & 15,654 & - \\
\hline & $0.64 * *$ & 85 & 97.7 & $\mathbf{3 0 , 3 7 7}$ & 18,360 & 23 \\
\hline & 0.7 & 117 & 98.9 & 30,422 & 18,559 & 23.1 \\
\hline & 1 & 79 & 100 & 31,379 & 19,646 & 24.3 \\
\hline \multirow{4}{*}{ House B } & $0 *$ & 0 & 0 & 77,707 & 34,984 & - \\
\hline & $0.28 * *$ & 110 & 75.7 & 60,516 & 38,406 & 37.3 \\
\hline & 0.7 & 242 & 99 & 65,286 & 44,070 & 41 \\
\hline & 1 & 323 & 100 & 69,158 & 47,964 & 44.6 \\
\hline
\end{tabular}




\subsection{Retrofit Analysis for Other Buildings}

In this section, a retrofit analysis was performed by using the building loads of a school, two highrise multi-residential buildings (HR A and HR B), a mid-rise multi-residential building, and an office in order to determine whether a hybrid GSHP system retrofit would be economical. The loads of the five buildings were obtained using Toronto's weather patterns, and are courtesy of CleanEnergy Developments Corporation.

Two tests were carried out for the three buildings (School, HR A and the Office). In the first test, the major overhaul costs for the electric baseboard heaters and window air conditioners were considered. Since no rough rules-of-thumb exists for approximating ductwork costs for these four buildings (personal communication with [92-94], February 10, 2014), the ductwork costs were incorporated as part of "other retrofit costs". In the second test the analysis remains the same as that of the first test, however, cooling towers ( $\$ 40$ per $\mathrm{kBtu} / \mathrm{h}$, overall $\mathrm{COP}=2)$ were used instead of window air conditioner units for the retrofit analysis.

\subsubsection{Test \#1: baseboard heaters and window air conditioners}

As mentioned, a COP value of 1.0 and 3.4 were used to determine the operating costs of the electric baseboard heaters and window air conditioner units respectively. The optimal designs for the buildings were determined and the results are presented in Table 5.7.

There are several factors contributing to the result of no optimal hybrid GSHP design (uneconomical) for the high-rise B and mid-rise buildings. In this analysis, the window air conditioner units were assumed to have COP values similar to that of a GSHP's while in the cooling mode (3.4 compared to 3.8). The high-rise B building requires a cooling-heating load ratio of $4: 1$. As a result, the high upfront costs for the GSHP system, and window air conditioner units (replaced every 10 years), for each corresponding shave factor value makes these buildings less economical to operate with a GSHP than by a pure conventional system. However, for example, if the COP of the window air conditioner units were 2.0 (not a reasonable assumption) instead of 3.4 , the high-rise B building would have an optimal design $(S F=0.34)$. A shave factor value of 
0.34 would provide $74 \%$ of the high-rise's total energy demands, resulting in a payback period of 12 years, and a total savings of $\$ 553,000$.

Table 5.7: Large buildings retrofit results (Test \#1)

\begin{tabular}{|c|c|c|c|c|c|c|}
\hline Building & $\begin{array}{l}\text { Heating } \\
\text { Dominant/ } \\
\text { Cooling } \\
\text { Dominant } \\
\text { (HD/CD) }\end{array}$ & $\begin{array}{l}\text { Shave } \\
\text { Factor }\end{array}$ & $\begin{array}{l}\text { Average } \\
\text { TEDM } \\
(\%)\end{array}$ & $\begin{array}{c}\text { Total Costs } \\
\text { (Net Present Value) } \\
(\$)\end{array}$ & $\begin{array}{l}\text { Initial } \\
\text { Costs } \\
(\$)\end{array}$ & $\begin{array}{c}\text { Payback } \\
\text { period } \\
\text { (years) }\end{array}$ \\
\hline \multirow{4}{*}{ School } & \multirow{4}{*}{ CD } & 0 & 0 & 677,928 & 92,094 & - \\
\hline & & $0.41 *$ & 91 & 420,001 & 142,061 & 9 \\
\hline & & 0.7 & 99 & 441,863 & 171,237 & 11 \\
\hline & & 1 & 100 & 482,334 & 211,950 & 13 \\
\hline \multirow{4}{*}{$\begin{array}{l}\text { High- } \\
\text { Rise A }\end{array}$} & \multirow{4}{*}{$\mathrm{CD}$} & 0 & 0 & 776,385 & 131,868 & - \\
\hline & & 0.1* & 43 & 541,595 & 127,868 & 11.1 \\
\hline & & 0.7 & 99 & 724,682 & 334,073 & 26.3 \\
\hline & & 1 & 100 & 790,871 & 400,642 & 31.5 \\
\hline \multirow{4}{*}{ Office } & \multirow{4}{*}{ HD } & 0 & 0 & $6,208,644$ & 626,649 & - \\
\hline & & $0.47 *$ & 95.4 & $3,794,023$ & $\mathbf{1 , 7 0 0 , 0 1 7}$ & 9.7 \\
\hline & & 0.7 & 99.8 & $4,042,560$ & $2,127,770$ & 11.6 \\
\hline & & 1 & 100 & $4,545,759$ & $2,638,445$ & 14.4 \\
\hline
\end{tabular}

*Optimal hybrid GSHP design

The optimal shave factor for the school is 0.41 , meeting $91 \%$ of the building's total energy demands. By sizing the hybrid GSHP system according to the optimal shave factor, the payback period is 9 years and a total savings of $\$ 257,900$ can be achieved. However, this analysis does not consider the ductwork costs. As presented in Figure 5.8, as the ductwork costs increases, so too does the payback period. The payback period would be twenty years if additional retrofit costs for the ductwork were $\$ 167,600$ (for the optimal design). 


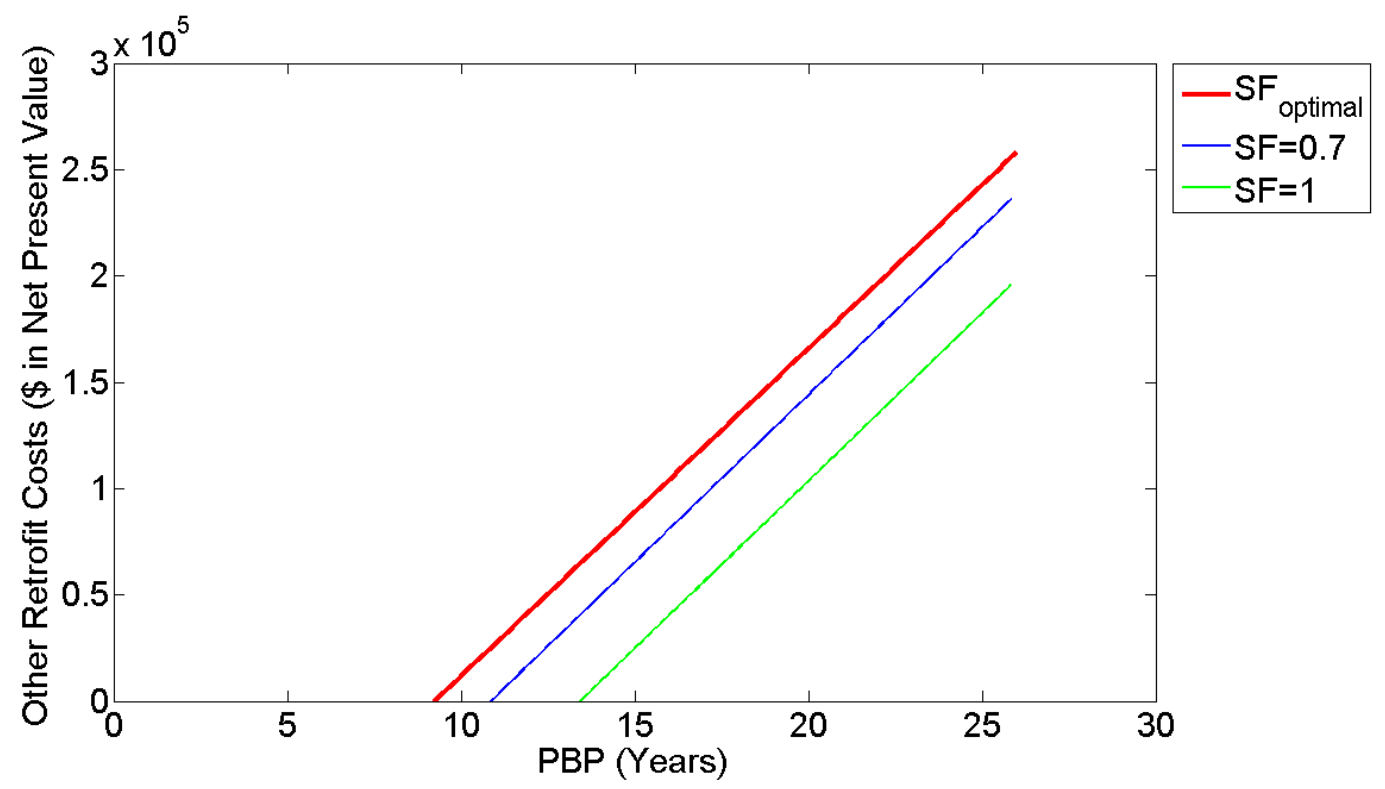

Figure 5.8: PBP vs. other retrofit costs (Test \#1) - Retrofit analysis for a school located in Toronto, Ontario. The ordinate corresponds to "other retrofit costs". For the case of $\$ 0$ for "other retrofit costs (ductwork costs)", the payback period corresponds to the costs of the GSHP system and overhaul costs (baseboard heaters and window air conditioner units).

The optimal shave factor for the high-rise A building is 0.1 , meeting $43 \%$ of the building's total energy demands. By sizing the hybrid GSHP system according to the optimal shave factor the payback period is 11.1 years and a total savings of $\$ 234,800$ can be achieved. However, when additional ductwork costs are considered, as presented in Figure 5.9, the payback period increases. The payback period would be twenty years if additional retrofit costs for the ductwork were $\$ 103,300$ (for the optimal design). 


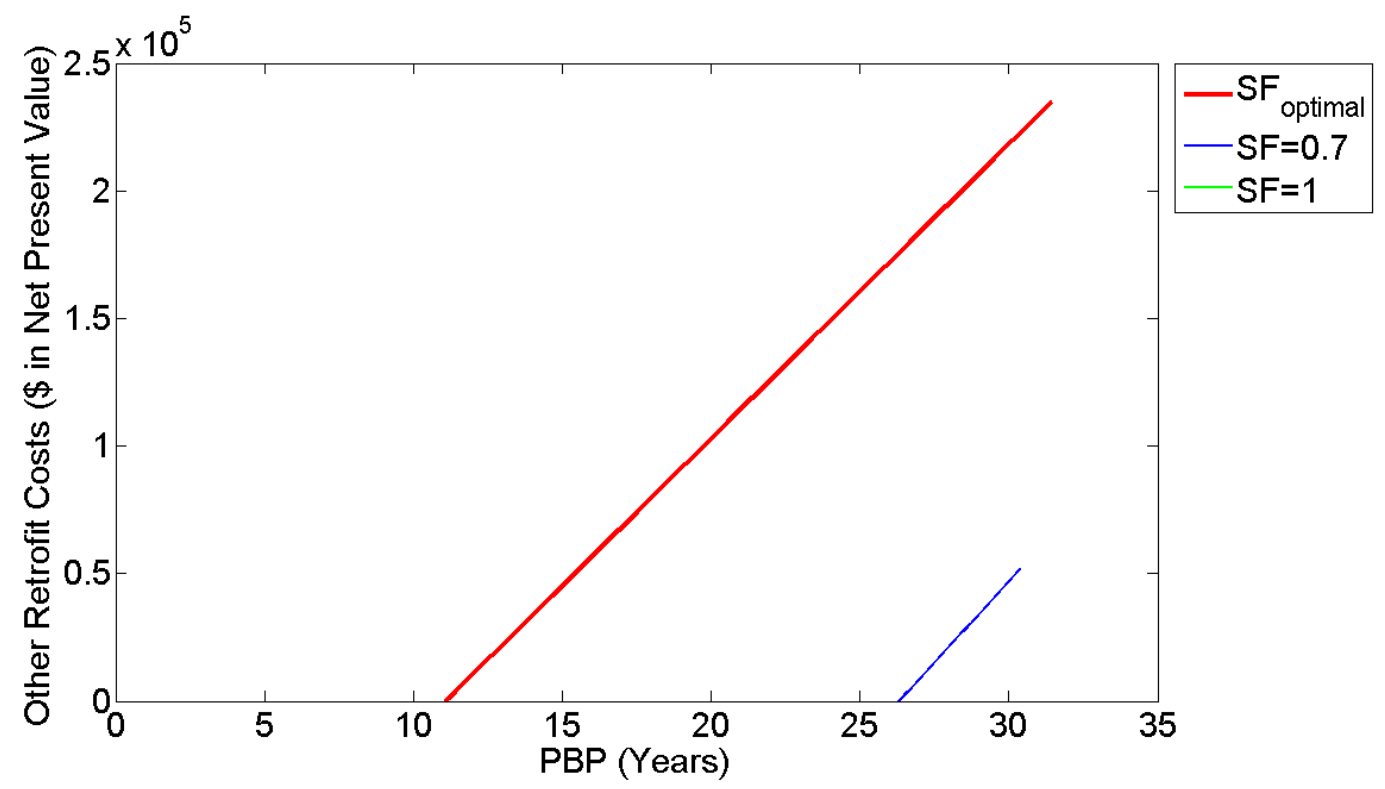

Figure 5.9: PBP vs. other retrofit costs (Test \#1) - Retrofit analysis for High-rise A located in Toronto, Ontario. The ordinate corresponds to "other retrofit costs". For the case of $\$ 0$ for "other retrofit costs (ductwork costs)", the payback period corresponds to the costs of the GSHP system and overhaul costs (baseboard heaters and window air conditioner units).

The optimal shave factor for the office building is 0.47 , meeting $95 \%$ of the building's total energy demands. By sizing the hybrid GSHP system according to the optimal shave factor the payback period is 9.7 years and a total savings of $\$ 2,415,000$ can be achieved. However, when additional ductwork costs is considered, as presented in Figure 5.10, as the ductwork costs increase, so too does the payback period. The payback period would be twenty years if additional retrofit costs were $\$ 1,787,000$ (for the optimal design). The large savings are due to the building being extremely heating dominant (more economical to provide heating by a GSHP) from an all-glass (wall) building envelope. 


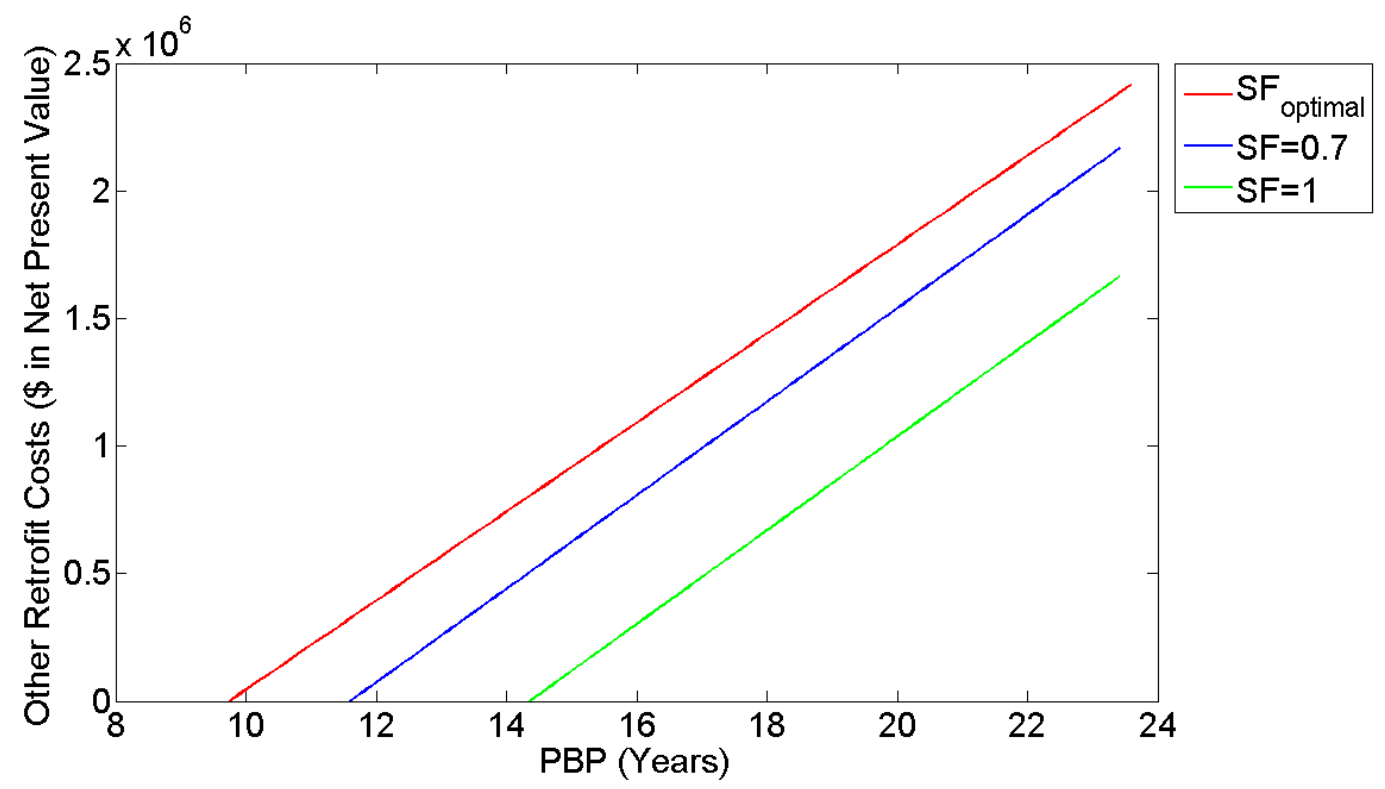

Figure 5.10: PBP vs. other retrofit costs (Test \#1) - Retrofit analysis for an office located in Toronto, Ontario. The ordinate corresponds to "other retrofit costs". For the case of $\$ 0$ for "other retrofit costs (ductwork costs)", the payback period corresponds to the costs of the GSHP system and overhaul costs (baseboard heaters and window air conditioner units).

\subsubsection{Test \#2: baseboard heaters and cooling towers}

The analysis remains the same as that of the first test, however, cooling towers $(\$ 40$ per $\mathrm{kBtu} / \mathrm{h}$, overall COP $=2.0$ ) were used instead of window air conditioner units for the retrofit analysis. This analysis would be more appropriate for commercial buildings where window air conditioner units are rare. The optimal designs for the buildings were determined and the results are presented in Table 5.8.

The optimal shave factor for the high-rise A building is 0.21 , meeting $64.3 \%$ of the building's total energy demands. The payback period is 8.1 years and a total savings of $\$ 302,900$ can be achieved. However, when additional ductwork costs are considered, as presented in Figure 5.11, the optimal shave factor curve exceeds a payback period of twenty years when other retrofit costs (such as ductwork costs) are greater than $\$ 213,000$. For the shave factors 0.7 and 1.0 (blue and green curves), payback period exceeds twenty years when other retrofit costs are greater than $\$ 150,000$ and $\$ 75,000$ respectively. 


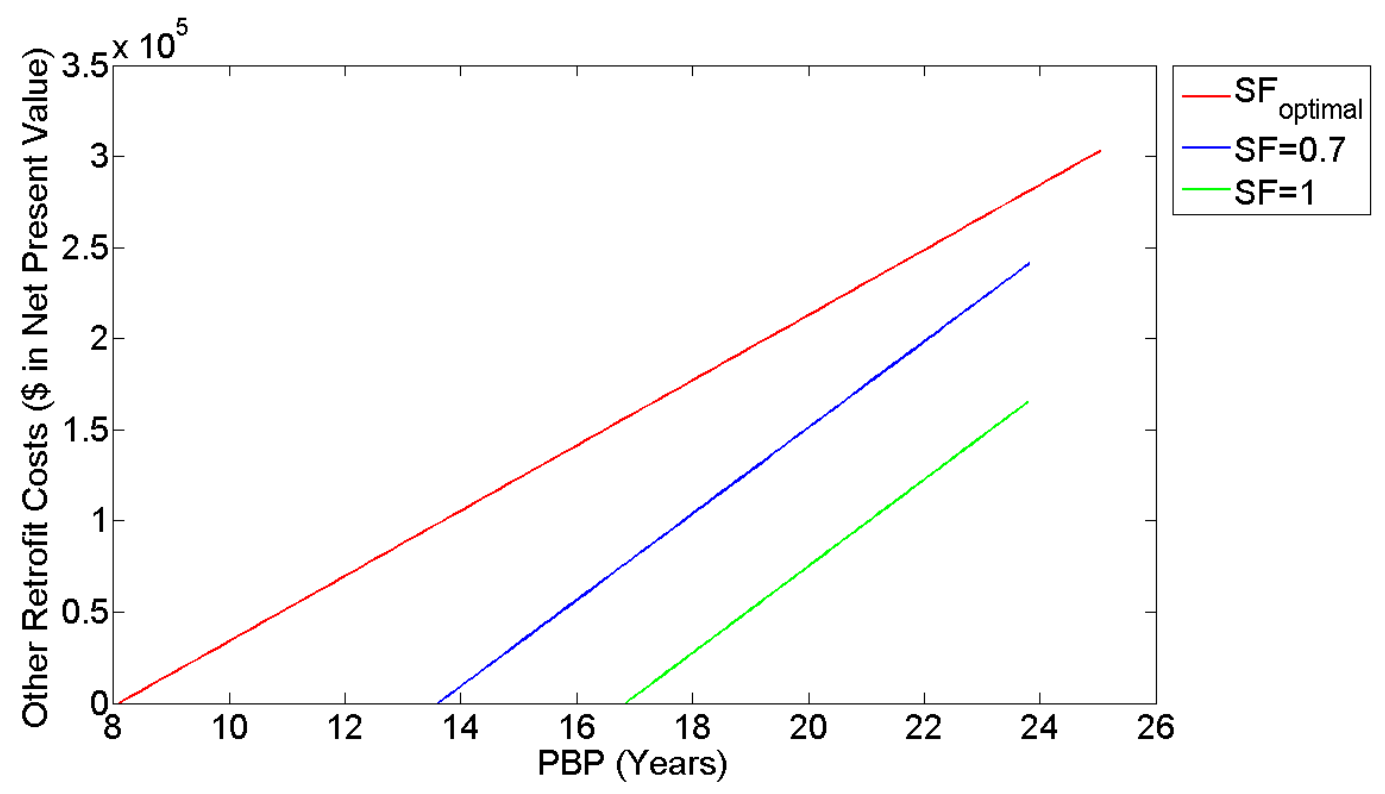

Figure 5.11: PBP vs. other retrofit costs (Test \#2) - Retrofit analysis for High-rise A located in Toronto, Ontario. The ordinate corresponds to "other retrofit costs". For the case of $\$ 0$ for "other retrofit costs (ductwork costs)", the payback period corresponds to the costs of the GSHP system and overhaul costs (baseboard heaters and cooling tower). 
Table 5.8: Large buildings retrofit results (Test \#2)

\begin{tabular}{|c|c|c|c|c|c|c|}
\hline Building & $\begin{array}{l}\text { Heating } \\
\text { Dominant/ } \\
\text { Cooling } \\
\text { Dominant } \\
\text { (HD/CD) }\end{array}$ & $\begin{array}{l}\text { Shave } \\
\text { Factor }\end{array}$ & $\begin{array}{c}\text { Average } \\
\text { TEDM } \\
(\%)\end{array}$ & $\begin{array}{c}\text { Total Costs } \\
\text { (Net Present Value) } \\
\text { (\$) }\end{array}$ & $\begin{array}{l}\text { Initial } \\
\text { Costs } \\
(\$)\end{array}$ & $\begin{array}{c}\text { Payback } \\
\text { period } \\
\text { (years) }\end{array}$ \\
\hline \multirow{4}{*}{$\begin{array}{l}\text { High- } \\
\text { Rise A }\end{array}$} & \multirow{4}{*}{$\mathrm{CD}$} & 0 & 0 & 955,881 & 90,066 & - \\
\hline & & $0.21 *$ & 64.3 & 652,979 & 144,715 & 8.1 \\
\hline & & 0.7 & 99.1 & 714,787 & 321,532 & 13.6 \\
\hline & & 1 & 100.0 & 790,871 & 400,642 & 16.9 \\
\hline \multirow{4}{*}{$\begin{array}{l}\text { High- } \\
\text { Rise B }\end{array}$} & \multirow{4}{*}{$\mathrm{CD}$} & 0 & 0 & $1,988,168$ & 173,516 & - \\
\hline & & $0.23^{*}$ & 60.9 & $1,459,675$ & 325,895 & 9.6 \\
\hline & & 0.7 & 98.0 & $1,561,148$ & 697,086 & 14.7 \\
\hline & & 1 & 100 & $1,714,959$ & 865,817 & 17.9 \\
\hline \multirow{4}{*}{ School } & \multirow{4}{*}{$\mathrm{CD}$} & 0 & 0 & 751,477 & 66,833 & - \\
\hline & & $0.46 *$ & 93.4 & 419,334 & 133,237 & 6.7 \\
\hline & & 0.7 & 99.1 & 435,964 & 163,658 & 7.9 \\
\hline & & 1 & 100 & 482,334 & 211,950 & 10.2 \\
\hline \multirow{4}{*}{ Office } & \multirow{4}{*}{ HD } & 0 & 0 & $6,263,760$ & 552,289 & - \\
\hline & & $0.47 *$ & 95.4 & $3,794,023$ & $1,700,017$ & 9.4 \\
\hline & & 0.7 & 99.8 & $4,042,560$ & $2,127,770$ & 11.2 \\
\hline & & 1 & 100 & $4,545,759$ & $2,638,445$ & 13.9 \\
\hline \multirow{4}{*}{ Mid-rise } & \multirow{4}{*}{$\mathrm{CD}$} & 0 & 0 & $1,067,332$ & 87,111 & - \\
\hline & & $0.34 *$ & 74 & 867,559 & 263,339 & 14 \\
\hline & & 0.7 & 98.3 & 929,000 & 429,898 & 17.9 \\
\hline & & 1 & 100 & $1,021,723$ & 529,753 & 21.7 \\
\hline
\end{tabular}

*Optimal hybrid GSHP design (optimal shave factor)

Previously, based on window air conditioner units and high-rise B's large cooling demands, it was uneconomical to install a GSHP system. For this analysis, using cooling towers (as the conventional cooling system), the optimal shave factor for high-rise B is 0.23 . Based on this optimal design, $60.9 \%$ of the building's total energy demands are met. The payback period is 9.6 years and a total savings of $\$ 528,500$ can be achieved. However, when additional ductwork costs is considered, as presented in Figure 5.12, the optimal shave factor curve exceeds a twenty year payback period when other retrofit costs are greater than $\$ 355,000$. For the shave factors 0.7 and 1.0 (blue and green curves), payback period exceeds twenty years when other retrofit costs are greater than $\$ 253,000$ and $\$ 99,000$ respectively. 


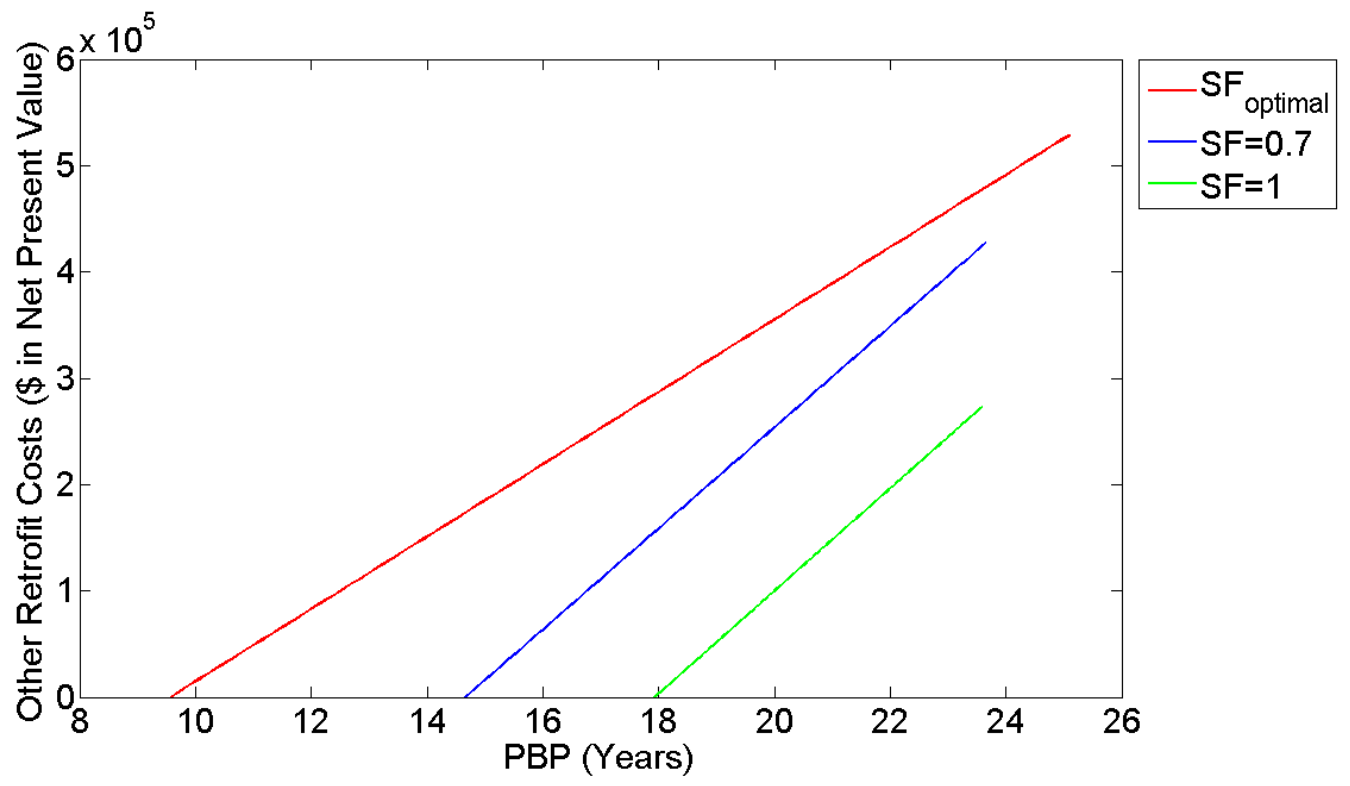

Figure 5.12: PBP vs. other retrofit costs (Test \#2) - Retrofit analysis for High-rise B located in Toronto, Ontario. The ordinate corresponds to "other retrofit costs". For the case of $\$ 0$ for "other retrofit costs (ductwork costs)", the payback period corresponds to the costs of the GSHP system and overhaul costs (baseboard heaters and window air conditioner units).

The optimal shave factor for the school is 0.46 , meeting $93.4 \%$ of the building's total energy demands. The payback period is 6.7 years and a total savings of $\$ 332,000$ can be achieved. However, when additional ductwork costs are considered, as presented in Figure 5.13, the optimal shave factor curve exceeds the twenty years payback period when other retrofit costs are greater than $\$ 264,000$. The curves for shave factors of 0.7 and 1.0 exceed the twenty-year payback period when other retrofit costs are greater than $\$ 248,000$ and $\$ 202,000$ respectively. 


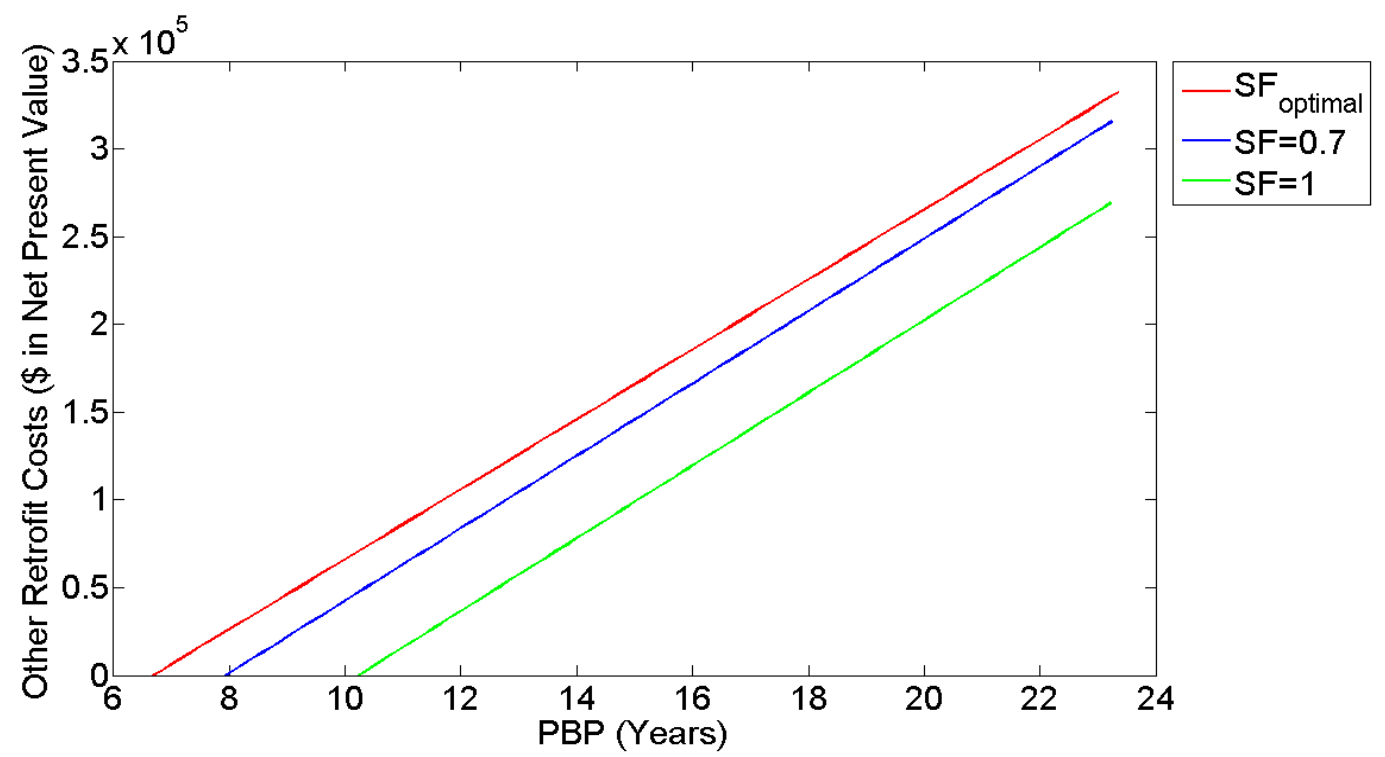

Figure 5.13: PBP vs. other retrofit costs (Test \#2) - Retrofit analysis for a school located in Toronto, Ontario. The ordinate corresponds to "other retrofit costs". For the case of $\$ 0$ for "other retrofit costs (ductwork costs)", the payback period corresponds to the costs of the GSHP system and overhaul costs (baseboard heaters and window air conditioner units).

Based on the five buildings analyzed, it was most economical (in terms of total savings) for the office building to install a hybrid GSHP system. The optimal shave factor for the office building is 0.47 , meeting $95.4 \%$ of the building's total energy demands, a payback period of 9.4 years, and a total savings of $\$ 2,470,000$. As presented in Figure 5.14, the curves for the optimal design, shave factors of 0.7 and 1.0 exceed twenty-year payback period when additional retrofit costs (such as ductwork costs) are more than $\$ 191,000, \$ 167,000$ and $\$ 116,000$ respectively. 


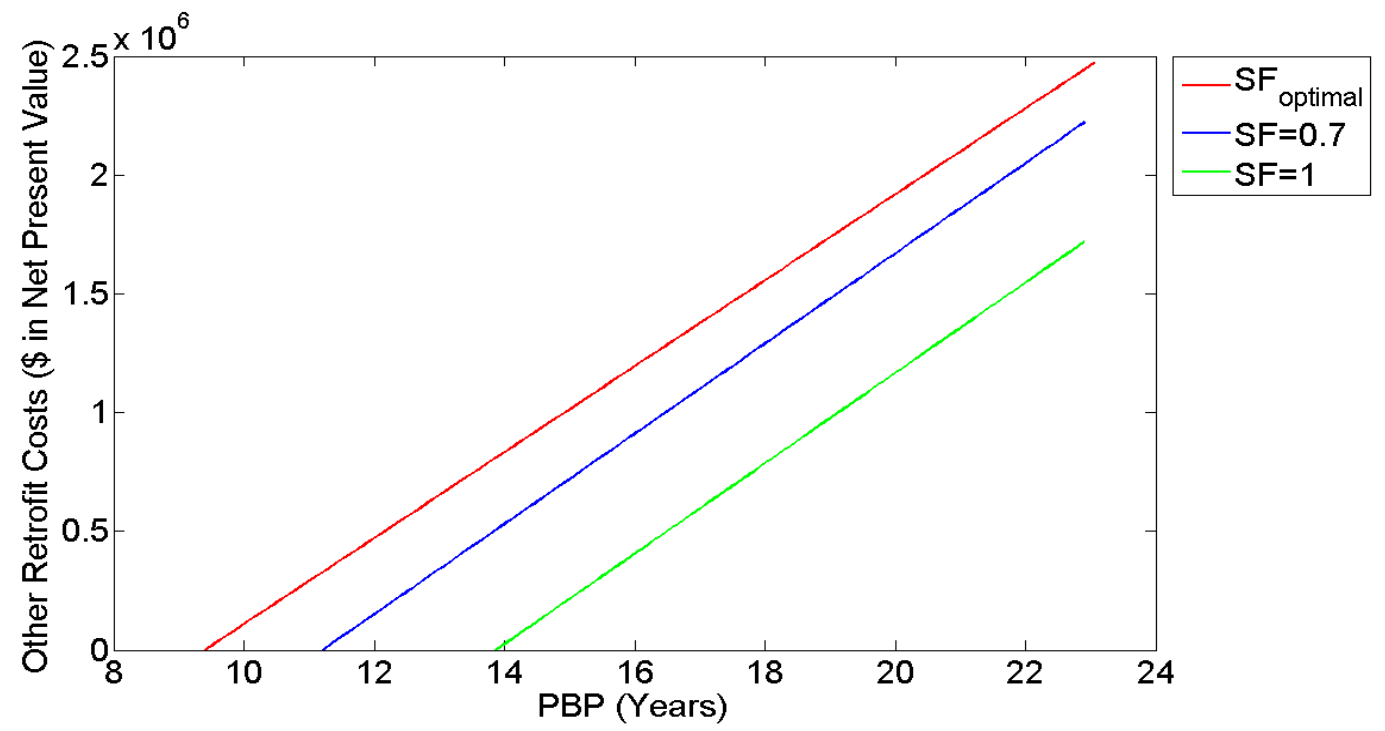

Figure 5.14: Office - PBP vs. other retrofit costs (Test \#2) - Retrofit analysis for an office located in Toronto, Ontario. The ordinate corresponds to "other retrofit costs". For the case of $\$ 0$ for "other retrofit costs (ductwork costs)", the payback period corresponds to the costs of the GSHP system and overhaul costs (baseboard heaters and window air conditioner units).

Lastly, the optimal shave factor for the mid-rise multi-residential building is 0.34. Based on the optimal design, $74 \%$ of the buildings total energy demands are met, a total savings of $\$ 199,800$ (compared to the base case, $S F=0$ ) and a payback period of 14 years. As presented in Figure 5.15, the curves for the optimal design and shave factor of 0.7 exceed the twenty-year payback period when additional retrofit costs (such as ductwork costs) are more than $\$ 112,000$ and $\$ 51,500$ respectively. 


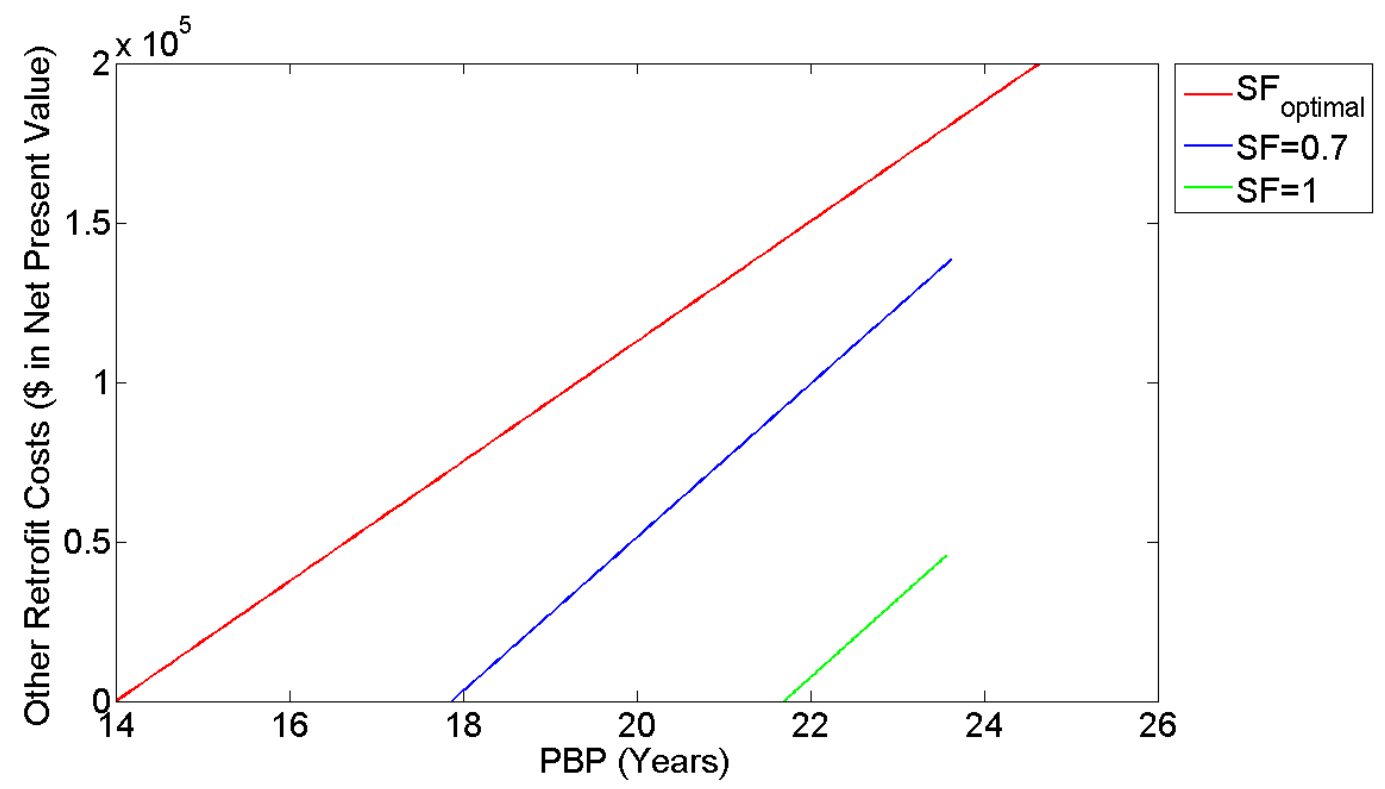

Figure 5.15: PBP vs. other retrofit costs (Test \#2) - Retrofit analysis for a mid-rise multiresidential building located in Toronto, Ontario. The ordinate corresponds to "other retrofit costs". For the case of $\$ 0$ for "other retrofit costs (ductwork costs)", the payback period corresponds to the costs of the GSHP system and overhaul costs (baseboard heaters and window air conditioner units). 


\subsection{Chapter Summary}

For the two residential houses, Houses A and B, the results in Test \#1 (only costs of GSHP system considered) shows that the potential savings $(\$ 20,821$ vs. $\$ 13,925)$ for House B is higher than for House A at their respective optimal shave factors; in addition, the payback periods are the same (6.1 years), despite higher hybrid GSHP initial costs for House B.

In Test \#2, retrofit ductwork costs, major overhaul costs of window air conditioners, and baseboard heaters are considered. The high costs of the ductwork resulted in longer payback periods for Houses A and B; 13.9 years and 20.1 years respectively. The ductwork costs for House B needs to be less than $\$ 16,500$ for the payback period to be less than twenty years. Due to reduced energy demands from upgrading the building envelope, there is lesser savings for hybrid GSHP systems compared to the conventional heating and cooling systems. As a result, in Test \#3, the addition of insulation costs resulted in longer payback periods for both houses. It is clear that, as the retrofit costs increase from Test \#1 to Test \#3, the optimal shave factor may not exhibit monotonic behavior.

For the other buildings analyzed (commercial and residential), hybrid-GSHP systems are not as economical for cooling dominant buildings with a high cooling to heating ratio. The economic viability for these particular buildings depend on the COP of the conventional system being less than that of the GSHP system. However, in Test \#1, the air conditioner and heat pump have similar cooling COPs (3.4 vs. 3.8), resulting in no economical designs (i.e., for the case of High-rise B). The results indicate that larger buildings generally benefit more from a hybrid GSHP retrofit larger energy savings tend to compensate for the high upfront costs of the system, especially for large buildings with a compatible distribution system (low ductwork costs). 


\section{Chapter 6}

\subsection{Conclusions}

The three studies performed gave an overview of how complex sizing of a hybrid GSHP system can be. However, as suggested by the literature [46 - 48], the use of sensitivity analysis has allowed for a better determination of the impact that variations in input parameters such as pricing, operating hours, inflation and ground temperatures have on the design and performance of hybrid GSHPs. The approach taken in these sensitivity analyses is consistent with that undertaken in recent modelling of GSHP energy systems [51, 53, 63]. The findings of the sensitivity analyses have implications for GSHP technology developers, energy utilities, energy regulators and operators of multi-residential and commercial building complexes who may be contemplating installation of a GSHP energy system. Based on the studies performed, a framework has been established and the algorithms and results can be used as tools and guides to complement existing ground loop design tools and aid the engineer during the design process.

The economic viability and optimal design of hybrid GSHPs is dependent on weather, operating costs (fixed or time-of-use rates), inflation rates, project life, heat pump EFT, carbon taxation, and the control strategies used. The conclusions from the three studies are:

Weather sensitivity:

- Extremely cooling dominant buildings had longer payback periods in warmer weather. The average change in payback periods (excluding the school) ranges between +1.2 (Charles, IA) and -3.1 (Austin, TX); a negative value indicates a longer payback period.

- It is more economical for extremely cooling dominant buildings to install GSHP systems in colder weather due to lower ground temperatures (better heat pump performance).

- In warmer weather where ground temperatures were higher, it was most economical to downsize the ground loop length and expand the cooling tower. The change in shave factor are between +0.07 (Kearney, NE) and -0.44 (Fresno, CA) using Toronto's rates. 
- Buildings situated in colder weather have larger heating demands. For heating dominant buildings, it is more economical to install conventional heating systems - the cost of natural gas per $\mathrm{kWh}$ heating is cheaper than electricity.

Natural gas, electricity and inflation rates:

- For buildings with long operating hours during off-peak periods (time-of-use rates), the GSHP system was downsized (shave factor) by $1 \%$ and $3 \%$ for the restaurant and fast-food restaurant respectively, reducing initial costs. However, downsizing of the GSHP system resulted in longer payback periods due to lower savings on operating cost.

- The widely varying electricity rates in North America significantly affect the shave factor values — in some cases generating much more economically viable designs in regions with higher rates.

- Inflation for natural gas or electricity rates can benefit or adversely affect the hybrid GSHP system's economic viability depending on the building and weather patterns.

- For cooling dominant buildings, hybrid GSHP systems become more favorable when electricity rates or inflation is increased.

- The economics for buildings with GSHPs that provided heating were worsened when electrical prices increased but were improved when natural gas price increases.

- For heating dominant buildings, the low rates for natural gas found in many parts of North America make it uneconomical to install a GSHP system.

Seasonality control:

- In the winter months, all cooling demands were set to zero (free cooling from cold outdoor air) and in the summer months, all heating demands were also set to zero (free heating from hot outdoor air). Under these conditions a hybrid GSHP system was only economical for the multifamily residential buildings that were considered. For all non-residential buildings considered, although some are cooling dominant, a conventional system was less expensive to install and to operate for twenty years compared to a hybrid-GSHP system when a seasonal control strategy is being implemented. 
Heat pump EFT:

- Although heat-pump EFT plays a crucial role in determining the efficiency of the system, the effects of varying the EFT pairs (for heating and cooling operations) on the optimal design is unsubstantial compared to other parameters such as weather patterns and utility rates.

- Varying the heat-pump EFT directly affects the COPs of the heating and cooling modes of the heat pump (operating costs), as such, improving the COP in turn reduces GHG emissions. However, EFT pairs that improve the COPs requires a larger ground loop which results in higher upfront costs (vice versa for reducing upfront costs).

- The largest savings achieved from the ten real buildings analyzed, compared to the base case (optimal EFT pair vs. fixed EFT pair) was only 3.6\% for a school located in Toronto, Canada.

$\mathrm{CO}_{2}$ emissions:

- In a scenario in which both total costs and $\mathrm{CO}_{2}$ emissions are important, sizing the system based on the optimal shave factor may result in higher $\mathrm{CO}_{2}$ emissions than desired, whereas sizing the system to a shave factor of 1.0 (for the least $\mathrm{CO}_{2}$ emissions) might result in high upfront costs than desired. An example would be the high-rise (II) building with an optimal shave factor of 0.23 in which sizing the system to a shave factor of 0.6 would reduce $\mathrm{CO}_{2}$ emissions, comparable to that of shave factor $=1$ (without the high upfront costs for shave factor $=0.6)$.

- The methods of analysis presented empower a designer to understand the increment in NPV and payback period associated with such an adjustment so as to make an informed decision. For the ten buildings analyzed, the average reduction in $\mathrm{CO}_{2}$ emissions for project life greater than twenty years (long term) are similar to those of twenty years operation. For twenty years operation, $\mathrm{CO}_{2}$ reductions are between $21 \%$ and $44 \%$ (average reduction of $20,000 \mathrm{~kg} \mathrm{CO} 2$ per year).

Carbon taxation:

- Based on a carbon tax of $\$ 30$ per tonne of $\mathrm{CO}_{2}$ emitted, a carbon tax increases the operating costs of a hybrid GSHP system. To accommodate the increase in operating costs, for all of 
the buildings analyzed the optimal shave factor increased between 0.01 and 0.02 , contributing to some reductions in $\mathrm{CO}_{2}$ emissions and payback periods (especially for the case of a shave factor of 0.0 ).

- Buildings that are best suited for a hybrid GSHP system from an economics perspective with high TEDM benefit the most from a carbon tax.

- In the analysis in which a carbon tax was not applied, using the optimization methodology outlined in Alavy et al. [15] yields $\mathrm{CO}_{2}$ emission levels similar to that of a $S F=1.0$. For example, the fast-food restaurant with a shave factor value of 0.62 produces only $8.5 \%$ more $\mathrm{CO}_{2}$ emissions than the minimum possible amount.

Project Life:

- The project life analysis was performed to determine its economic and environmental effects on sizing hybrid GSHP systems. Using the "NPV/operating duration" (NPV per operating year) parameter, to determine the amortized system cost per year, reductions in annual amortized system costs are achieved as the assumed project life increases.

- The economic benefits of increasing a hybrid GSHP's assumed project life (exceeding the break-even point), on average, begins to asymptote at year 50 (and no changes occur at around year 100 or more). This analysis may be of particular interest when government owned buildings or schools are considered, as such buildings infrequently change ownership.

- The same conclusions are also observed for $\mathrm{CO}_{2}$ emissions. For example, for the case of the fast-food restaurant, when the project life exceeds the break-even point (13 years), the reduction in $\mathrm{CO}_{2}$ emissions per operating year is the greatest at the operation duration of 30 years $\left(41 \%\right.$ or $18,000 \mathrm{~kg}$ of $\mathrm{CO}_{2}$ ) and begins to level-off thereafter. All buildings analyzed emit no more than $10 \% \mathrm{CO}_{2}$ for project life between twenty and twenty-five years compared to a project life of 100 years.

\section{Building Retrofit:}

- For single detached houses, a full GSHP installation meeting all of the building's energy demands can cost $\$ 20,000$ or more. However, using the methodology outlined in Alavy et al. [15], a GSHP sized to meet $37 \%$ of House B's (a large $5000 \mathrm{ft}^{2}$ house) peak energy 
demands can still provide $83.8 \%$ TEDM without other retrofit costs. However when the house requires major retrofit costs, including ductwork and major overhaul costs of electric baseboard heaters and window air conditioners, a larger GSHP sized to meet $45 \%$ and $90 \%$ of House B's peak energy demands and TEDM, respectively, would be required with an extra 14 years of payback period.

- Due to retrofit costs such as ductwork, for building owners with low capital, it may be more economical to use the building's existing systems and improve the building's insulation. Heating demands for House A (a smaller house with $2000 \mathrm{ft}^{2}$ ) and House B were reduced by $24.3 \%$ and $33.8 \%$, respectively, when building insulation was improved from 1986 OBC insulation standards of R30 (ceiling) and R13 (wall) to the new OBC standards of R50 and R29, respectively.

- Applying the rough rule-of-thumb ductwork costs for Houses A and B, hybrid GSHP systems remain more economical than the conventional systems (based on a project life of twenty years). However, if insulation costs are considered, hybrid GSHP systems will remain more economical but payback period will exceed twenty years.

- Large buildings such as the school, high-rise A, and office, a hybrid GSHP system is more economical than a conventional system after twenty years of operation. However, the overall benefit depends on the ductwork retrofit costs.

Table 6.1 provides a summary of all the parameters studied giving their effects on the design, payback period and/or feasibility of a hybrid GSHP system. 
Table 6.1: Summary of trends based on sensitivity variations

\begin{tabular}{|c|c|c|}
\hline Parameter & $\begin{array}{c}\text { Sensitivity } \\
\text { Variation }\end{array}$ & Trend \\
\hline Discount rate & Increase & $\begin{array}{l}\text { The dollar value for annual savings in subsequent } \\
\text { years reduces. As a result, payback period } \\
\text { increases. } \\
\text { The payback period was increased by at least } 2.3 \\
\text { years due to an increase in discount rate from } 4 \% \\
\text { to } 8 \% \text { (chapter 3.6). }\end{array}$ \\
\hline $\begin{array}{l}\text { Electricity } \\
\text { inflation }\end{array}$ & Increase & $\begin{array}{l}\text { For cooling dominant buildings, hybrid GSHP } \\
\text { systems become more favorable when electricity } \\
\text { rates or inflation is increased. } \\
\text { - For heating dominant buildings, the low rates for } \\
\text { natural gas found in many parts of North America } \\
\text { make it uneconomical to install a GSHP system. } \\
\text { As electricity rates or inflation is increased, boilers } \\
\text { become more favorable than GSHPs. }\end{array}$ \\
\hline $\begin{array}{l}\text { Natural gas } \\
\text { inflation }\end{array}$ & Increase & $\begin{array}{l}\text { - Inflation for natural gas adversely affect the } \\
\text { economic viability of boilers (hybrid GSHP } \\
\text { systems become a more favorable). }\end{array}$ \\
\hline $\begin{array}{l}\text { Weather } \\
\text { patterns }\end{array}$ & Warmer & $\begin{array}{l}\text { - In warmer weather, cooling demands increases and } \\
\text { heating demand decreases. } \\
\text { - Due to higher ground temperatures and cooling } \\
\text { demands (reduced ground loop efficiency for the } \\
\text { cooling mode) substantially larger ground loops are } \\
\text { required. } \\
\text { - To reduce high upfront costs, the ground loop is } \\
\text { downsized and the cooling tower is expanded. } \\
\text { - Payback period increases. }\end{array}$ \\
\hline Project life & Increase & $\begin{array}{l}\text { - Shave factor increases. } \\
\text { - Total annual } \mathrm{CO}_{2} \text { emission reduces. } \\
\text { - Annual operating cost savings increases. }\end{array}$ \\
\hline Carbon tax & Increase & $\begin{array}{l}\text { - Payback period for conventional system increases. } \\
\text { - Payback period for hybrid GSHP system decreases. } \\
\text { - Shave factor increases. } \\
\text { - Economical designs with high TEDM benefit more } \\
\text { from a carbon tax. }\end{array}$ \\
\hline $\begin{array}{l}\text { Building } \\
\text { insulation } \\
\text { (R-value) }\end{array}$ & Increase & $\begin{array}{l}\text { - Building energy demands decreases. } \\
\text { - Upfront costs increases and shave factor decreases. } \\
\text { - Cost reduction by shave factor parameter reduces. }\end{array}$ \\
\hline $\begin{array}{l}\text { Conventional } \\
\text { system } \\
\text { efficiency }\end{array}$ & Increases & - Economic viability of GSHP system decreases. \\
\hline
\end{tabular}




\subsection{Recommendations}

Based on the findings from the analyses performed in this thesis (and in Alavy et al. [15, 97]), a general knowledge base of automatically sizing GSHPs as a component of a hybrid system has been achieved. However, the findings are based on vertical hybrid-GSHP systems. As such, there are several questions that have now become subjects of further inquiry:

- To continue expanding the knowledge base of automatically sizing hybrid GSHP systems, similar studies performed thus far should be carried out for other commonly used ground loop configurations such as the horizontal configuration.

- It would also be interesting to investigate the feasibility of combining multiple residential buildings into one district system/common ground loop (i.e., a utility model).

- An investigation on the efficiency of a common water loop system should be investigated.

- Supply mix for power generation varies throughout the day, as such, it is of interest to investigate the effects of time-of-use electricity rates and the variation in the supply mix on $\mathrm{CO}_{2}$ emissions. The analysis can be further expanded by providing how much $\mathrm{CO}_{2}$ is produced from each supply mix for each component of a hybrid GSHP system.

- Discount rate and inflation rate are not 1:1 relationship. As such, it is of interest to further test the sensitivity of these parameters.

- The COPs of the cooling tower, heat pump, boiler, soil thermal properties, and local material and installation costs used in this thesis (data courtesy of CleanEnergy ${ }^{\mathrm{TM}}$ ) can be better quantified for Toronto and other geographical locations.

- The assumed cost of $\$ 65 / \mathrm{m}$ vertical borehole length is more applicable for large buildings. For smaller buildings, the fixed costs (such as, rental and/or transportation of drilling equipment) of a GSHP installation may result in higher cost and should be better quantified.

- The COP of a heat pump will likely to vary from high to low over a heating or cooling season due to changes in heat pump entering fluid temperature. As such, the heat pump entering fluid temperature analysis can be improved to consider such variations over a season.

- The $\mathrm{CO}_{2}$ analysis can also be furthered improved by implementing a module for the algorithm to take into account long-term supply mix profiles; in an ideal case, all power generation will be green electricity in the next twenty years. 
- Lastly, the findings can be used towards studying the long-term system performance of (and improvement to) the GSHP system at the TRCA house.

\subsection{Author's Contributions}

The author's contribution can be summarized as follows:

- Studied and explained in detail GSHP technology and the procedure in sizing hybrid GSHP systems

- Assisted in the development of a rigorous computer program in minimizing the net present value of total costs of GSHPs as a component of a hybrid system.

- Co-developed an algorithm, for Chapter 4 of this thesis, capable of determining the optimal entering fluid temperatures of a heat pump (varying inlet temperature). The algorithm can be used as a tool to complement existing ground loop design tools and aid the engineer during the design process.

- Co-developed an algorithm, for the $\mathrm{CO}_{2}$ analysis in Chapter 4 of this thesis, capable of determining the $\mathrm{CO}_{2}$ emissions for the hybrid GSHP system. The algorithm can be used as a tool to complement existing ground loop design tools and aid the engineer during the design process.

- An algorithm was developed, for the retrofit analysis in Chapter 5, to consider the total costs of the electric baseboard heating, building envelope retrofit costs, ductwork costs, and other retrofit costs. The algorithm can be used as a tool to complement existing ground loop design tools and aid the engineer during the design process.

- Three studies were performed, a framework was established, as a way of increasing the knowledge base of automatically sizing GSHPs as a component of a hybrid system. The three studies are as follows:

- A sensitivity analysis (Study \#1) was performed to determine the effects of operating costs, inflation, geographical location within North America, and a seasonality control strategy on sizing hybrid GSHP systems.

$\circ$ The effects of EFT for heat pump, $\mathrm{CO}_{2}$ emissions and carbon taxation on a hybrid GSHP system were studied for a variety of commercial installations (Study \#2). 
- A retrofit analysis (Study \#3) was performed to determine the economic viability of retrofitting a hybrid GSHP system for electrically heated (baseboards) and cooled (air-conditioners/cooling towers) residential and commercial buildings. 


\section{Appendix A}

\section{Building Loads}

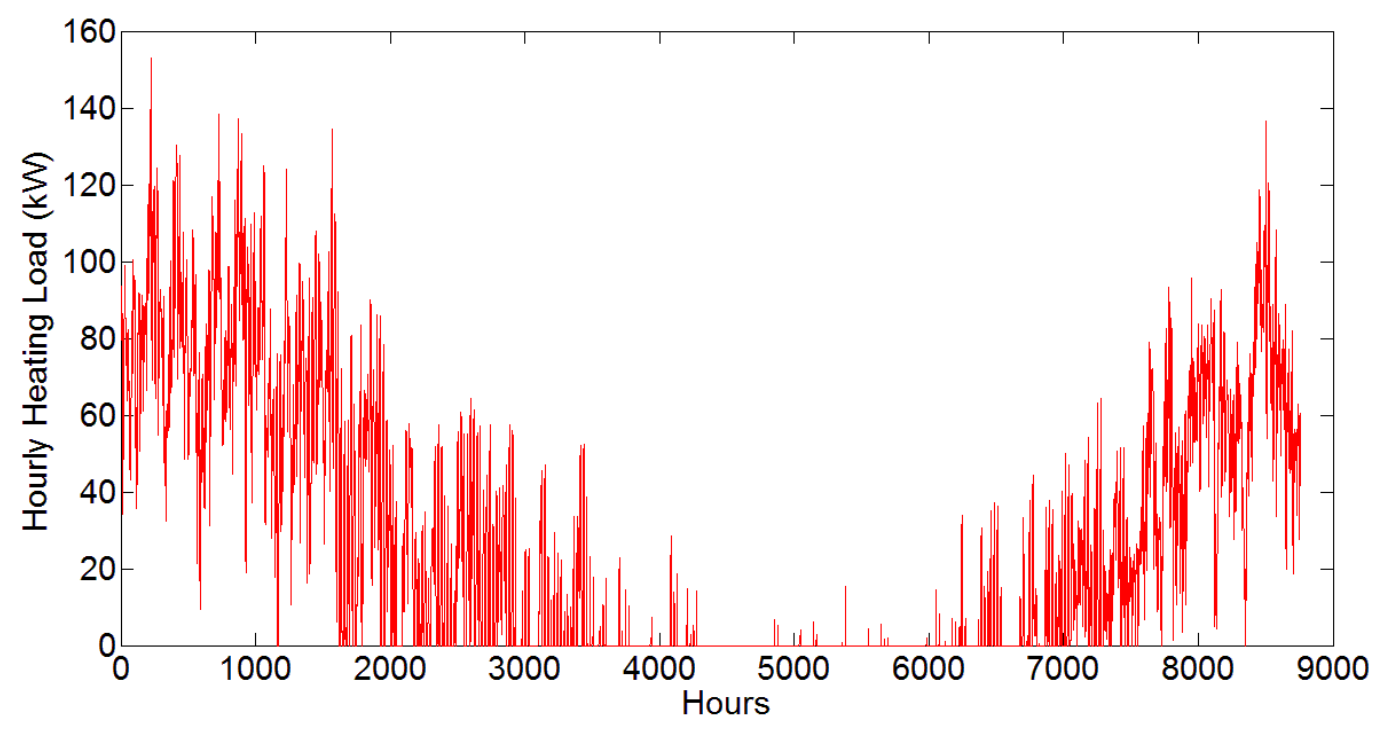

Figure A.1: Hourly heating loads for a hospital located in Toronto, Ontario. The hours in a year (8760 hours in a year) are along the abscissa. The peak and total heating loads are $153 \mathrm{~kW}$ and $243,000 \mathrm{kWh}$ respectively.

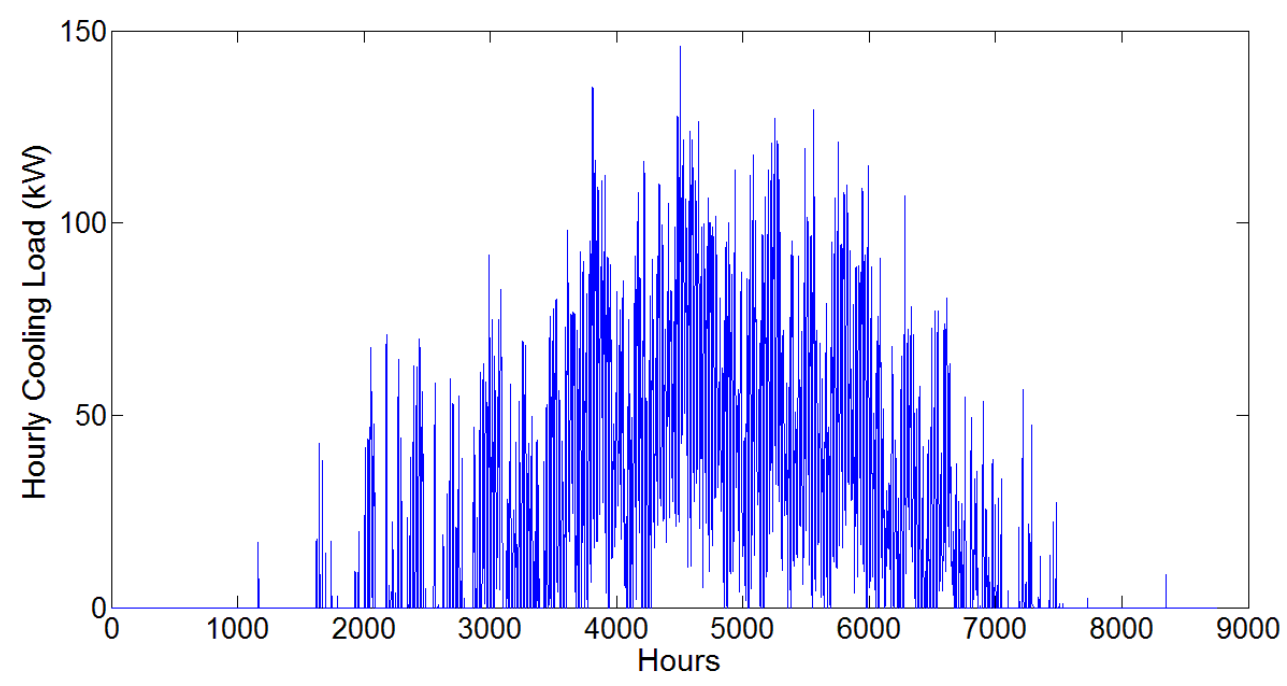

Figure A.2: Hourly cooling loads for a hospital located in Toronto, Ontario. The hours in a year (8760 hours in a year) are along the abscissa. The peak and total cooling loads are $146 \mathrm{~kW}$ and $175,000 \mathrm{kWh}$ respectively. 


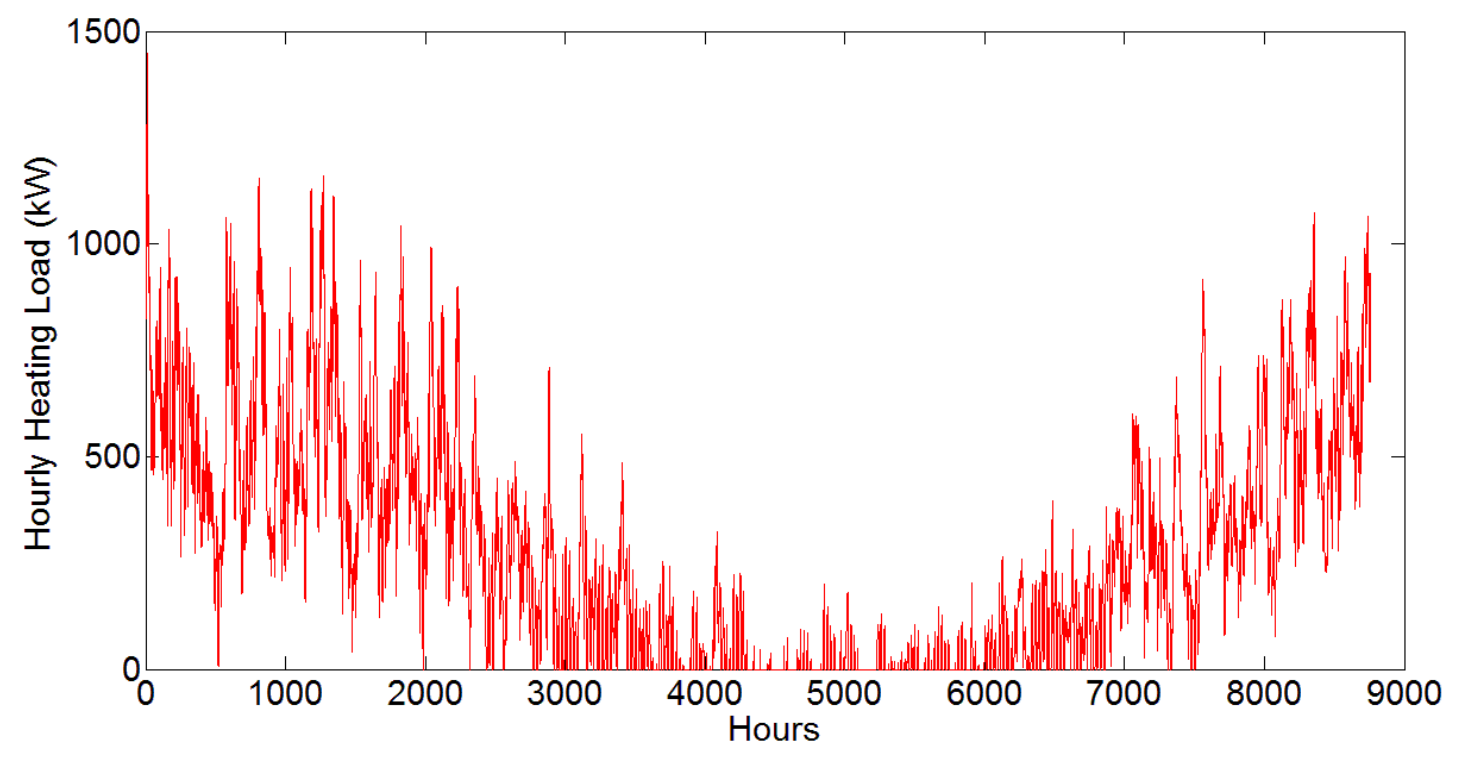

Figure A.3: Hourly heating loads for an office building located in Toronto, Ontario. The hours in a year (8760 hours in a year) are along the abscissa. The peak and total heating loads are 1,449$\mathrm{kW}$ and 2,396,500 $\mathrm{kWh}$ respectively.

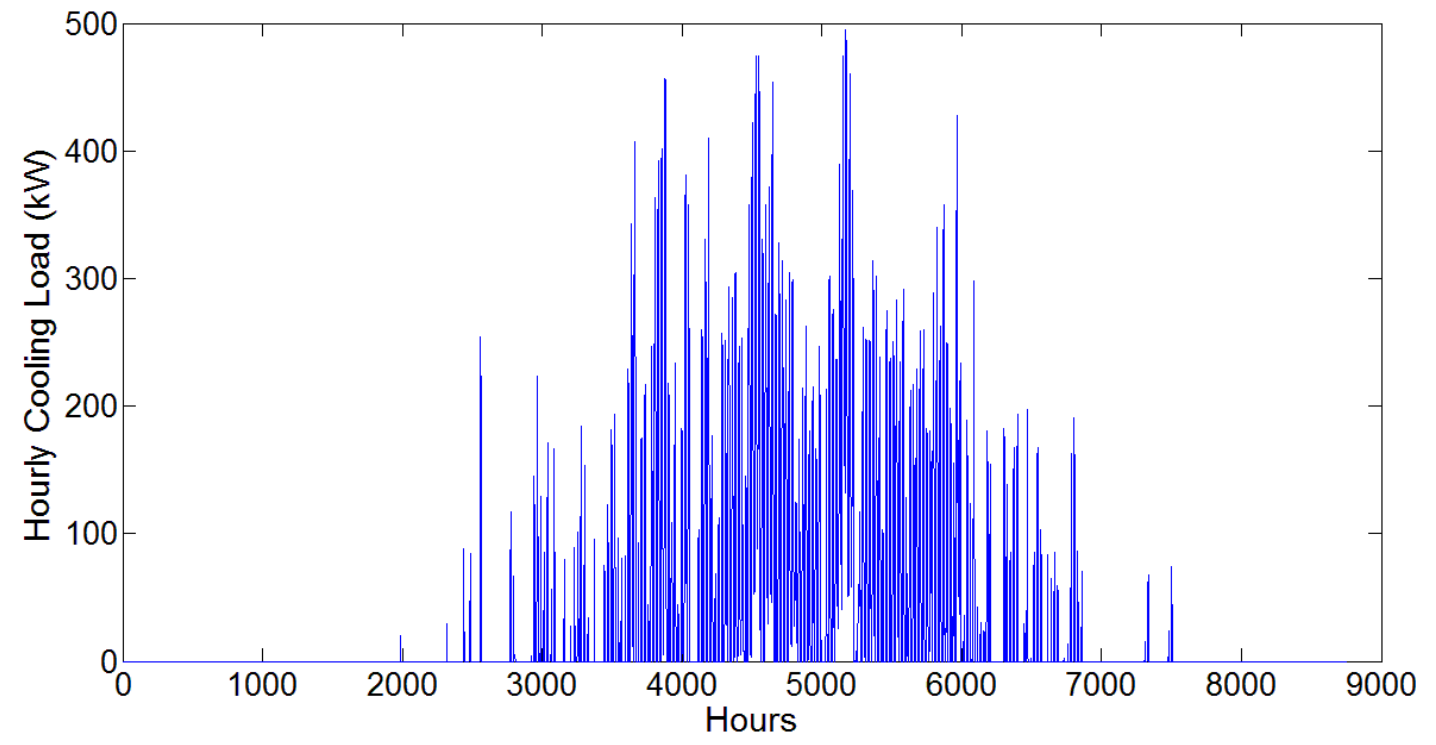

Figure A.4: Hourly cooling loads for an office building located in Toronto, Ontario. The hours in a year (8760 hours in a year) are along the abscissa. The peak and total cooling loads are $495 \mathrm{~kW}$ and 279,200 kWh respectively. 


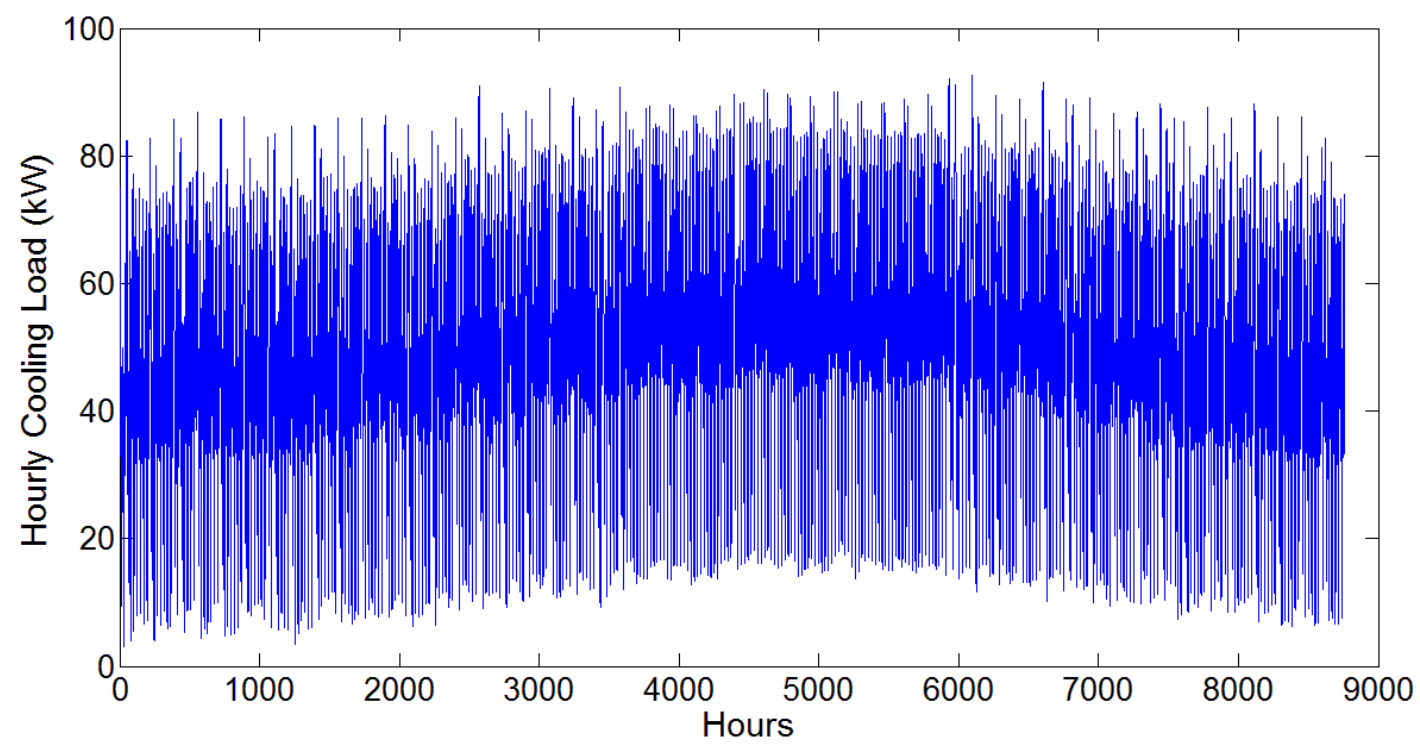

Figure A.5: Hourly cooling loads for a restaurant located in Toronto, Ontario. The hours in a year ( 8760 hours in a year) are along the abscissa. The peak and total cooling loads are $93 \mathrm{~kW}$ and 430,950 kWh respectively (No hourly heating loads).

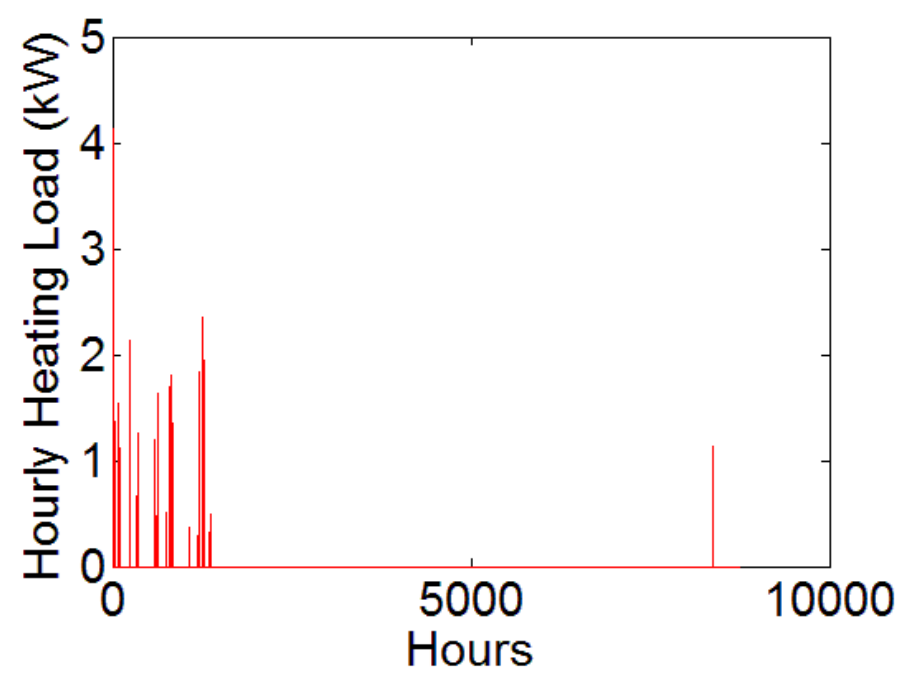

Figure A.6: Hourly heating loads for a fast-food restaurant located in Toronto, Ontario. The hours in a year (8760 hours in a year) are along the abscissa. The peak and total heating loads are $4 \mathrm{~kW}$ and $40 \mathrm{kWh}$ respectively. 


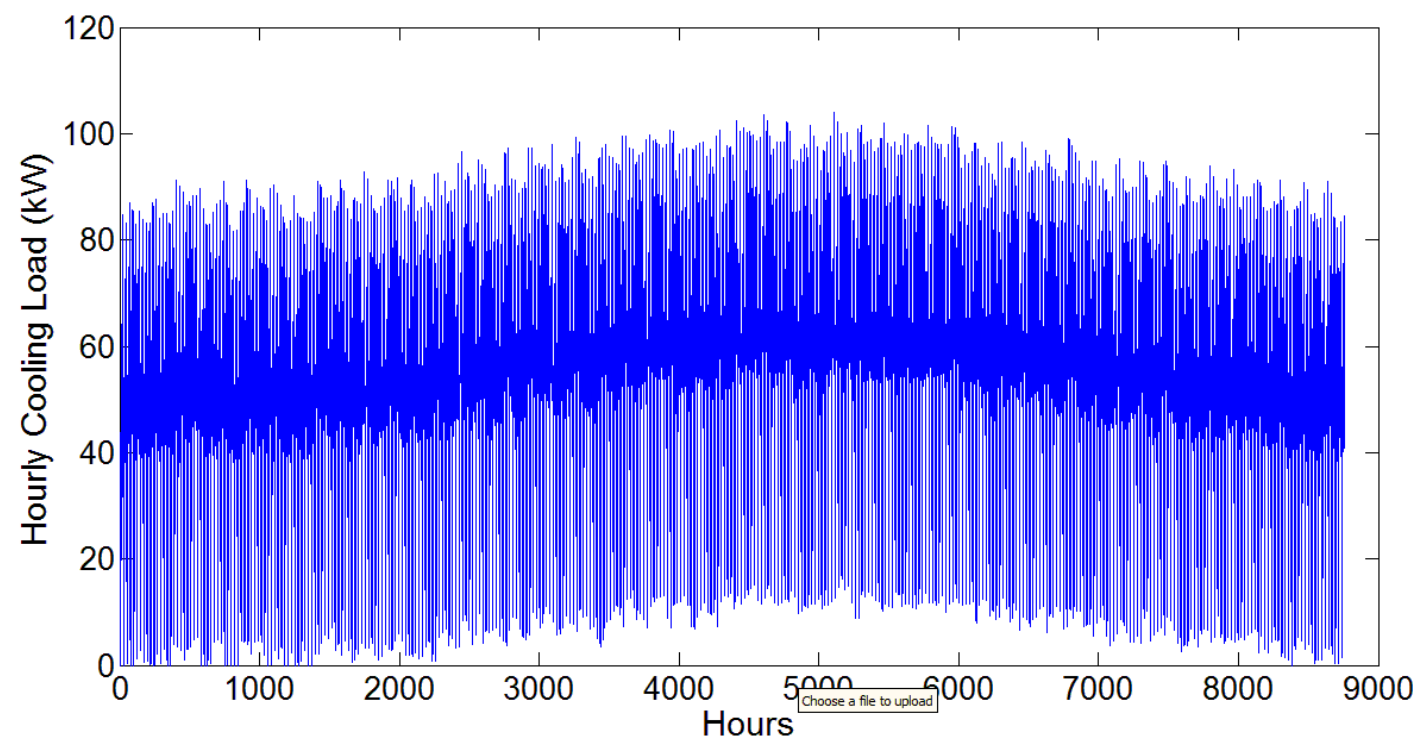

Figure A.7: Hourly cooling loads for a fast-food restaurant located in Toronto, Ontario. The hours in a year ( 8760 hours in a year) are along the abscissa. The peak and total cooling loads are $104 \mathrm{~kW}$ and 475,150 kWh respectively.

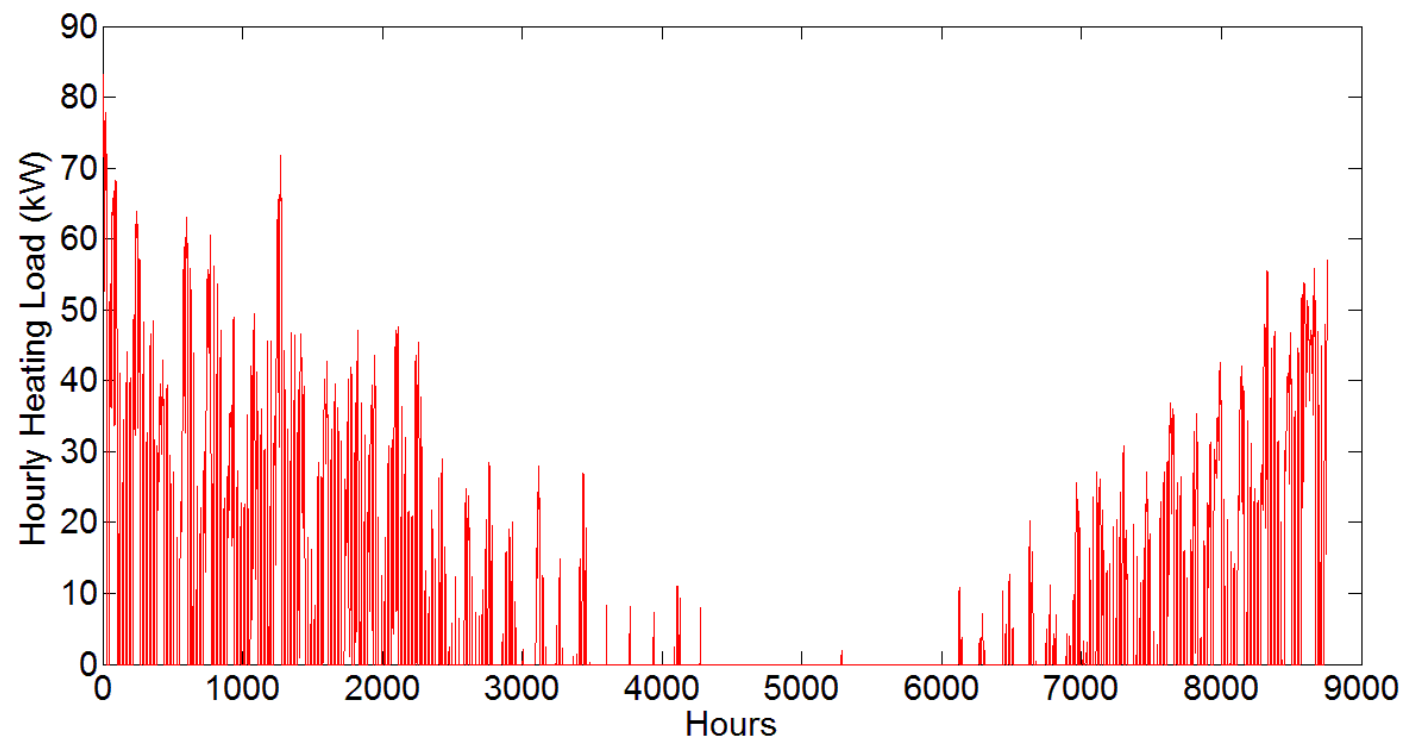

Figure A.8: Hourly heating loads for a transit facility located in Toronto, Ontario. The hours in a year ( 8760 hours in a year) are along the abscissa. The peak and total heating loads are $83 \mathrm{~kW}$ and $66,460 \mathrm{kWh}$ respectively. 


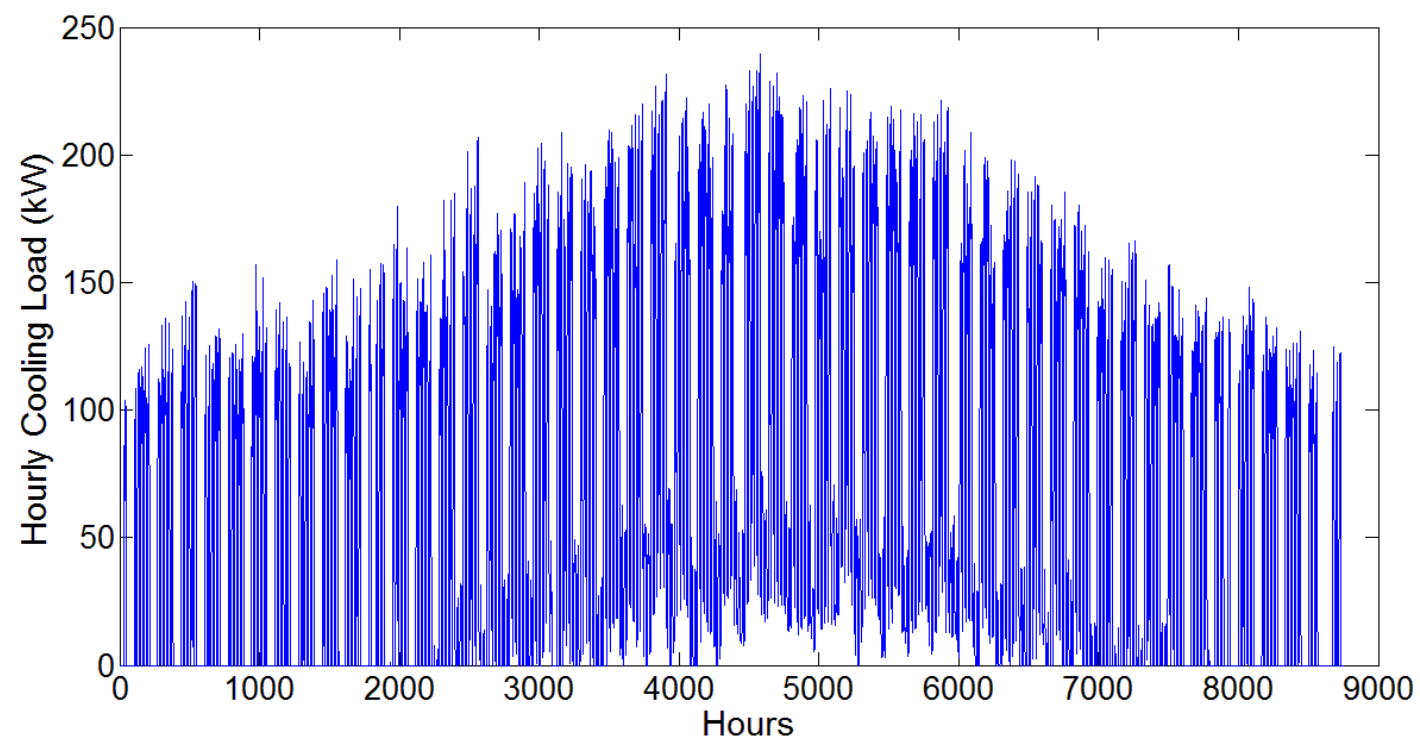

Figure A.9: Hourly cooling loads for a transit facility located in Toronto, Ontario. The hours in a year ( 8760 hours in a year) are along the abscissa. The peak and total cooling loads are $239 \mathrm{~kW}$ and $606,220 \mathrm{kWh}$ respectively.

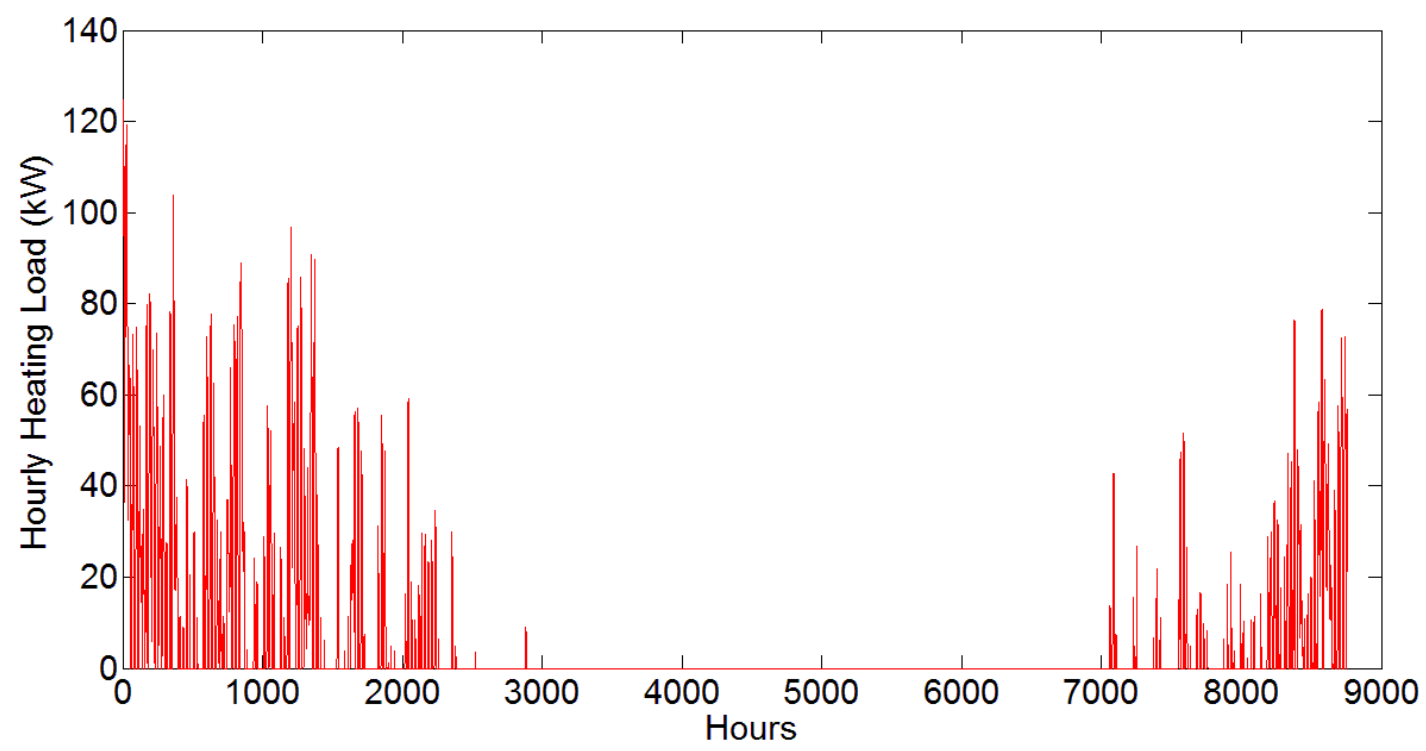

Figure A.10: Hourly heating loads for a mid-rise multi-residential building located in Toronto, Ontario. The hours in a year ( 8760 hours in a year) are along the abscissa. The peak and total heating loads are $125 \mathrm{~kW}$ and 50,290 $\mathrm{kWh}$ respectively. 


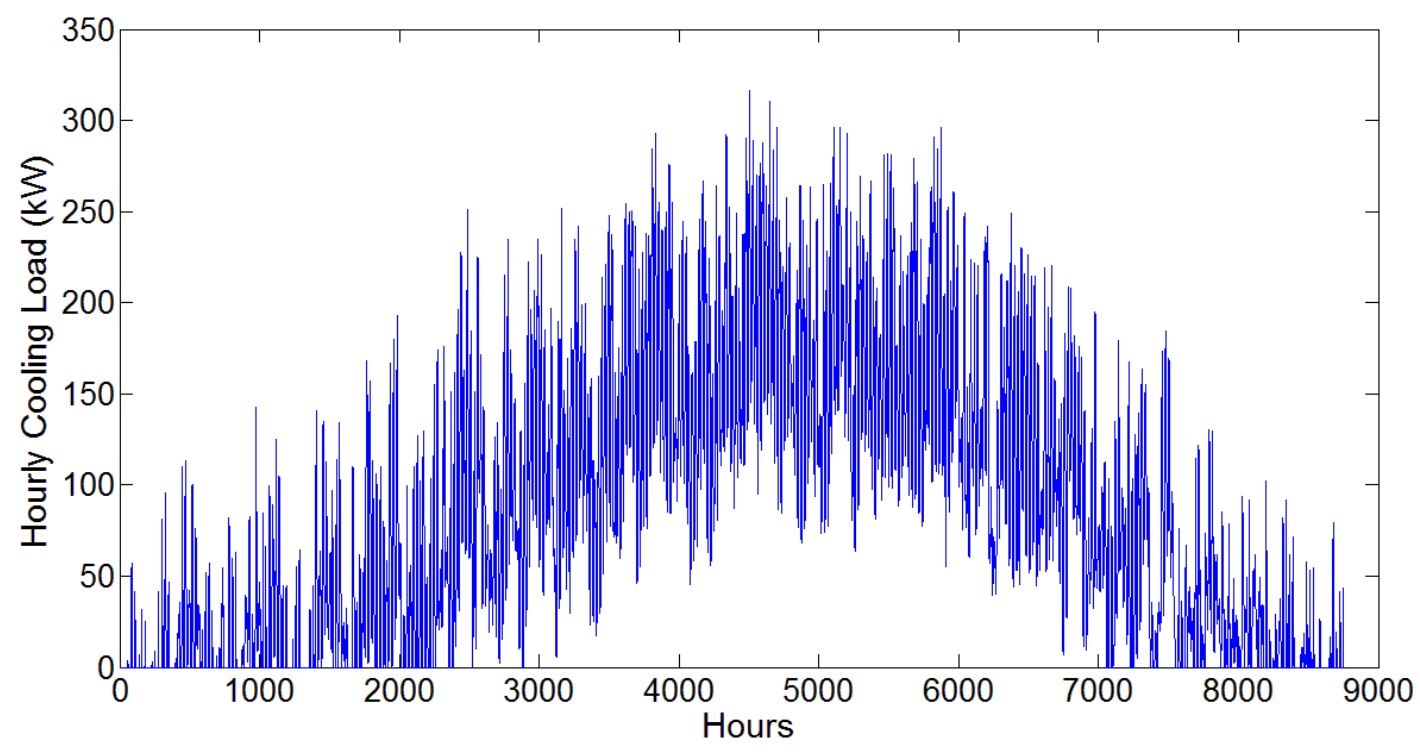

Figure A.11: Hourly cooling loads for a mid-rise multi-residential building located in Toronto, Ontario. The hours in a year (8760 hours in a year) are along the abscissa. The peak and total cooling loads are $316 \mathrm{~kW}$ and 765,510 $\mathrm{kWh}$ respectively.

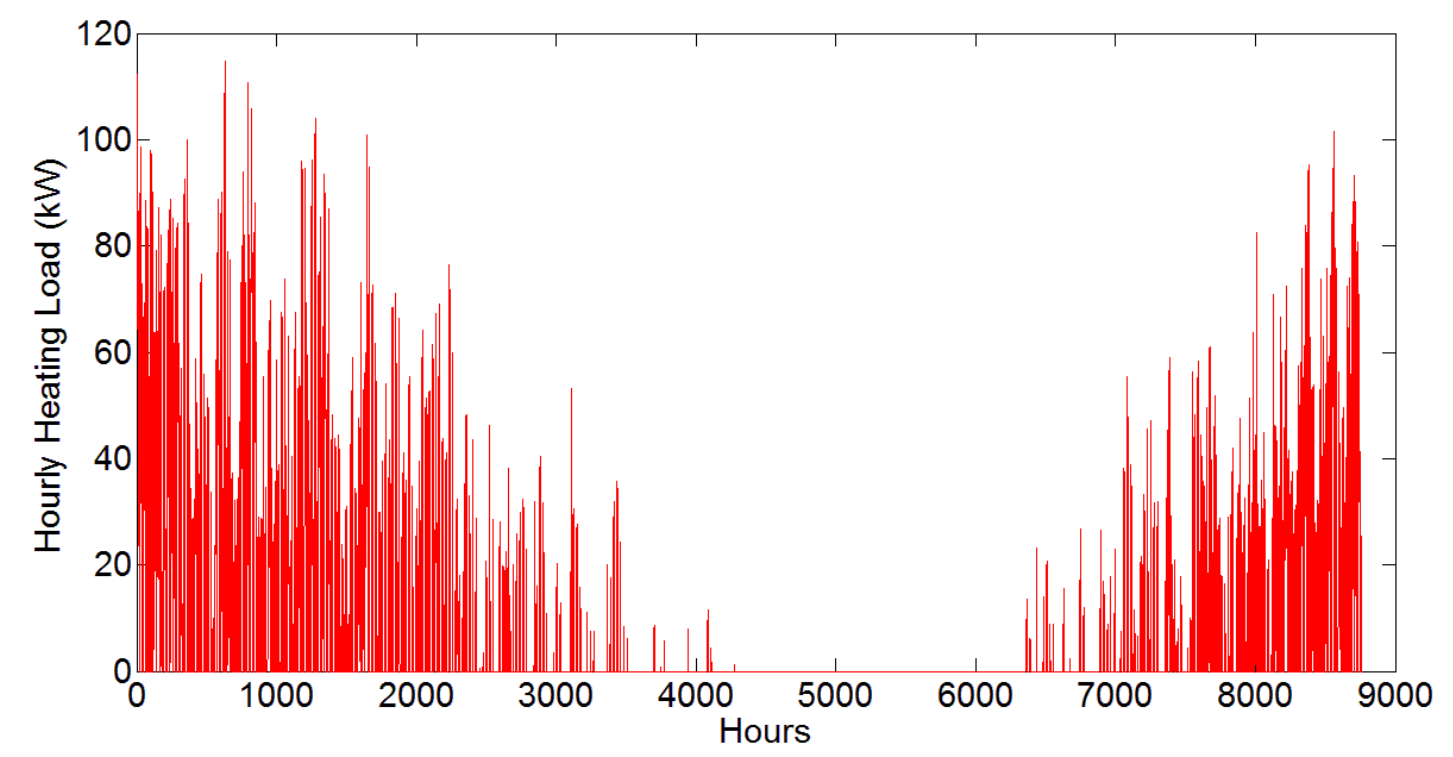

Figure A.12: Hourly heating loads for High-rise A (multi-residential building) located in

Toronto, Ontario. The hours in a year ( 8760 hours in a year) are along the abscissa. The peak and total heating loads are $114 \mathrm{~kW}$ and $8,700,000 \mathrm{kWh}$ respectively. 


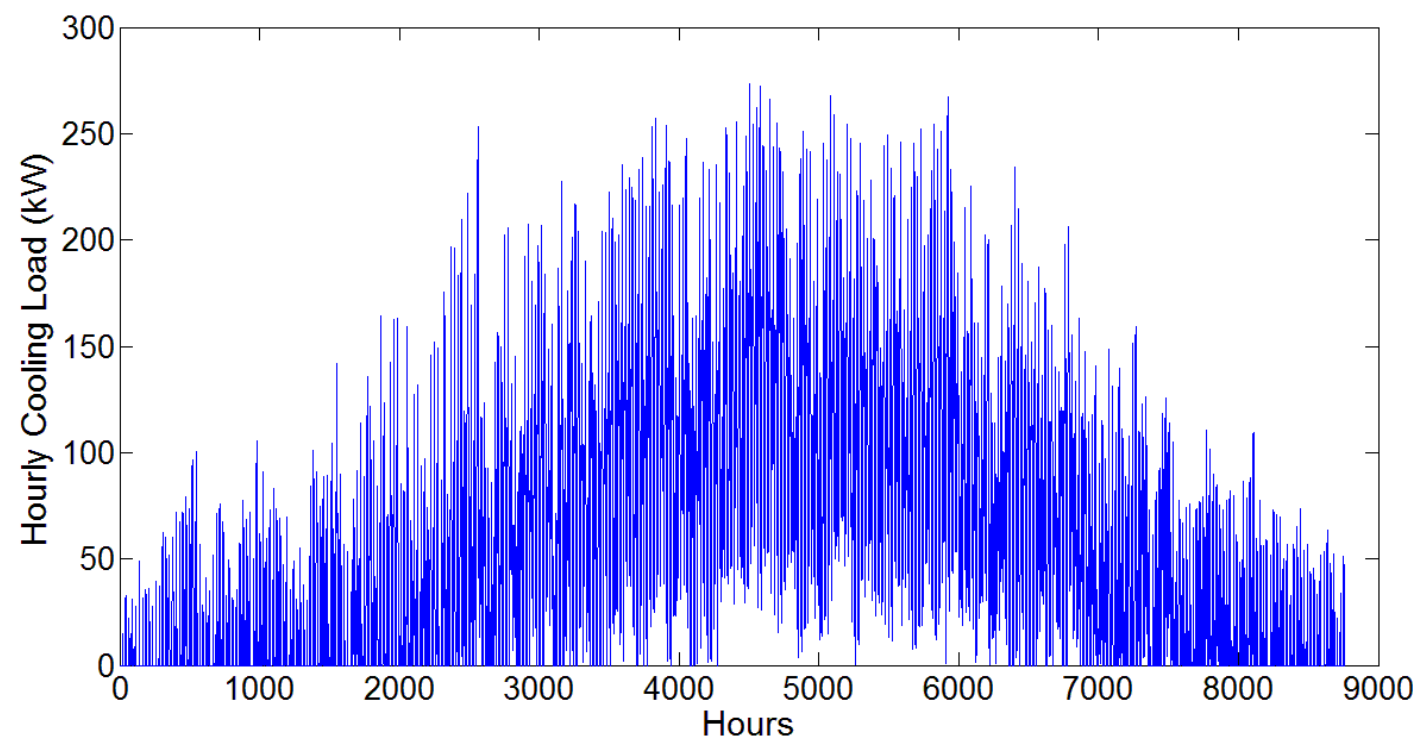

Figure A.13: Hourly cooling loads for High-rise A (multi-residential building) located in Toronto, Ontario. The hours in a year (8760 hours in a year) are along the abscissa. The peak and total cooling loads are $273 \mathrm{~kW}$ and $518,000 \mathrm{kWh}$ respectively.

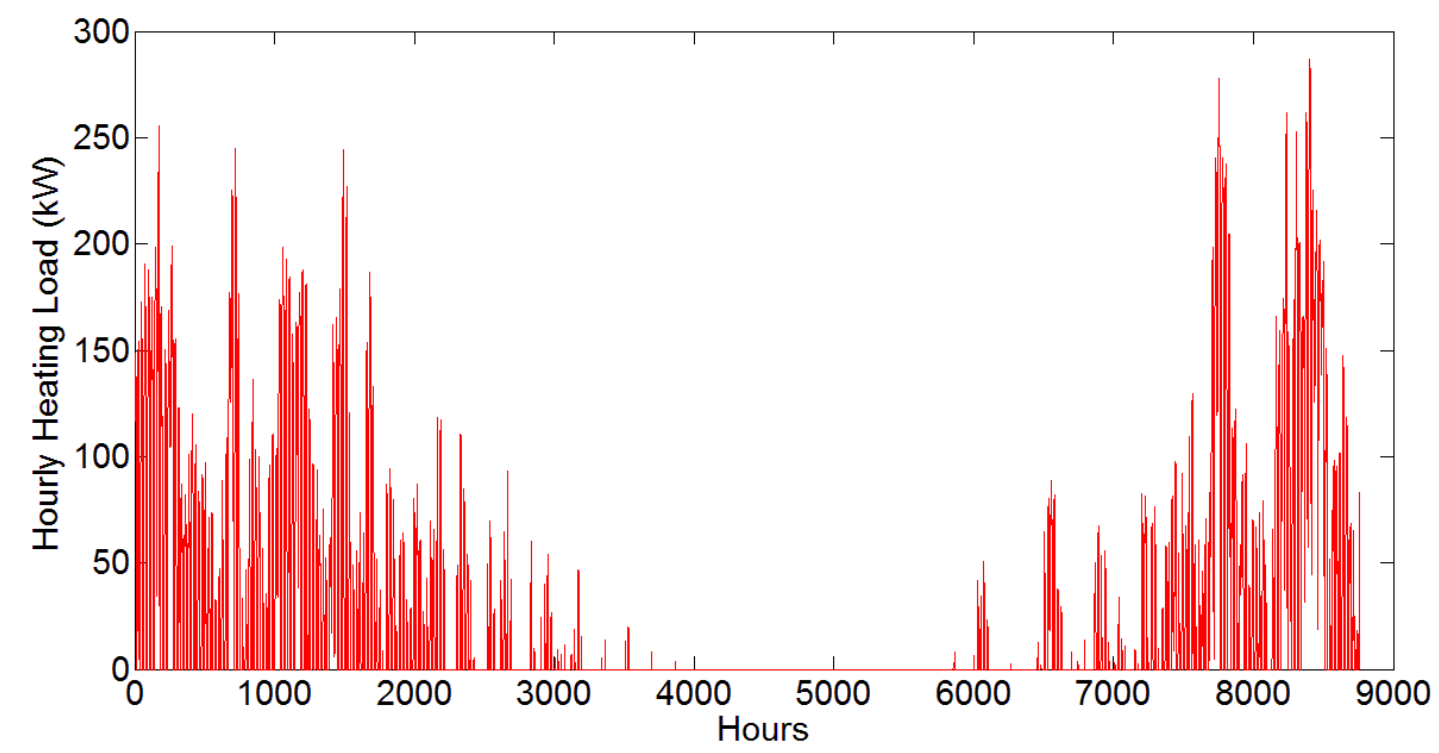

Figure A.14: Hourly heating loads for High-rise B (multi-residential building) located in

Toronto, Ontario. The hours in a year ( 8760 hours in a year) are along the abscissa. The peak and total heating loads are $287 \mathrm{~kW}$ and $240,000 \mathrm{kWh}$ respectively. 


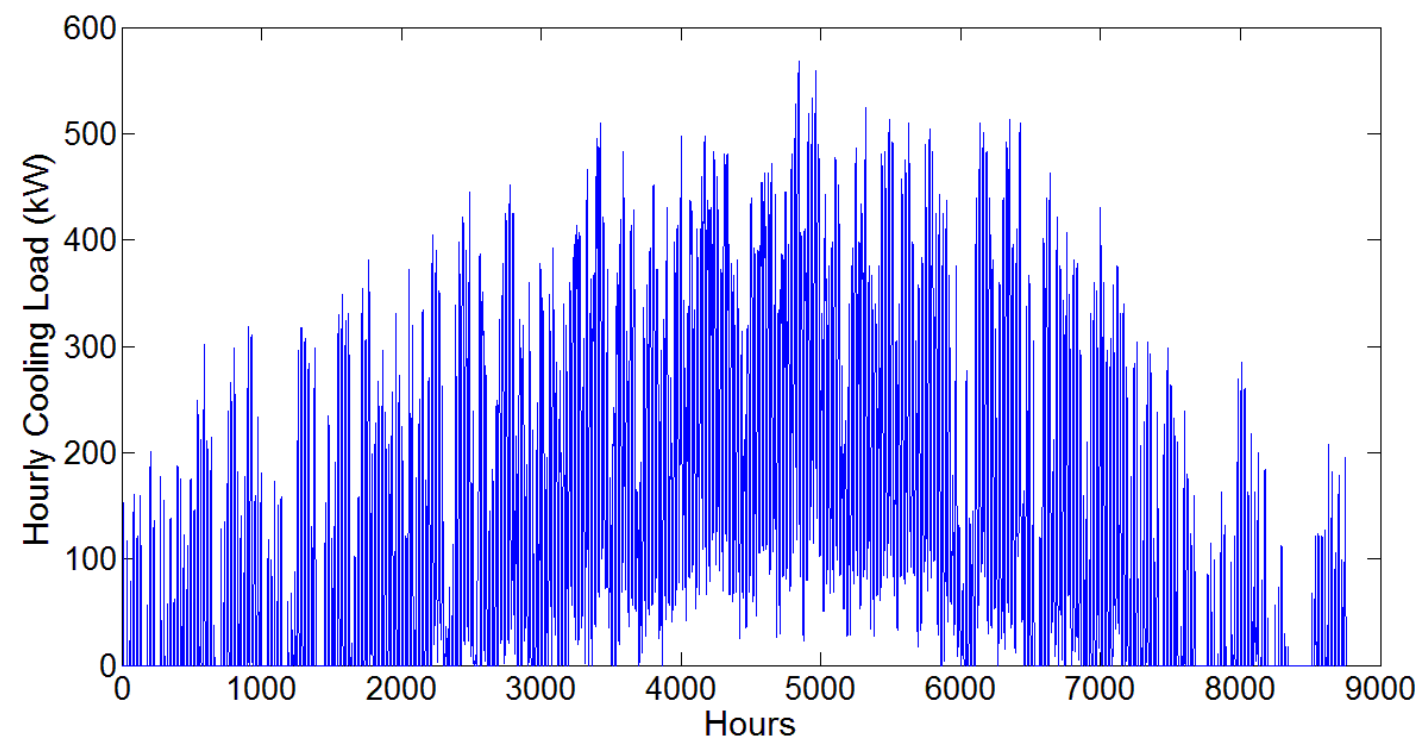

Figure A.15: Hourly cooling loads for High-rise B (multi-residential building) located in Toronto, Ontario. The hours in a year ( 8760 hours in a year) are along the abscissa. The peak and total cooling loads are $568 \mathrm{~kW}$ and 1,140,000 kWh respectively.

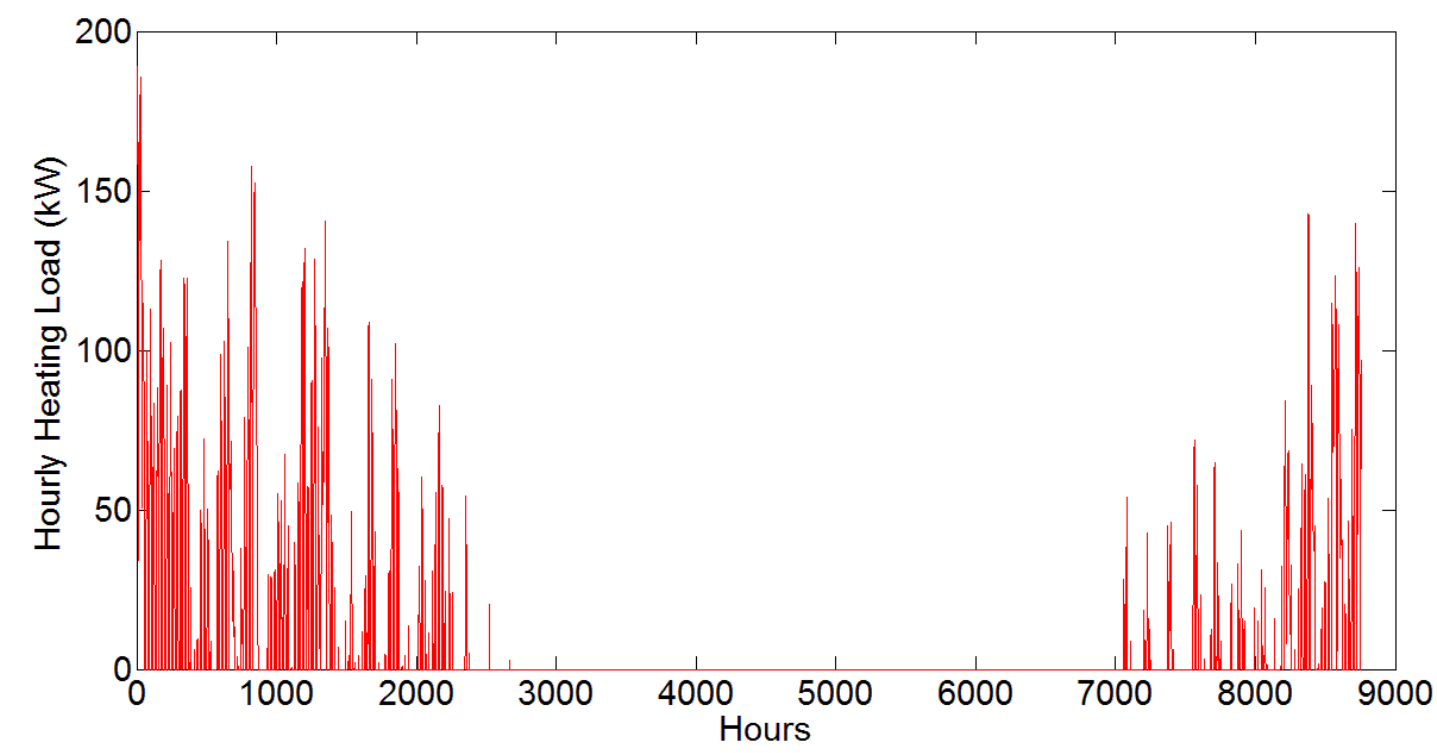

Figure A.16: Hourly heating loads for High-rise C (multi-residential building) located in Toronto, Ontario. The hours in a year ( 8760 hours in a year) are along the abscissa. The peak and total heating loads are $189 \mathrm{~kW}$ and $80,000 \mathrm{kWh}$ respectively. 


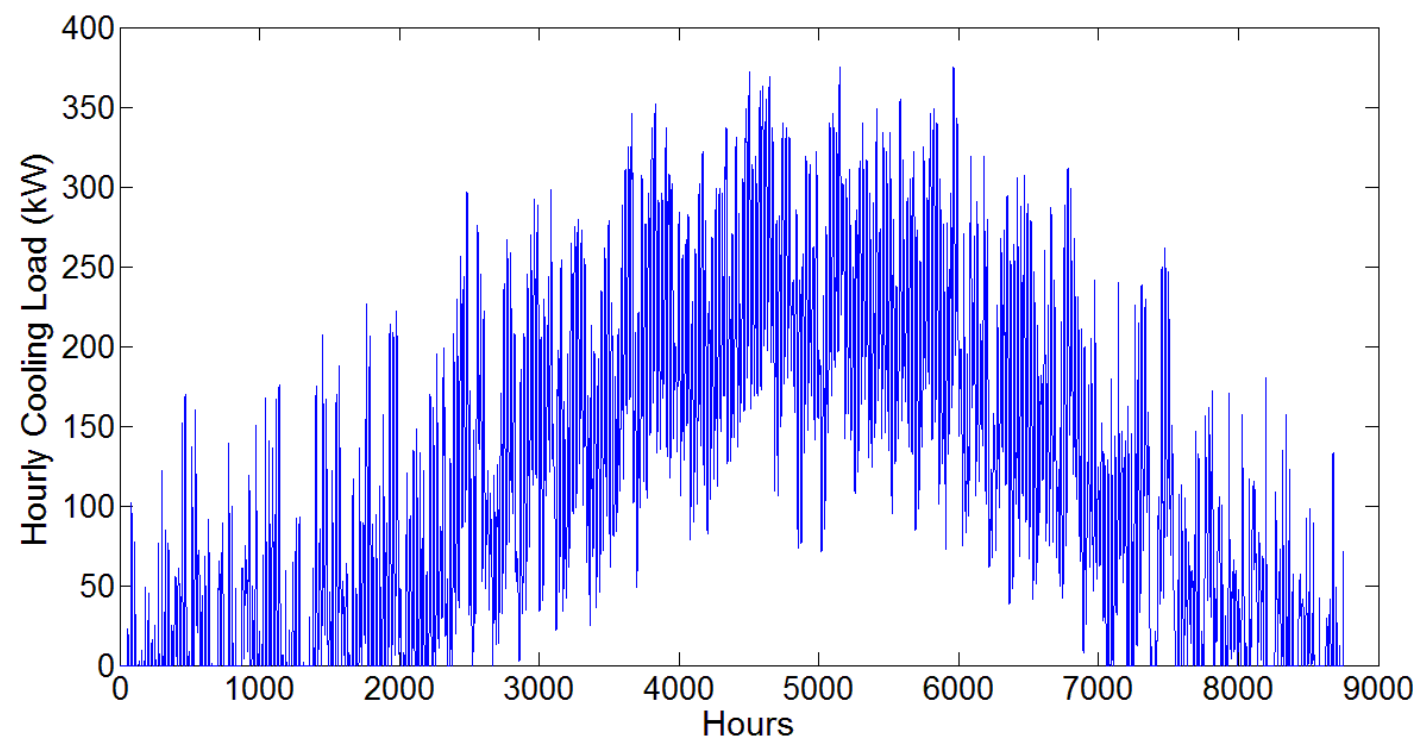

Figure A.17: Hourly cooling loads for High-rise C (multi-residential building) located in Toronto, Ontario. The hours in a year ( 8760 hours in a year) are along the abscissa. The peak and total cooling loads are $375 \mathrm{~kW}$ and 1,030,000 $\mathrm{kWh}$ respectively.

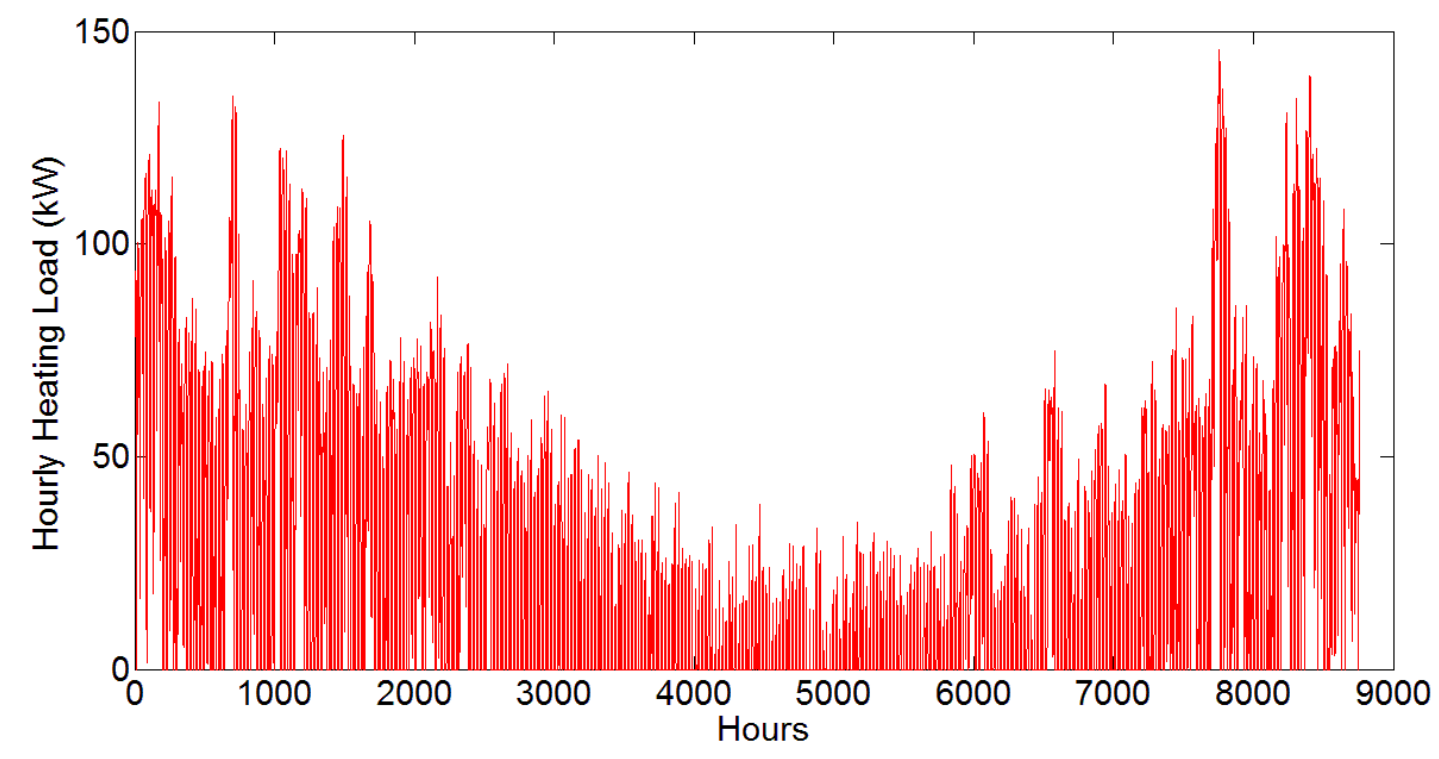

Figure A.18: Hourly heating loads for a school located in Toronto, Ontario. The hours in a year ( 8760 hours in a year) are along the abscissa. The peak and total heating loads are $146 \mathrm{~kW}$ and $247,180 \mathrm{kWh}$ respectively. 


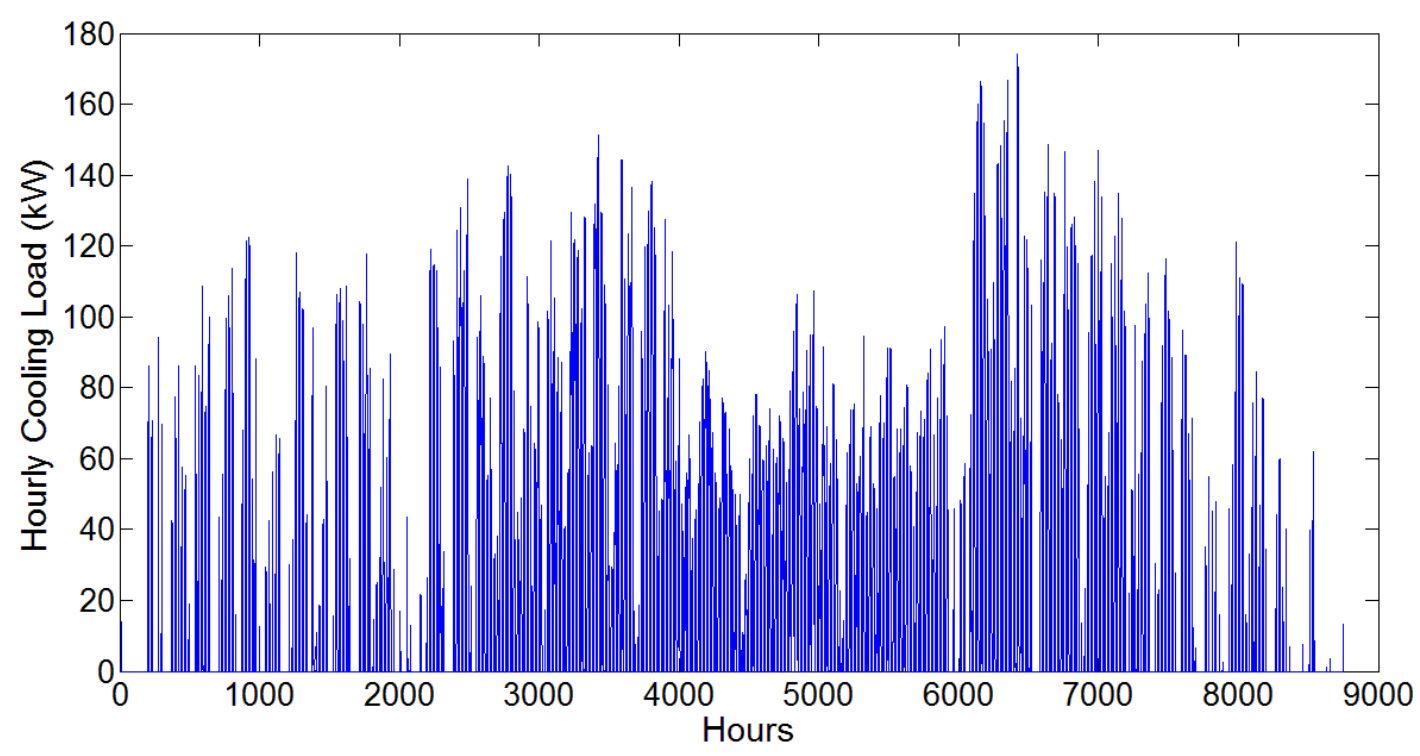

Figure A.19: Hourly cooling loads for a school located in Toronto, Ontario. The hours in a year (8760 hours in a year) are along the abscissa. The peak and total cooling loads are $174 \mathrm{~kW}$ and $203,350 \mathrm{kWh}$ respectively. 


\section{References}

[1] Chiotti, Q. (1998). An assessment of the regional impacts and opportunities from climate change in Canada. Canadian Geographer, 42(4), 380-393. Retrieved from http://ezproxy.lib.ryerson.ca/login?url=http://search.proquest.com/docview/228306910?a ccountid=13631

[2] Ekrami, N. (2013). Feasibility of residential combined cooling, heating and power generation system in Canada: Master's Thesis. Ryerson University: Toronto, Ontario, Canada.

[3] Natural Resources Canada. (2013). Energy Use Data Handbook Table. Retrieved on June 28, 2013 from http://oee.nrcan.gc.ca/corporate/statistics/neud/dpa/showTable.cfm?type=HB\&sector=aaa \&juris $=$ ca\&rn $=2 \&$ page $=6 \&$ CFID $=30320730 \&$ CFTOKEN

[4] Natural Resources Canada. (2012). Commercial earth energy systems: A buyer's guide. Retrieved on June 28, 2013 from http://canmetenergy.nrcan.gc.ca/node/2764

[5] Omer, A.M. (2008). Ground-source heat pumps systems and applications. Renewable \& Sustainable Energy Reviews, 12(2), 344-371.

[6] Self, S.J., Reddy, B.V., \& Rosen, M.A. (2013). Geothermal heat pump systems: Status review and comparison with other heating options. Applied Energy, 101, 341-348.

[7] Guo, Y., Zhang, G., Zhou, J., Wu, J., \& Shen, W. (2012). A techno-economic comparison of a direct expansion ground-source and a secondary loop ground-coupled heat pump system for cooling in a residential building. Applied Thermal Engineering. 35, 29-39.

[8] RETScreen International. (2005). Clean energy project analysis: Ground-source heat pump project analysis. Canada: Ministers of Natural Resource Canada

[9] Bi, Y., Guo, T., Zhang, L., \& Chen, L. (2004). Solar and ground source heat-pump system. Applied Energy, 78, 231-245.

[10] Chua, K.J., Chou, S.K., \& Yang, W.M. (2010). Advances in heat pump systems: A review. Applied Energy, 87, 3611-3624.

[11] Wang, X., Zheng, M., Zhang, W., Zhang, S., \& Yang, T. (2010). Experimental study of a solar-assisted ground-coupled heat pump system with solar seasonal thermal storage in severe cold areas. Energy and Buildings, 42, 2104-2110. 
[12] Kjellson, E., Hellström, G., \& Perers, B. (2010). Optimization of systems with the combination of ground-source heat pump and solar collectors in dwellings. Energy, 35, 2667-2673

[13] Bagdanavicius, A., \& Jenkins, N. (2013). Power requirements of ground source heat pumps in a residential area. Applied Energy, 102, 591-600.

[14] Chen, C., Sun, F., Feng, L., \& Liu, M. (2005). Underground water-source loop heatpump air-conditioning system applied in a residential building in Beijing. Applied Energy, 82(4), 331-344.

[15] Alavy, M., Nguyen, H.V., Leong, W.H., \& Dworkin, S.B. (2013). A methodology and computerized approach for optimizing hybrid ground source heat pump system design. Renewable Energy, 57, 404-412.

[16] Ni, L., Song, W., Zeng, F., \& Yao, Y. (2011). Energy saving and economic analyses of design heating load ratio of ground source heat pumps with gas boiler as auxiliary heat source. Conference on Electric Technology and Civil Engineering (ICETCE), 1197-1200. Lushan, China.

[17] Sagia, Z., Rakopoulos, C., \& Kakaras, E. Cooling dominated Hybrid Ground Source Heat Pump System application. Applied Energy, 94, 41-47.

[18] Kavanaugh, S.P. \& Rafferty, K. (1997). Ground-source heat pumps: Design of geothermal systems for commercial and institutional buildings. Atlanta, Georgia: American Society of Heating Refrigerating and Air-Conditioning Engineers, Inc.

[19] Natural Resources Canada. (2009). Ground-source heat pumps (earth-energy systems). Retrieved from http://oee.nrcan.gc.ca/publications/residential/heating-heat-pump/7158

[20] Florides, G. \& Kalogirou, K. (2007). Ground heat exchangers: A review of systems, models and applications. Renewable Energy, 32(15), 2461-2478.

[21] Dugan, G. (2011). HDD geothermal loop installation. National Driller, 32(10), 28-32. Retrieved from http://ezproxy.lib.ryerson.ca/login?url=http://search.proquest.com/docview/898605689?a ccountid=13631

[22] Thermal Dynamics Inc. (2014). Ground loop design. Retrieved from http://www.groundloopdesign.com/ 
[23] Canadian Geoexchange Coalition. (2014). Geo analyser [Software]. Retrieved from http://www.geoanalyser.com/

[24] Office of Energy Efficiency and Renewable Energy. (2011). Building energy software tools directory: GLHEPRO. Retrieved from

http://apps1.eere.energy.gov/buildings/tools_directory/software.cfm/ID=537/pagename=a lpha_list_sub

[25] Natural Resource Canada. (2013). RETScreen international: Empowering cleaner energy decisions [Software]. Retrieved from http://www.retscreen.net/ang/home.php

[26] European Ground Source Heat Pump Association. (2014). Ground loop sizing: RETScreen Clean Energy Project Analysis [Software]. Retrieved from http://www.egshpa.com/ground-loop-sizing/

[27] Hirsch, J.J \& Associates. (2009). eQuest: The quick energy stimulation tool [Software]. Retrieved from http://www.doe2.com/equest/

[28] TRNSYS. (2014). Transient system simulation tool [Software]. Retrieved from http://www.trnsys.com/

[29] Office of Energy Efficiency and Renewable Energy. (2013). EnergyPlus energy simulation software [Software]. Retrieved from http://apps1.eere.energy.gov/buildings/energyplus/

[30] Hewitt, N.J. (2011). Heat pumps: Challenges for new build and retrofit in domestic applications. International Journal of Ambient Energy, 32(4), 169-169.

[31] Zhu, N., Hu, P. \& Yu, J. (2013). A case study of building retrofit using ground source heat pump technology. Asian-Pacific Economic Cooperation, paper ID: ACLE2013-E0230, 211-217.

[32] Caneta Research Inc. (2002). Investigation of a ground-source heat pump retrofit to an electrically heated multi-family building (CR File No: 6585-C108). Ottawa, Ontario: CMHC, External Research Program

[33] Larson, B., Geraghty, K., Davis, B., \& Gilman, L. (2012). Ductless heat pump retrofits in multifamily and small commercial buildings: A report of BPA energy efficiency's emerging technologies initiative. Retrieved from http://www.bpa.gov/energy/n/emerging_technology/pdf/DHPx_Multifamily\%20_Small_ Commercial_Report_02-08-13.pdf 
[34] Qi, Z., Gao, Q., Liu, Y., Yan, Y.Y., \& Spitler, J.D. (2014). Status and development of hybrid energy systems from hybrid ground source heat pump in China and other countries. Renewable and Sustainable Energy Reviews, 29, 37-51.

[35] Gang, W., \& Wang, J. (2013). Predictive ANN models of ground heat exchanger for the control of hybrid ground source heat pump systems. Applied Energy, 112, 1146-1153.

[36] Montagud, C., Corberán, J.M., \& Ruiz-Calvo, F. (2013). Experimental and modeling analysis of a ground source heat pump system. Applied Energy. 109, 328-336.

[37] Sagia, Z., Rakopoulos, C. (2012). New control strategy for a hybrid ground source heat pump system coupled to a closed circuit cooling tower. J Appl Mech Eng, 1(2), 1-8.

[38] Montagud, C., Corberán, J.M., \& Montero, Á. (2014). In situ optimization methodology for the water circulation pumps frequency of ground source heat pump systems. Energy and Buildings, 68, 42-53.

[39] Park, H., Lee, J.S., Kim, W., \& Kim, Y. (2013). The cooling seasonal performance factor of a hybrid ground-source heat pump with parallel and serial configurations. Applied Energy, 102, 877-884.

[40] Yang, H., Cui, P., \& Fang, Z. (2010). Vertical-borehole ground-coupled heat pumps: A review of models and systems. Applied Energy, 87, 16-27.

[41] Wang, E., Fung, A.S., Qi, C., \& Leong, W.H. (2012). Performance prediction of a hybrid solar ground-source heat pump system. Energy and Buildings, 47, 600-611.

[42] Man, Y., Yang, H., Spitler, J.D., \& Fang, Z. (2011). Feasibility study on novel hybrid ground coupled heat pump system with nocturnal cooling radiator for cooling load dominated buildings. Applied Energy, 88, 4160-4171.

[43] Man, Y., Yang, H., \& Wang, J. (2010). Study on hybrid ground-coupled heat pump system for air-conditioning in hot-weather areas like Hong Kong. Applied Energy, 87, 2826-2833.

[44] Ozyurt, O., \& Ekinci, D.A. (2011). Experimental study of vertical ground-source heat pump performance evaluation for cold climate in Turkey. Applied Energy, 88, 12571265.

[45] Wu, W., Wang, B., You, T., Shi, W., \& Li, X. (2013). A potential solution for thermal imbalance of ground source heat pump systems in cold regions: Ground source absorption heat pump. Renewable Energy, 59, 39-48. 
[46] Saltelli, A., \& Annoni, P., (2010). How to avoid a perfunctory sensitivity analysis. Environmental Modelling \& Software, 25(12), 1508-1517.

[47] Ardente, F., Beccali, G., Cellura, M. \& Lo Brano, V. (2005). Life cycle assessment of a solar thermal collector: Sensitivity analysis, energy and environmental balances, Renewable Energy, 30(2), 109-130.

[48] Borgonovo, E., Castaings, W., \& Tarantola, S. (2012). Model emulation and momentindependent sensitivity analysis: An application to environmental modelling.

Environmental Modelling \& Software, 34, 105-115.

[49] Bakirci, K., Ozyurt, O., Comakli, K., \& Comakli, O. (2011). Energy analysis of a solarground source heat pump system with vertical closed-loop for heating applications. Energy, 36(5), 3224-3232.

[50] Blum, P., Campillo, G., \& Kölbel, T. (2011). Techno-economic and spatial analysis of vertical ground source heat pump systems in Germany. Energy, 36(5), 3002 - 3011.

[51] Entchev, E., Yang, L., Ghorab, M., \& Lee, E.J. (2013). Simulation of hybrid renewable microgeneration system sharing applications. Energy, 50, 252-261.

[52] Lee, W., Kim, H., Park, J., Cho, K., Roh, J.H. \& Son, S. (2012). Economic analysis of heating and cooling systems from the various perspectives: Application to EHP and GHP in Korea. Renewable and Sustainable Energy Reviews, 16(6), 4116-4125.

[53] Rad, F.M., Fung, A.S. \& Leong, W.H. (2013). Feasibility of combined solar thermal and ground source heat pump systems in cold climate, Canada. Energy and Buildings, 61, 224-232.

[54] Canadian Standard Association. (2002). Design and installation of earth energy systems for residential and other small buildings. Standard C448.2e02, 35.

[55] Hirsch, J.J. (2006). Weather data \& weather data processing utility programs. Retrieved on June 28, 2013 from http://doe2.com/index_wth.html

[56] Ontario Energy Board. (2013). Your Electricity Utilitiy. Retrived on June 28, 2013 from http://www.ontarioenergyboard.ca/OEB/Consumers/Electricity/Your\%20Electricity\%20 Utility

[57] Ontario Energy Board. (2013). Historical Electricity Prices. Retrieved on June 28, 2013 from 
http://www.ontarioenergyboard.ca/OEB/Consumers/Electricity/Electricity\%20Prices/Hist orical\%20Electricity\%20Prices

[58] Ontario Energy Board. (2012). Electricity price. Retrieved on June 28, 2013 from http://www.ontarioenergyboard.ca/OEB/Consumers/Electricity/Electricity+Prices

[59] National Oceanic and Atmospheric Administration. (2012). National climatic data center. Retrieved on June 28, 2013 from http://gis.ncdc.noaa.gov/maps

[60] eia. (2012). Natural gas prices: Residential. Retrieved on June 28, 2013 from http://www.eia.gov/dnav/ng/ng_pri_sum_a_EPG0_PRS_DMcf_a.htm

[61] eia. (2012). Natural gas prices: Commercial. Retrieved on June 28, 2013 from http://www.eia.gov/dnav/ng/ng_pri_sum_a_EPG0_PCS_DMcf_a.htm

[62] U.S. Department of Energy. (2012). State electricity profiles 2010: U.S. electricity Prices. Retrieved on June 28, 2013 from DOE/EIA-0348(01)/2

[63] Jenkins, D.P., Tucker, R. \& Rawlings, R. (2009). Modelling the carbon-saving performance of domestic ground-source heat pumps. Energy and Buildings, 41(6), 587595.

[64] Younis, M., Bolisetti, T., \& Ting, D. S. (2010). Ground source heat pump systems: Current status. International Journal of Environmental Studies, 67(3), 405-415.

[65] Florides, G. A., Christodoulides, P., \& Pouloupatis, P. (2013). Single and double U-tube ground heat exchangers in multiple-layer substrates. Applied Energy, 102, 364-373.

[66] Marmaras, J., Burbank, J., \& Kosanovic, D. (2013). Ground source heat pump operation and optimal entering liquid temperature. ASHRAE Transactions, 119(1), 1-8

[67] Greening, B., \& Azapagic, A. (2012). Domestic heat pumps: Life cycle environmental impacts and potential implications for the UK. Energy, 39(1), 205-217.

[68] Soimakallio, S., Kiviluoma, J., \& Saikku, L.(2011). The complexity and challenges of determining GHG (greenhouse gas) emissions from grid electricity consumption and conservation in LCA. Energy, 36(12), 6705.

[69] Sivasakthivel, T., Murugesan, K., \& Sahoo, P.K. (2012). Potential reduction in $\mathrm{CO}_{2}$ emission and saving in electricity by ground source heat pump system for space heating applications-A study on northern part of India. Procedia Engineering, 38, 970-979.

[70] Blum, P., Campillo, G., Münch, W., \& Kölbel, T. (2010). $\mathrm{CO}_{2}$ savings of ground source heat pump systems : A regional analysis. Renewable Energy, 35(1), 122-127. 
[71] Mallia, E., \& Lewis, G. (2013). Life cycle greenhouse gas emissions of electricity generation in the province of Ontario, Canada. The International Journal of Life Cycle Assessment, 18(2), 377-391.

[72] U.S. Environmental Protection Agency. (2004). Unit Conversions, Emissions Factors, and Other Reference Data. Retrieved from United States Environmental Protection Agency: http://www.epa.gov/cpd/pdf/brochure.pdf

[73] Carbon Trust. (2011). Conversion factors. Retrieved from http://www.carbontrust.com/media/18223/ctl153_conversion_factors.pdf

[74] AECOM. (2010). Carbon emission factors for fuels: Methodology and values for 2013 \& 2016. Retrieved from http://www.zerocarbonhub.org/resourcefiles/Carbon_Emission_Factors_for_Fuelsmethodology_and_values_for_2013_and_2016.pdf

[75] Independent Electricity System Operator. (2013). Supply Overview. Retrieved from http://www.ieso.ca/imoweb/media/md_supply.asp

[76] U.S. Energy Information Administration. (2013). Carbon Dioxide Emissions Coefficients. Retrieved from http://www.eia.gov/environment/emissions/co2_vol_mass.cfm

[77] Province of British Columbia. (2013). How the Carbon Tax Works. Retrieved from http://www.fin.gov.bc.ca/tbs/tp/climate/A4.htm

[78] Carbon Tax Center. (2013, September 6). Where carbon is taxed. Retrieved from http://www.carbontax.org/progress/where-carbon-is-taxed/

[79] Intergovernmental Panel on Climate Change. (2007). Climate change 2007: Migration of climate change. Retrieved from http://www.ipcc.ch/pdf/assessmentreport/ar4/wg3/ar4_wg3_full_report.pdf

[80] Popp, D., Hascic, I. \& Medhi, N. (2011). Technology and the diffusion of renewable energy. Energy Economics, 33(4), 648-662.

[81] Rhodes, E. \& Jaccard, M. (2013). A tale of two climate policies: Political economy of British Columbia's carbon tax and clean electricity standard. Canadian Public Policy, 39, 37-51.

[82] Deichmann, U. Meisner, C., Murray, S., \& Wheeler, D. (2011). The economics of renewable energy expansion in rural Sub-Saharan Africa. Energy Policy, 39(1), 215-227. 
[83] Melikoglu, M. (2013). Vision 2023: Feasibility analysis of Turkey's renewable energy projection. Renewable Energy, 50, 570-575.

[84] Statistics Canada. (2013). Type of main heating equipment, by province, 2011. Retrieved from http://www.statcan.gc.ca/pub/11-526-s/2013002/t001-eng.htm

[85] Natural Resources Canada. (2013). Energy Consumption in kWh by Province. Retrieved from http://www.nrcan.gc.ca/energy/publications/efficiency/eeproducts/roomaircond/6659\#on

[86] Natural Resources Canada's Office of Energy Efficiency. (2003). Air conditioning your home. Retrieved from http://publications.gc.ca/collections/Collection/M91-23-72003E.pdf

[87] Home Inspect. (2013). Average renovation prices. Retrieved from http://www.ihomeinspect.ca/average-renovation-prices.html

[88] Electric Heat Canada. (2011). RCC12012C: 1200W| 120V. Retrieved from www.electricheatcanada.ca/RCC12012C-1200W-120V_p_278.html

[89] Canadian Tire. (2014). Garrison 8,000 btu vertical window air conditioner. Retrieved from http://www.canadiantire.ca/en/pdp/garrison-8000-btu-vertical-window-airconditioner-0435493p.html\#.UzzeyFc3kY0

[90] The Home Depot. (2014). Comfort Aire vertical window AC 12000 btu with remote $115 \mathrm{~V}$. Retrieved from http://www.homedepot.ca/product/vertical-window-ac-12000-btu-withremote-115v/992596

[91] Rona. (2014). Horizontal air conditioner. Retrieved from http://www.rona.ca/en/horizontal-air-conditioner-87795010--1

[92] HVAC Mechanical Systems Inc. (2014). What we do. Retrieved from http://www.hvacmechanicalsystems.com/

[93] Abeco. (2013). Residential. Retrieved from http://generalcontractorsintoronto.com/homerenovations-toronto/

[94] Spring Home: Heating and cooling Systems Inc. (2012). Toronto heating and cooling. Retrieved from http://www.springhome.ca/

[95] Home Wyse. (2014). Cost to insulate your home. Retrieved from http://www.homewyse.com/ services/cost_to_insulate_your_home.html 
[96] Ministry of Housing: Buildings Branch. (1986). The building code: Containing the building code act and O. Reg. 419/86. Ontario: The Ontario Government Bookstore

[97] Alavy, M., Dworkin, S.B., \& Leong, W.H. (2013). A design methodology and analysis of combining multiple buildings into a single district hybrid ground source heat pump system. Renewable Energy, DOI: 10.1016/j.renene.2013.12.030

[98] Weiss, W. (2003). Solar Heating systems for houses a design handbook for solar combisystems. London: James \& James (Science Publisher) Ltd.

[99] Manrique, J.A. (1991). Thermal performance of an ammonia-water refrigeration system. International Communication in Heat Mass Transfer, 18(6), 779-789.

[100] Hasib, Z.M. (2013). A residential micro tri-generation system based on a gas fired stirling engine CHP and thermo-chemical accumulator (TCA): Master's Thesis. Ryerson University: Toronto, Ontario, Canada 